\title{
Methods to improve forage quality for mammalian herbivores in nutrient poor savannas
}

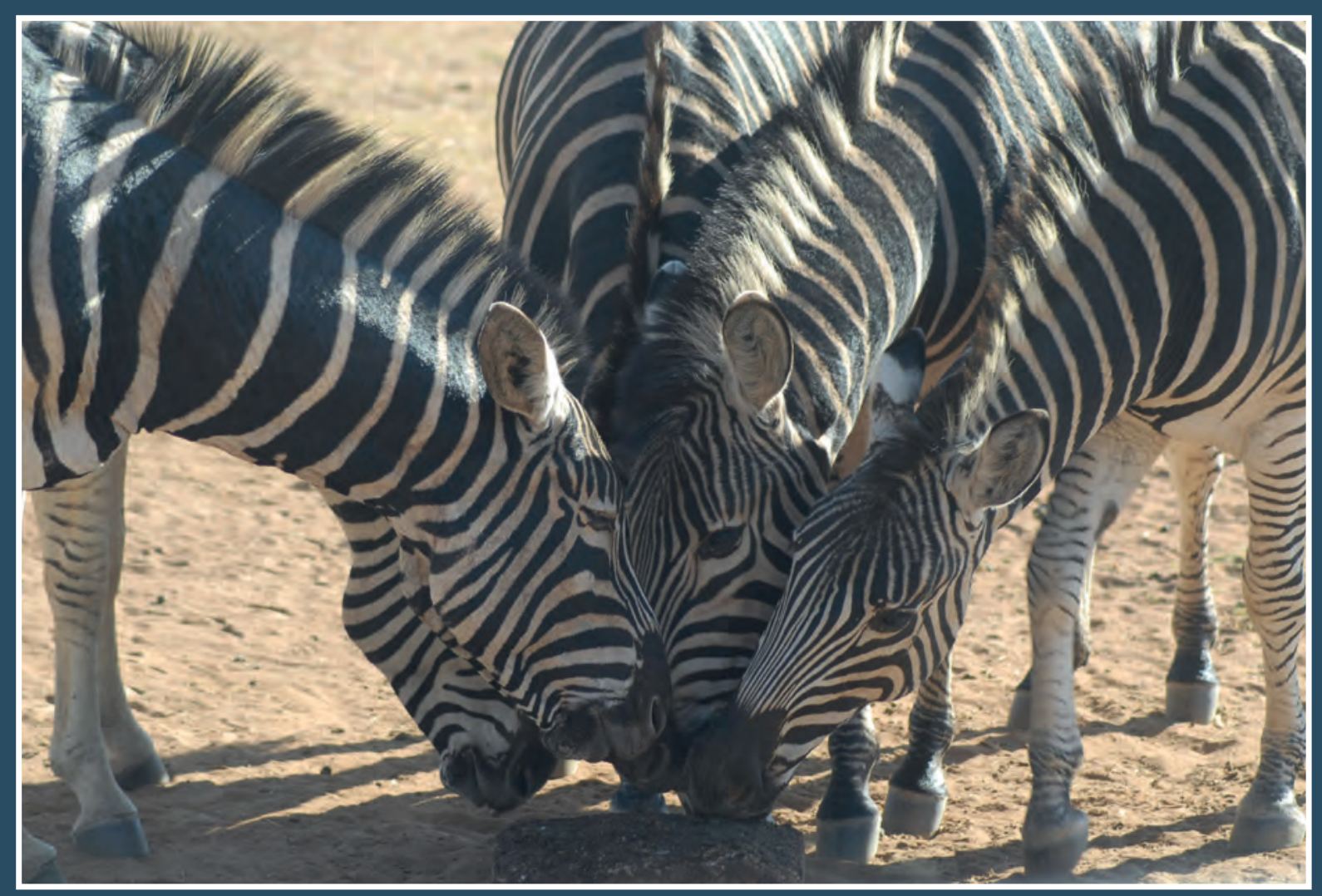

Bradley Schroder 


\section{Propositions}

1. More free-roaming large herbivores will be attracted to grassland in nutrient poor savannas when nitrogen is added.

(this thesis)

2. Polyethylene glycol as a supplement in diets of free-roaming herbivores in areas where trees have high levels of tannin will change the diet of these herbivores to plants with higher levels of tannin.

(this thesis)

3. When conservation managers and environmental scientists fail to have a common understanding of evidence-based conservation, the risk of failing to achieve objectives is high.

4. When a pandemic establishes commonalities between countries for the survival of humans, this results in collaboration to solve further international issues.

5. The productivity of land will increase when unskilled workers are trained in agricultural skills prior to land acquisition.

6. The benefits of training and education far outweigh the practice of handouts to achieve economic growth in poor rural communities.

Propositions belong to the thesis, entitled:

Methods to improve forage quality for mammalian herbivores in nutrient poor savannas

Bradley Schroder

Wageningen, Date 21-06-2021 

Methods to improve forage quality for mammalian herbivores in nutrient poor savannas 


\section{Thesis committee}

\section{Promotors}

Prof. Dr Herbert H. T. Prins

Professor Emeritus of Resource Ecology

Wageningen University \& Research

Prof. Dr Frank van Langevelde

Professor of Wildlife Ecology and Conservation

Wageningen University \& Research

\section{Other members}

Prof. Dr F. J. J. M. Bongers, Wageningen University \& Research

Prof. Dr H. Olff, University of Groningen

Dr E. Klop, Altenburg \& Wymenga, Feanwâlden

Dr E. M. Veenendaal, Wageningen University \& Research

This research was conducted under the auspices of the C.T. de Wit Graduate School for Production Ecology and Resource Conservation. 


\title{
Methods to improve forage quality for mammalian herbivores in nutrient poor savannas
}

\author{
Bradley Schroder
}

\section{Thesis}

Submitted in fulfilment of the requirements for the degree of doctor at Wageningen University

by the authority of the Rector Magnificus

$$
\text { Prof. Dr A. P. J. Mol, }
$$

in the presence of the

Thesis Committee appointed by the Academic Board

to be defended in public

on Monday 21 June 2021

at 1:30 p.m. in the Aula. 
Bradley Schroder

Methods to improve forage quality for mammalian herbivores in nutrient poor savannas

PhD thesis, Wageningen University, Wageningen, The Netherlands (2021)

With references, with summaries in Dutch, Afrikaans and English

ISBN: 978-94-6395-740-3

DOI: https://doi.org/10.18174/543076 


\section{Table of contents}

Dedication iv

Acknowledgements $\mathrm{V}$

Chapter 1

General Introduction

Bradley Schroder

Chapter 2

Protected area establishment in Southern and Eastern Africa:

Consequences for management today

Bradley Schroder, Frank Van Langevelde and Herbert H. T. Prins

Chapter 3

Effects of mineral addition on the establishment of grazing lawns in a nutrient poor savanna

Bradley Schroder, Frank Van Langevelde and Herbert H. T. Prins

Chapter 4

Nutrient addition on grazing lawns and selection by free-roaming mammalian herbivores in a nutrient poor savanna

Bradley Schroder, Frank Van Langevelde and Herbert H. T. Prins

Chapter 5

Provisioning Polyethylene Glycol to large herbivores in nutrient poor savannas can break food limitation

Bradley Schroder, Frank Van Langevelde and Herbert H. T. Prins

Chapter 6

Methods to improve forage quality for mammalian herbivores in nutrient poor savannas: A Synthesis

Bradley Schroder

References

Summary (English)

Samenvatting (Dutch)

Samevatting (Afrikaans)

Biography - Bradley Schroder

List of publications

PE\&RC Training and Education Statement 


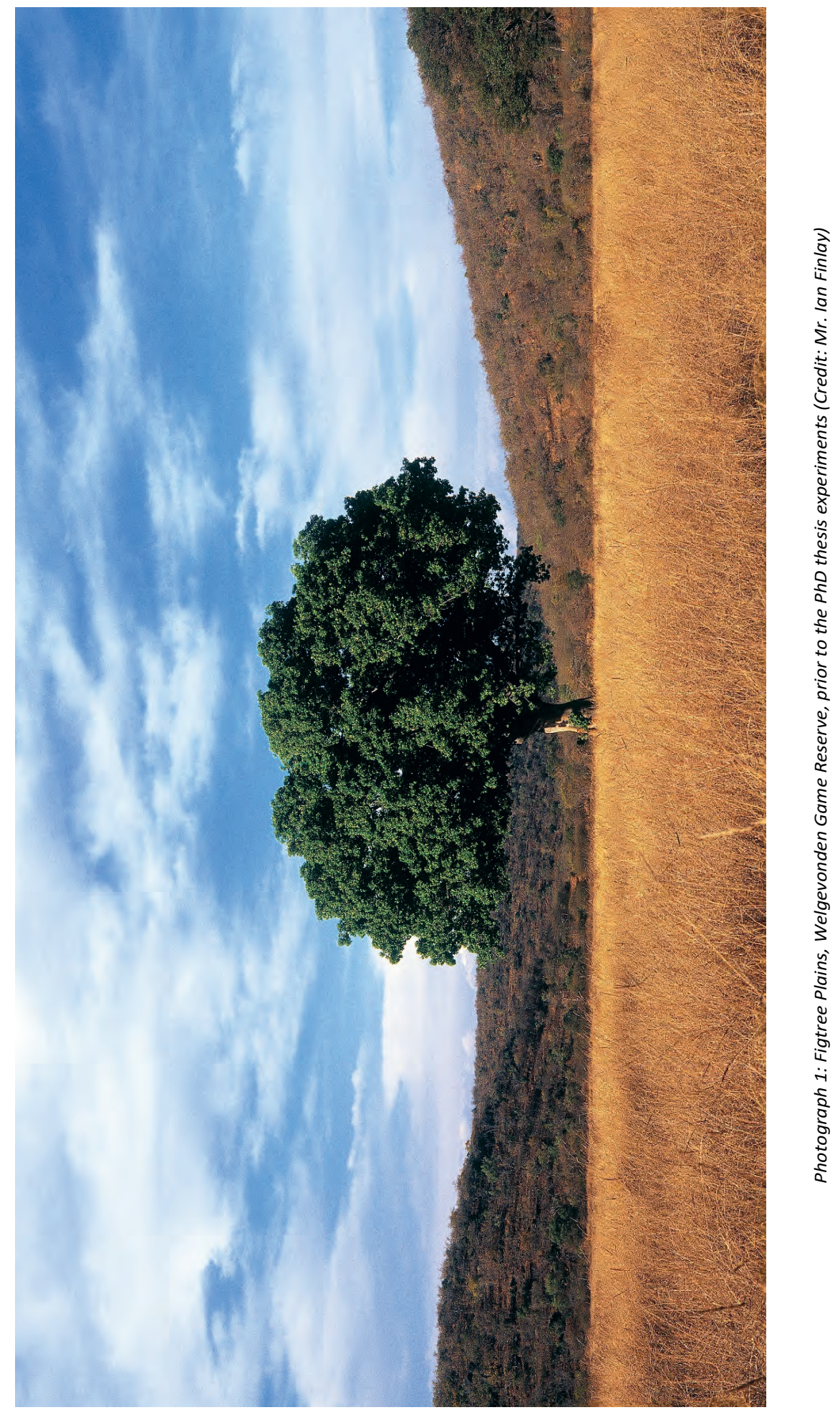




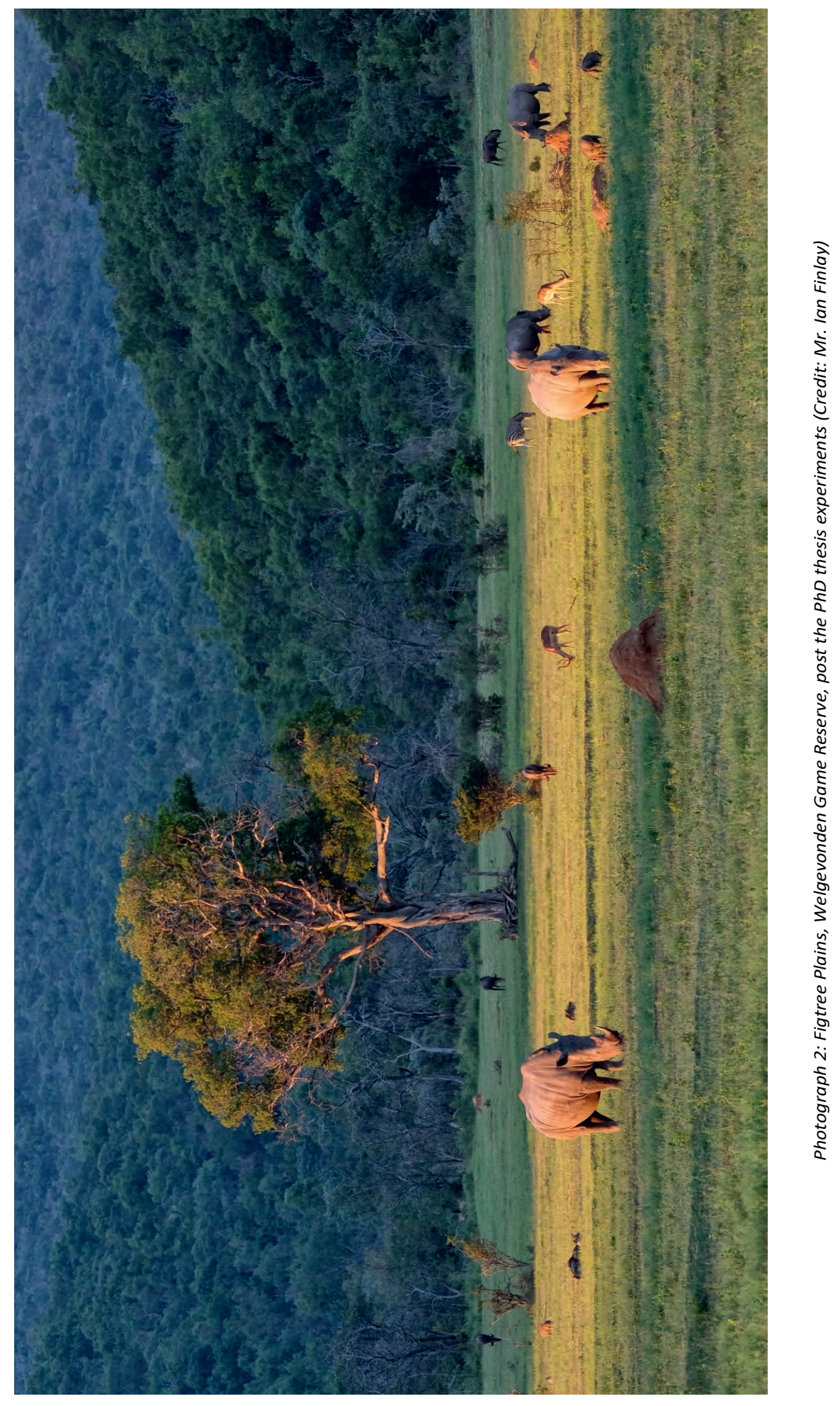




\section{Dedication}

I wish to dedicate this thesis to all the people around the world, who think that the impossible is not achievable. More especially, to those who have been told that they simply are not gifted academically, not achievers or simply not clever enough! Believe in yourselves and the goodness of others, you are never written off unless you allow yourself to be! There are two kinds of people in this world, "talkers" and "doers". Go and get want you want out of life, only you can make it happen. 


\section{Acknowledgements}

First and foremost, I would like to thank Professor Herbert Prins my promotor, for seeing potential in me and this study and for helping me in all aspects of getting my thesis underway and for affording me the opportunity to study through Wageningen University. Without his personal interest and drive in this project, I would never have started or finished this journey. I wish to thank Professor Frank van Langevelde, my second promotor, for opening his home to me and for all the time, effort and personal interest that he has invested and shown over the past four years. I have learnt a huge amount from both Herbert and Frank in all aspects of science and the various viewpoints, which can be different and yet so similar. I would like to thank Herbert for his balance between science and fun, coupled with all the discussions over philosophical topics (especially about living life). I would like to thank Frank for the many hours spent discussing the PhD, life, opportunities and all other topics over skype, at Wageningen or in his home with his family. While I appreciate all he did for me, it generally ended up giving me huge amounts of extra work! Most importantly, I would like to thank them both for their generosity and friendship over the past years and I look forward to maintaining these friendships for many years to come.

Welgevonden Game Reserve, the Board, Members and Staff will forever be close to my heart. I would especially like to extend my thanks to Francois Spruyt (Chairman of the Board and close friend) and the Board for affording me the opportunity to undertake my studies on the Reserve. I would like to thank all the Staff and Management of Welgevonden for their assistance with my PhD, their support at work and friendship. There are certain people that have really helped me to achieve this goal and deserve special mention. In alphabetical order they are Andre Burger, Armstrong Maluleke, Carmen Warmenhove, Gregory Canning, 
Jonathan Swart, Mdududzi Vilikazi, Phillipa Myram Davidson-Phillips, Rebecca Beith and Samuel Davidson-Phillips.

There are a number of people who deserve a special mention of thanks for either assisting me with the $\mathrm{PhD}$ in one way or another, or being there to motivate me during the difficult times. In alphabetical order they are Audrey Delsink, Ben Bokhout, Brian Reilly, Marilize Greyling, Mike Peel, Nicola-Anne Jack, Rina Grant, Rob Slotow and Veronica Pieterse.

There are many people from the Netherlands, especially from Wageningen, who I would like to thank for playing a role in helping me to achieve my $\mathrm{PhD}$, opening their homes to me or just being a friend. They have all played such an amazing part in helping me to feel welcome and at home on my numerous trips to the Netherlands. In alphabetical order they are Brit Köhler, Coby van Dooremalen, Elmar Veenendaal, Henjo de Knegt, Jasper and Lieke Eikelboom, Joost de Jong, Koen de Koning, Lennart Suselbeek, Marit ter Bogt, Patricia Meijer, Yorick Liefting and students from Wageningen University and Van Hall Larenstein, who helped with the Agouti identification.

A special thanks must go to my two dear friends and paranymphs Gregory Canning from South Africa and Louis Vertegaal from the Netherlands. They have both been amazing friends for many years and huge support during my PhD. I thank them both from the bottom of my heart for agreeing to serve as my paranymphs and supporting me right through to the end of my $\mathrm{PhD}$, and most importantly for becoming part of my family.

It is extremely difficult to thank that one person, who has had to endure your highs and lows on a daily basis. That very same person, who understands that your time has to be shared with work and studies, yet selflessly ensures that your daily needs are taken care of. In saying 
this, I want to thank my partner Nicola-Anne Jack for her selfless role in giving me support, understanding, motivation and love right through to the end of my PhD.

Lastly, I want to thank my family for all their love and support over the years. I was by no means an academic and this thesis shows that through hard work, with love and support from ones family, one can achieve great things. I have no words to express my thanks and love to my father Bill and my mother Cherry (who sadly did not live to see me achieve this momentous task), for all the years of believing in me, not just in the PhD but everything I have tackled in my life... good or bad you have always loved, supported and believed in me. My father has always been an inspiration to me and his support, guidance, patience, trust, love and mostly his friendship over the years, no son could ever be as fortunate or grateful as I am. 


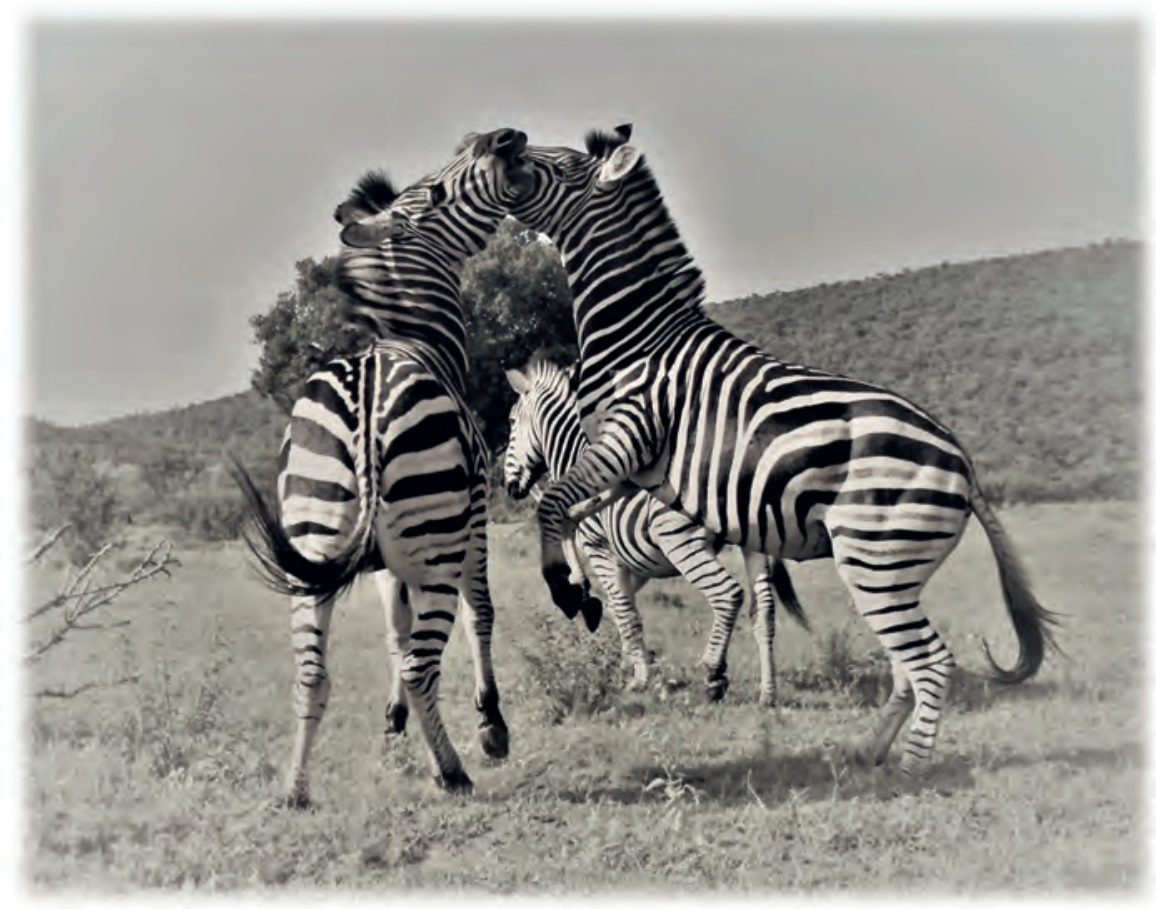

Photograph 3: Zebra fighting on Figtree Plains, Welgevonden Game Reserve (Camera trap photograph) 


\section{Chapter 1}

\section{General Introduction}

Bradley Schroder 


\section{Chapter 1}

\section{Challenge - protected areas require evidence-based conservation}

In this thesis, I study the relationship between large free-roaming herbivores in a nutrient poor savanna and ways of improving the quality of the forage, in Welgevonden Game Reserve (South Africa). Welgevonden is a nutrient poor savanna (Mucina and Rutherford 2006; Codron et al. 2016). The soils are acidic and nutrient deficient, resulting in broad-leaved savanna with the majority of trees and grasses having low nutritional value and high levels of condensed tannins, which support relatively small numbers of large herbivores (Andrews and O'Brien 2000; Parker 2004). The mean annual precipitation is $650 \mathrm{~mm}$ per year and falls during the hot summer months from November to April with the winters being cold and dry. Welgevonden is situated on the Waterberg Plateau in South Africa $\left(24^{\circ} 10^{\prime} \mathrm{S} ; 27^{\circ} 45^{\prime} \mathrm{E}\right.$ to $\left.24^{\circ} 25^{\prime} \mathrm{S} ; 27^{\circ} 56^{\prime} \mathrm{E}\right)$, approximately $20 \mathrm{~km}$ west of the town of Vaalwater and $270 \mathrm{~km}$ north of Johannesburg (Figure 1.1). Welgevonden has an area of $348 \mathrm{~km}^{2}$, it is a privately owned nonprofit protected area, which was established in 1993 and declared a protected area by government gazette in November 2014. Welgevonden adjoins the Marakele National Park to the southwest, Shambala Private Game Reserve to the southeast and the remainder of the reserve is surrounded by a combination of cattle, agricultural, hunting and private game farms.

Welgevonden was established in an area not ideally suited for the creation of any form of protected area, and yet was established for the "Big 5" (lion - Panthera leo, leopard Panthera pardus, African elephant - Loxodonta africana, hook-lipped "black" rhinoceros Diceros bicornis and African buffalo - Syncerus caffer), which are the iconic eco-tourism viewing species. It is the owner's opinions (by way of the Board of Director's) that due to the investment and expected yield of the reserve from an ownership and tourism perspective, it 


\section{Chapter 1}

is of paramount importance that the reserve be successful and produces the expected and required output for financial optimality. This can only be achieved through game viewing as Welgevonden's Memorandum of Incorporation does not permit hunting. The charismatic "Big $5 "$ concept is considered key for financial competitiveness of protected areas in South Africa (Di Minin et al. 2013).

In order to achieve this, the management of Welgevonden is required to monitor and manage the animals and vegetation to ensure that the biodiversity of the reserve remains as high as possible. Yet, at the same time the management is required to achieve the highest possible game viewing satisfaction of animals (mammals and birds), and it would like to become the "Best Managed Big 5 Game Reserve in the world".

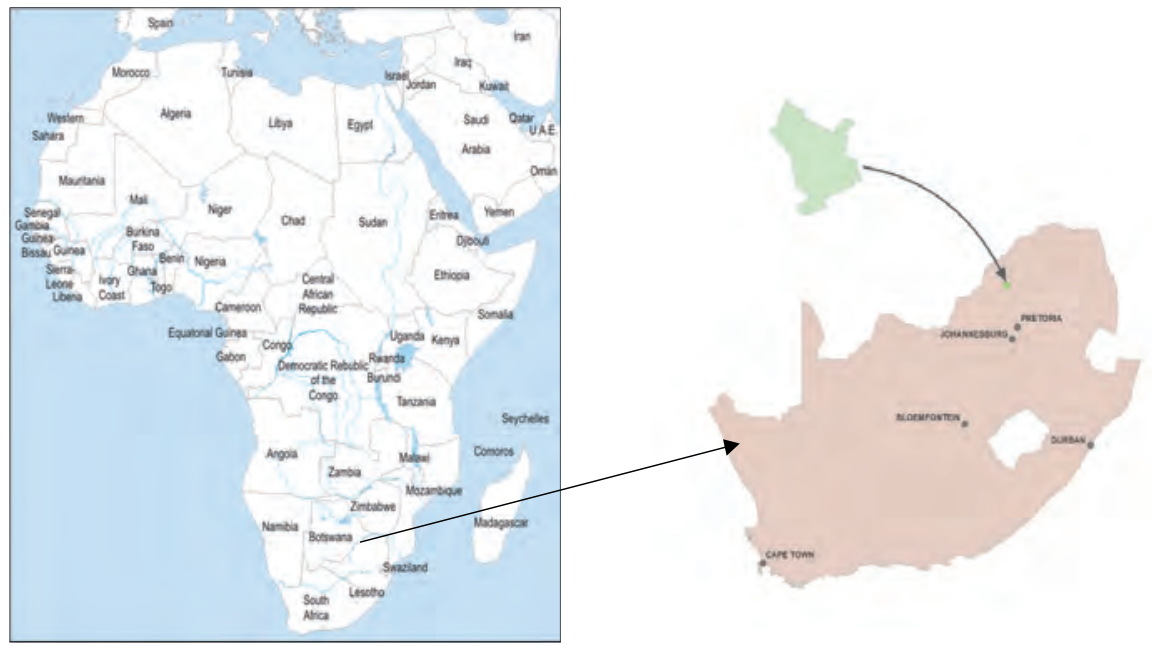

Figure 1.1 A map indicating the African continent with an insert showing South Africa. The additional insert shows the location and layout of Welgevonden Game Reserve, the study area on the Waterberg Plateau, where all the research and experiments were undertaken 


\section{Chapter 1}

Sixty-four mammal species have been recorded in the study area. Due to the nutrient poor soils and the erecting of game fences to protect surrounding farms and communities against potentially dangerous animals, the management has identified that in order to ensure the long-term survival of mammal species within the system, manipulation and interventions of the vegetation may be vital to provide food of high quality in large amounts for the large herbivores and hence food for carnivores. Nowadays, Welgevonden may be characterized by a 'fire-driven state', in which the annual grass production is not used by large herbivores, becomes unpalatable, and poses a high fire risk to properties, people and the overall biodiversity of the area. Low densities of large free-roaming herbivores are found in such areas. A 'herbivore-driven state' with grazing lawns due to frequent and intense grazing would be more beneficial for the all-round reserve management objects. In such systems, high densities of large free-roaming herbivores can be maintained.

The reality of biodiversity preservation in an ever-more crowded Africa is that areas that are prime for agricultural production are increasingly needed for just that: agricultural production to feed the human population. In Africa, the human population is currently estimated at 1.3 billion people and is projected by the United Nation's medium growth scenario to be approximately 4.3 billion people by the year 2100 (United Nations 2011). This implies that biodiversity preservation has to find a societally acceptable setting, namely, that the costs associated with conservation can hardly be paid for by governments that face financial burdens such as social upliftment of people out of poverty. This results in an increasing need to focus on agriculturally marginal areas for conservation. However, such marginal areas carry low densities of wildlife, thus drawing few tourists. Hence, in my thesis, the management question stands central of how to turn a marginal, fire-driven system into a herbivore-driven system with high densities of grazers and browsers supporting large predators that draw 


\section{Chapter 1}

tourists (Lindsey et al. 2007). To achieve this target, management is needed and required to be based on the best available science and well-executed experiments to investigate whether such management interactions are effective (and ultimately cost-effective).

\section{Quest - does current ecological theory meet the challenge?}

The greatest threats to biodiversity globally, according to the Intergovernmental SciencePolicy Platform on Biodiversity and Ecosystem Services (IPBES) (2019), are summed up in five major categories (1) land and sea use changes, (2) resource extraction, (3) pollution, (4) invasive alien species and (5) climate change. Agricultural expansion (with over one third of the terrestrial land surface being used for crops or animal husbandry at the expense of forests, wetlands, grasslands and many other natural land cover types) and human population growth (with the association of urbanization and higher income, which are linked to increasing per capita resource consumption) are the drivers of these threats (Asner et al. 2009; Ripple et al. 2015; IPBES 2019). In order to conserve biodiversity, these threats need to be addressed (although the directions of the solutions are highly debated), which will allow for long-term conservation, social upliftment and economic sustainability of protected areas.

Savannas generally contain high levels of biodiversity, including many large animals, and are at the same time commonly used by humans for food, water, grazing and browsing for livestock and fuel (Osborne et al. 2018). More than half of Africa and Australia, about $45 \%$ of South America and $10 \%$ of India and Southeast Asia are covered by savannas (approximately $20 \%$ of the earth's land surface). Savannas are thus important from a socio-economic aspect as the majority of the earth's rangeland and livestock are located in savannas (Scholes and Archer 1997; Reilly 2014; Osborne et al. 2018). Savannas are amongst the most variable of terrestrial ecosystems (Walker and Noy-Meir 1982) and can be found on both nutrient rich 


\section{Chapter 1}

soils, characterized by palatable grasses with often well-digestible fine leaved woody vegetation, and on nutrient poor soils (like Welgevonden Game Reserve), characterized by less palatable grasses with often indigestible broad leafed woody vegetation (Scholes and Archer 1997; Mucina and Rutherford 2006). Besides soil nutrients, woody vegetation and grass cover, savannas are influenced by mean annual precipitation (or more precisely infiltration), fire and herbivory (Van Langevelde et al. 2003; Sankaran et al. 2008; Holdo et al. 2009; Mbatha and Ward 2010; Venter et al. 2017). The two soil resources, water and nutrients, are considered prime resources in controlling the structure of savannas, both for plant production and herbivore survival (Olff et al. 2002; Mbatha and Ward 2010; Van der Waal 2010). Plant abundance increases with rainfall and the leaf tissue content of nitrogen as an index of plant quality to herbivores decreases with availability of water for plants (Prins and Olff 1998; Olff et al. 2002).

Savannas are characterized by different states of grass layers (Asner et al. 2009; De Michele et al. 2012; Venter et al. 2017). One state with tall grasses with low large free-ranging herbivore numbers and low predator numbers, resulting in high grass biomass that provides fuel load for high frequencies of hot fires (fire-driven system). The tall grass has low quality food for mammalian grazers (Heitkönig and Owen-Smith 1998; Ferwerda et al. 2006; Klop and Prins 2008; Kleynhans et al. 2011). The other state with short grasses and high large freeroaming herbivore numbers with subsequent potential high predator numbers, resulting in low grass biomass as fuel load, which results in few fires (herbivore-driven system). The short grasses are generally of high quality, i.e., high concentrations of minerals ( $\mathrm{Na}, \mathrm{N}, \mathrm{P}, \mathrm{K}, \mathrm{Mg}$ and Ca) in their tissues (McNaughton 1984, Stock et al. 2010, Anderson et al. 2013, Veldhuis et al. 2014), have high digestibility and result in a high intake rate (Drescher 2003; Drescher et al. 2006) as food for large free-roaming herbivores (Scholes and Archer 1997; Sankaran et al. 


\section{Chapter 1}

2008; Holdo et al. 2009; De Michele et al. 2012; Venter et al. 2017). Venter et al. (2017) suggest that rewilding of African rangelands with mid-Holocene herbivory pressure and diversity may shift a system from a tall unpalatable grass to a short nutritious grass state, which may enhance nutrient cycling, conserve soil nutrient pools and benefit herbivore productivity.

One of the major problems associated with many nutrient poor (or dystrophic) savannas, is the fact that these areas are generally fire-driven systems, resulting in nutrient poor grass that is unpalatable for most large free-roaming herbivores. Research has shown that fire may lead to nitrogen depletion from savanna ecosystems (Holdo et al. 2007) but fires (because of their scale in size) also cause the dispersion of grazers over a large area thus "diluting" grazing intensity. Both processes result in low grazing pressure that allow grasses to escape herbivory and become low in food quality, which cascades into lower fecundity of the herbivores, reducing the herbivore numbers, thus creating a feedback loop towards additional tall grasses and higher risks of fire (Van Langevelde et al. 2003).

According to Van der Waal (2010) there have been few studies done on nutrients in the soils of savannas and his literature review of articles dealing with determinants of vegetation structures in savannas shows that only $17 \%$ of the articles deal with nutrients. There seems to be agreement that savanna grass production is strongly co-limited by both nitrogen and phosphorous (Craine et al. 2008; Van der Waal 2010; Kambatuka et al. 2013). Asner et al. (2009) posit that the impact of herbivores on vegetation is strongly mediated by the distribution of nutrients on the landscape. The relations between soil nutrients, plants and herbivores are however poorly understood (Pringle et al. 2016). Some studies investigate these relationships, such as Pringle et al. (2016) who found that large herbivores filter plant 


\section{Chapter 1}

communities which superficially appear to be abiotically determined, showing that herbivory interacts with abiotic forces to generate savannas. Bardgett and Wardle (2003) stated that soil fertility determined plant productivity and the direction of nutrient-mediated herbivore effects. They also showed that herbivore effects and plant productivity are large on nutrient rich soil and low on nutrient poor soil. There is an under appreciation of the role large herbivores play in creating and maintaining soil nutrient heterogeneity (Jacobs et al. 2007).

It thus appears that grazing lawns can occur in an area, which is advantageous for large grazers: (1) they can reach a high intake rate of (2) well-digestible, nutritious grass in areas that if sufficiently large (3) offer no cover for predators. It is also clear that if tall grass dominates an area, grazers get (1) an insufficient intake rate, of (2) low digestible food; such a system will stay in a fire state, which results in (3) low herbivore densities, (4) few predators and (5) poor wildlife viewing. This fire state is then the stable state (Van Langevelde et al. 2003), and the question is then how can one 'jolt' the system out of this undesired state? Once a system is in a 'lawn-state', however, it (1) cannot burn, (2) it can carry high densities of grazers, (3) that can maintain large predators, which (4) are well visible to support a viable tourist industry (generating political and economic support). The 'jolting' from the stable fire state into the productive high grazer - high predator state occurs rarely in nature. As a result, human intervention may be the key!

For many years conservationists and scientists have used the laissez-faire approach of descriptive science, which is basically a policy of "leaving things to take their own course without interference". It is important to change this focus to evidence-based conservation, which allows conservationists and scientists the opportunity to achieve their goals through the use of science. With numerous threats affecting conservation world-wide, especially 


\section{Chapter 1}

competition for land use between agriculture and conservation, many protected areas are limited in size and fenced to protect humans from animals and vice versa. Thus, the laissezfaire approach is not viable in nowadays protected areas as both fauna and flora need to be managed to ensure the long-term survival of the biodiversity of these areas. Evidence-based conservation on the other hand allows for scientific studies to guide management in achieving their goals and objectives pertaining to the management of the fauna and flora of each protected area to ensure longevity of the biodiversity of the area. The scientific results of studying vegetation afford management the opportunity to understand how vegetation supports herbivores. It is important to understand what herbivores require from their diet in order to survive. Most herbivores strive to acquire a diet, which is of higher quality in terms of nutrient and energy content, and digestibility, than the average quality of the available forage (Drescher 2003; Prins and Van Langevelde 2008).

Protected areas are often too small or insufficiently fertile to sustain large numbers of herbivores and predators, which has a negative effect on game viewing and the financial income sustained from this. Textbook solutions to manage protected areas do not exist even after 50 years of ecological studies (Fryxell et al. 2001; Owen-Smith 2007; Prins and Van Langevelde 2008). One of the largest challenges faced by management in maintaining both game viewing and prey species, is to ensure that herbivore densities are sufficiently high to maintain sustainable populations of both herbivores and predators, especially on nutrient poor soils.

To answer the question "does current ecological theory meet the challenge?" the answer is "no". It is evident that approaches such as laissez-faire management do not work, especially in fenced, nutrient poor savannas. Large free-roaming herbivores require nutrients in their 


\section{Chapter 1}

diet to ensure fecundity and thus in a nutrient poor savanna, evidence-based conservation is required to produce the desired outcomes of owners and managers of these protected areas.

\section{Scientific challenges}

The vegetation structure in savannas is known to be controlled by the availability of water and nutrients, and further influenced by fire and herbivory. This has been confirmed by voluminous studies on the savanna ecosystems (Van Langevelde et al. 2003; Sankaran et al. 2004; Sankaran et al. 2008; Holdo et al. 2009; Mbatha and Ward 2010; Venter et al. 2017). However, the exact interfaces between soil nutrients on the one hand, and plants and herbivores on the other hand are poorly understood (House et al. 2003; Sankaran et al. 2004; Cech et al. 2008). The grazing lawn concept was first identified by Vesey-FitzGerald (1969). McNaughton (1984) described grazing lawns as an assemblage of grass species, which can tolerate intensive grazing, are more drought tolerant (Hasegawa et al. 2000; Munns 2002; Bartlett et al. 2012) and produce higher productivity and food quality. The primary focus of this thesis is to understand how soil nutrients, grass categories (short stoloniferous lawn grasses and tall bunch grasses) and herbivores in nutrient poor savannas interact, and to establish how to increase the forage quality for large free-roaming herbivores in these areas. In this thesis, I address the question whether nutrient addition leads to the establishment of the desired grazing lawns in a nutrient poor savanna. Such addition is hypothesized to result in a switch ("jolt") from tall, nutritionally poor grass to short, highly nutritional grass species. I expect to find that the addition of nutrients will result in a higher number of grazers utilising the grazing lawns with the result that the grazing lawns can be initiated and subsequently expand. 


\section{Chapter 1}

\section{Research objectives and questions}

In this study, I aim to obtain a better understanding of the relationship between large freeroaming herbivores in a nutrient poor savanna and ways of improving the quality of the forage. The main hypothesis of this thesis is that a savanna can be forced from a state with low quality forage as food for large free-roaming herbivores, to a state with high-quality forage through proactive management of these systems. My thesis provides scientific understanding of how sustainable populations of large herbivores in an area with tall grass with low nutritional value can be established. This will improve our understanding of managing nutrient poor savannas in order for conservationists to look outside the currently recognised practices of conservation principles to establish unique ways of creating protected areas in regions with no or limited alternative land use and thus no or limited competition from humans and their associated needs. The establishment of grazing lawns has further benefits to management by promoting the area to be less prone to natural fires, which results in a safer environment for people, infrastructure and animals in the protected area, resulting in economic savings. Therefore, I will address four topics:

As many protected areas in savannas contain nutrient poor soils such as large parts of Kruger National Park (Biggs 2003; Redfern et al. 2003), Marakele National Park (South African National Park 2020) and Saadani National Park (Cech et al. 2008), I made an overview to unravel the reasons for establishing protected areas in Southern and Eastern Africa, and the possible consequences for management of these areas today.

To understand the effects of the addition of different nutrients into a nutrient poor savanna on both soil and grasses. I expect that lawn grasses will establish due to these nutrient additions. 


\section{Chapter 1}

To establish the effect of nutrient addition to the grass on visitation and grazing time of different herbivore species. I expect that nutrient addition will increase the visitation and grazing time of different herbivore species allowing and maintaining the establishment of grazing lawns.

To establish the effects of polyethylene glycol (PEG, a polymer that binds with tannins) on the diet change of five large free-roaming herbivore species. I expect that the addition of PEG to the diet of especially browsers will allow them to change their diet to include species with higher condensed tannin levels thus reducing food shortage during certain times of the year.

\section{Study design}

To test the effect of nutrient addition on the grass cover, the study design consisted of field experiments with eight sites spread throughout Welgevonden. We divided each of the sites into five plots, each minimally $300 \mathrm{~m} \times 150 \mathrm{~m}$. The plots were treated annually between the months of January and February with either the addition of nitrogen or phosphorus. We further investigated the supplementation of lime. For that reason, we also fertilised with nitrogen and lime, phosphorus and lime or a plot with no treatment (control). Cameras were used to assess animal abundance and utilisation of the various plot experiments (Figure 1.2). Game lick blocks were placed at various intervals throughout the reserve with or without polyethylene glycol (PEG). This was done to establish if browsers utilising PEG would be able to eat leaves with higher secondary compounds (tannins). 


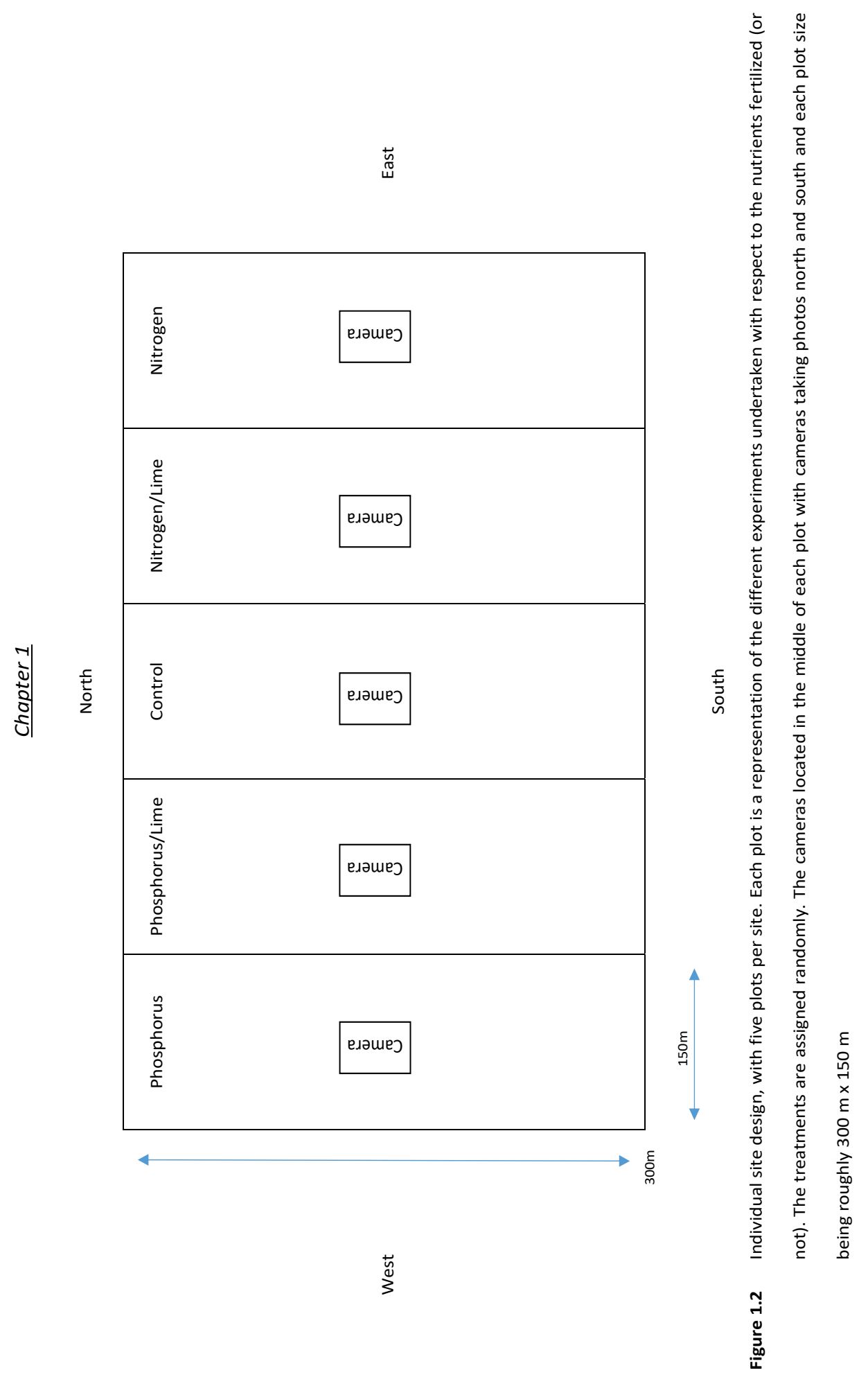




\section{Chapter 1}

\section{Thesis Outline}

To address the overall objective and answer the research questions, the thesis has the following outline (Figure 1.3):

In chapter 2, I dealt with how game reserves were established in Southern and Eastern Africa and the effects which this has potentially had on modern day conservation managers. This paper addresses the questions of what the reasons were for establishing protected areas and what may be the consequences for management of these areas today? The paper identifies three distinctive periods in which protected areas were established.

In chapter 3, I tested whether nutrient addition could lead to establishment of grazing lawns in Welgevonden Game Reserve, a nutrient poor savanna in the north of South Africa, in order to achieve a switch from tall and nutritionally poor grass species to short and highly nutritional grass species.

In chapter 4, I investigated differences in the visitation of large free-roaming herbivore species on fertilized and control sites. This study will add to understanding which animals can help to establish and maintain grazing lawns after the nutrient pulse.

In chapter 5, I looked at the effects of supplying nutrient supplement game lick blocks for large free-roaming herbivores in a protected area with poor quality vegetation. The addition of PEG to the standard game lick block should result in animals being able to utilise more plant species with higher tannin contents.

In the final chapter 6 , I summarized and integrated all the results obtained from the previous chapters and discuss new perspectives obtained through the thesis pertaining to grazing lawn establishment and speculate about the effects on populations of large free-roaming 


\section{Chapter 1}

herbivores, with the end goal being to have contributed to the scientific understanding of the establishment and maintenance of grazing lawns and establishing better forage quality in nutrient poor savannas.

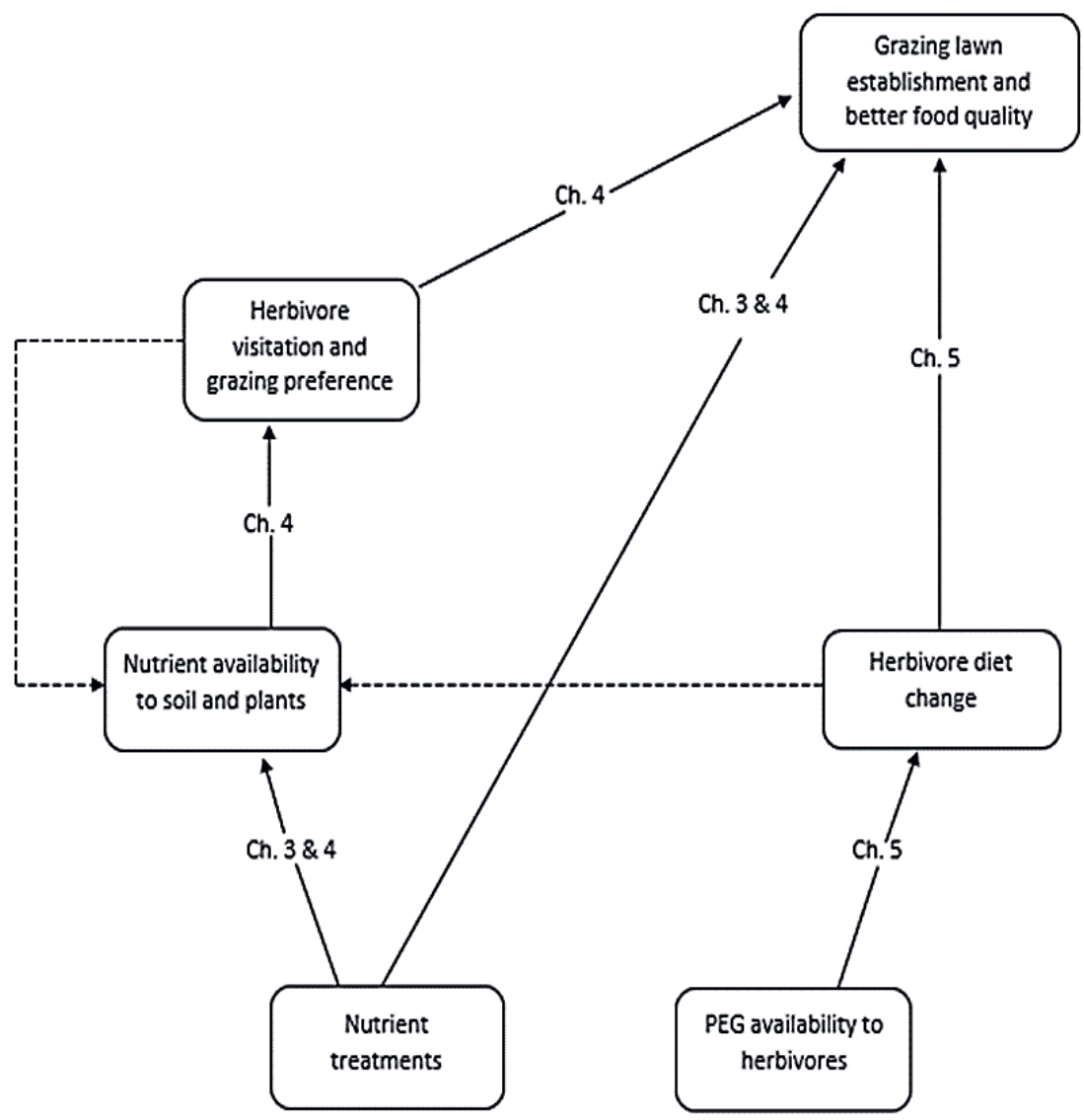

Figure 1.3 A framework showing the research aspects for the individual chapters. The solid lines show the increased nutrient availability, resulting in grazing lawn establishment and better quality food for the herbivores. Chapters 3 and 4 had a range of nutrients fertilized on the research plots, increasing nutrient availability to the soil and expectantly to the plants. The increase in nutrient availability expectantly attracts herbivores to the study sites, changing the grass type and ultimately producing grazing lawns and better quality food. Chapter 5 shows with the addition of Polyethylene glycol (PEG), there is an expectant change in herbivore diet choice/selection allowing 


\section{Chapter 1}

herbivores to browse species with higher secondary compounds (tannins). This will ultimately lead to better food availability for the herbivores. The dotted lines represent the return flow of nutrients into the soil as faeces and urea 


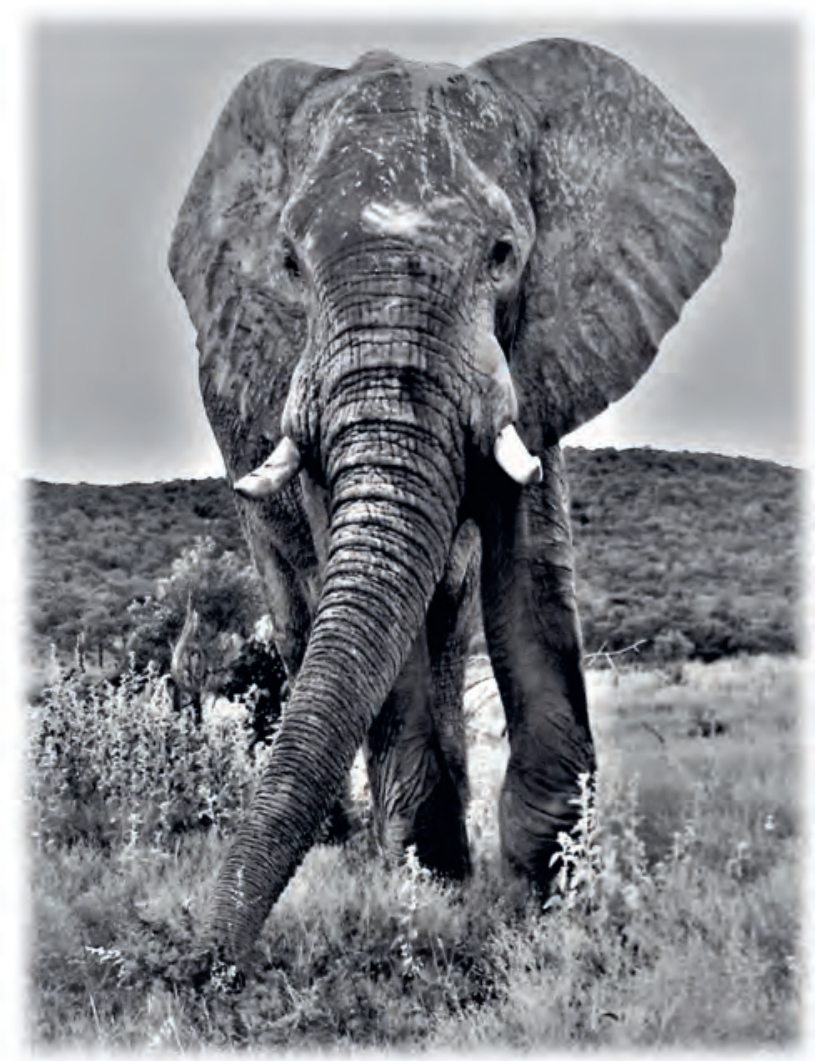

Photograph 4: Elephant bull foraging, Figtree Plains, Welgevonden Game Reserve (Camera trap photograph) 


\title{
Chapter 2
}

\section{Chapter 2}

\section{Protected area establishment in Southern and Eastern Africa: Consequences for}

\author{
management today
}

\section{BRADLEY SCHRODER}

Wildlife Ecology and Conservation Group, Wageningen University, Droevendaalsesteeg 3a, 6708 PB Wageningen, the Netherlands

FRANK VAN LANGEVELDE

Wildlife Ecology and Conservation Group, Wageningen University, Droevendaalsesteeg 3a, 6708 PB Wageningen, the Netherlands and School of Life Sciences, Westville Campus, University of KwaZuluNatal, Durban 4000, South Africa

HERBERT H. T. PRINS

Animal Sciences Group, Wageningen University, De Elst 1, 6708 WD Wageningen, the Netherlands

Submitted to Tropical Conservation Science 


\section{Chapter 2}

\section{Abstract}

To understand the complexities of managing protected areas, it is important to understand the causes for their establishment. We summarized the motives for establishing protected areas in Southern and Eastern Africa, and the possible consequences for management of these areas today. We scrutinised documents for 48 protected areas and investigated, (1) when and why each of the protected areas was established? (2) what the management implications were of the reasons for incorporation for these areas? and (3) how/if the original management still impacts conservation in these areas today? First, we learnt that the establishment of protected areas occurred in three periods, namely, Period 1: Area protection was started to protect wild animals from decimation; Period 2: Areas considered marginal for agriculture, prone to disease or sickness and considered uninhabitable for human settlement at the time; and Period 3: Areas are proclaimed with protected status due to ecological or cultural importance. Second, we showed that the establishment of protected areas has ramifications for management of these areas today, which for Period 1 were remote logistics and tourism, anti-poaching difficulties, large size logistics and human wildlife conflict. Period 2 has consequences for community-land issues and intensive management, with Period 3 having intensive management to meet the objectives of these parks. Our insights have consequences for management of protected areas today, with Period 1 protected areas managed (or not) in some form of benign neglect or crisis intervention (laissez-faire approach) and Period 2 and 3 protected areas being managed more intensively approaching passive adaptive management.

Keywords: agriculture, conservation, historical, human population growth, management, nature, wildlife 


\section{Chapter 2}

\section{Introduction}

"Only 50 years ago, man had to be protected from the beasts; today the beasts must somehow be protected from man" (Beard, 1988). Biodiversity is declining rapidly, caused by a variety of factors including human population growth, habitat loss, intensification of agriculture, urban sprawl, alien plant invasion and plantation forestry (Cousins et al., 2008; Huang et al., 2016; Sandbrook et al., 2019) which has the potential to threaten human life (Buitenland, 2019) but also nature. In Africa, subsistence hunting was undertaken since the Palaeolithic period, with populations of many wild animals, in Southern and Eastern Africa, being decimated especially after the commencement of a market driven economy and associated human population boom (Spinage, 1973; Waller, 1985; Carruthers, 2008; Cioc, 2009; Zulu, 2015). Early writers, missionaries and traders described Southern and Eastern Africa as the 'nursery grounds' for wild animals (game) and a hunter's paradise (Elton, 1873; Wagner, 1980; Cioc, 2009). It must be recognised that most literature produced at that time in Africa were diaries written by Europeans, so we may have a distorted view point of the history of game utilisation due to the African people not documenting observations; indeed, much African history is captured in oral narration and will never be known in detail (Waller, 1985; Nash and Endfield, 2002) unless carefully analyzed (e.g., Kesteloot, 1992; Giles-Vernick, 2011). For many African peoples, game had a symbolic meaning with the most valuable animal products such as leopard (Panthera pardus) skins and African elephant (Loxodonta africana) ivory being reserved for special use by the kings and chiefs (Zulu, 2015) and hunting itself was primarily a subsistence activity (Duffy, 2014).

During the 1830s and 1840s in Southern Africa, the "Voortrekkers" (Dutch for pioneers, also called Boers) moved away from the coastal colonies under British rule to establish 


\section{Chapter 2}

independent states in the interior and flee foreign occupation. As the Voortrekkers moved inland, their lifestyles depended on and revolved around hunting and pastoralism (Plug et al., 2000; Zulu, 2015). This coupled with the so-called hunting expeditions by European "sportsmen" and the ivory trade, led to the largest slaughter of wildlife in the mid-nineteenth century (Spinage, 1973; Murombedzi, 2003; Carruthers, 2008; Cioc, 2009; Zulu, 2015). This was by no means only a problem associated with Africa; for example, vast herds of bison (Bison bison) were decimated in North America due to hunting and the establishment of human settlements (Muir-Leresche and Nelson, 2000; Child et al., 2012).

In the first half of the twentieth century, it was considered common practice in Southern and Eastern Africa, that game should be exterminated to make way for domestic animals such as cattle (Bos taurus), sheep (Ovis aries) and other domestic species (Murombedzi, 2003; Carruthers, 2008; Cioc, 2009). In 1903, for example, the government of Kenya introduced a scheme whereby settlers were paid to kill certain species of wild animals, especially carnivores (Murombedzi, 2003). The various agricultural and game departments acted accordingly and decimated game throughout Southern and Eastern Africa (Carruthers, 2008). For example in Rhodesia (now Zimbabwe) and Zambia, it became an official government policy to eliminate wildlife wherever it was perceived to threaten or compete with agriculture in any way or form.

Not only competition for resources and predation of livestock resulted in a decline in wild animal populations, disease control implemented for diseases such as bovine pleuropneumonia (1850), rinderpest (1896) and tsetse fly, also lead to game decimation (Mutwira, 1989; Cioc, 2009). The idea that wild animals were the primary vectors of disease, almost brought wildlife to extinction in Southern and Eastern Africa. In the Zambezi and Savé 


\section{Chapter 2}

valleys between 1919 and 1958, for example, over 660,000 head of game were shot as part of disease control (Child and Riney, 1987), and between 1919 to the 1980s, thousands of wild animals including rhinoceroses were shot in the name of tsetse fly control (Taylor and Martin, 1987; Prins, 1996). Moreover, during the 1980s, large areas were fenced to control foot-andmouth disease in a number of Southern African countries (Child et al., 2012), which lead to animals dying from starvation and lack of water (especially migratory animals).

It was becoming obvious by the late eighteenth century that the continued decimation of wild animals could not be sustained, or extinction of the majority of species would be imminent (Carruthers, 1988; Gibson and Marks, 1995). In pre-colonial Botswana, for example, the reduction of animal populations led to a monopolization of access to wildlife; the Tswana chiefs were given control over traditional, foreign commercial and sport hunting (Hitchcock, 2001; Neumann, 2002; Murombedzi, 2003; Pangeti and Manyanga, n.d.), which may have led to a form of protection. In the late 1800 s a number of people including conservationists, sports hunters and military personnel decided that wild animals needed protection to ensure their survival and for sustainable utilisation in the future. Pre-colonial conservation in South Africa was devised by means of several strategies for conserving nature while at the same time guaranteeing access to it (Murombedzi, 2003). Examples of these are the Sabi Game Reserve which was established to protect animals for hunting (this was a decision made by the Volksraad in 1898), Kruger National Park started through political agendas, and the Bontebok National Park started to protect the Bontebok species. The cutting edge of conservation at that time lay in South Africa, with the establishment of the continent's first game reserve in 1895, Hluhluwe-Imfolozi, in Zululand. This was followed by the first protected area in 1898, the Sabi Game Reserve, which in 1926 became the country's first National Park and was renamed, the Kruger National Park (Rangarajan, 2003). 


\section{Chapter 2}

In the beginning of the twentieth century, there were three policy decisions taken in South Africa which would have long-lasting implications for conservation. Firstly, promotion of the formation of state protected areas; secondly, restriction of the commercial use of wildlife, rendering wildlife valueless except for low-value subsistence uses; and thirdly, centralization of ownership of wildlife in the state, disenfranchising landholders and taking upon themselves the burden of protecting wildlife from people (anti-poaching) and protecting people from wildlife (problem animal control) (Heijnsbergen, 1997; Child et al., 2012). While the origins of European interest in Southern and Eastern African wildlife conservation can be traced to the activities of aristocratic hunter-naturalists, late colonial Africa became the proving ground for political and technical strategies of conservation organisations that are today key parts of global environmental management (Neumann, 2002). This was supported by European countries in 1900, at the conference of the "Preservation of Wild Animals, Birds and Fish in Africa", held in London (Neumann, 2002; Coic, 2009) and in 1933 at the conference of the "Protection of the Fauna and Flora of Africa" (Neumann, 2002). The conference only included certain African countries under European control and the majority of people involved in the conferences came from British or European aristocracy and all big game hunters. The conference primarily focussed on what they called the "indiscriminate slaughter" of wildlife by Africans and their recommendations were to outlaw most customary African hunting practices. It only protected a handful of animals, declared subsistence hunting as poaching and only allowed hunting of wild animals with a permit (Mutwira, 1989; Grobler, 1996; Cioc, 2009). Yet, many efforts failed and even the leading politician of the Union of South Africa (General Jan Smuts) was unable to sway land owners, miners and the civil administration into the creation of a large protected area centred on what is now the Mapungubwe National Park in the 1940s (Carruthers, 1992). 


\section{Chapter 2}

There were many changes to conservation policies over the coming century but it was in the early 2000s, that the South African Government noticed numerous flaws in the legal framework for the identification, declaration and management of the majority of protected areas, which led in 2003 to the overhaul of the country's national conservation regime with the establishment of the National Environmental Management: Protected Areas Act 2003 (NEM:PAA) (Paterson, 2009) (Supporting information 2A).

\section{The protection of natural resources during the colonial era}

During the colonial era, in Southern and Eastern Africa there were similar motives for the establishment of protected areas. To illustrate this, we describe the developments in a number of countries, i.e., Sudan (in what is now South Sudan), Rhodesia (now Zambia and Zimbabwe) and Kenya. In the Sudan, for example, the decimation of wildlife started with colonial sport hunting parties such as those undertaken by Roosevelt in 1909, which brought the concept of the 'safari' to international attention (Duffy, 2014). In more recent times, the bush meat trade and especially the years of warfare in which wild animals were used to feed soldiers, had a large toll on wildlife. Rhodesia based its game legislation on Roman Dutch law, which established that wild animals were "res nullius", which is "a thing or things which can belong to no one" (Oxford Dictionary, 2017). This resulted in wild animals being seen as "Royal Game", to be held by the king (of Britain), in his "sovereign capacity for the people" (we will not delve into the justification of that: see for instance Strang (1996) or Culhane (1998) but from the colonial power's point of view it was based on its concept of lus publicum (public law) (Marston, 1996), even though that was perhaps merely a fictitious concept to justify resource grabbing by right of conquest (Kirby and Kirby, 1931). In 1889, the policy of game preservation was written into the Charter of Incorporation, which signalled the beginning of 


\section{Chapter 2}

game legislation in Rhodesia. The ordinance declared the preservation of certain wild animals, specifically African elephant (Loxodonta africana) and that no interference with hunting rights bestowed on native chief's or peoples could be undertaken unless to enforce closed seasons (Charter of the British South Africa Company, 1889). The Game Preservation Ordinance, No 6 of 1899 , was the first official law to protect wildlife and declared species such as the African elephant, common eland (Taurotragus oryx), giraffe (Giraffa camelopardalis), gemsbok (Oryx gazella), hippopotamus (Hippopotamus amphibius), greater kudu (Tragelaphus strepsiceros), ostrich (Struthio camelus), square-lipped "white" rhinoceros (Ceratotherium simum), hooklipped rhinoceros (Diceros bicornis) and Burchell's zebra (Equus quagga burchellii) as "Royal Game" and prohibited their killing, hunting or capture, unless permission was granted by the administration (Mutwira, 1989). The Game and Fish Preservation Act in Rhodesia (No. 35 of 1929) allowed for the establishment of game reserves, and in 1929 the Matopo National Park was established as Rhodesia's first national park. This was intended to preserve all species of flora and fauna occurring in the designated area, which would be protected from hunting and used for scientific, educational and aesthetic purposes (Murombedzi, 2003). The 1930s saw a vast increase in game reserves, the appointment of wardens and the legislation of private game reserves (Mutwira, 1989). The Department of National Parks was established in 1949, which led to the single most important change in Rhodesia's conservation history, the promulgation of the Parks and Wildlife Act in 1975, which conferred privileges on the owners and occupiers of alienated land as custodians of wildlife.

In 1899 and 1900, respectively, the Kenyan government established the Southern and Northern Game Reserves, covering nearly $70,000 \mathrm{~km}^{2}$, and the establishment of the Game Department in 1907 to protect reserves and enforce game laws. As with most other game departments of the time, this was hampered by a lack of money, insufficient and unqualified 


\section{Chapter 2}

staff. The Kenya Game Department established a "vermin policy" which eradicated all species seen to be a threat to humans or agriculture, both inside and outside of protected areas. This included but was not limited to species such as lion (Panthera leo), leopard, spotted hyaena (Crocuta crocuta) and wild dog (Lycaon pictus), with devastating effects on these species (Carruthers, 1988; Mutwira, 1989; Waithaka, 2012). In 1932, the British government decided on the establishment of "National Parks and reserves where hunting, killing or capturing of fauna, and the collection or destruction of flora would be limited or prohibited", which resulted in the establishment of the $117 \mathrm{~km}^{2}$ Nairobi National Park in 1946.

Wildlife formed a focus for the divergent interests of the black Africans, Afrikaners and British in South Africa (Carruthers, 1988). As rural African populations grew, local subsistence hunting was deemed to threaten wildlife and this was treated as poaching (Mutwira, 1989). Poachers were prosecuted by the colonial authority of the time, which embedded military approaches and values in modern conservation practices, this has become known as "green militarization" (Mutwira, 1989; Dahlberg et al., 2010; Duffy, 2014; Hitchcock, 2019). The local populations saw this traditional style of livelihood as a right and by removing their hunting rights it established a sense of injustice and negativity towards protected areas, wildlife and the state (Gibson and Marks, 1995; Child et al., 2012). At the twilight of colonial Africa, many leading conservationists met at the Arusha Conference on the 'Conservation of Nature and Natural Resources in Modern African States', realizing that a new post-colonial narrative was needed to conserve wildlife (Watterson, 1961) and that wildlife needed to become an economic asset according to the emerging 'use it or lose it' philosophy. This was formalized at the Conference of Parties of the Convention on Biological Diversity (1998) by all Member States accepting the Principles of Sustainable Use (Supporting information 2A). 


\section{Chapter 2}

During the period from 1970 to 2005 , a number of national parks and wildlife reserves across Africa lost up to $60 \%$ of their wild animals. Researchers studied animal population changes on 78 protected areas across Africa and found that West Africa had lost up to $85 \%$ of its wildlife in 35 years, and East Africa nearly 50\% (Ottichilo et al., 2000; Ottichilo et al., 2001; Vidal, 2011). It was only found that wildlife numbers increased in Southern Africa (Child et al., 2012). There is a large amount of speculation as to why there has been a decline in wildlife numbers across the continent and with limited scientific proof as to the exact causes. It is certain that politics, historically poor management of conservation areas, lack of funding, lack of qualified personnel, lack of political support, human activities encroaching on wildlife areas, wars, bush meat trade, veterinary interventions and poaching are all severe causes of the decline (Mbaiwa and Mbaiwa, 2006; Cioc, 2009; Vidal, 2011). Growing human populations, unsustainable hunting, high densities of livestock, and habitat loss have devastating consequences for large herbivore species, their ecosystems, and the services they provide (Ottichilo et al., 2001; Ripple et al., 2015).

\section{Different periods of the establishment of protected areas in Southern and Eastern Africa}

Given the various timelines (Supporting information 2A) and explanations for the establishment of protected areas as given in this overview, we defined the establishment of protected areas in Southern and Eastern Africa in three "periods". It is known that not all countries have identical timelines in history, thus we distinguish "periods" which are not necessarily in synchrony in the different Southern and Eastern African countries but which we believe all these countries undergo.

We identify Period 1 as the establishment of protected areas that were initially started to protect wild animals from decimation for utilisation and enjoyment in the future (primarily by 


\section{Chapter 2}

sports hunters) (Carruthers, 1988; Murombedzi, 2003). An example of Period 1 is the Sabi Game Reserve in South Africa, established in 1898, later to become known as the Kruger National Park (1926). With the establishment of the continent's first national park, the Kruger National Park, conservation paradigms throughout the continent had begun to change. In the Kruger Park, sports hunting was forbidden in an attempt to protect the last remaining wild animals. Such an act of creating a park was not merely a gesture to save nature, but to redefine who owned it (Rangarajan, 2003). The creation of many protected areas around the world often resulted in the alienation of indigenous populations from their land and resources (Kepe et al., 2005; Hitchcock, 2019).

Period 2 is identified as areas that were initially considered marginal for agriculture (both crop and stock), prone to disease or sickness, considered uninhabitable for human settlement at the time, with a struggling yet established wildlife population (Department of Environmental Affairs and Tourism, 1997; Paterson, 2009). Due to the marginal land not being sustainable for agriculture and/or farming, it was used for hunting and tourism in order to secure an income. An example of this type of protected area is the St Lucia Game Reserve in Zululand (South Africa), established in 1895. The locations of these types of protected areas were predetermined by the presence of Tsetse fly and malaria, hence unsuitable for livestock, or by the fact that their agricultural potential was poor (Department of Environmental Affairs and Tourism, 1997).

Period 3 only commenced later, with the promulgation of the first National Parks Act in South Africa, when protected areas are proclaimed for ecological or cultural importance, such as the protection of a cultural site, a specific threatened species (animals and vegetation) or a water 


\section{Chapter 2}

source (Paterson, 2009). Examples are the Bontebok and Kalahari National Parks in South Africa in 1931 and Gonarezhou National Park (Zimbabwe), in 1975.

It became clear over the years that nature conservation and the protection of natural areas were initiated based on different motives, which may have consequences for the management of the land and biodiversity which is protected today (Renwick and Schellhorn, 2016). In this paper, we analyse the establishment of protected areas in their current locations in Southern and Eastern Africa to understand the motives for establishing the protected areas and the possible effects which this has on modern day conservation managers.

\section{Methods}

To better understand the three periods of establishment of protected areas in Southern and Eastern Africa, 48 protected areas from various countries (the countries which form part of the study are Botswana, Kenya, Namibia, South Africa, Tanzania, Uganda, Zambia and Zimbabwe) were chosen (Supporting information 2B) in an attempt to understand the following three main questions, (1) when and why each of the protected areas was established? (2) what the management implications were of the reasons for incorporation for these areas? and (3) how/if the original management still impacts conservation in these areas today?

We only selected protected areas that are situated in the savanna biome. Savannas represent one of the largest biomes of the world, comprising roughly $20 \%$ of the earth's land area (Shorrocks and Bates, 2015; Huntley and Walker, 2012). Savannas in Africa occupy almost 50\% of the land area of the continent and support not only a large portion of its humans, and livestock, but some of the highest densities and diversity of wild herbivores and carnivores in 


\section{Chapter 2}

the world (Scholes and Archer, 1997; Shorrocks and Bates, 2015; Sankaran and Anderson, 2009). This study has no relevance to rain forests or desert areas as we are looking at protected areas in savannas that are under a higher threat from human populations and their requirements for arable land. The 48 protected areas were selected using Google search (key words - Africa, Southern, Eastern, Conservation, Protected areas). Both the English and Afrikaans languages were used in the literature research criteria. Literature from 689 articles, 25 books and 31 management plans of these 48 protected areas were either obtained from the protected area directly or from search engines. All the literature obtained was scrutinised for any information pertaining to the three main questions and other relevant information. Based on the data obtained the information was tabulated and compared to establish commonalities and / or differences (Supporting information 2B). Lusophone and Francophone countries were not included in the search criteria to ensure that protected areas for only Southern (excl. Mozambique and Angola) and Eastern Africa (excl. Rwanda and Burundi) were obtained. Based on the historic overview, we assumed that protected areas established in Period 1 would be established on an ad-hoc basis, primarily to protect animals for later use and that they would generally be larger than protected areas in the other two periods. The protected areas in this period would have been established on land previously used for hunting. We assumed that protected areas in Period 2 would be established on marginal lands, previously used for agriculture and/or domestic animal farming. For those protected areas we expected certain forms of manipulation (i.e. active management) as nutrient rich vegetation for large mammalian herbivores is not prolific on marginal lands. Period 3 protected areas would have been established on conservation and/or biodiversity principles with previous land use being cultural uses of one form or another. 


\section{Chapter 2}

The following sub-questions were addressed for each protected area to obtain a better understanding of the three main questions.

- What were the primary motives for the establishment of the protected area? (Question 1)

- What was the previous land use prior to establishment of the protected area? (Questions 2 and 3)

- What are the consequences for present day management based on the site selection of the protected area? (Question 3)

- What is the main current attraction of the protected area? (Questions 2 and 3)

- Has the management of the protected area used manipulation of animals and/or vegetation as a management tool? (Questions 2 and 3)

For each sub-question we found categories (identified in column one of each table) that were compared among the three periods. We counted the number of protected areas per period and per category to calculate a ratio per period and to indicate whether this category was more frequently mentioned than expected based on how many parks were assigned to each period:

$\mathrm{a}=$ Number of parks in a period $/$ Total number of parks

$b=$ Number of parks in a period that mention this category / Total number of parks that mention this category per period

Ratio $=\mathrm{b} / \mathrm{a}$

When the ratio is $>1$, then the category is mentioned more frequently than expected ("preferred"), whereas the category is mentioned less frequently than expected the ratio is < 


\section{Chapter 2}

1 ("avoided"). To address the sub-questions, we only looked at ratios $>1$ as these ratios highlight the consequences for management of the protected areas today. We considered ratios between $1-1.1$ as only slightly deviating from no "preference" (the baseline), ratios between $1.1-1.2$ as having a moderate deviation and ratios $>1.2$ as having a large deviation from no "preference".

\section{Results}

The primary motives for establishing the protected areas (Table 2.1) varied, with the majority being established for tourism and the protection of animal species. Conservation and biodiversity only ranked third. Parks established with protection of animal species, hunting, scenery, geography and game breeding as the primary motives for establishing protected areas were assigned to Period 1 (Table 2.1). The protected areas that were established more for tourism, hunting, education, joint conservation initiatives and to protect lions were assigned to Period 2. Period 3 protected areas were established for conservation and/or biodiversity, community and/or culture, education and for the protection of specific animal species.

Table 2.1 Motives for the establishment of the 48 protected areas investigated. Multiple motives for their establishment were reported, yielding a total of 83 motives. This has been tabulated in the second column "primary motive for establishment". The ratio per period indicates whether the primary motive for establishment was "preferred" (>1) or "avoided" $(<1)$ 


\section{Chapter 2}

\begin{tabular}{|c|c|c|c|c|}
\hline $\begin{array}{c}\text { The } 13 \text { primary motives for } \\
\text { the establishment of the } \\
\text { protected areas }\end{array}$ & $\begin{array}{l}\text { Frequency with which a } \\
\text { motive is given for the } \\
\text { establishment of a } \\
\text { protected area }\end{array}$ & \multicolumn{3}{|c|}{$\begin{array}{l}\text { The protected areas using the individual primary } \\
\text { motive for establishment for each period. Ratio } \\
\text { per period indicating whether the reason was } \\
\text { "preferred" }(>1) \text { or "avoided" }(<1)\end{array}$} \\
\hline & & Period 1 & Period 2 & Period 3 \\
\hline Tourism & 25 & $4(0.55)$ & $19(1.52)$ & $2(0.38)$ \\
\hline Protect animal species & 24 & $9(1.29)$ & $11(0.92)$ & $4(0.79)$ \\
\hline Conservation \& Biodiversity & 14 & $4(0.99)$ & $4(0.57)$ & $6(2.04)$ \\
\hline Community \& Culture & 3 & $0(0)$ & $1(0.67)$ & $2(3.17)$ \\
\hline Hunting & 3 & $1(1.15)$ & $2(1.33)$ & $0(0)$ \\
\hline Scenery & 3 & $3(3.45)$ & $0(0)$ & $0(0)$ \\
\hline Education & 2 & $0(0)$ & $1(1.00)$ & $1(2.38)$ \\
\hline Geography & 2 & $2(3.45)$ & $0(0)$ & $0(0)$ \\
\hline Joint conservation initiative & 2 & $0(0)$ & $2(2.00)$ & $0(0)$ \\
\hline Protect elephants & 2 & $0(0)$ & $0(0)$ & $2(4.76)$ \\
\hline Game breeding & 1 & $1(3.45)$ & $0(0)$ & $0(0)$ \\
\hline Protect lions & 1 & $0(0)$ & $1(2.00)$ & $0(0)$ \\
\hline Protect rhinoceros & 1 & $0(0)$ & $0(0)$ & $1(4.76)$ \\
\hline
\end{tabular}

The previous land use for the majority of protected areas fell into four main categories, colonial hunting, ranching, agriculture and indigenous hunter-gatherers (Table 2.2). Period 1 protected areas were used for colonial hunting, indigenous hunter-gatherers, fishing and iron smelting. The Period 2 protected areas were used for cattle ranching (and other ranching) and rhinoceros conservation, while Period 3 protected areas were used for colonial hunting, agriculture (mixed crops), indigenous hunter-gatherers, fishing, iron smelting and mining. 


\section{Chapter 2}

Table 2.2 Previous land use of the 48 protected areas investigated, multiple previous land uses were established, yielding a total of 105 uses. This has been tabulated in the second column "frequency of previous land use". The ratio per period indicates whether the previous land use was "preferred" (>1) or "avoided" (<1)

\begin{tabular}{|c|c|c|c|c|}
\hline \multirow[t]{2}{*}{$\begin{array}{l}\text { The } 8 \text { previous land uses for } \\
\text { the } 48 \text { protected areas }\end{array}$} & \multirow[t]{2}{*}{$\begin{array}{c}\text { Frequency of previous } \\
\text { land use in the } 48 \\
\text { protected areas }\end{array}$} & \multicolumn{3}{|c|}{$\begin{array}{l}\text { The protected areas using the individual } \\
\text { previous land use for each period. Ratio per } \\
\text { period indicating whether the reason was } \\
\text { "preferred" }(>1) \text { or "avoided" }(<1)\end{array}$} \\
\hline & & Period 1 & Period 2 & Period 3 \\
\hline Colonial hunting & 32 & $10(1.08)$ & $15(0.94)$ & $7(1.04)$ \\
\hline $\begin{array}{l}\text { Cattle ranching (and other } \\
\text { ranching) }\end{array}$ & 29 & $3(0.36)$ & $20(1.38)$ & $6(0.99)$ \\
\hline Agriculture (mixed crops) & 19 & $5(0.91)$ & $9(0.95)$ & $5(1.25)$ \\
\hline Indigenous hunter-gatherers & 16 & $7(1.51)$ & $5(0.63)$ & $4(1.19)$ \\
\hline Fishing & 3 & $2(2.30)$ & $0(0)$ & $1(1.59)$ \\
\hline Iron smelting & 3 & $1(1.15)$ & $1(0.67)$ & $1(1.59)$ \\
\hline Mining & 2 & $0(0)$ & $0(0)$ & $2(4.76)$ \\
\hline Rhinoceros conservation & 10 & $0(0)$ & $1(2.00)$ & $0(0)$ \\
\hline
\end{tabular}

We found that protected areas established during Period 1 on average $\left(1844 \times 10^{2} \mathrm{~km}^{2}\right)$ are considerably larger than both Period $2\left(9 \times 10^{2} \mathrm{~km}^{2}\right)$ and Period $3\left(12 \times 10^{2} \mathrm{~km}^{2}\right)$. This is primarily due to the earlier protected areas in Period 1 being established in remote areas with minimal human inhabitants at the time, while in the latter years protected areas were established for specific motives and often close to human settlements constraining the size of the protected area (see Supporting information $2 \mathrm{~B}$ for the information pertaining to each 


\section{Chapter 2}

of the 48 protected areas). Twenty-nine percent of the 48 protected areas included in this study were established in Period 1 as they were primarily established (by sports hunters) to protect wild animals from decimation, for utilisation and enjoyment in the future. The majority of the 48 protected areas in our overview (50\%) were established in Period 2, and were areas considered marginal for agriculture, prone to disease or sickness, considered uninhabitable for human settlement at the time, or with a struggling yet established wildlife populations. Period 3, which only became a reality after 1926 with the establishment of the National Parks Act in South Africa, were represented by $21 \%$ of the protected areas. The protected areas proclaimed in Period 3 were established due to ecological or cultural importance.

The consequences of site selection of the protected areas have varying ramifications for conservation management today. Table 2.3 shows current management constraints due to the original site selection with the ratios clearly illustrating which of the consequences are frequently mentioned per period.

Because Period 1 includes protected areas established to protect species for later use, and due to their very large sizes, the main consequences for management today is the practice of management through the laissez-faire approach (non-interventionist approach, neither interference nor manipulations) coupled with remote logistics and tourism, anti-poaching difficulties, large size logistics, human animal conflict, climatic issues, military incursions and poor management.

Because Period 2 includes protected areas that were established on marginal or cultural land, the main consequences for management today are community-land issues and intensive 


\section{Chapter 2}

management (including but not limited to bush clearing and control, alien plant control, supplementary feeding, lick blocks or vegetation restoration).

Because Period 3 protected areas were established on conservation and/or biodiversity principles, the main consequence for management today is intensive management (again including but not limited to bush clearing and control, alien plant control, supplementary feeding, lick blocks or vegetation restoration).

Table 2.3 Consequences of site selection of the 48 protected areas investigated, multiple consequences of site selection were established, yielding 195 consequences. This has been tabulated in the second column "frequency of consequences of site selection". The ratio per period indicates whether the consequence of site selection was "preferred" (>1) or "avoided" $(<1)$

\begin{tabular}{|c|c|c|c|c|}
\hline $\begin{array}{c}\text { The } 11 \text { consequences of site } \\
\text { selection for the } 48 \text { protected } \\
\text { areas }\end{array}$ & $\begin{array}{c}\text { Frequency of } \\
\text { consequences of } \\
\text { site selection for the } \\
48 \text { protected areas }\end{array}$ & \multicolumn{3}{|c|}{$\begin{array}{l}\text { The protected areas using the individual } \\
\text { consequences of site selection for each } \\
\text { period. Ratio per period indicating whether } \\
\text { the reason was "preferred" (>1) or "avoided" } \\
\qquad(<1)\end{array}$} \\
\hline & & Period 1 & Period 2 & Period 3 \\
\hline Veterinary restrictions & 48 & $14(1.01)$ & $25(1.04)$ & $9(0.89)$ \\
\hline Community-land issues & 23 & $6(0.90)$ & $14(1.22)$ & $3(0.62)$ \\
\hline Remote logistics (hard to access) & 20 & $13(2.24)$ & $5(0.50)$ & $2(0.48)$ \\
\hline Remote tourism (hard to access) & 20 & $13(2.24)$ & $5(0.50)$ & $2(0.48)$ \\
\hline Intensive management & 20 & $1(0.17)$ & $13(1.30)$ & $6(1.43)$ \\
\hline Anti-poaching difficulties & 19 & $14(2.54)$ & $3(0.32)$ & $2(0.50)$ \\
\hline Large size logistics & 16 & $11(2.37)$ & $2(0.25)$ & $3(0.89)$ \\
\hline Human animal conflict & 12 & $8(2.30)$ & $2(0.33)$ & $2(0.79)$ \\
\hline Climatic issues (drought/flood) & 7 & $6(2.96)$ & $0(0)$ & $1(0.68)$ \\
\hline
\end{tabular}




\section{Chapter 2}

Military incursions

\begin{tabular}{l|lll}
5 & $3(2.07)$ & $1(0.40)$ & $1(0.95)$ \\
5 & $2(1.38)$ & $2(0.80)$ & $1(0.95)$
\end{tabular}

The current main attractions for each of these protected areas has an influence on the management goals and objectives of these protected areas today. Table 2.4 shows current main attractions for the 48 protected areas with the ratios clearly illustrating which of the consequences are mentioned frequently per period. It is evident that the current main attraction for the majority of areas is the iconic Big 5 (81\%) (viz., lion, leopard, elephant, hooklipped rhinoceros and African buffalo - Syncerus caffer). The nine protected areas, which did not have the Big 5, all had the Big 4 (Big 5 less the rhinoceros).

Because Period 1 includes protected areas established to protect species for later use, the main attractions are special species, scenery, popular profile, Big 4, birding, flora, boating, remoteness and conservation diversity.

Because Period 2 includes protected areas that were established on marginal or cultural land for hunting and tourism, the main attractions were Big 5, location, exclusivity, family orientated activities, hunting and interventions.

Because Period 3 protected areas were established on conservation and/or biodiversity principles, the main attractions are special species, scenery, self-drive, Big 4, birding, culture, boating, exclusivity, family orientated activities, remoteness and conservation diversity.

Table 2.4 Current main attractions of the 48 protected areas investigated, multiple current main attractions were established, yielding 171 attractions. This has been tabulated in the second column "frequency of the current main attractions". The ratio per period indicates whether the current main attraction was "preferred" (>1) or "avoided" $(<1)$ 


\section{Chapter 2}

\begin{tabular}{|c|c|c|c|c|}
\hline \multirow[t]{2}{*}{$\begin{array}{l}\text { The } 17 \text { current main attractions of } \\
\text { the } 48 \text { protected areas }\end{array}$} & \multirow[t]{2}{*}{$\begin{array}{l}\text { Frequency of the } \\
\text { current main } \\
\text { attractions for the } \\
48 \text { protected areas }\end{array}$} & \multicolumn{3}{|c|}{$\begin{array}{l}\text { The protected areas using the individual } \\
\text { current main attractions for each period. Ratio } \\
\text { per period indicating whether the reason was } \\
\text { "preferred" (>1) or "avoided" }(<1)\end{array}$} \\
\hline & & Period 1 & Period 2 & Period 3 \\
\hline $\begin{array}{l}\text { Big } 5 \text { (five most sought after } \\
\text { species to see on safari: lion } \\
\text { (Panthera leo), leopard (Panthera } \\
\text { pardus), elephant (Loxodonta } \\
\text { africana), buffalo (Syncerus caffer) } \\
\text { and rhinoceros (Diceros bicornis) }\end{array}$ & 39 & $11(0.97)$ & $21(1.08)$ & $7(0.85)$ \\
\hline Special species & 30 & $11(1.26)$ & $12(0.80)$ & $7(1.11)$ \\
\hline Scenery & 22 & $13(2.04)$ & $4(0.36)$ & $5(1.08)$ \\
\hline Popular profile & 13 & $6(1.59)$ & $5(0.77)$ & $2(0.73)$ \\
\hline Self-drive & 11 & $2(0.63)$ & $4(0.73)$ & $5(2.16)$ \\
\hline Big 4 (Big 5 less the Rhinoceros) & 9 & $4(1.53)$ & $3(0.67)$ & $2(1.06)$ \\
\hline Birding & 8 & $4(1.72)$ & $2(0.50)$ & $2(1.19)$ \\
\hline Location & 7 & $2(0.99)$ & $4(1.14)$ & $1(0.68)$ \\
\hline Culture & 6 & $1(0.57)$ & $2(0.67)$ & $3(2.38)$ \\
\hline Flora & 5 & $3(2.07)$ & $1(0.40)$ & $1(0.95)$ \\
\hline Boating & 4 & $2(1.72)$ & $1(0.50)$ & $1(1.19)$ \\
\hline Exclusivity & 4 & $0(0)$ & $3(1.50)$ & $1(1.19)$ \\
\hline Family orientated activities & 4 & $1(0.86)$ & $2(1.00)$ & $1(1.19)$ \\
\hline Remoteness & 4 & $3(2.59)$ & $0(0)$ & $1(1.19)$ \\
\hline Conservation diversity & 2 & $1(1.72)$ & $0(0)$ & $1(2.38)$ \\
\hline Hunting & 2 & $0(0)$ & $2(2.00)$ & $0(0)$ \\
\hline Interventions & 1 & $0(0)$ & $1(2.00)$ & $0(0)$ \\
\hline
\end{tabular}




\section{Chapter 2}

Of the 48 protected areas, 37 of the protected areas partook in the manipulation of animal populations or vegetation (i.e. active management) and 2 undertook minimal manipulation. We were unable to establish if the remaining 9 protected areas partook in any form of manipulation (Appendix 2A). The ratios illustrate that Periods 2 and 3 were identified as using manipulations as an often mentioned reason as part of their protected areas management.

\section{Discussion}

In this paper we discerned the motives for establishing protected areas in Southern and Eastern Africa, and the possible consequences for management of these areas today.

Based on our historical overview of the establishment of protected areas in Southern and Eastern Africa, we distinguished three periods in which these protected areas were established, the primary motives for establishing the protected areas, what the previous land uses were, the consequences of the site establishment for management today, the current attractions and whether or not they participated in animal population or vegetation manipulation.

Period 1 protected areas were primarily established to protect species for later use. Prior to being established as a protected area, the previous land uses included colonial hunting and indigenous hunter-gatherers (including fishing) and iron smelting. According to Dahlberg et al. (2010) protected areas were proclaimed primarily to protect wildlife and as a refuge from ills of civilisation and for the recreation of the human spirit. The consequences of establishing these protected areas in the locations resulted in the areas being more complicated to manage than either Period 2 or 3 for current management, from a logistics perspective based on their larger size and remoteness of the protected areas. This includes but is not limited to fence management, anti-poaching, supply chain, tourism access and poor management. 


\section{Chapter 2}

These consequences are recognised for the majority of large protected areas in remote places (Worboys and Trzyna, 2015). All 14 protected areas identified in Period 1 are managed by the relevant National Parks Board Authorities of these countries and manipulation (active management) of the populations of animals and/or the vegetation is not viewed as a preferred strategy when it comes to management planning. Due to the size of the areas, animals and vegetation are generally managed on a laissez-faire approach (noninterventionist approach, neither interference nor manipulations). This is in contrast to earlier stages when in remote areas within the protected areas predator control was the norm for a long-time (Stevenson-Hamilton, 1938). One should note that in many of the protected areas where laissez-faire is advocated, the construction of artificial water points is a very intense form of management and has been executed for decades (Hilbers et al., 2015) and burning is considered acceptable even if the consequences are largely ignored (Groen et al., 2008; Klop and Prins, 2008; Masocha et al., 2011). The current main attractions for these protected areas include conservation biodiversity which includes special species, scenery, birding and flora, coupled with these areas being attractive for their popular profiles and remoteness. Due to these protected areas being owned by government, the areas are not as intensively driven by economic survival as there is state funding to ensure the longevity of these protected areas.

Period 2 protected areas were primarily established for tourism and hunting. Prior to being established as a protected area, the previous land use was dominated by cattle ranching (and other ranching). Enghoff (1990) states that wildlife as a form of land use must be considered as one of the major forms of alternative use for semi-arid pastoral land. The consequences of establishing these protected areas in their locations resulted in the areas being less complicated to manage from the perspective of size and location but due to the marginal land the requirement for intensive management of both animal populations and vegetation 


\section{Chapter 2}

increased, with higher rates of issues pertaining to local communities. Seventy-one percent of the protected areas identified in Period 2 are privately owned and managed. Manipulation of the animal populations and vegetation in one way or another is often mentioned when it comes to management planning, primarily due to the marginal land. According to Ajathi and Krumme (2002), anthropogenic disturbances in natural ecosystems are of a foreign character with vast ecological consequences in degradation. The current main attraction for these protected areas is tourism (Big 5). Due to these protected areas being owned and managed by private entities they are driven by tourism as the primary form of economic survival to ensure the longevity, resulting in the management today focusing their efforts on the tourism portfolio. James et al. (1999), posit that effective management of protected areas depends greatly upon adequacies of available resources and that smaller protected areas require great budgetary and staffing inputs.

Period 3 protected areas were established primarily on the principles of conservation and/or biodiversity and community and/or culture. The past century has seen a vast increase in the establishment of protected areas, to protect biodiversity and refuges for particular species to entire ecosystems (Rao et al., 2009). Prior to being established as a protected area, the previous land uses included colonial hunting and agriculture (mixed). Due to all the protected areas in Period 3 being established after 1926, with the establishment of the National Parks Act in South Africa, this resulted in more strategic planning prior to the areas being established. The consequences of establishing these protected areas in their current locations resulted in there being fewer consequences for management today than either Period 1 or 2 , with the only consequence being intensive management. The manipulation of the animal populations and vegetation is often mentioned when it comes to management planning as the primary objective of these protected areas is the protection of a specific species, a habitat 


\section{Chapter 2}

or for a cultural reason. Over the past few decades there has been a global shift in policy thinking concerning conservation and protected areas, which now emphasises democracy, environmental justice, local involvement and development (Adams and Jeanrenaud, 2008; Rao et al., 2009; Dahlberg et al., 2010), which have ramifications for protected area managers of these areas today. The current main attractions for these protected areas include conservation biodiversity which includes special species, scenery, culture, birding and flora. Owing to these protected areas being owned primarily by government or not for profit organizations (NGO's), the areas are not as intensively driven by economic survival as there is funding to ensure the longevity of these protected areas.

The majority of manipulations of animal populations and vegetation in Period 2 and 3 , include but are not limited to bush clearing and control, alien plant control, supplementary feeding, lick blocks, fire management or vegetation restoration. Only one protected area refers to the manipulation of old agricultural lands with the establishment of grazing lawns as an official conservation objective, in an attempt to manipulate the vegetation and its nutritional value for the benefit of large herbivores, and is an area established in Period 2.

According to research done by Carruthers (1988) and Hitchcock (2019), conservation approaches in Southern Africa have varied from strict preservationist approaches to community-based conservation. Sandbrook et al. (2019) have shown in their study that there are three independent dimensions of conservation thinking: 1) people-centred conservation - community-based conservation supported by social scientists; 2) science-led ecocentrism traditional conservation supported by biological scientists and 3) conservation through capitalism - new conservation thinking. There is a lot of speculation about competing goals between the three proponents as to why, what and how to conserve natural areas going 


\section{Chapter 2}

forward into the future. The new conservationists argue that the natural capital approach and the use of market based tools is the way to protect biodiversity, whilst the traditional conservationists argue that we should protect nature for its own sake. The social scientists, or community-based conservationists argue that conservation should be for the benefit of people (Sandbrook et al., 2019). The one area where all three proponents have consensus was that the maintenance of biodiversity and ecosystem processes need to be goals of conservation and that local communities need to benefit from protected areas. The analysis of the selected protected areas showed that with the early establishment of protected areas minimal thought was given to establishing the areas for biodiversity, ecosystems and ignored the interests of the local people in or around the areas, which aligns with Dahlberg et al. (2010). This has changed significantly over the years and the newer protected areas are established on the principles of biodiversity and ecosystems with an emphasis on local communities and their involvement and benefit from protected areas, coupled with the fact that there must be a relationship between conservation, corporations and capitalism.

There is evidence around many protected areas, that the most significant consequences of population growth are the loss and fragmentation of natural habitats through conversion to land uses which support relatively low levels of biodiversity (Ajathi and Krumme, 2002). The world has changed considerably over the past 100 years since the establishment of the first protected areas. Currently, conservation of established or newly protected areas have to deal with the rapidly growing human population in the world but especially in Africa. For example, the population of Southern Africa has grown from 48 million in 1960 to 212 million in 2020 and Eastern Africa has grown from 68 million in 1960 to 374 million in 2020 (STATS SA, 2020; Trading Economics, 2020; World Bank, 2020). The World Bank believes that over the next 30 years the population will increase to approximately 385 million in Southern Africa and 705 


\section{Chapter 2}

million in Eastern Africa (World Bank, 2020). Since the 1970s, agriculture for food has increased by $300 \%$ on earth, with $55 \%$ of the oceans being used for fishing (Buitenland, 2019). The increase in the human population leads to more pressure on productive land both for agriculture (the supply of food), land for housing, businesses and bioenergy demands (Anderson-Teixeira et al., 2012). These land uses will be in direct competition with the land currently being used for conservation (Emmott, 2013). The 'people factor' in Africa's current wildlife crisis is by far the most important of all issues involved for protected area conservation (Thomson, 2003; Emmott, 2013).

\section{Contribution for Conservation}

Our study suggests that in Southern and Eastern Africa, conservation is on the rebound from poor pre-colonial decisions based on political power, land grabs, uncontrolled hunting, stock farming, agriculture, disease control, mining, a lack of proper conservation knowledge and the disregard for local African knowledge of wild animals. To ensure the long-term survival of protected areas in an era with vastly growing human populations and their attendant needs for food and economic development, one needs to establish ways of making protected areas on marginal land sustainable for conservation. Thus, the establishment of a fourth phase to use marginal land with intensive management of both the animals and plants to capitalise on the conservation outcomes from an ecological and economical viewpoint is imperative. A further or alternative solution would be to degazette land afforded conservation status from prime agricultural land, but this is a far more complex option. 


\section{Chapter 2}

Appendix 2A Protected areas in which animal populations or vegetation are actively managed ('manipulated'). Of the 48 protected areas, we could not obtain information about active management or absence of it for 9 of these areas (i.e., "unestablished" in the Table). The ratio per period indicates whether manipulation was "preferred" $(>1)$ or "avoided" $(<1)$

\begin{tabular}{|c|c|c|c|c|}
\hline \multirow[t]{2}{*}{ Manipulation utilised } & $\begin{array}{l}\text { Of the } 48 \text { protected } \\
\text { areas identified to be } \\
\text { actively/ minimally } \\
\text { involved or } \\
\text { unestablished with } \\
\text { respect to manipulations }\end{array}$ & \multicolumn{3}{|c|}{$\begin{array}{l}\text { The protected areas using manipulations for } \\
\text { each period. Ratio per period indicating } \\
\text { whether manipulation was "preferred" }(>1) \text { or } \\
\qquad \text { "avoided" (<1) }\end{array}$} \\
\hline & & Period 1 & Period 2 & Period 3 \\
\hline Yes & 37 & $7(0.65)$ & $21(1.14)$ & $9(1.16)$ \\
\hline Minimal & 2 & $1(1.72)$ & $0(0)$ & $1(2.38)$ \\
\hline $\begin{array}{l}\text { Participation in manipulation } \\
\text { unestablished }\end{array}$ & 9 & $6(2.30)$ & $3(0.67)$ & $0(0)$ \\
\hline
\end{tabular}



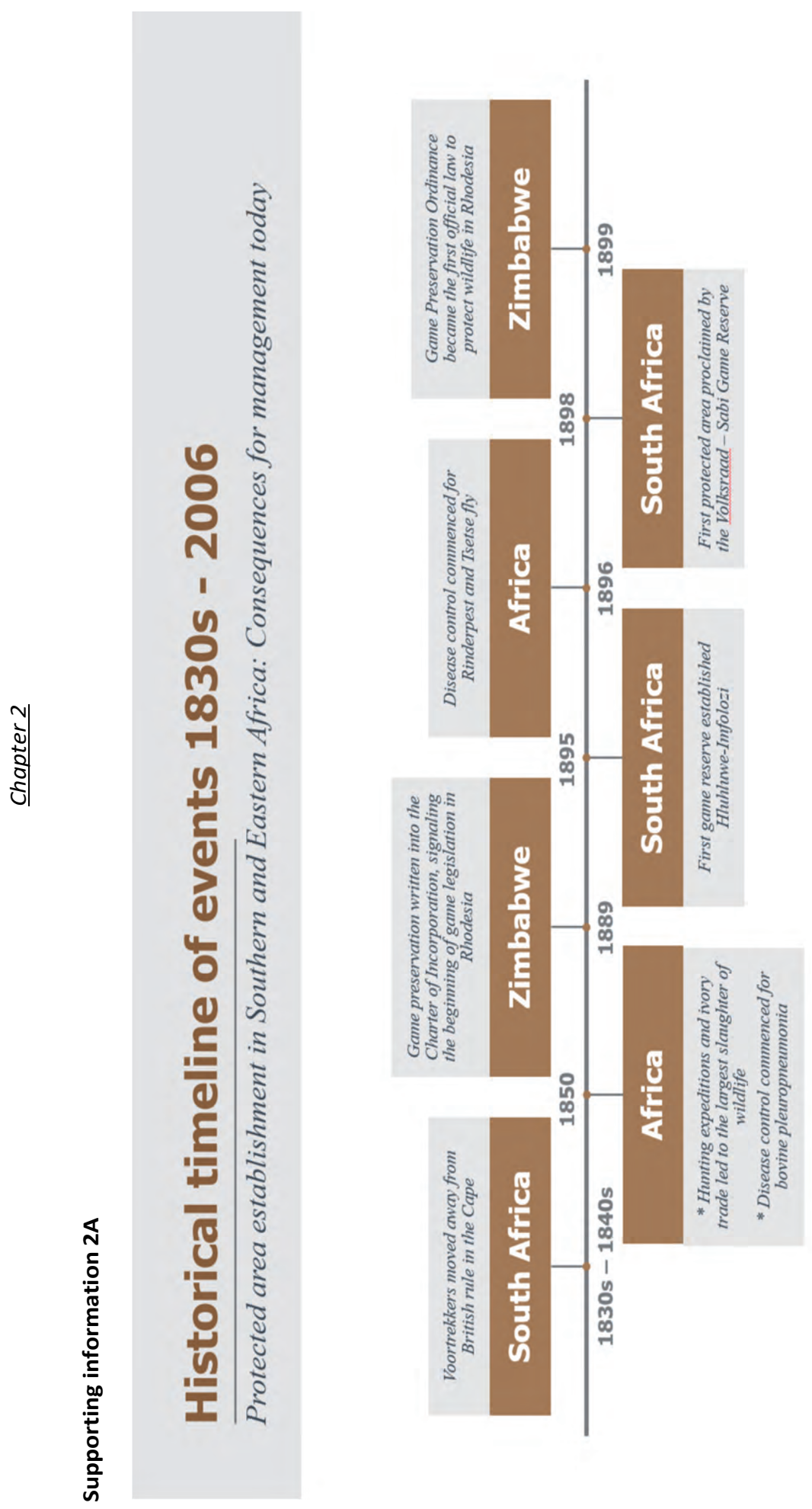

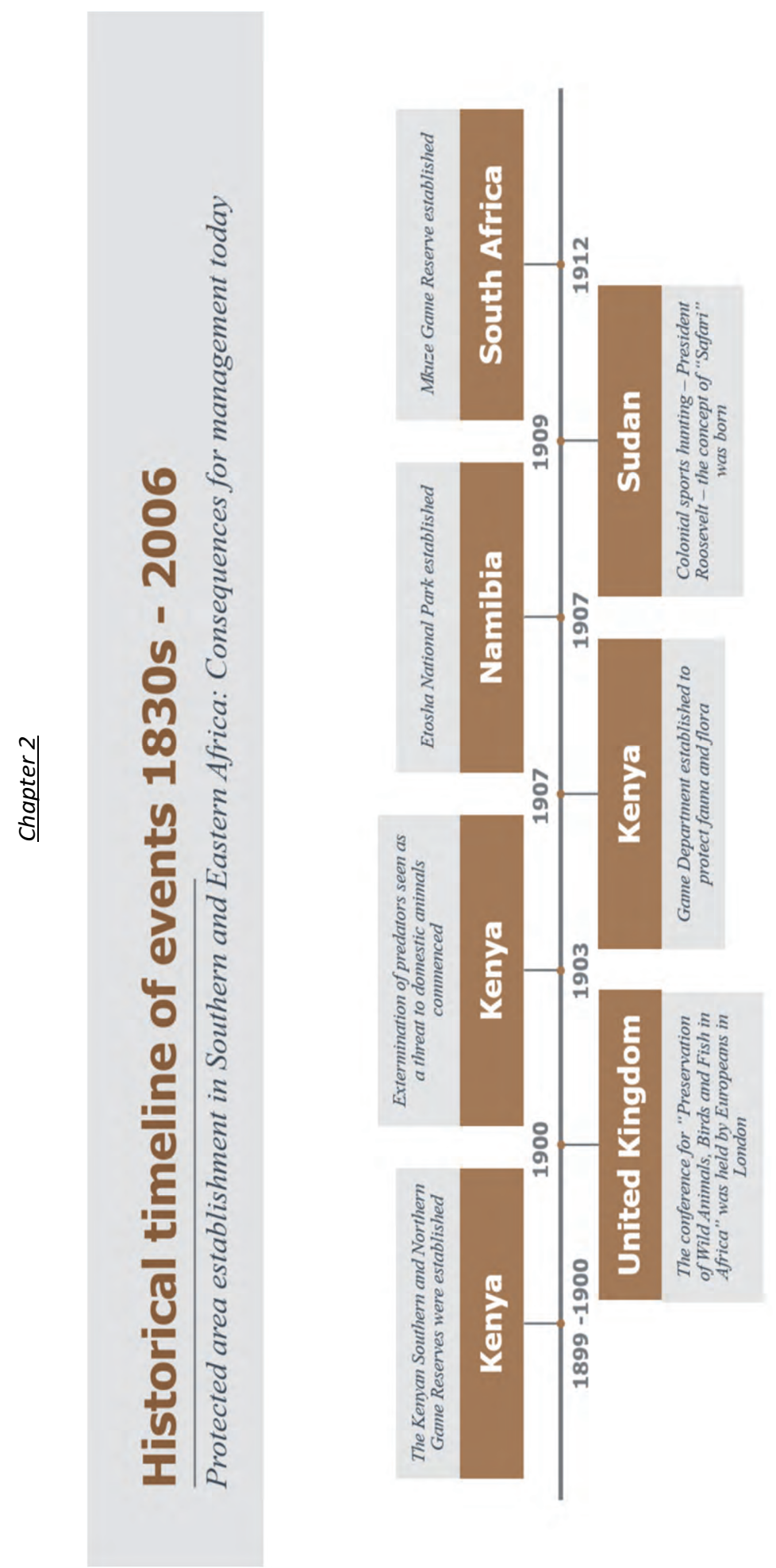

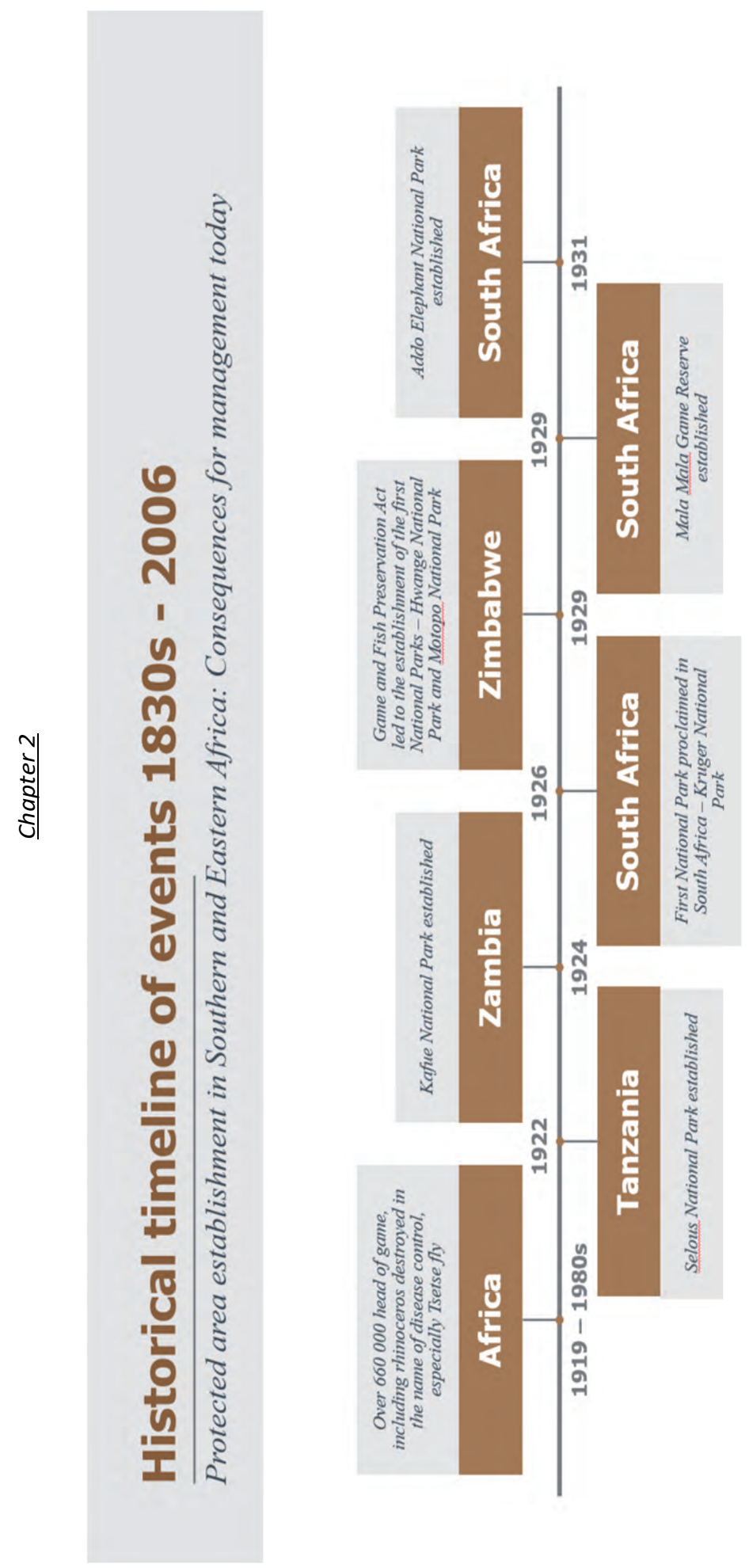

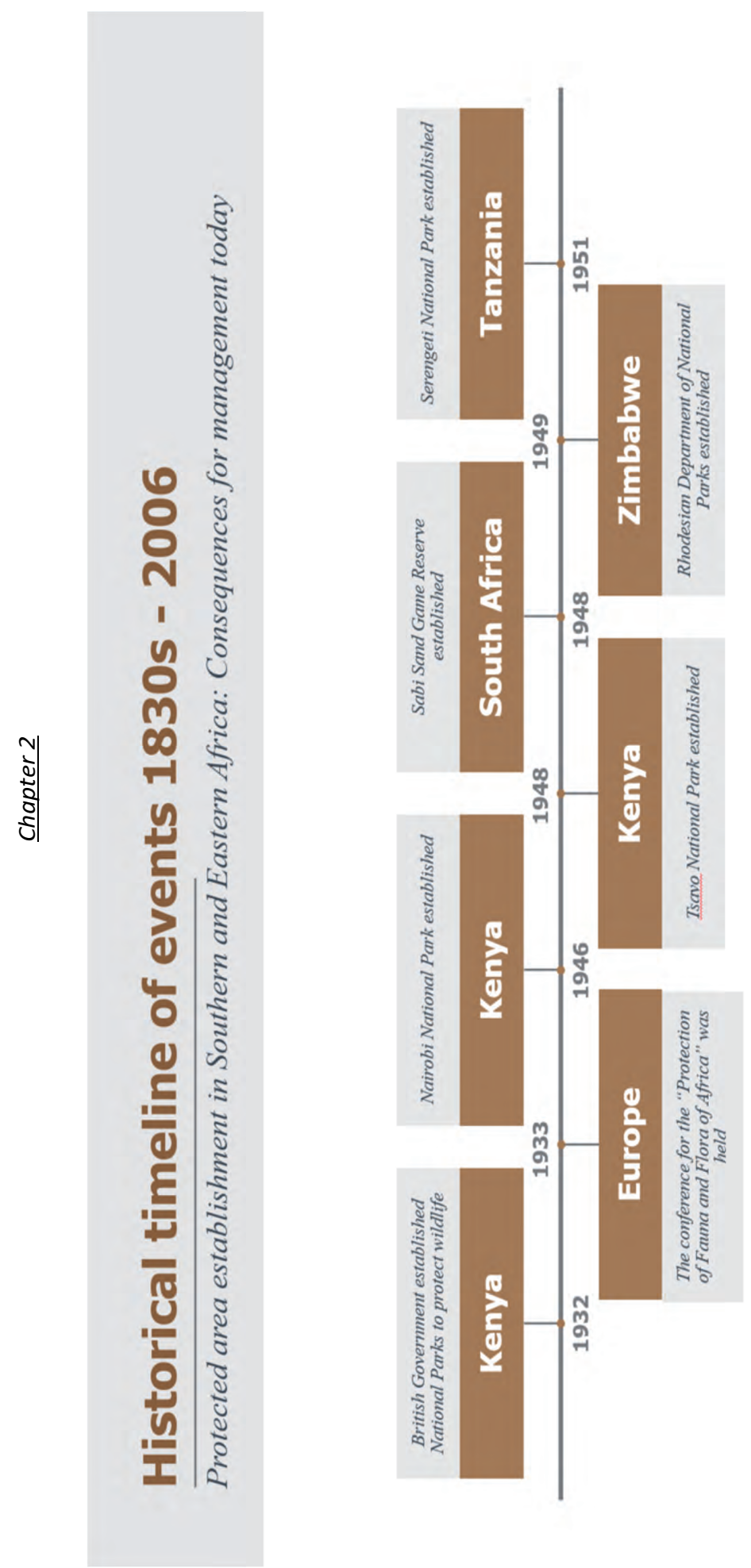

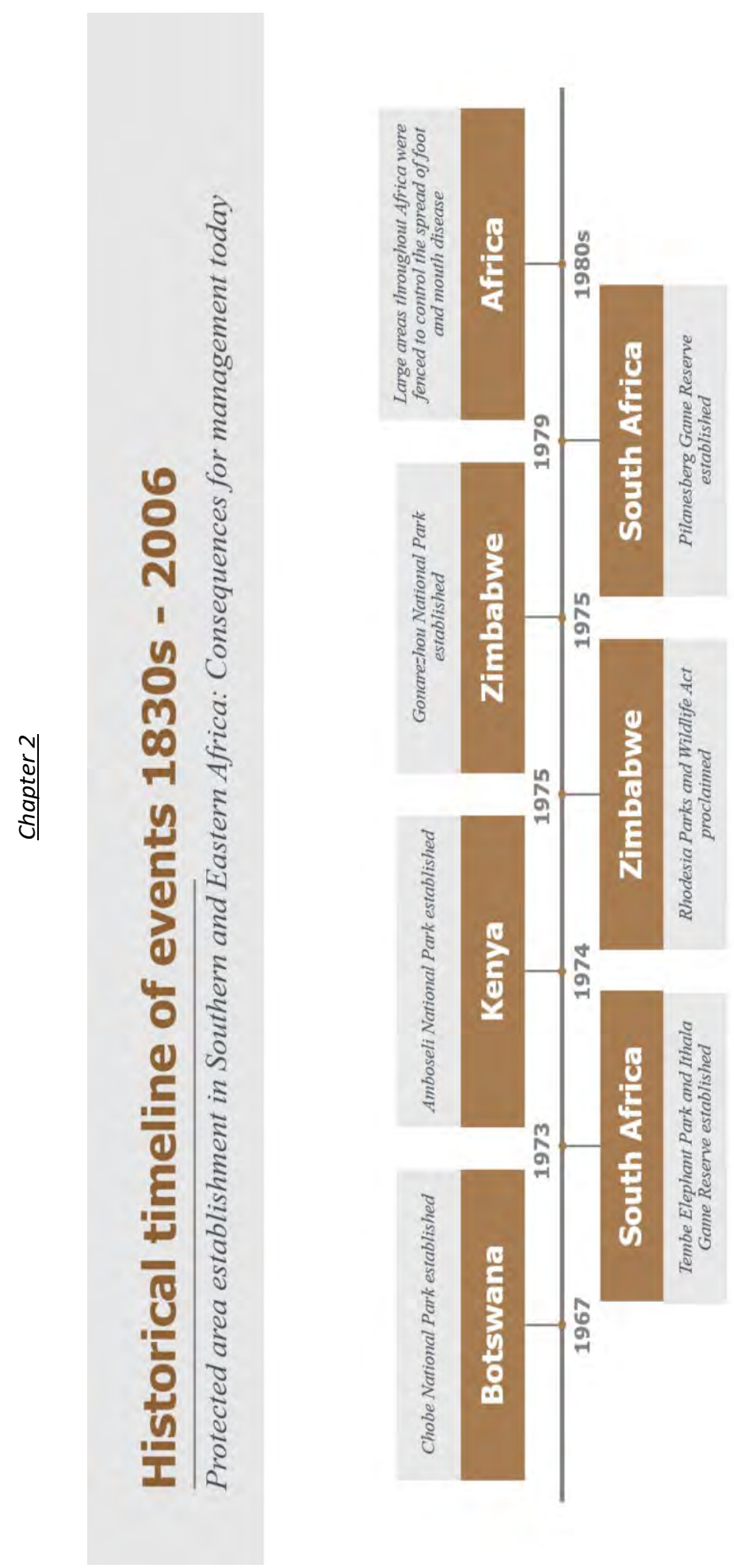

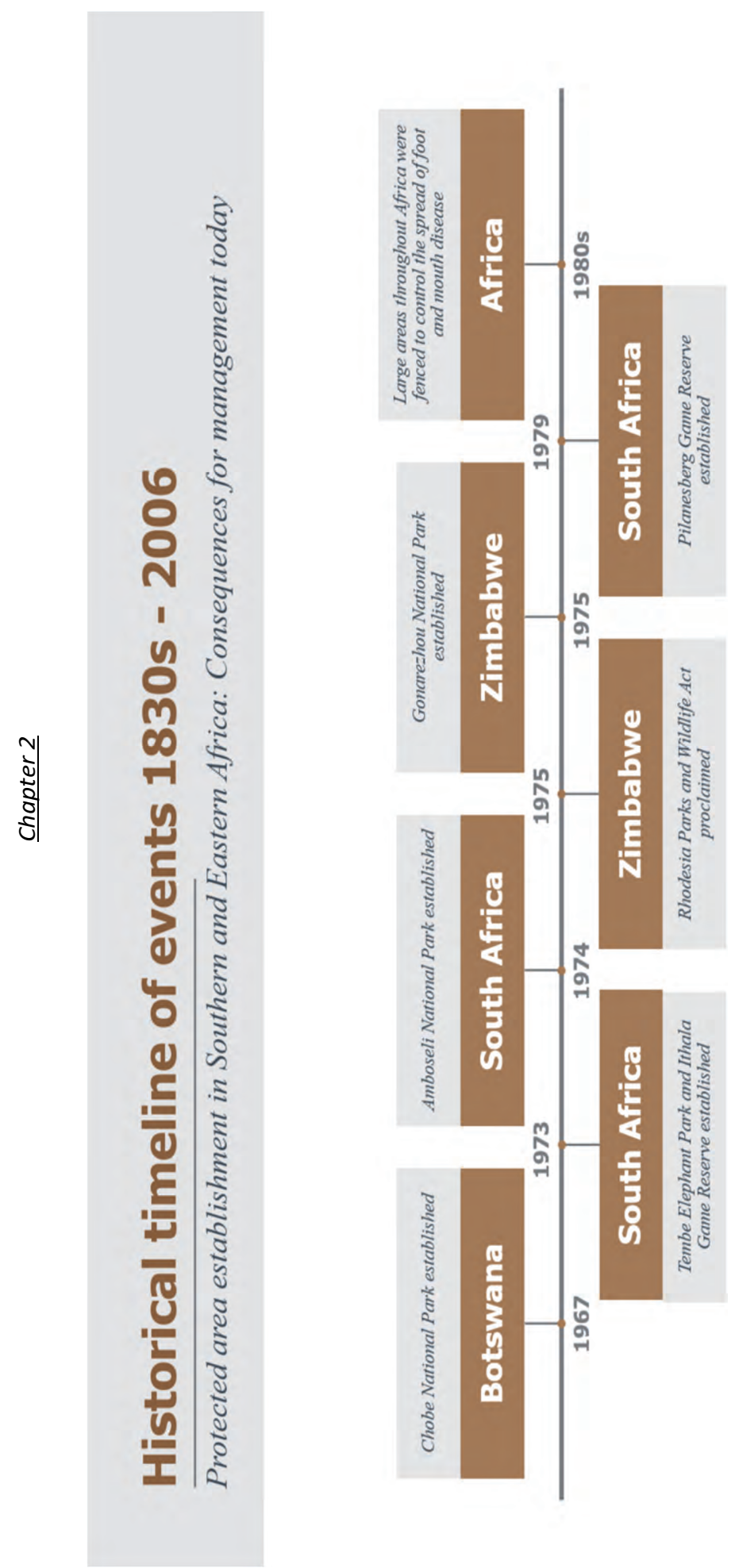

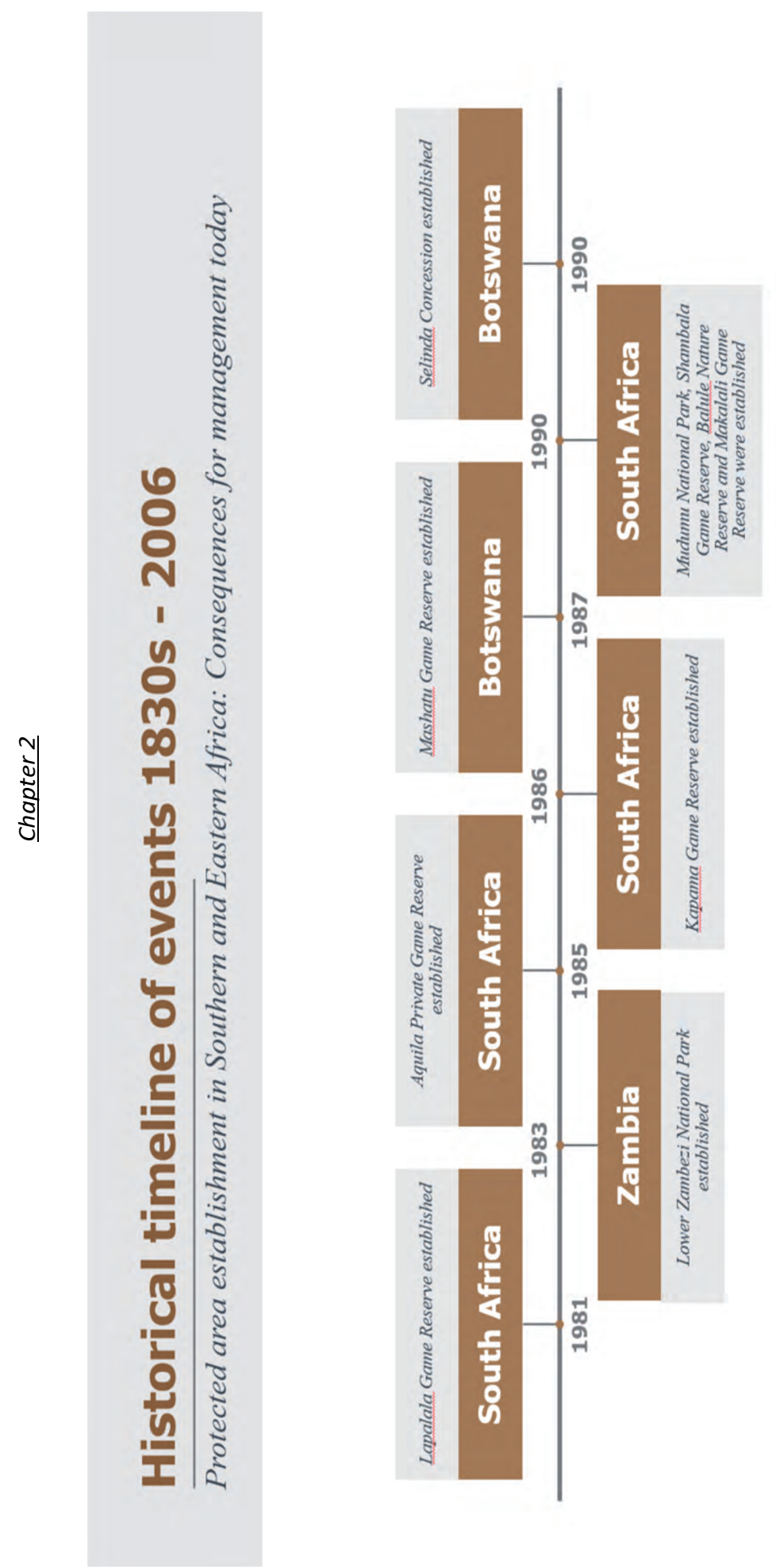

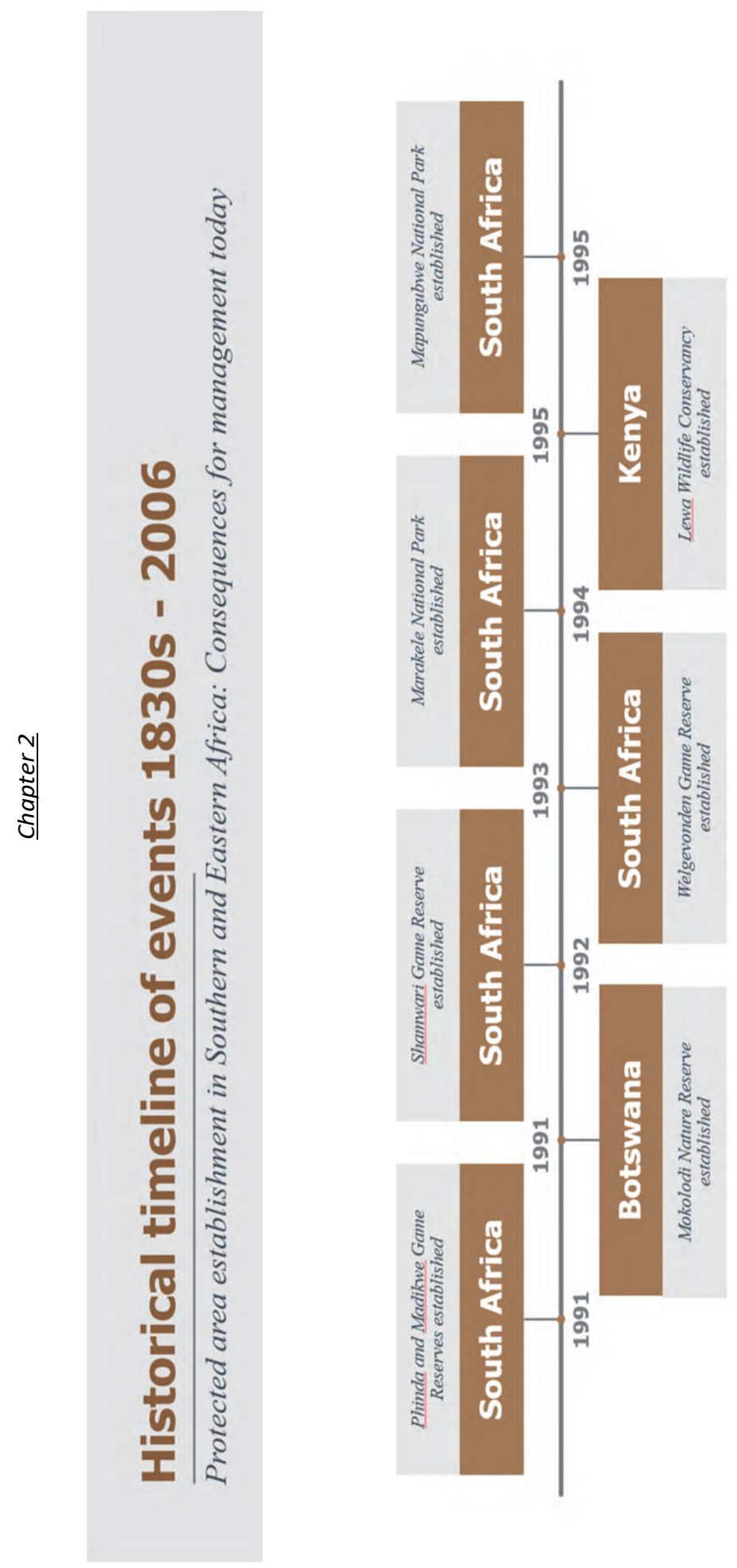


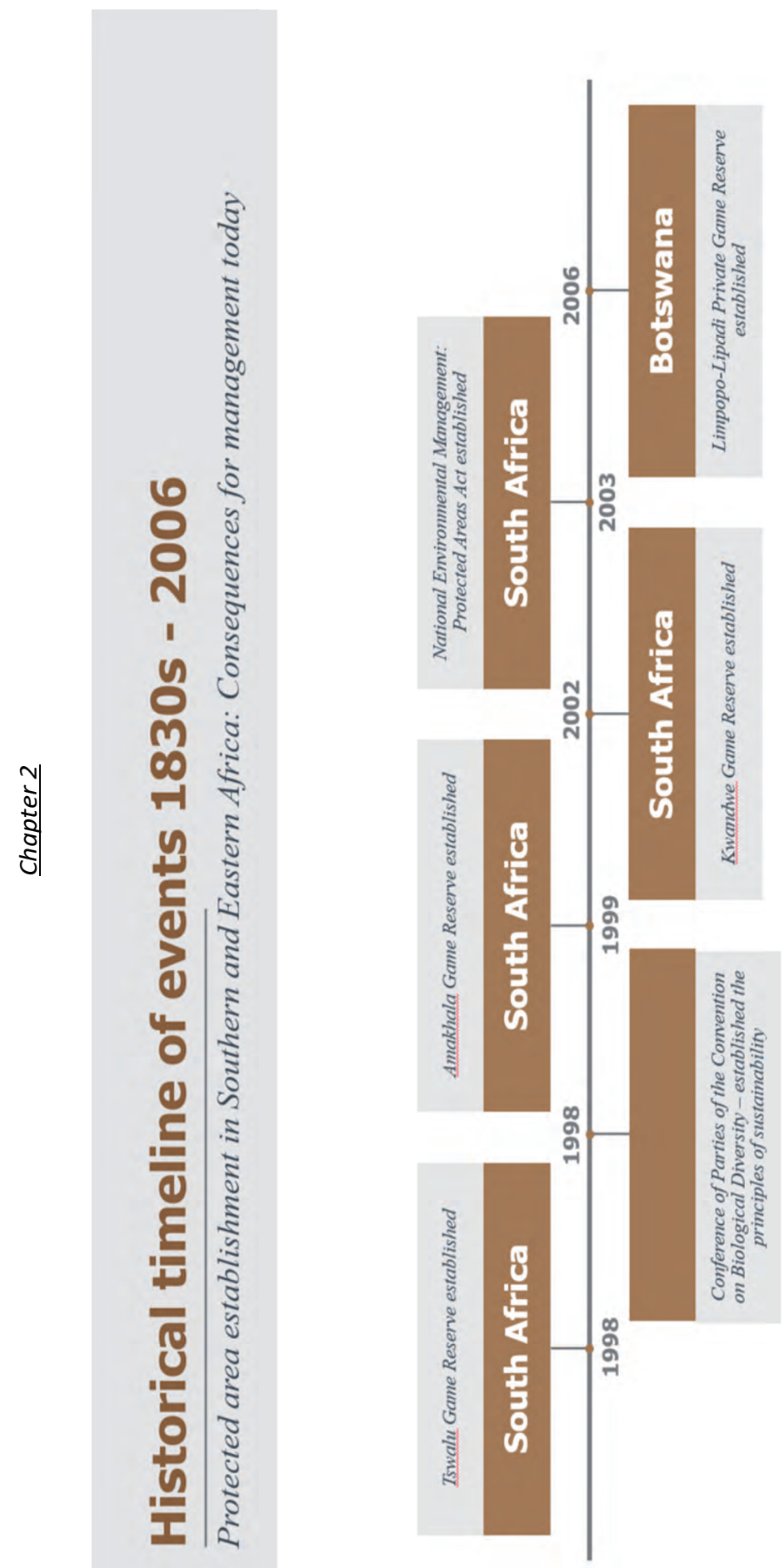




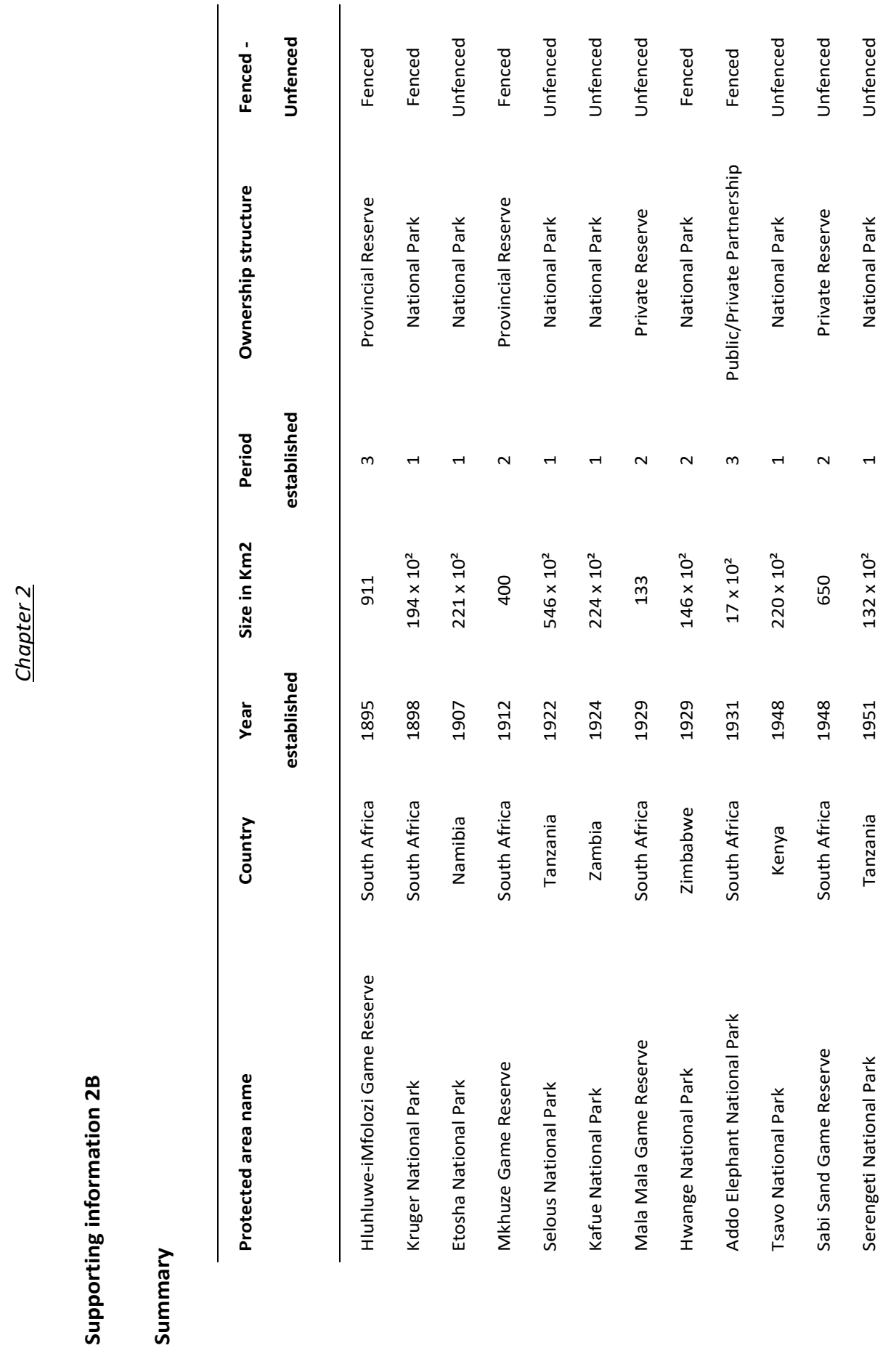




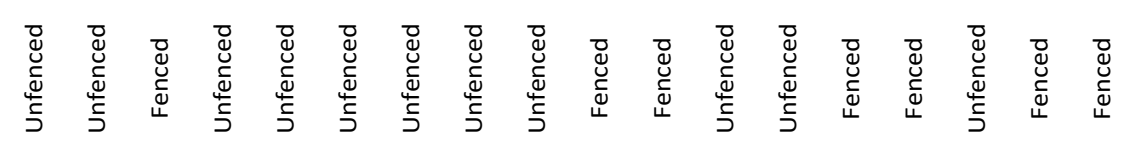

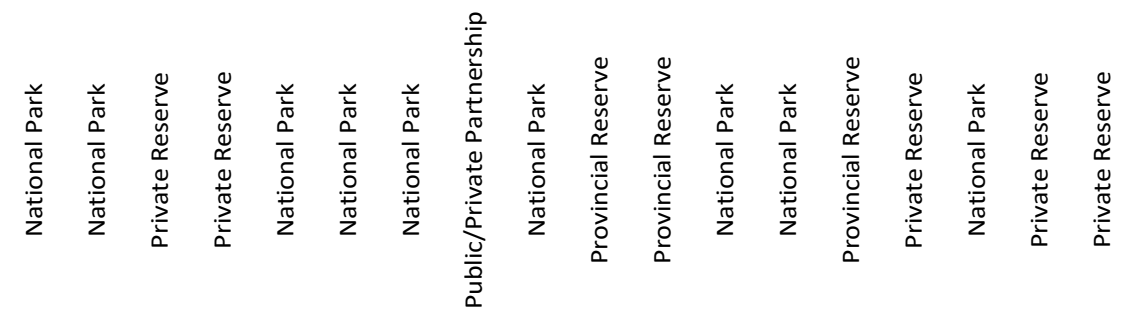

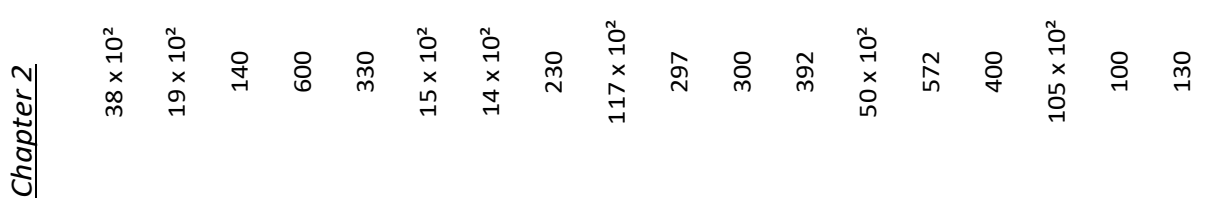

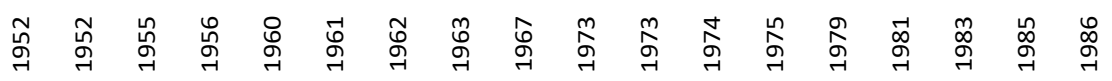

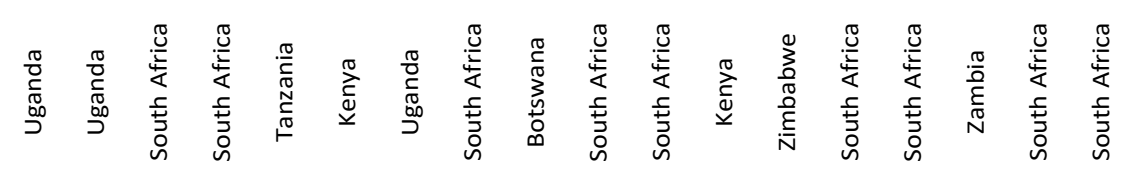

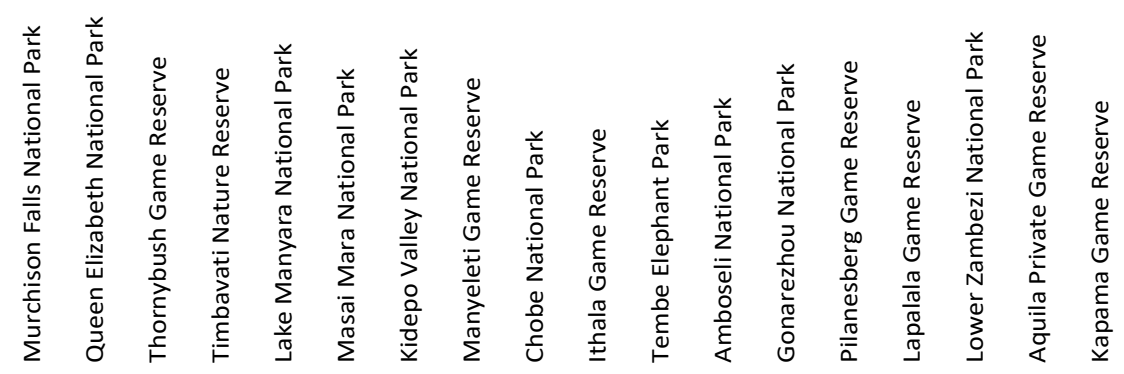




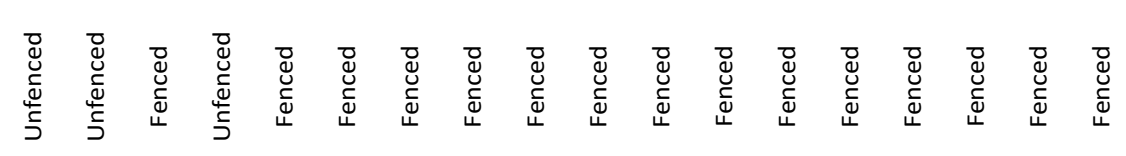

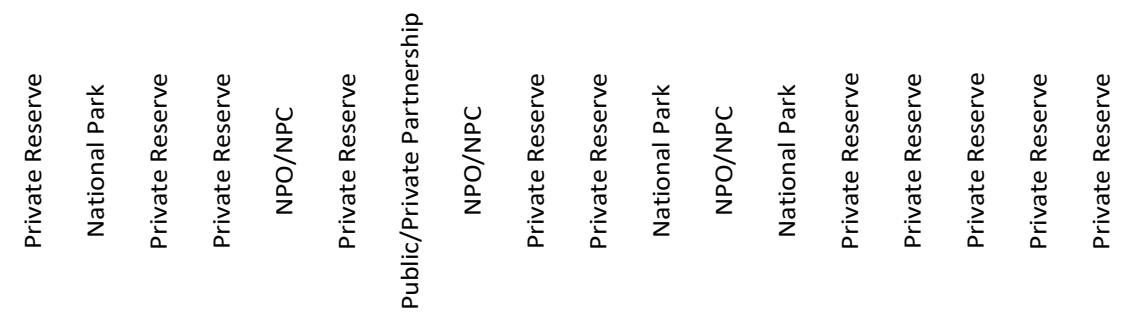

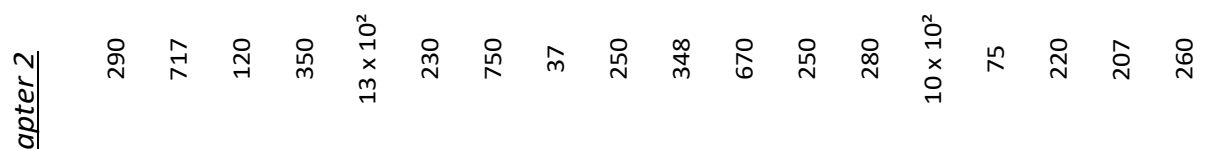

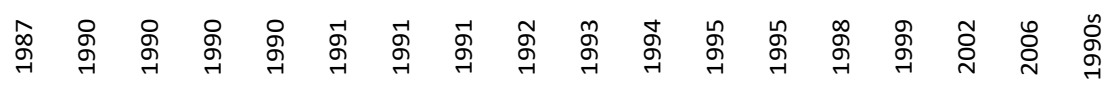

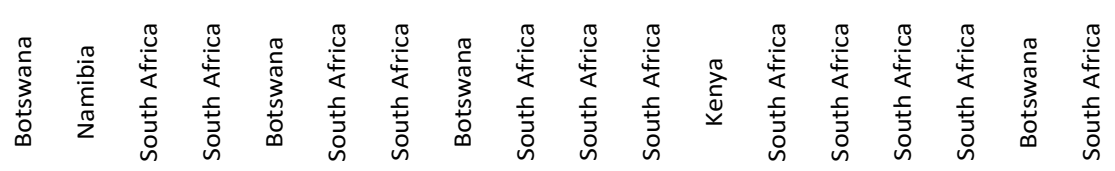

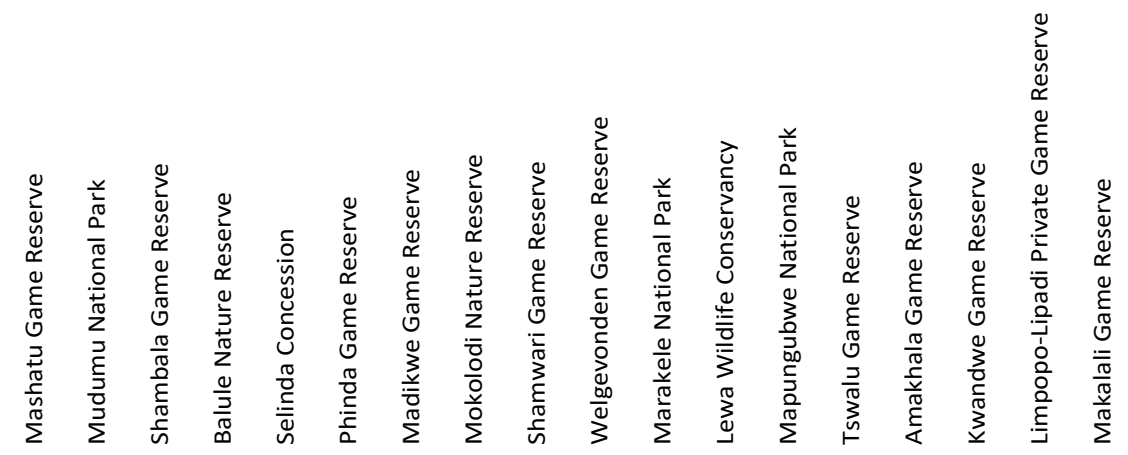




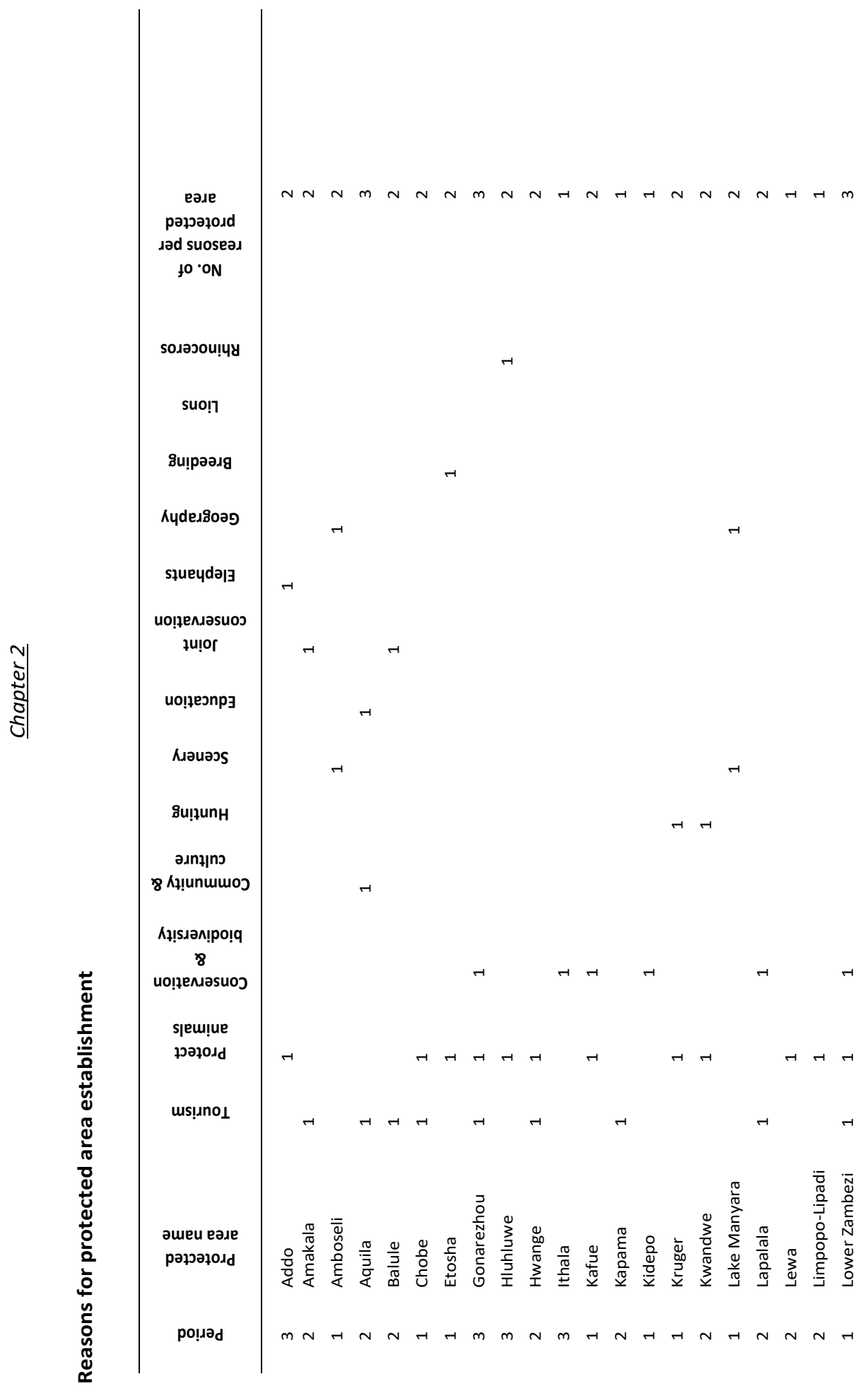




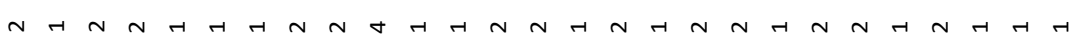

ำ

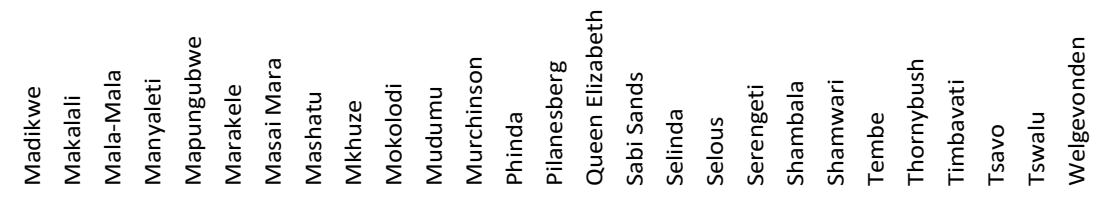

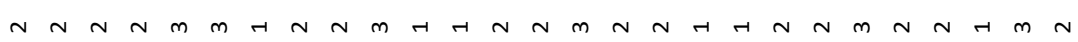




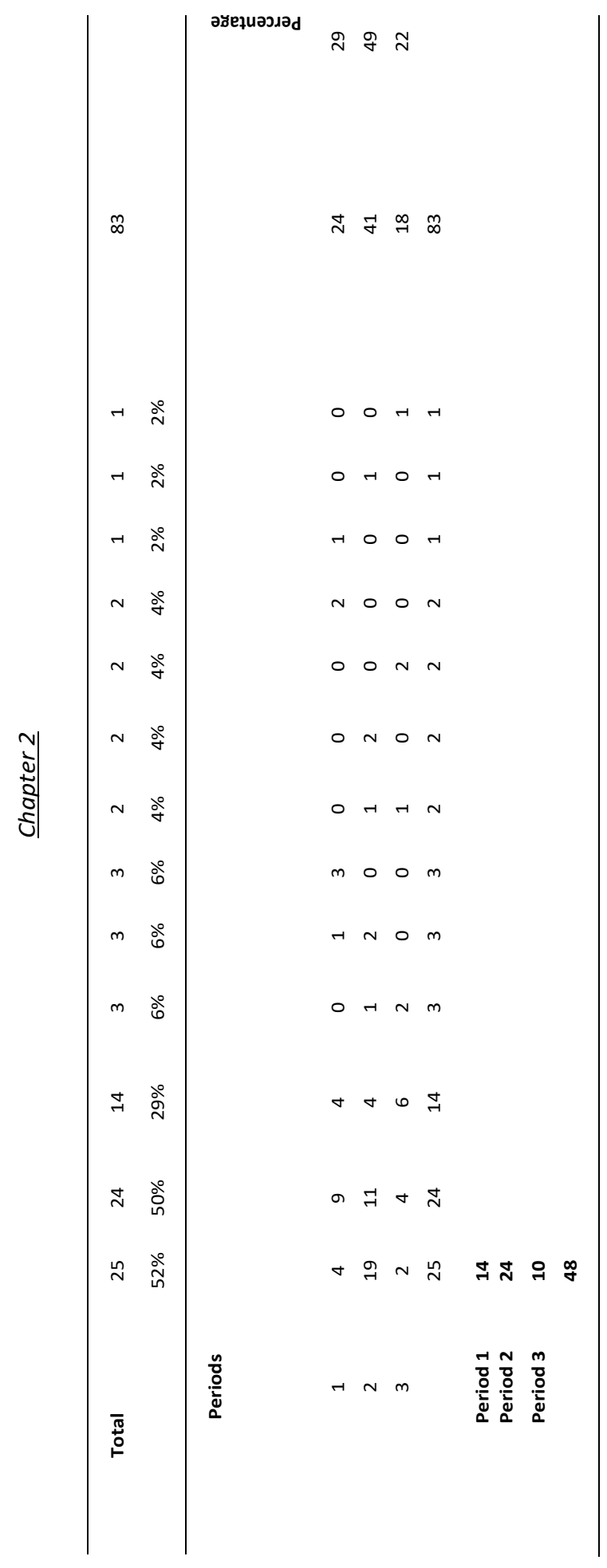




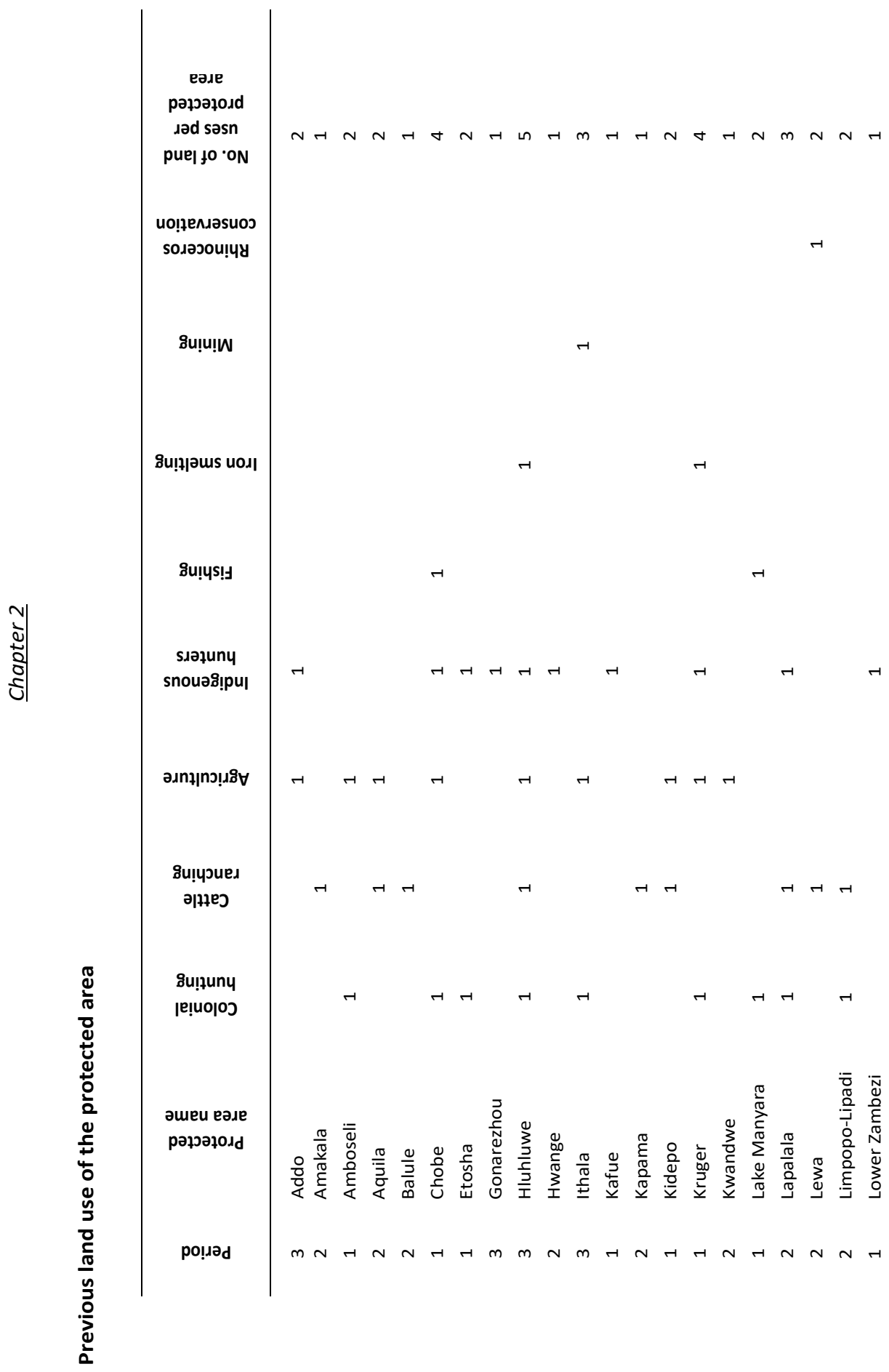




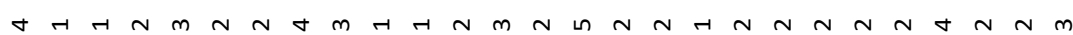

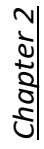

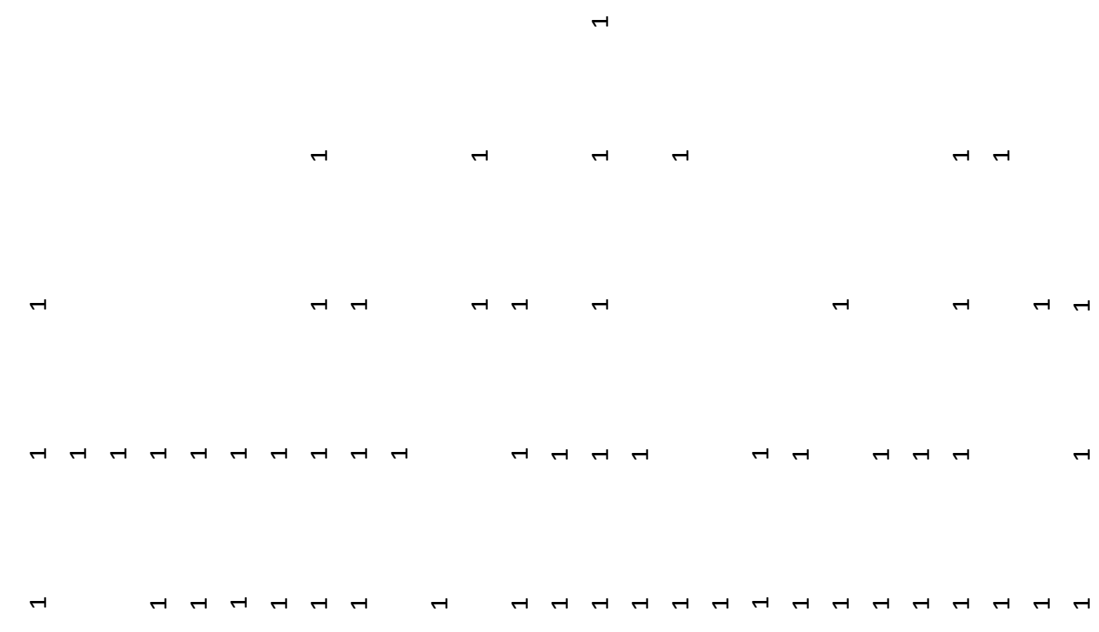

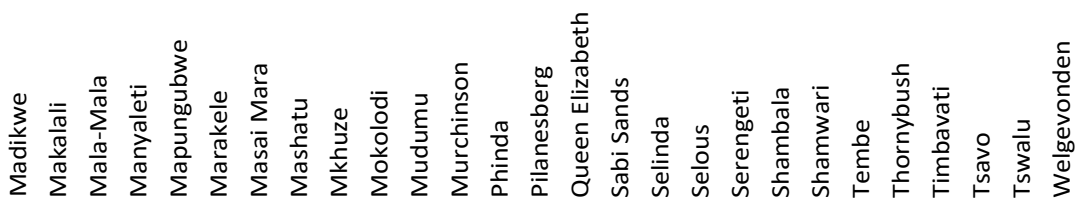

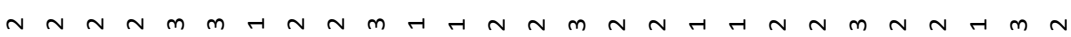




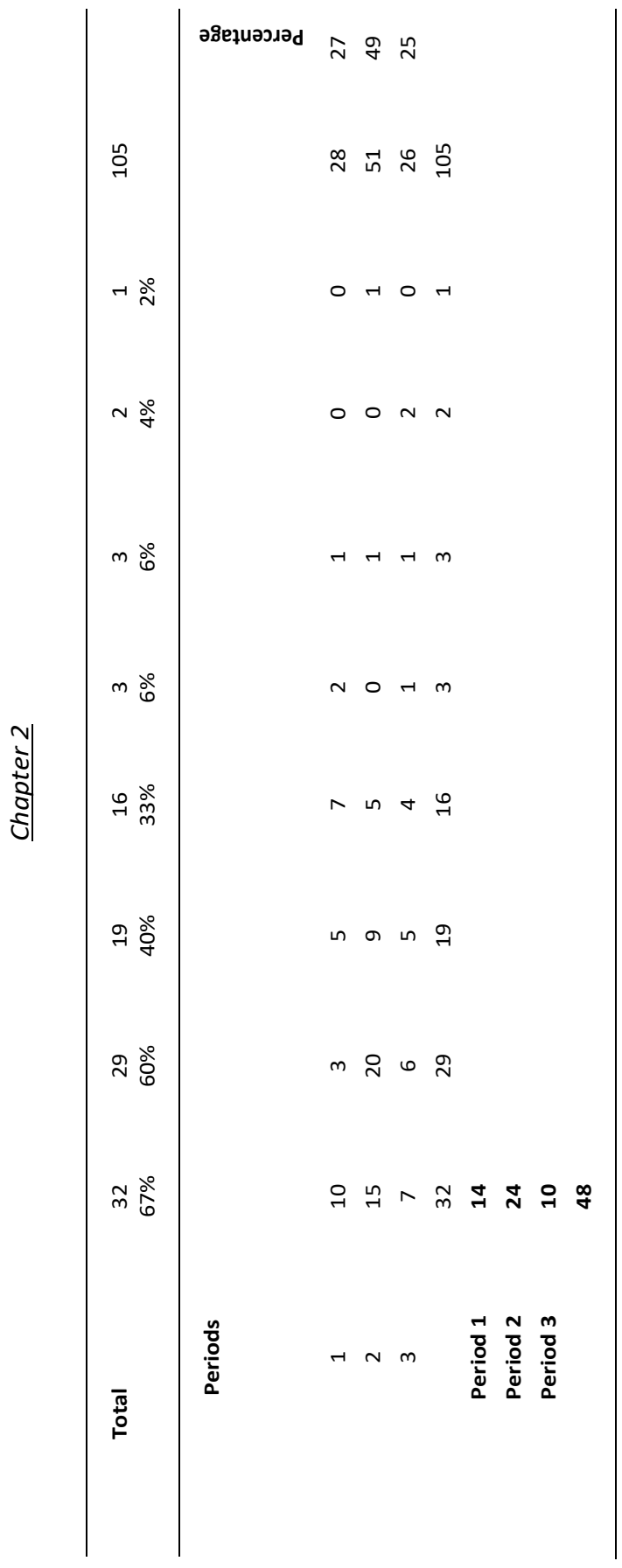




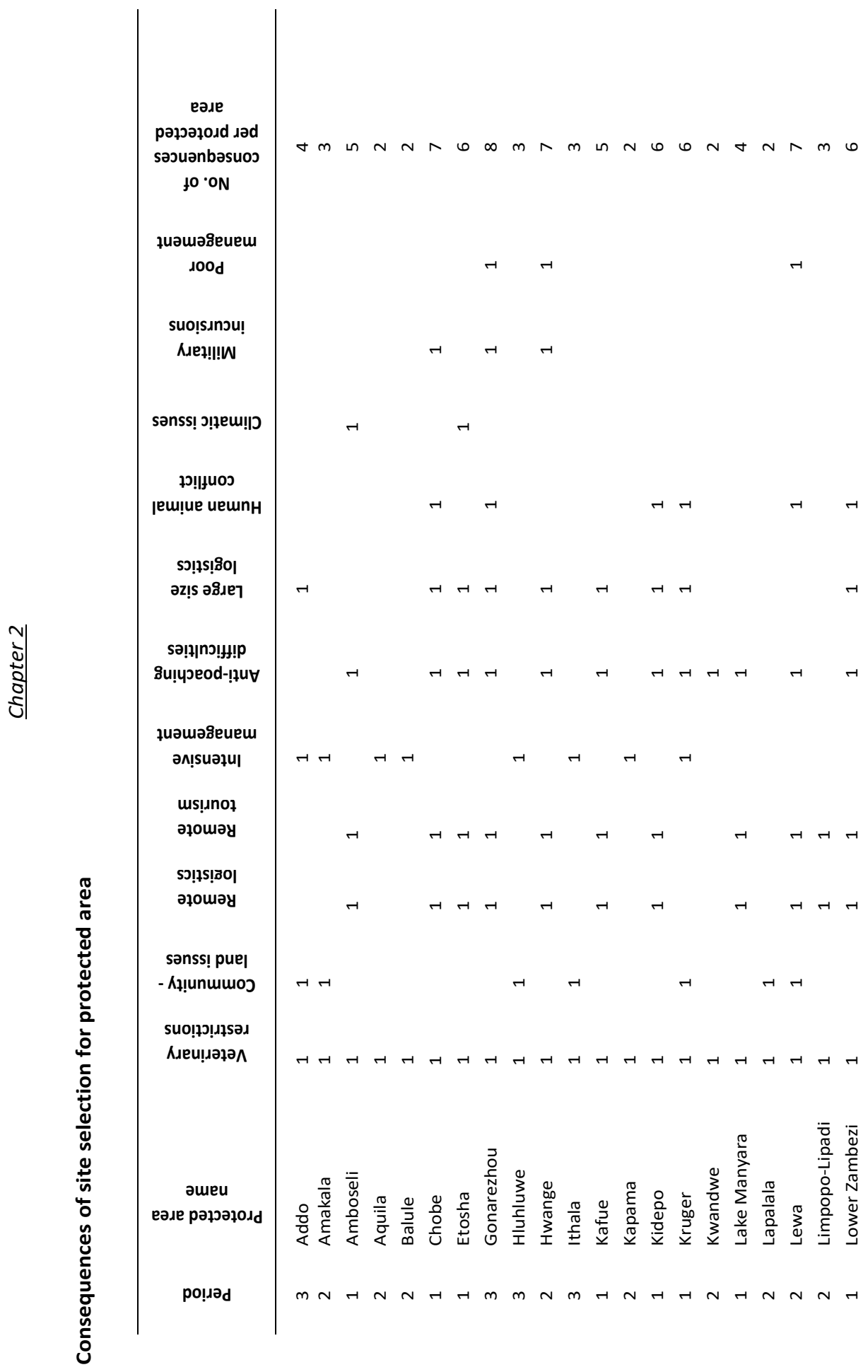




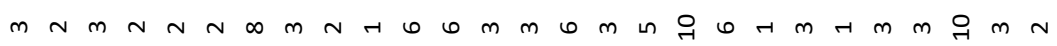

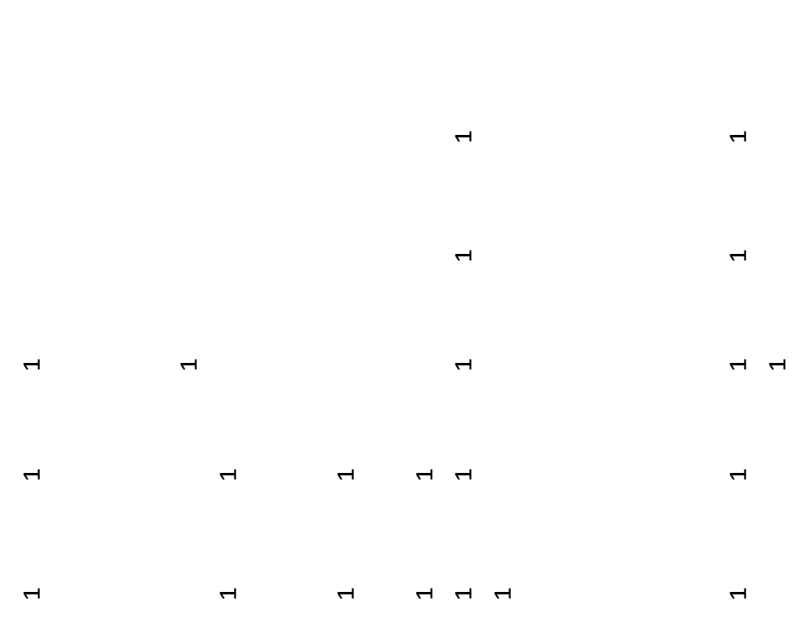

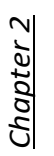

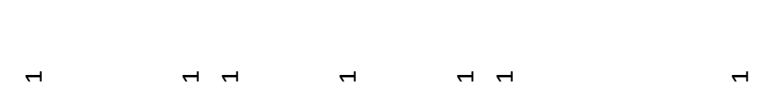

$4 \quad-4 \quad-4$

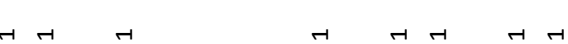

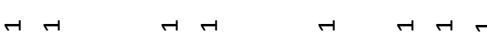

$\rightarrow$

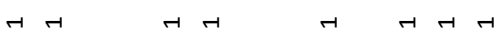

4

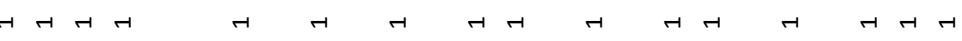

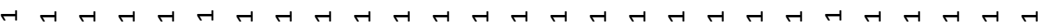

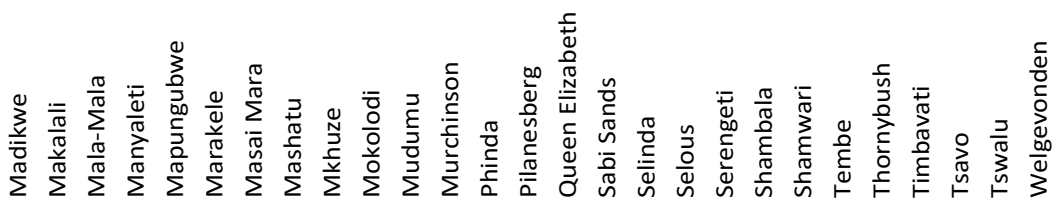

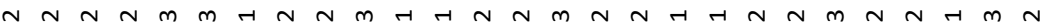




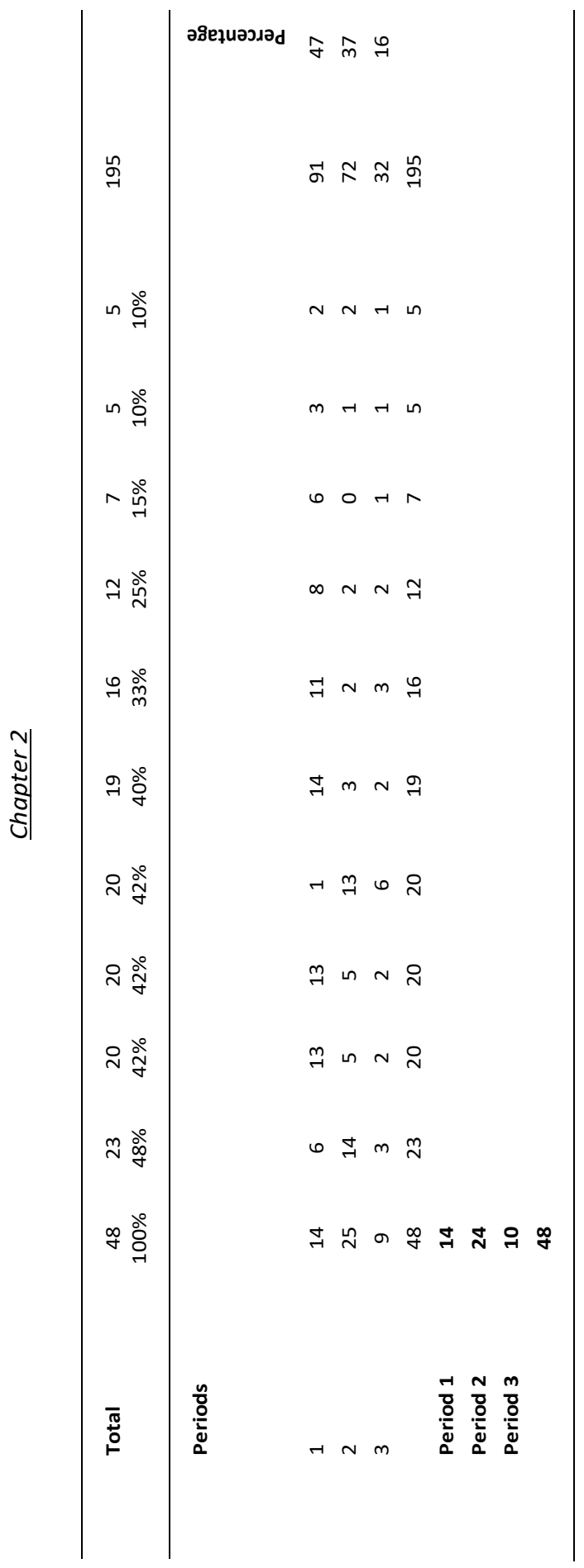




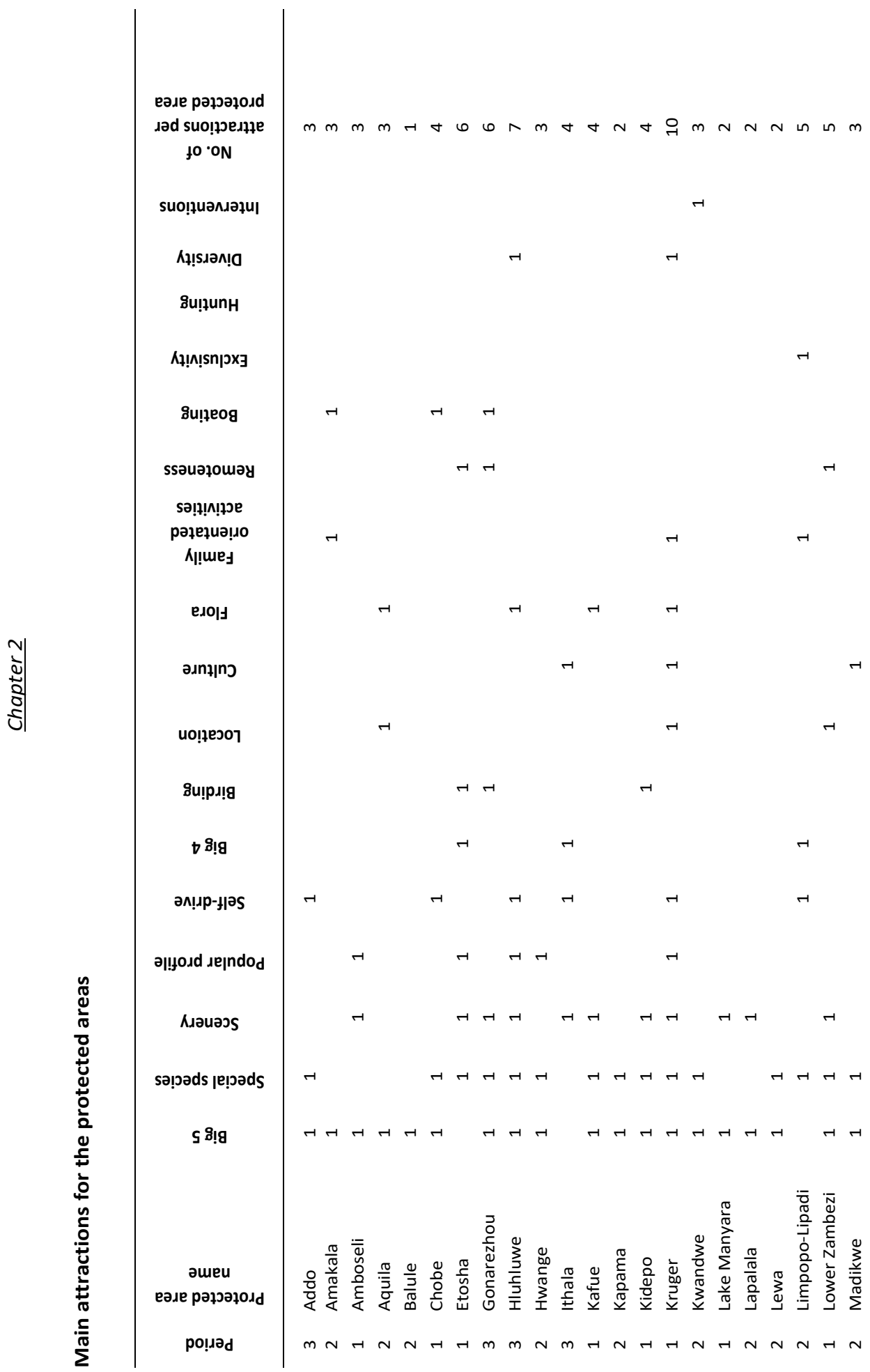




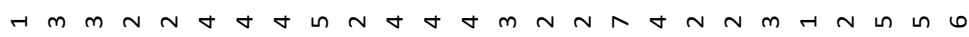

1े
$\vdots$
$\vdots$
$\vdots$
$\vdots$
$\vdots$

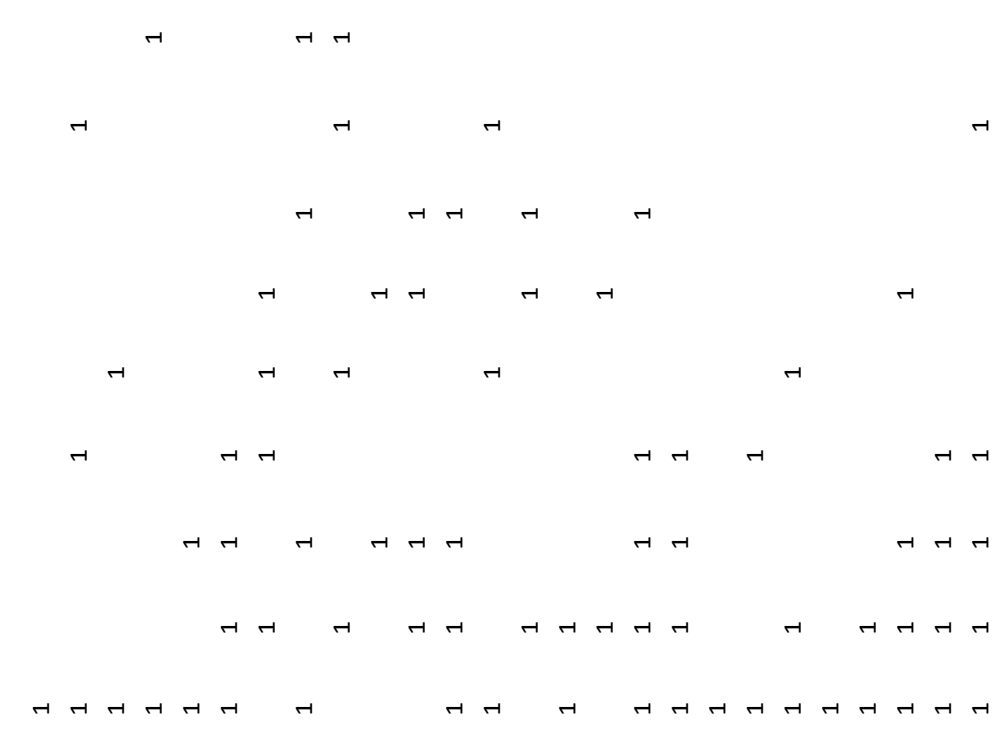

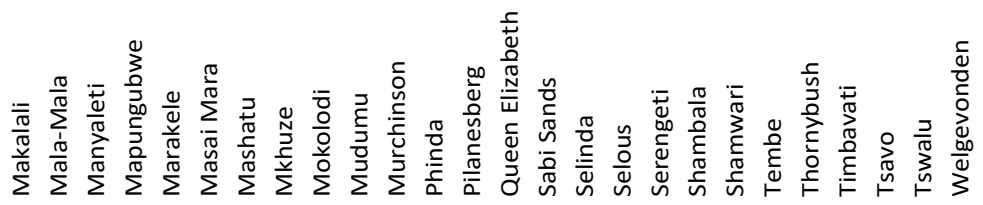

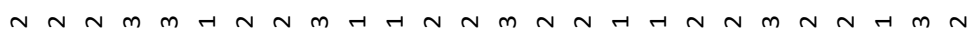




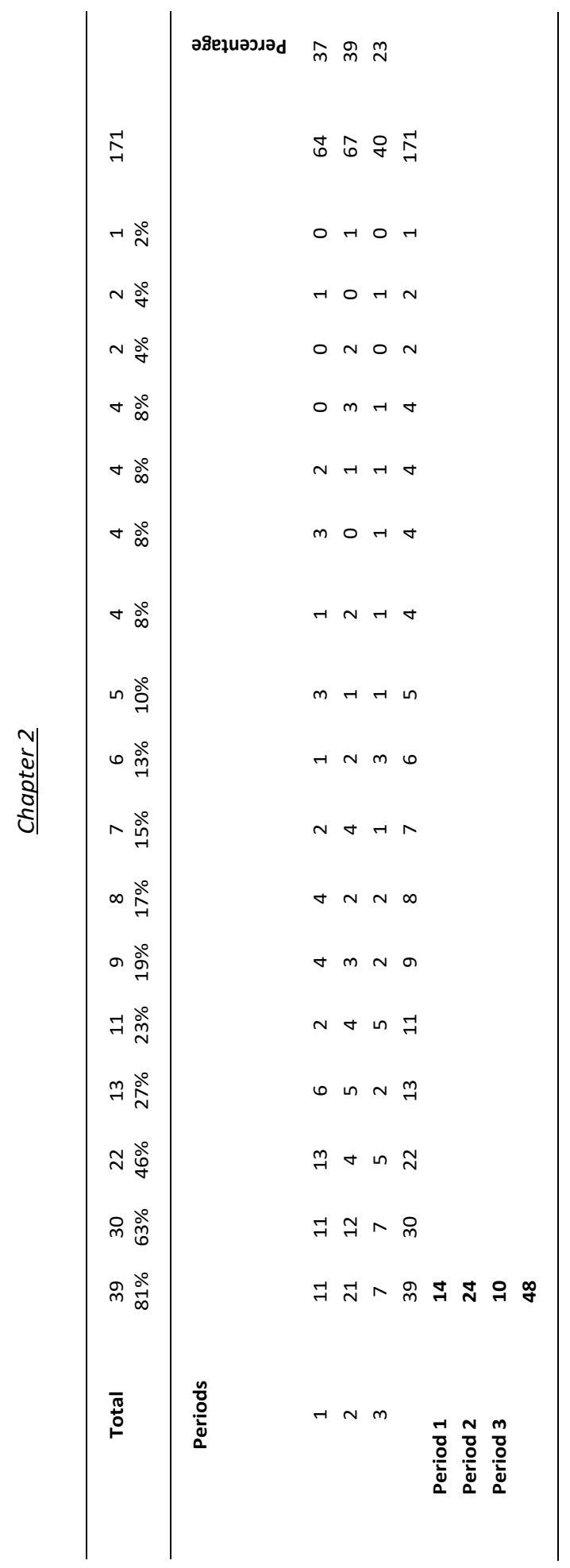




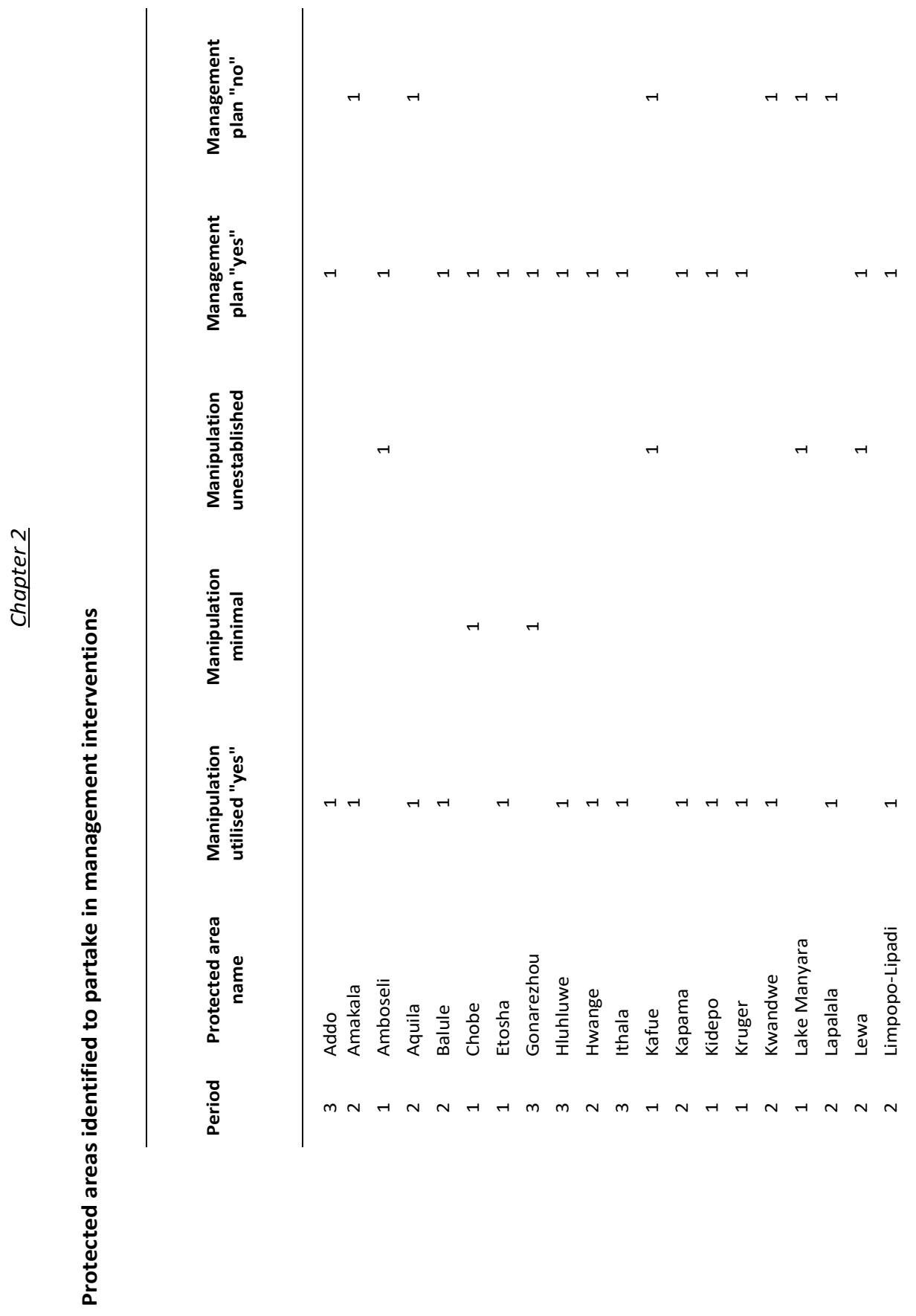




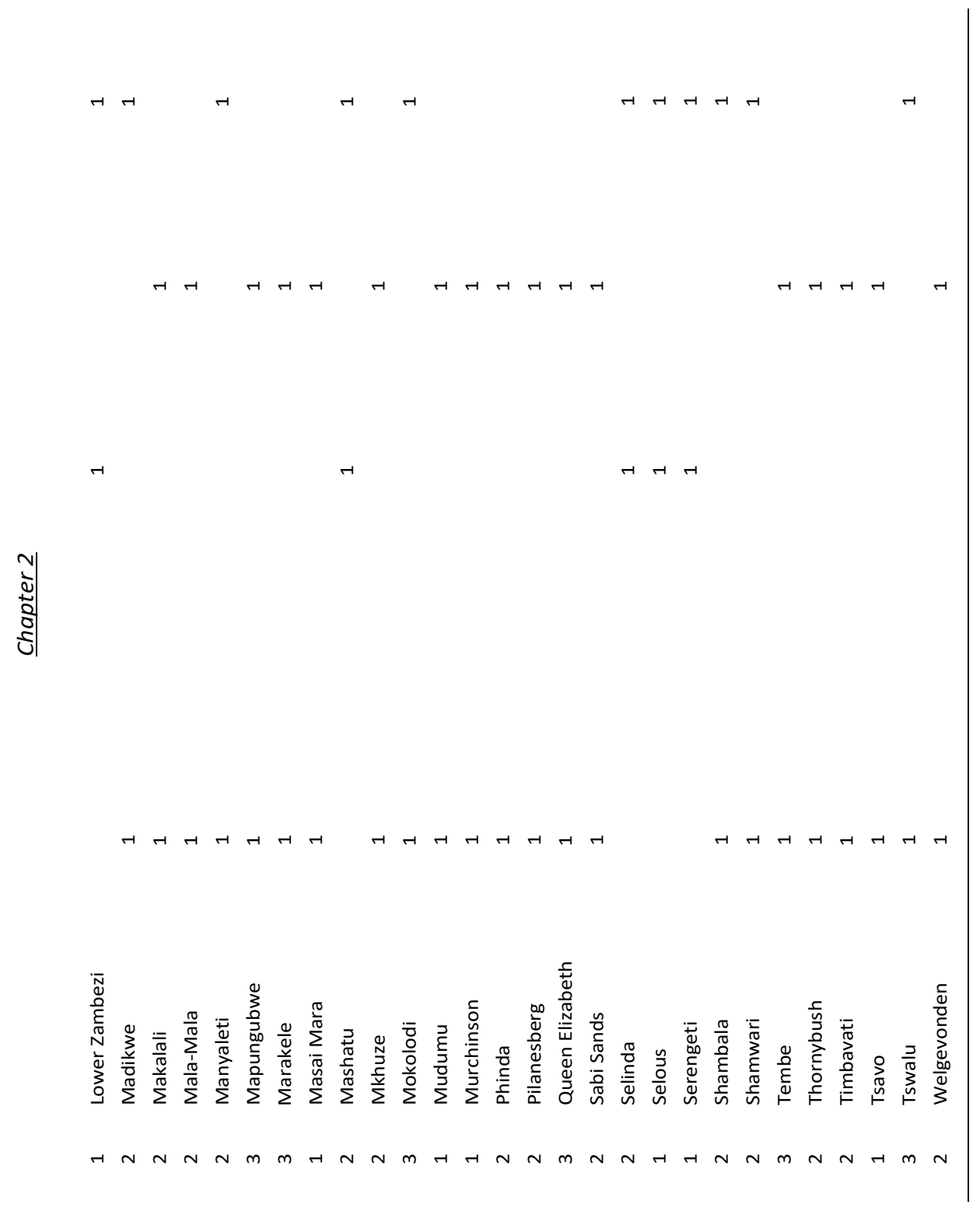




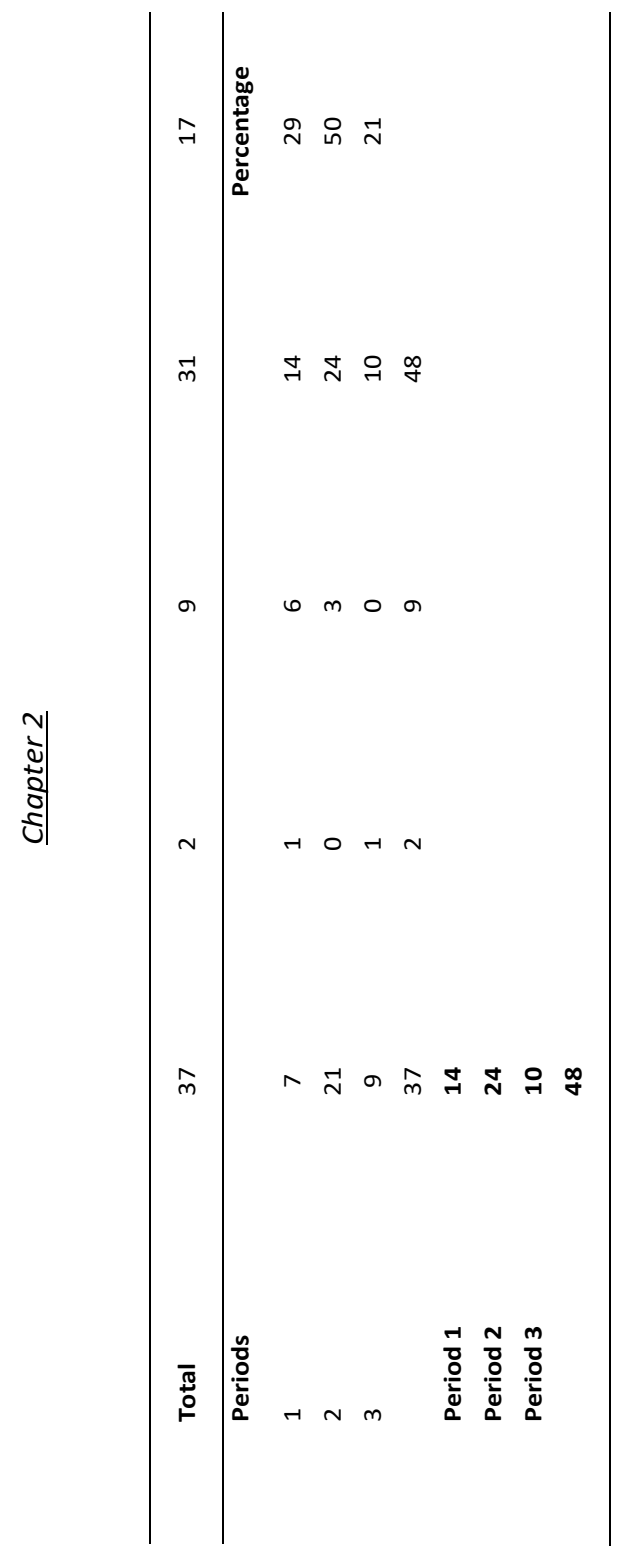




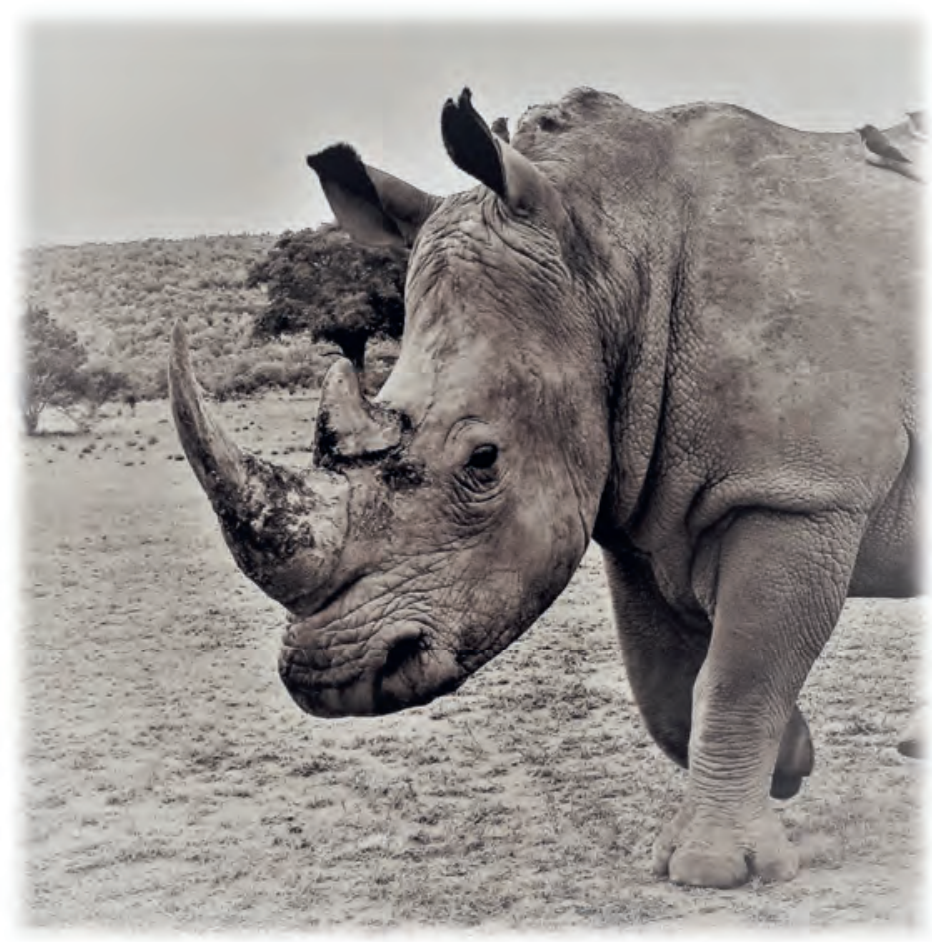

Photograph 5: Square-lipped rhinoceros, Figtree Plains, Welgevonden Game Reserve (Camera trap photograph) 


\section{Chapter 3}

\section{Chapter 3}

Effects of mineral addition on the establishment of grazing lawns in a nutrient poor savanna

\section{BRADLEY SCHRODER}

Wildlife Ecology and Conservation Group, Wageningen University, Droevendaalsesteeg 3a, 6708 PB Wageningen, the Netherlands

\section{FRANK VAN LANGEVELDE}

Wildlife Ecology and Conservation Group, Wageningen University, Droevendaalsesteeg 3a, 6708 PB Wageningen, the Netherlands and School of Life Sciences, Westville Campus, University of KwaZuluNatal, Durban 4000, South Africa

HERBERT H. T. PRINS

Animal Sciences Group, Wageningen University, De Elst 1, 6708 WD Wageningen, the Netherlands

Submitted to Ecosphere 


\section{Chapter 3}

\section{Abstract}

Nutrient poor savannas are often characterized by unpalatable grasses for mammalian grazers. So-called grazing lawns, with short, stoloniferous grasses, could provide high-quality food for grazers, but these grasses are rare in nutrient poor savannas. We tested whether we could use mineral addition to establish grazing lawns in a nutrient poor (or dystrophic) African savanna, in order to achieve a switch from tall, nutritionally poor grass species to short, highly nutritional grass species. The key finding of this study is that phosphorus supplementation resulted in a shift from tall grasses to short grasses within three years with a higher nutrient concentration in the grass species than without supplementation. When grazed, the cover of lawn grasses was higher compared to the other grasses when not grazed, demonstrating the role of grazers in maintaining and expanding lawn grass patches. We conclude that local fertilization in nutrient poor savannas is a viable method of increasing mineral levels in the soil and grass, resulting in an increase of lawn grass biomass, ensuring that herbivores obtain high-quality forage in these areas.

Keywords: fertilization, grass, grass growth forms, grazing systems, herbivory, soil 


\section{Chapter 3}

\section{Introduction}

In nutrient poor savannas, tall grass is the predominant grass type with low nutritional value that can only support small numbers of mammalian grazers (Bond and Archibald 2003; Parker 2004; Mucina and Rutherford 2006). In these areas, fires are frequent and the so-called grazing lawns are nearly always absent (Bond and Archibald 2003). Grazing lawns are areas with nutritious, grazing-tolerant indigenous grass species with a short-stature, such as couch grass (Cynodon dactylon; a.k.a. Bermuda grass), caused by frequent and intense grazing (Grant and Scholes 2006; Arnold 2012; Hempson et al. 2014). Lawn grass patches are often interspersed with patches of bunch grasses, which are tall, and therefore often have higher stem to leaf ratio and higher $\mathrm{C}: \mathrm{N}$ concentrations, and can therefore be less palatable than species found on grazing lawns. They grow in clusters and are intolerant to both drought and herbivory, such as common thatching grass (Hyparrhenia hirta) (Archibald et al. 2005; Archibald 2008; Coetsee et al. 2010). The vegetation is predicted to switch from lawn grasses to bunch grasses in the absence of grazing (with a shortage of grazing, short statured lawn grasses can be shaded out by the invasion of tall grasses) or with frequent fires (fire-grasses have a rapid post-fire regrowth providing little opportunity for other grasses to establish) (Cromsigt and Olff 2008; Novellie and Gaylard 2013; Hempson et al. 2014; Hempson et al. 2019). Grazing lawns are generally found in areas with relatively high soil nutrient status and high enough grazing pressure (Grant et al. 2011; Seymour et al. 2013; Veldhuis et al. 2014). The high soil mineral concentrations lead to high mineral concentrations in the plants. Owing to these high mineral values, mammalian herbivores concentrate their grazing in these areas. The more the animals utilise the area, the quicker the switch from tall unpalatable to short palatable grasses (Gillard 1969; Coetsee et al. 2010; Novellie and Gaylard 2013; Hempson et al. 2014). Hippopotamus (Hippopotamus amphibius) and square-lipped rhinoceros 


\section{Chapter 3}

(Ceratotherium simum) are examples of grazers which may create and maintain grazing lawns (Vesey-Fitzgerald 1974; Owen-Smith 1988; Cromsigt and Olff 2006; Verweij et al. 2006; Grant et al. 2011).

Grazing lawns are often found on old agriculture lands or former cattle kraals, where the collective cattle manuring during a long period of time has led to locally high soil nutrient status (Van der Waal et al. 2011a). This is more prevalent in areas with low annual rainfall and results in nutrient hotspots persisting for decades (Young et al. 1995; Veblen 2012). Grazing lawns do not carry fire due to the low fuel load (Bond and Archibald 2003) and can typically be described as a herbivore-driven system. Such a herbivore-driven system is stimulated by grazers, which create heterogeneity in the landscape, with patches often grazed and regrazed (De Knegt et al. 2008). In contrast, a fire-driven system generally has a homogenising influence on a landscape (Archibald and Bond 2004, Groen et al. 2017). Bond and Archibald (2003) suggest that fire can reduce grazing lawns due to creating green flushes which draw the grazers away from the lawns, resulting in less grazing pressure and hence a potential increase of tall grasses at the expense of lawn grass species. In areas with higher fire frequencies, grazing lawns seem to be infrequent (Bond and Archibald 2003).

The application of minerals is predicted to attract grazers to specific grass areas and thus through additional concentrations of localised grazing establish and / or expand the grazing lawn system further. We tested whether we could use fertilization of nitrogen, phosphorus and with a combination of lime (calcitic and dolomitic lime) as a possible mechanism by which grazing lawns could be established in Welgevonden Game Reserve, a nutrient poor savanna in the north of South Africa. Our hypothesis is that the addition of minerals (N, P and a combination with $\mathrm{Ca}$ ) into a nutrient poor savanna system will increase the minerals in the 


\section{Chapter 3}

soil and thus have a positive effect on the mineral levels in the grass leaf. A further hypothesis was that we predicted an increase in lawn grasses, specifically couch grass on the areas which were fertilized. The choice of minerals to be utilised as fertilizer was due to importance of both $\mathrm{N}$ and $\mathrm{P}$ to free-roaming herbivores and that they are paramount to their survival (Prins and Van Langevelde 2008). If there is a deficiency of $P$ it has effects on the growth and lactation of grazing animals (Murry 1995), whereas $\mathrm{N}$ is important to make amino acids, proteins and DNA (Martin 2017). Several studies have shown that savannas are either limited by $\mathrm{N}$ or $\mathrm{P}$ (Augustine et al. 2003; Cech et al. 2008). In a study close to Kruger National Park, South Africa, Van der Waal et al. (2011a) found that $P$ fertilization increased leaf $P$ concentrations in grasses on nutrient poor granite-gneiss soils, more than the expected response of grasses to $\mathrm{N}$ fertilization.

\section{Methods}

The study was conducted in Welgevonden Game Reserve, situated on the Waterberg Plateau in South Africa $\left(24^{\circ} 10^{\prime} \mathrm{S} ; 27^{\circ} 45^{\prime} \mathrm{E}\right.$ to $\left.24^{\circ} 25^{\prime} \mathrm{S} ; 27^{\circ} 56^{\prime} \mathrm{E}\right)$. The average rainfall for the study area is $650 \mathrm{~mm}$ per annum, with most of the area characterized primarily by the soil types dystrophic to mesotrophic yellow-brown apedal coarse sands (Parker 2004). Welgevonden is characterised by ferruginous soils with a low $\mathrm{pH}$. Accordingly, the vegetation type is dominated by broad-leaved savanna with tall, nutritionally poor grasses such as common thatching grass. The area has a diverse number of grazers, which is dominated by Burchell's zebra (Equus quagga burchellii), blue wildebeest (Connochaetes taurinus) and square-lipped rhinoceros. We tested our hypothesis in a field experiment consisting of eight sites spread throughout the reserve (Figure 3.1). We divided each of the sites into five plots, each minimally $300 \mathrm{~m} \times 150 \mathrm{~m}$. The plots were treated annually between the months of January 


\section{Chapter 3}

and February with either the addition of nitrogen ( $\mathrm{N}$ at $0.25 \mathrm{ton} / \mathrm{ha}=250 \mathrm{~g} / \mathrm{m}^{2}$ ) or phosphorus ( $P$ at 0.50 ton/ha $=500 \mathrm{~g} / \mathrm{m}^{2}$ ). We further investigated the supplementation of lime (in the form of calcitic lime at 1.5 tons/ha and dolomitic lime at 1.5 tons/ha); Ca concentration was 3 tons/ha on the availability of $\mathrm{N}$ and $\mathrm{P}$ for the plants. For that reason, we also fertilised with nitrogen and lime ( $\mathrm{N}$ at 0.25 tons/ha and $\mathrm{Ca}$ at 3 tons/ha) (calcitic and dolomitic lime), phosphorus and lime ( $\mathrm{P}$ at 0.50 tons/ha and $\mathrm{Ca}$ at 3 tons/ha) (calcitic and dolomitic lime) or a

plot with no treatment (control) (Figure 3.1). Given the low pH in the soils of Welgevonden, lime was added to our experiment to increase the soil pH levels as it is difficult for plants to absorb P if the pH is low (Chimdi et al. 2012), for example Higgins et al. 2012, showed that lime increased the $\mathrm{P}$ value in the grass leaf. The fertilizer used was ammoniacal nitrate-based and applied in the form of small granular pellets via a tractor and spreader. We controlled the encroachment of trees and shrubs on the various sites by mowing with a tractor and slasher to reduce the woody components which could compete with the grasses (Van der Waal 2010). The trees and shrubs were controlled annually (if required) and were slashed to a height of $10 \mathrm{~cm}$ above the ground. According to Coetsee et al. (2010) and Zwerts et al. (2015), it remains unknown whether local fertilization in a nutrient poor system can trigger a transition from tall grass species to short grass species. Van der Waal et al. (2011b) contradicts this and shows that wild herbivores contribute to structural heterogeneity of an area. According to studies by Parker (2004), the two most sought after grass species by grazers in Welgevonden are finger grass (Digitaria eriantha) and couch grass. The Welgevonden grass species list with the grazing palatability values is available in appendix $3 \mathrm{~A}$. 


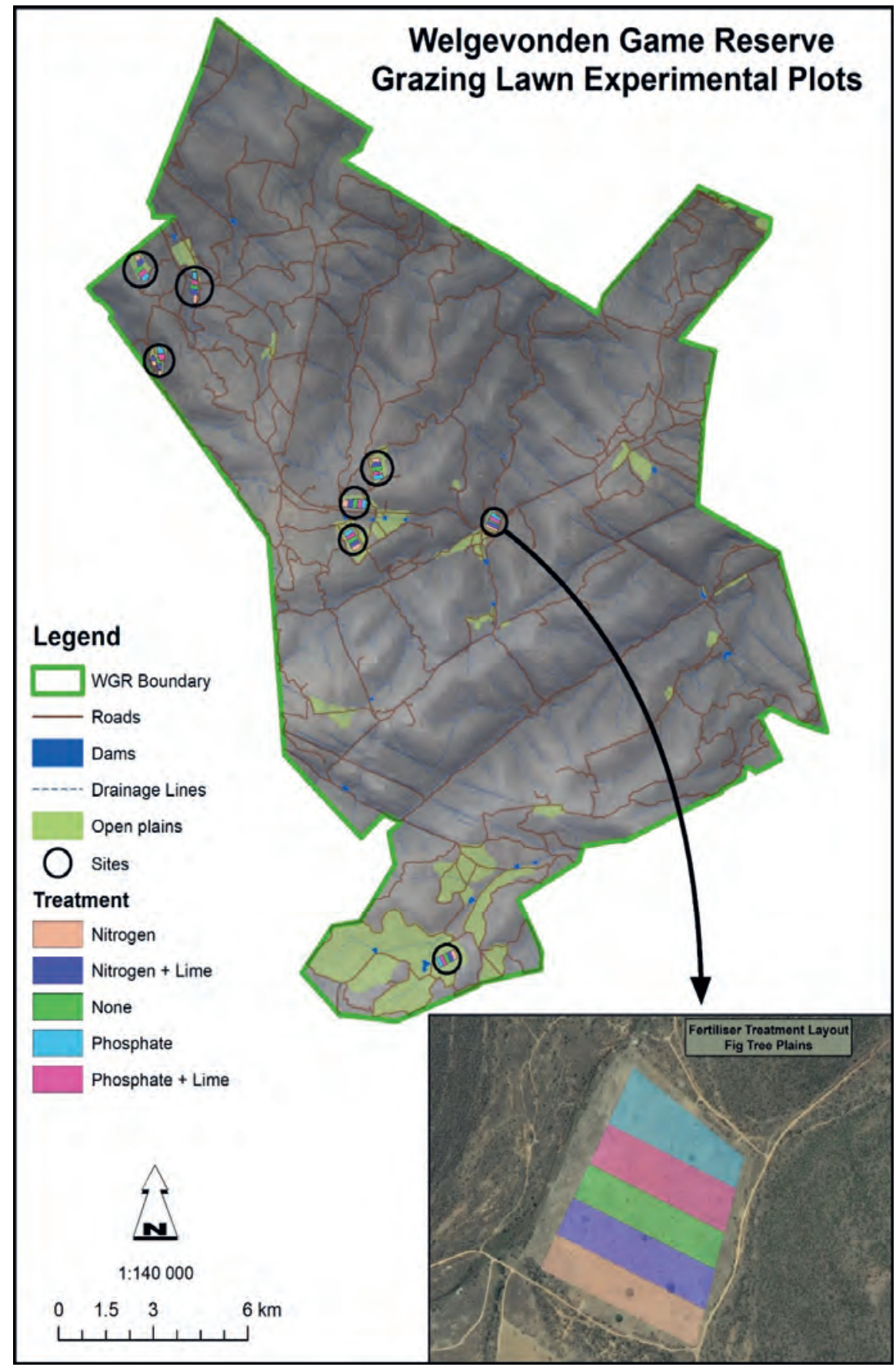

Figure 3.1 Map of the Welgevonden Game Reserve showing the grazing lawn experiment plots 


\section{Chapter 3}

\section{Soil samples}

Over the three year period $2016-2018$, we collected a total of 1290 soil samples during the first (January to April), second (May to August) and third periods (September to December) of the year. We sampled these three periods to account for the possible variation in soil mineral status over the year. These samples were collected from the centre of each plot, per treatment at three depths, $0-5,10-15$ and $25-30 \mathrm{~cm}$. We collected the soil using a narrow soil auger. The reason for collecting the three different depths was to establish leaching levels of the various minerals as soon as rain fell.

Prior to the analyses, we dried the samples in an oven at a temperature of $40^{\circ} \mathrm{C}$ (low temperature to prevent $\mathrm{N}$-losses) and sieved them through a $0.5-1 \mathrm{~mm}$ mesh sieve. Soil sample minerals were analysed either as a percentage in the case of Acid saturation, milligrams per kilogram $(\mathrm{mg} / \mathrm{kg}$ ) for $\mathrm{P}, \mathrm{K}, \mathrm{Na}, \mathrm{Ca}, \mathrm{Mg}, \mathrm{S}$ and $\mathrm{N}$, the $\mathrm{KCl}$ extractable to remove aluminium was used for $\mathrm{pH}$ or grams per centimetre cubed $\left(\mathrm{g} / \mathrm{cm}^{3}\right)$ for Density. $\mathrm{pH}$ samples were mixed with 1.0 Molar Potassium Chloride at a ratio of 1: 2.5 and read with a pH meter and a glass electrode. P was extracted using BRAY I extractant and determined colorimetric. $\mathrm{K}, \mathrm{Na}$ and Ca samples were extracted by 1.0 Molar Ammonium Acetate and determined by Inductive Coupled plasma (Barnard et al. 1990; Rayment and Lyons 2011; NviroTek Laboratories 2018).

\section{Grass samples}

To test the effect of the herbivores, we set up exclusion cages from January 2017 (1 m x $1 \mathrm{~m}$ ) in the middle of each plot where couch grass was in abundance, to establish the grass species composition, growth and biomass of the grass in the presence and absence of herbivores. Over the two year period 2017-2018, we collected 688 grass samples both inside and outside 


\section{Chapter 3}

exclusion cages during the first (January to April), second (May to August) and third periods (September to December) of the year. The grass leaf was cut in the $1 \mathrm{~m} \times 1 \mathrm{~m}$ exclusion plots and a $1 \mathrm{~m} \times 1 \mathrm{~m}$ plot outside the exclusion cages. We included fresh leaf material and dry leaf material depending on the time of year of the collection of the grass samples. The grass samples were identified per species using the Welgevonden grass species reference list. The biomass of the different grass species was measured both in the exclusion cages and adjacent to the exclusion cages using a calibrated disc pasture meter.

We air-dried the grass leaf samples, followed by drying in an oven at $70^{\circ} \mathrm{C}$. We then analysed the grass sample minerals, either as a percentage in the case of $\mathrm{N}, \mathrm{Ca}, \mathrm{Mg}, \mathrm{K}, \mathrm{S}$ and $\mathrm{P}$ or $\mathrm{mg} / \mathrm{kg}$ as with $\mathrm{Na}, \mathrm{Fe}, \mathrm{Mn}, \mathrm{Cu}, \mathrm{Zn}$ and $\mathrm{B}$. $\mathrm{N}$ was determined by a Dumas (total combustion) method and measured against organic material with a known $\mathrm{N}$ content. All the other compounds were digested with a Nitric and Perchloric acid mixture at $230^{\circ} \mathrm{C}$, allowing for the elements to be determined by Inductive Coupled plasma (NviroTek Laboratories 2018; AGRILASA 2019). Drying and chemical analyses were carried out at NviroTek laboratories which is an independent certified analytical testing facility. Nvirotek uses the international accredited determination of total nitrogen by the DUMAS combustion method as approved by the Agricultural laboratory Association of Southern Africa.

\section{Environmental impact of fertilization}

To ascertain that our large-scale fertilization had no negative impact on the environment, Welgevonden Game Reserve contracted three independent laboratories (NviroTek Laboratory, Hartbeespoort, South Africa; UIS Analytical services, Centurion, South Africa and the Witwatersrand University, Johannesburg, South Africa) to take and analyse separate water samples. The samples were collected from one site, viz., 'Figtree Plains', as this is the 


\section{Chapter 3}

only site which has a river system in its immediate vicinity. Samples were taken in October 2017, April 2018 and August 2018, with each sample being collected at three different locations within the river. Sample 1 was taken upstream from the site $\left(24^{\circ} 17^{\prime} 24.21^{\prime \prime} \mathrm{S} 27^{\circ} 49^{\prime}\right.$ $\left.42.73^{\prime \prime} \mathrm{E}\right)$, sample 2 was taken just below the site ( $24^{\circ} 17^{\prime} 07.71^{\prime \prime} \mathrm{S} 27^{\circ} 49^{\prime} 53.57^{\prime \prime} \mathrm{E}$ ) and sample 3 was taken a few kilometres downstream from the site ( $\left.24^{\circ} 14^{\prime} 47.53^{\prime \prime} S 27^{\circ} 50^{\prime} 43.13^{\prime \prime} \mathrm{E}\right)$. The analyses showed that there was no measurable change in the nitrate levels at any of the test locations. $\mathrm{N}(<0.5 \mathrm{mg} / \mathrm{l})$ and $\mathrm{P}(<5 \mathrm{mg} / \mathrm{l})$ showed that the system is extremely oligotrophic and in a pristine condition. There was no discernible effect of the fertilisation on the river system or water quality.

\section{Statistical analysis}

We tested our hypothesis using linear mixed models (LMMs) for each of the minerals in the soil and in the plants, and the fraction of lawn grass in the total grass biomass as response variables, the fertilization treatments as a fixed factor, and year, sampling moment and site as random factors. The differences between the fertilization treatments were compared using the Šidák multiple comparisons tests. We also ran LMMs to test the correlation between N, P and $\mathrm{Ca}$ concentrations in the soil and in the grass. Again, site and year were added as random factors. We used year as a random factor as we were not interested in differences between the years assuming that the response of the grasses to the mineral addition was within a few weeks after the application (Van der Waal et al. 2011a). We checked whether the residuals of the LMMs were normally distributed and, if not, $\log _{\mathrm{e}}$ transformation of the response variable

was used. Analysis were performed in SPSS v. 23 (SPSS Inc., Chicago, USA) and Canoco 5.12 (Ter Braak and Smilauer 1998).

\section{Results}




\section{Chapter 3}

\section{Soil minerals}

In the soil samples that we collected at different depths $(0-5,10-15$ and $25-30 \mathrm{~cm})$, there were no major differences between the treatments in the sample levels from $10-15$ and $25-30 \mathrm{~cm}$ (Appendix 3B). The three random factors, year, sampling moment and site were not significant. This shows that the increased mineral availability due to fertilisation was mainly found in the upper soil layer from $0-5 \mathrm{~cm}$, suggesting that there is no leaching. Hence, we only considered the mineral quantities in the upper soil layer in further analyses. We found differences in levels of $\mathrm{P}, \mathrm{N}, \mathrm{Ca}$ and $\mathrm{Mg}$ in the $0-5 \mathrm{~cm}$ soil layer between the treatments (Figure 3.2, Table 3.1). As expected, there are higher concentrations of $\mathrm{N}$ in the soil of plots which have been treated with $\mathrm{N}$, and higher $\mathrm{P}$ concentrations in those that are fertilized with $\mathrm{P}$, this agrees with the findings of Higgins et al. (2012). Ca and Mg concentrations are higher in the soils of plots treated with lime.
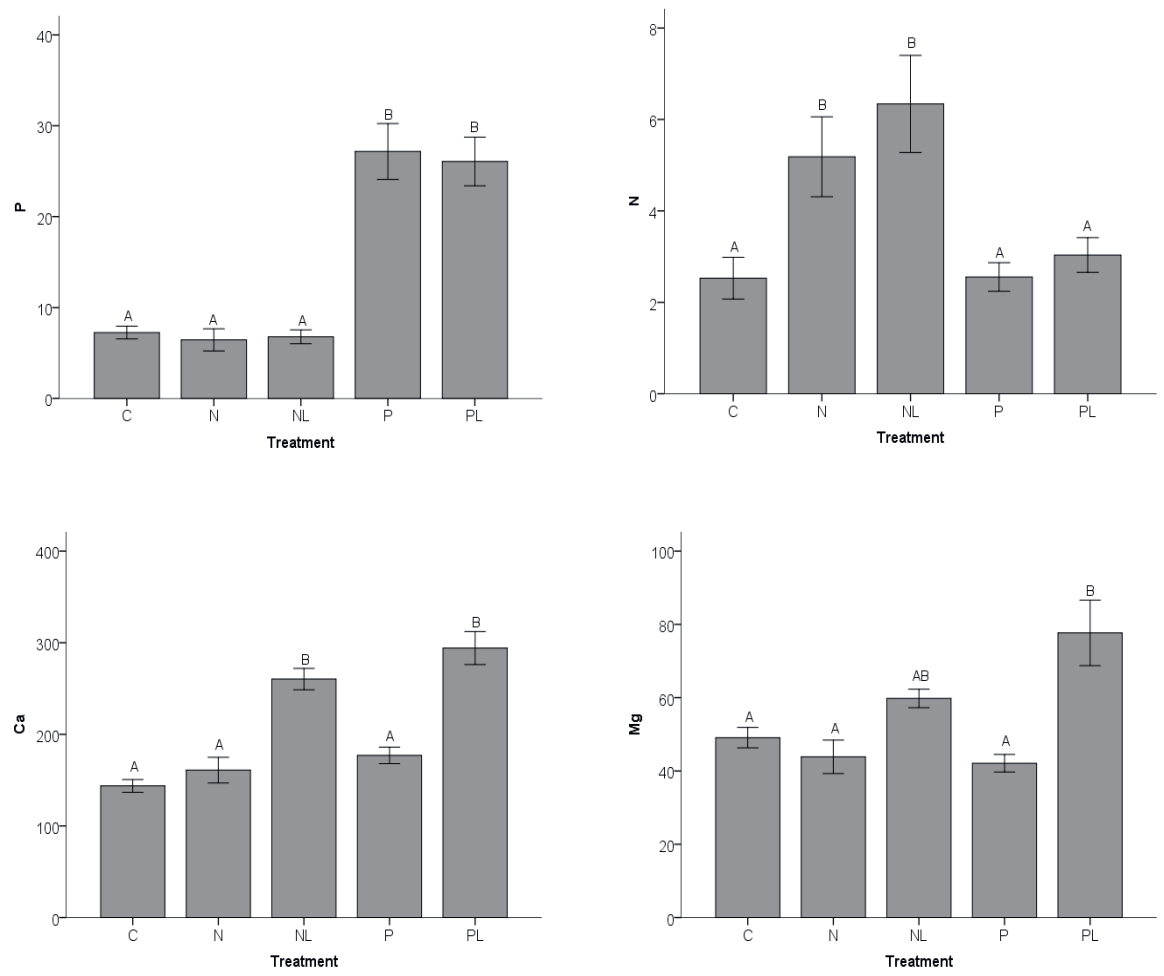


\section{Chapter 3}

Figure 3.2 Soil minerals ( $\mathrm{P}$ - phosphorus, $\mathrm{N}$ - nitrogen, $\mathrm{Ca}$ - calcium, $\mathrm{Mg}$ - magnesium - all expressed in $\mathrm{mg} / \mathrm{kg})$ in the $0-5 \mathrm{~cm}$ soil layer per treatment $(\mathrm{C}=$ control, $\mathrm{N}=$ nitrogen, $\mathrm{NL}=$ nitrogen and calcitic and dolomitic lime, $\mathrm{P}=$ phosphorus, $\mathrm{PL}=$ phosphorus and calcitic and dolomitic lime). Error bars represent the standard error of the mean. Letters indicate significant differences between the treatments based on the Šidák multiple comparisons tests using a linear mixed model (see Table 3.1 for the statistics)

Table 3.1 Results of the linear mixed model for differences in soil minerals in the $0-5 \mathrm{~cm}$ soil layer between the treatments $(\mathrm{C}=$ control, $\mathrm{N}=$ nitrogen, $\mathrm{NL}=$ nitrogen and calcitic and dolomitic lime, $\mathrm{P}=$ phosphorus, $\mathrm{PL}=$ phosphorus and calcitic and dolomitic lime). Separate mixed effects models were run for each mineral. Year and Site were the random factors, estimation methods was REML and the sample size $n=361$ (see Figure 3.2 for the graphs)

\begin{tabular}{l|c|c|c|c|c}
\hline & & $\mathbf{P}$ & $\mathbf{N}$ & $\mathbf{C a}$ & $\mathbf{M g}$ \\
\hline Treatment & $\mathrm{F}$ & 12.4 & 3.4 & 8.2 & 3.5 \\
\hline & $\mathrm{df}$ & 34.7 & 34.9 & 35.0 & 35.0 \\
\hline & $\mathrm{P}$ & $<0.001$ & 0.019 & $<0.001$ & 0.017 \\
\hline Year & Wald Z & 1.0 & 0.9 & 0.9 & 0.5 \\
\hline Site & $\mathrm{P}$ & 0.338 & 0.358 & 0.362 & 0.617 \\
\hline & Wald Z & 2.9 & 2.3 & 3.3 & 2.8 \\
\hline AlC & $\mathrm{P}$ & 0.003 & 0.023 & 0.001 & 0.005 \\
\hline
\end{tabular}

\section{Grass minerals}

The treatments resulted in differences in concentrations of $\mathrm{N}, \mathrm{P}, \mathrm{Ca}, \mathrm{Mg}, \mathrm{S}$ and $\mathrm{Mn}$ (Figure 3.3, Table 3.2) in the plants. As per our hypothesis N, P and Ca in the grass were at higher values in the plots treated with these minerals. The three random factors, year, sampling moment and site were not significant. 


\section{Chapter 3}
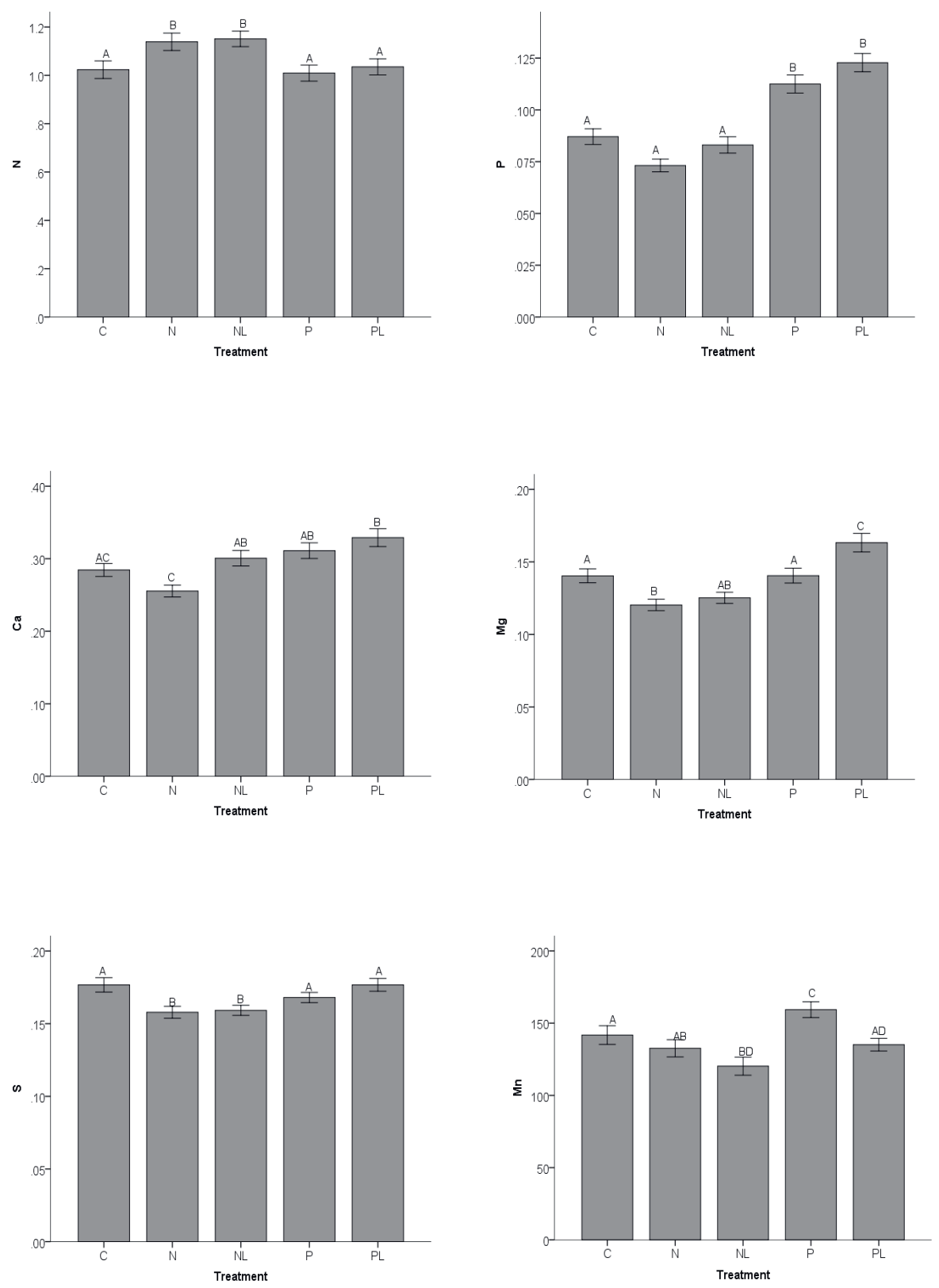

Figure 3.3 Grass minerals ( $\mathrm{N}$ - nitrogen, $\mathrm{P}$ - phosphorus, $\mathrm{Ca}$ - calcium, $\mathrm{Mg}$ - magnesium, $\mathrm{S}-$ sulphur, $\mathrm{Mn}$ manganese - all expressed as a percentage except for $\mathrm{Mn}$ which is expressed in $\mathrm{mg} / \mathrm{kg}$ ) with significant values per plot. $(\mathrm{C}=$ control, $\mathrm{N}=$ nitrogen, $\mathrm{NL}=$ nitrogen and calcitic and dolomitic lime, 


\section{Chapter 3}

$\mathrm{P}=$ phosphorus, $\mathrm{PL}=$ phosphorus and calcitic and dolomitic lime). Error bars represent the standard error of the mean. Letters indicate significant differences between the treatments based on the Šidák multiple comparisons tests using a linear mixed model (see Table 3.2 for the statistics)

Table 3.2 Results of the linear mixed model for differences in minerals in the grass between the treatments ( $\mathrm{C}=$ control, $\mathrm{N}=$ nitrogen, $\mathrm{NL}=$ nitrogen and calcitic and dolomitic lime, $\mathrm{P}=$ phosphorus, $\mathrm{PL}=$ phosphorus and calcitic and dolomitic lime). Separate mixed effects models were run for each mineral. Year and Site were the random factors, estimation methods was REML and the sample size $n=569$ (see Figure 3.3 for the graphs)

\begin{tabular}{l|c|c|c|c|c|c|c}
\hline & & $\mathbf{N}$ & $\mathbf{P}$ & $\mathbf{C a}$ & $\mathbf{M g}$ & $\mathbf{S}$ & $\mathbf{M n}$ \\
\hline Treatment & $\mathrm{F}$ & 4.1 & 36.5 & 7.8 & 12.9 & 7.1 & 8.3 \\
\hline & $\mathrm{df}$ & 557.0 & 556.1 & 556.1 & 556.1 & 556.1 & 557.0 \\
\hline Year & Wald Z & 0.3 & 0.7 & 0.7 & 0.6 & 0.70 & - \\
\hline & $\mathrm{P}$ & 0.760 & 0.486 & 0.507 & 0.545 & 0.482 & - \\
\hline Site & Wald Z & 1.2 & 1.8 & 1.7 & 1.7 & 1.8 & 1.8 \\
\hline & $\mathrm{P}$ & 0.257 & 0.075 & 0.094 & 0.091 & 0.075 & 0.071 \\
\hline AlC & & 487.9 & -2078.2 & -905.0 & -1743.0 & -2130.8 & 6128.1 \\
\hline
\end{tabular}

Unlike what we had hypothesized we found that the correlation between $\mathrm{N}$ in the soil and $\mathrm{N}$ in the grass was negligible. However, there was a positive correlation between $\mathrm{P}$ in the soil and the $\mathrm{P}$ in the grass, as well as for $\mathrm{Ca}$ in the soil and $\mathrm{Ca}$ in the grass (Figure 3.4 and Table 3.3). 


\section{Chapter 3}
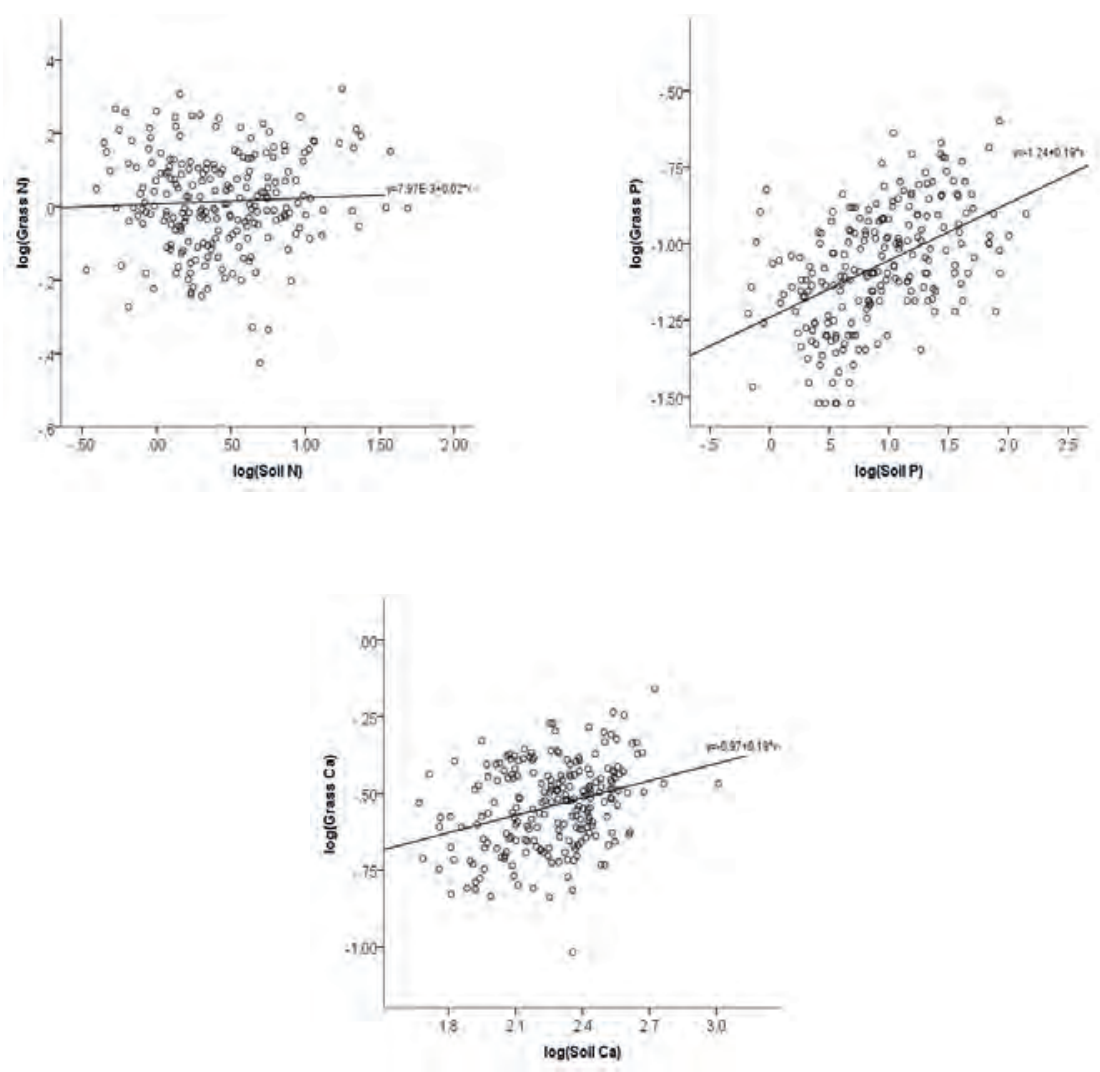

Figure 3.4 Correlation between N, P and Ca in the soil (all expressed in $\mathrm{mg} / \mathrm{kg}$; $\log _{10}$ transformed) and $\mathrm{N}, \mathrm{P}$ and $\mathrm{Ca}$ in the grass leaf (all expressed as a percentage; log10 transformed) (see Table 3.3 for the statistics)

Table 3.3 Results of the linear mixed model for the correlation between (i) N, (ii) P and (iii) Ca in the soil and the grass (all variables were log10 transformed). Separate mixed effects models were run for each correlation. Year and Site were the random factors, estimation methods was REML, and the sample size $n=224$ (see Figure 3.4 for the graphs)

\begin{tabular}{l|c|c|c|c}
\hline & & Grass N & Grass P & Grass Ca \\
\hline Soil N & F & 0.8 & - & - \\
\hline & df & 204.1 & - & - \\
\hline & P & 0.372 & - & - \\
\hline Soil P & F & - & 81.0 & - \\
\hline
\end{tabular}


Chapter 3

\begin{tabular}{l|c|c|c|c}
\hline & $\mathrm{df}$ & - & 221.7 & - \\
\hline & $\mathrm{P}$ & - & - & -0.001 \\
\hline Soil Ca & $\mathrm{F}$ & - & - & 13.0 \\
\hline & $\mathrm{df}$ & - & - & 204.9 \\
\hline Year & $\mathrm{P}$ & - & 0.7 & $<0.001$ \\
\hline & Wald Z & - & 0.491 & - \\
\hline Site & $\mathrm{P}$ & - & 1.4 & 1.5 \\
\hline & Wald Z & 1.0 & 0.157 & 0.140 \\
\hline AIC & P & 0.303 & -189.4 & -270.3 \\
\hline
\end{tabular}

In line with our second hypothesis, the proportion of couch grass outside the cages was higher than inside for all treatments except for $\mathrm{P}$ with lime (Figure 3.5, Table 3.4). We found a larger difference between inside and outside the cages for the treatments $\mathrm{N}$ and $\mathrm{P}$ compared to the treatments of $\mathrm{N}$ and $\mathrm{P}$ with lime. The three random factors, year, sampling moment and site were not significant.

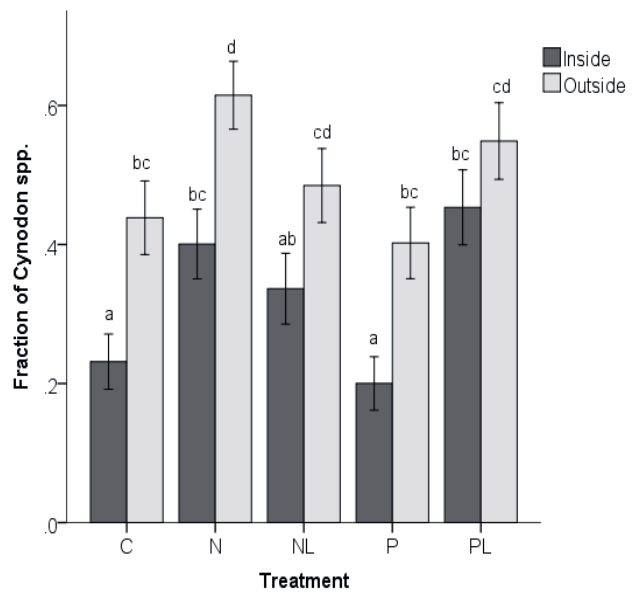




\section{Chapter 3}

Figure 3.5 The proportion of Cynodon dactylon (biomass Cynodon / total biomass) inside and outside the cages $(\mathrm{C}=$ control, $\mathrm{N}=$ nitrogen, $\mathrm{NL}=$ nitrogen and calcitic and dolomitic lime, $\mathrm{P}=$ phosphorus, $\mathrm{PL}$ $=$ phosphorus and calcitic and dolomitic lime). Error bars represent the standard error of the mean. Letters indicate significant differences between the treatments based on the Šidák multiple comparisons tests using a linear mixed model (see Table 3.4 for the statistics)

Table 3.4 Results of the linear mixed model for differences in the fraction of Cynodon dactylon (biomass Cynodon / total biomass $)$ between the treatments $(\mathrm{C}=$ control, $\mathrm{N}=$ nitrogen, $\mathrm{NL}=$ nitrogen and calcitic and dolomitic lime, $\mathrm{P}=$ phosphorus, $\mathrm{PL}=$ phosphorus and calcitic and dolomitic lime) and inside or outside the cages. Year, period and site were the random factors, estimation methods was REML (see Figure 3.5 for the graphs)

\begin{tabular}{|c|c|c|}
\hline Treatment & $\mathrm{F}$ & 11.7 \\
\hline & $\mathrm{df}$ & 4 \\
\hline & $P$ & $<0.001$ \\
\hline \multirow[t]{3}{*}{ Inside/Outside } & $\mathrm{F}$ & 45.9 \\
\hline & $\mathrm{df}$ & 1 \\
\hline & $P$ & $<0.001$ \\
\hline \multirow[t]{3}{*}{ Treatment $x$ Inside/Outside } & $\mathrm{F}$ & 0.8 \\
\hline & df & 4 \\
\hline & $P$ & 0.527 \\
\hline \multirow[t]{2}{*}{ Year } & Wald Z & - \\
\hline & $P$ & - \\
\hline \multirow[t]{2}{*}{ Period } & Wald Z & 0.9 \\
\hline & $P$ & 0.342 \\
\hline \multirow[t]{2}{*}{ Site } & Wald Z & 1.9 \\
\hline & $P$ & 0.051 \\
\hline AIC & & 406.9 \\
\hline $\mathrm{n}$ & & 628 \\
\hline
\end{tabular}




\section{Chapter 3}

\section{Discussion}

We tested the hypothesis that the addition of minerals to a nutrient poor savanna will increase mineral levels in the soil and in the grasses, resulting in an increase in lawn grass biomass. Our results support this hypothesis. Seymour et al. (2013) and Veldhuis et al. (2014) state that grazing lawns are generally found in areas with relatively high soil nutrient status. Our experiments demonstrate that fertilization in nutrient poor savannas can trigger the establishment of grazing lawns under the condition that initial mowing is required to enable the grazers to graze by removing stalks that hinder their foraging (Drescher et al. 2006). More specifically, we found that the addition of $\mathrm{P}$ and lime had significant increases on the amounts of available $\mathrm{P}$ and $\mathrm{Ca}$ in the grass leaf, which was also found in the study by Higgins et al. (2012). Because our study area is dominated by soils with a low ph, adding calcitic and dolomitic lime increases the ph thus promoting P-availability in the soil to the plants (Chimdi et al. 2012; Higgins et al. 2012). $\mathrm{N}$ did not show increased mineral levels in the grass. The differences in the effect of $\mathrm{N}$ and $\mathrm{P}$ fertilization on the minerals in the grass is supported by Van der Waal et al. (2011a). They showed that P fertilization increased leaf P concentrations more in grasses than trees, whereas $\mathrm{N}$ fertilization increased leaf $\mathrm{N}$ concentration moderately in both trees and grasses. We conclude from this study that $\mathrm{N}$ and more especially $\mathrm{P}$ increased in the soil when $\mathrm{N}$ and $\mathrm{P}$ were applied, but that $\mathrm{P}$ was the mineral absorbed into the grass leaf. The data suggests that $P$ is limiting (Figure 3.4). This is supported by the differences in grass biomass inside the cages. We found that the total grass biomass in the plots where $P$ was added was higher than in the plots where $\mathrm{N}$ was added (LMM for 2017: $\mathrm{P}=0.012, \mathrm{~F}_{1,59.0}$ $=6.7$, but not for 2018: $P=0.823, F_{1,43.7}=0.05$ ). The growth of lawn grasses (especially couch grass) is likely due to the elevated minerals in the grass leaf which increases the proportions of couch grass, furthermore it attracts more grazers to the fertilized areas which ensures that 


\section{Chapter 3}

the grazing lawns remain well-grazed (Schroder et al. submitted), resulting in the long-term sustainability of the lawn grass patches. Our results also show that when the grass is not grazed (inside the cages), lawn grasses (especially couch grass) are outcompeted by other grass species (Figure 3.5). Fire reduces grazing lawn success by creating green flushes in other areas which draw the grazers away from the lawns (Bond and Archibald 2003) and thus restricting the development and maintenance of lawns and perpetuating fire-driven ecological systems. Increases in mineral concentration in the grass may result in grazing lawns that are herbivore-driven (Waldram et al. 2007; Archibald 2008; Cromsigt and Olff 2008; Novellie and Gaylard 2013; Hempson et al. 2014; Zwerts et al. 2015). In nutrient poor savannas with grasses of low nutritional value, herbivores may have poor body condition resulting in low levels of nutritional value in their milk and thus a negative effect on fecundity. This has been reflected by low $\mathrm{P}$ and $\mathrm{N}$ concentrations in faeces in several studies (Dörgeloh et al. 1998; Grant et al. 2000). To ensure that grazers have the highest chances for survival, the forage quality of the grass in nutrient poor savannas needs to be improved and maintained.

In mesic savannas (rainfall $>650 \mathrm{~mm}$ ), such as Kruger National Park, where there is a higher amount of nutrients available, overgrazing may lead to the replacement of palatable species by unpalatable species (Grant et al. 2011). This is similar to areas which are lightly grazed by selective feeders, resulting in the increase in more unpalatable grass species. Our study area has a historic annual rainfall of $>650 \mathrm{~mm}$ but is in an area with poorer nutrient availability than found in Kruger National Park. We concur with findings by Schroder et al. (submitted) that through the manipulations as described in this study, that intensive grazing is no longer a valid concern for these types of areas (Schroder et al. submitted), as the grazing helps to stimulate the change in grass species from nutrient poor (viz., common thatching grass) to 


\section{Chapter 3}

nutrient rich grasses (viz., couch grass). Figure 3.5 shows how grazing pressure and manipulation have increased the biomass of the lawn grasses over a period and changed the grass species from tall nutritionally poor to short nutritionally rich grasses. The grazing pressure maintained by large numbers of grazers, especially species with high muzzle width to body ratio such as square-lipped rhinoceros, hippopotamus and Burchell's zebra, has a positive effect on the change in grass composition (Schroder et al. submitted), which ultimately may have a positive effect on the herbivore species and their fecundity.

\section{Practical implications}

With these findings we contribute to the understanding of under what conditions grazing lawns can establish. The manipulation of grazing lawns through the addition of $\mathrm{P}$ and $\mathrm{Ca}$ specifically can be attributed to the increased mineral value of grass leaf in nutrient poor savannas. Future studies should test the hypothesis that herbivores will maintain grazing lawns in a sustainable state in nutrient poor savannas of Welgevonden Game Reserve. 


\section{Chapter 3}

Appendix 3A Welgevonden Game Reserve grass species list (Jonathan Swart - Reserve Ecologist - Personal communication) with the grazing palatability values obtained from the guide to grasses of Southern Africa (Van Oudtshoorn 2002)

\begin{tabular}{|c|c|c|}
\hline Scientific name & English name & Grazing value \\
\hline Alloteropsis semialata & Black-seed Grass & Average \\
\hline Andropogon appendiculatus & Vlei Bluestem & High \\
\hline Andropogon chinensis & Hairy Blue Grass & Average \\
\hline Andropogon eucomus & Snowflake Grass & Low \\
\hline Andropogon huillensis & Large Silver Andropogon & Average \\
\hline Andropogon schirensis & Stab Grass & Average \\
\hline Aristida adscensionis & Annual Three-awn & Low \\
\hline Aristida congesta ssp. barbicollis & Spreading Three-awn & Low \\
\hline Aristida congesta subsp. congesta & Tassel Three-awn & Low \\
\hline Aristida diffusa burkei & Iron Grass & Low \\
\hline Aristida junciformis ssp. junciformis & Ngongoni Three-awn & Low \\
\hline Aristida meridionalis & Giant Three-awn & Low \\
\hline Aristida scabrivalvis ssp. scabrivalvis & Purple Three-awn & Low \\
\hline Aristida stipitata ssp. graciliflora & Long-awned-three-awn & Low \\
\hline Aristida transvaalensis & Rock Three-awn & Low \\
\hline Bewsia biflora & False Love Grass & Low \\
\hline Brachiaria brizantha & Common Signal Grass & Average \\
\hline Brachiaria deflexa & False Panicum & Average \\
\hline Brachiaria eruciformis & Sweet Signal Grass & Average \\
\hline Brachiaria nigropedata & Black-footed Signal Grass & High \\
\hline Brachiaria serrata & Velvet Signal Grass & Average \\
\hline Cenchrus cilliaris & Blue Buffalo Grass & High \\
\hline Chloris gayana & Rhodes Grass & Low \\
\hline
\end{tabular}




\section{Chapter 3}

Chloris pycnothrix

Chloris virgata

Chrysopogon serrulatus

Cymbopogon caesius

Cymbopogon pospischilii

Cynodon dactylon

Cynodon nlemfuensis

Dactyloctenium aegyptuim

Dactyloctenium giganteum

Digitaria brazzae

Digitaria eriantha

Digitaria longiflora

Digitaria monodactyla

Digitaria ternata

Digitaria velutina

Diheteropogon amplectens

Diplachne fusca

Echinochloa colona

Eleusine coracana ssp. africana

Elionurus muticus

Enneapogon pretoriensis

Eragrostis aspera

Eragrostis biflora

Eragrostis caesia

Eragrostis capensis

Eragrostis chloromelas

Eragrostis curvula

Eragrostis gummiflua
Spiderweb Grass

Low

Feathered Chloris

Average

Golden Beard Grass

High

Broad-leaved Turpentine Grass

Low

Narrow-leaved Turpentine Grass

Low

Couch Grass

High

Star Grass

High

Common Crowfoot

Average

Giant Crowfoot

High

Brown Finger Grass

High

Finger Grass

High

False Couch Grass

Average

One-finger Grass

Average

Black-seed Finger Grass

Low

Flaccid Finger Grass

Low

Broad-leaved Bluestem

Average

Swamp Grass

High

Jungle Rice

High

Goose Grass

Low

Wire Grass

Low

Nineawn Grass

Low

Rough Love Grass

Low

Shade Eragrostis

Low

Weeping Lovegrass

Low

Heart-seed Love Grass

Average

Curly Leaf

Average

Weeping Love Grass

High

Gum Grass

\section{Low}


Chapter 3

Eragrostis heteromera

Eragrostis lehmanniana

Eragrostis micrantha

Eragrostis nindensis

Eragrostis patens

Eragrostis pallens

Eragrostis plana

Eragrostis pseudosclerantha

Eragrostis racemosa

Eragrostis rotifer

Eragrostis superba

Eragrostis viscosa

Eustachys paspaloides

Fingerhutia africana

Heteropogon contortus

Hyperthelia dissoluta

Hyparrhenia filipendula

Hyparrhenia hirta

Imperata cylindrica

Ischaemum fasciculatum

Leersia hexandra

Leptocarydion vulpiastrum

Loudetia simplex

Melinis nerviglumis

Melinis repens ssp. repens

Miscanthus junceus

Monocymbium ceresiiforme

Panicum coloratum var. coloratum
Bronze Love Grass

Average

Lehmann's Love Grass

Average

Finesse Grass

Low

Wether Love Grass

Average

Japanese Lovegrass

Low

Broom Love Grass

Low

Tough Love Grass

Low

Footpath Love Grass

Low

Narrow Heard Love Grass

Average

Pearly Love Grass

Average

Sawtooth Love Grass

Average

Sticky Love Grass

Low

Fan Grass

High

Thimble Grass

Average

Spear Grass

Average

Yellow Thatching Grass

Average

Fine Thatching Grass

Average

Common Thatching Grass

Average

Cottonwool Grass

Low

Hippo Grass

Average

Southern Cutgrass

High

Spade Grass

Low

Common Russet Grass

Average

Bristle-leaved Red Top

Average

Natal Red Top

Low

Wireleaf Daba Grass

Average

Boat Grass

Average

White Buffalo Grass

\section{High}


Chapter 3

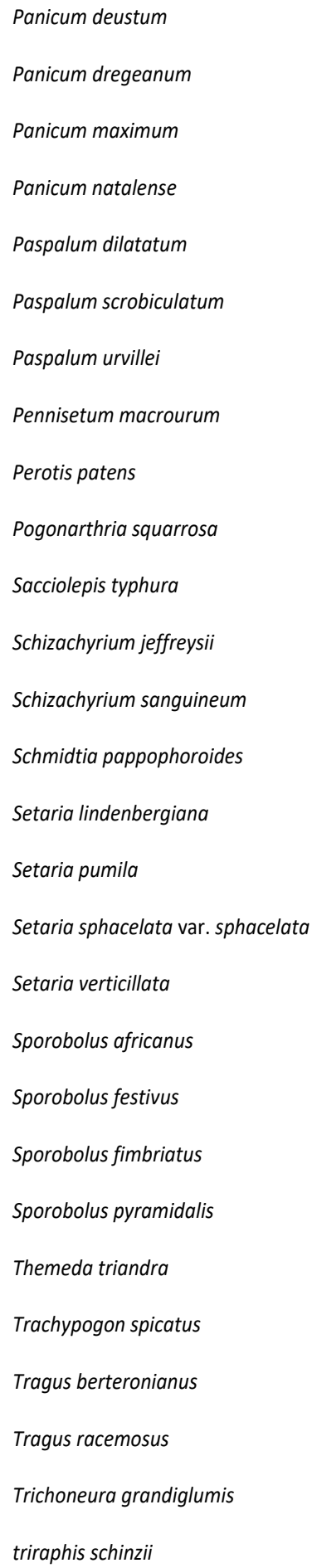

Broad-leaved Panicum

High

Plum Panicum

Average

Guinea Grass

High

Natal Panicum

Low

Common Paspalum

High

Ricegrass Paspalum

Average

Giant Paspalum

Average

Riverbed Grass

Average

Cat's Tail

Low

Herringbone Grass

Low

Purple-hood Grass

Low

Silky Autumn Grass

Low

Red Autumn Grass

Low

Sand Quick

High

Mountain Bristle Grass

High

Shade Bristle Grass

Low

Common Bristle Grass

High

Bur Bristle Grass

High

Ratstail Dropseed

Low

Red Dropseed

Low

Bushveld Dropseed

High

Catstail Dropseed

Low

Redgrass

Average

Giant Spear Grass

Low

Common Carrot Seed Grass

Low

Large Carrot Seed Grass

Low

Small Rolling Grass

low

Sandveld Broom Grass

Low 


\section{Chapter 3}

Tristachya biseriata

Tristachya leucothrix

Tristachya rehmannii

Urelytrum agropyroides

Urochloa mosambicensis

Urochloa panicoides
Trident Grass

Hairy Trident Grass

Trident Grass

Quinine Grass

Bushveld Signal Grass

Garden Signal Grass
Average

Average

Low

Low

High

Low 


\section{Chapter 3}

Appendix 3B Soil minerals ( $\mathrm{P}$ - phosphorus, $\mathrm{N}$ - nitrogen, $\mathrm{Ca}$ - calcium, $\mathrm{Mg}$ - magnesium - all expressed as $\mathrm{mg} / \mathrm{kg})$ in the soil layer at $0-5,10-15$ and $25-30 \mathrm{~cm}$ per treatment $(\mathrm{C}=$ control, $\mathrm{N}=$ nitrogen, $\mathrm{NL}=$ nitrogen and calcitic and dolomitic lime, $\mathrm{P}=$ phosphorus, $\mathrm{PL}=$ phosphorus and calcitic and dolomitic lime). Error bars represent the standard error of the mean
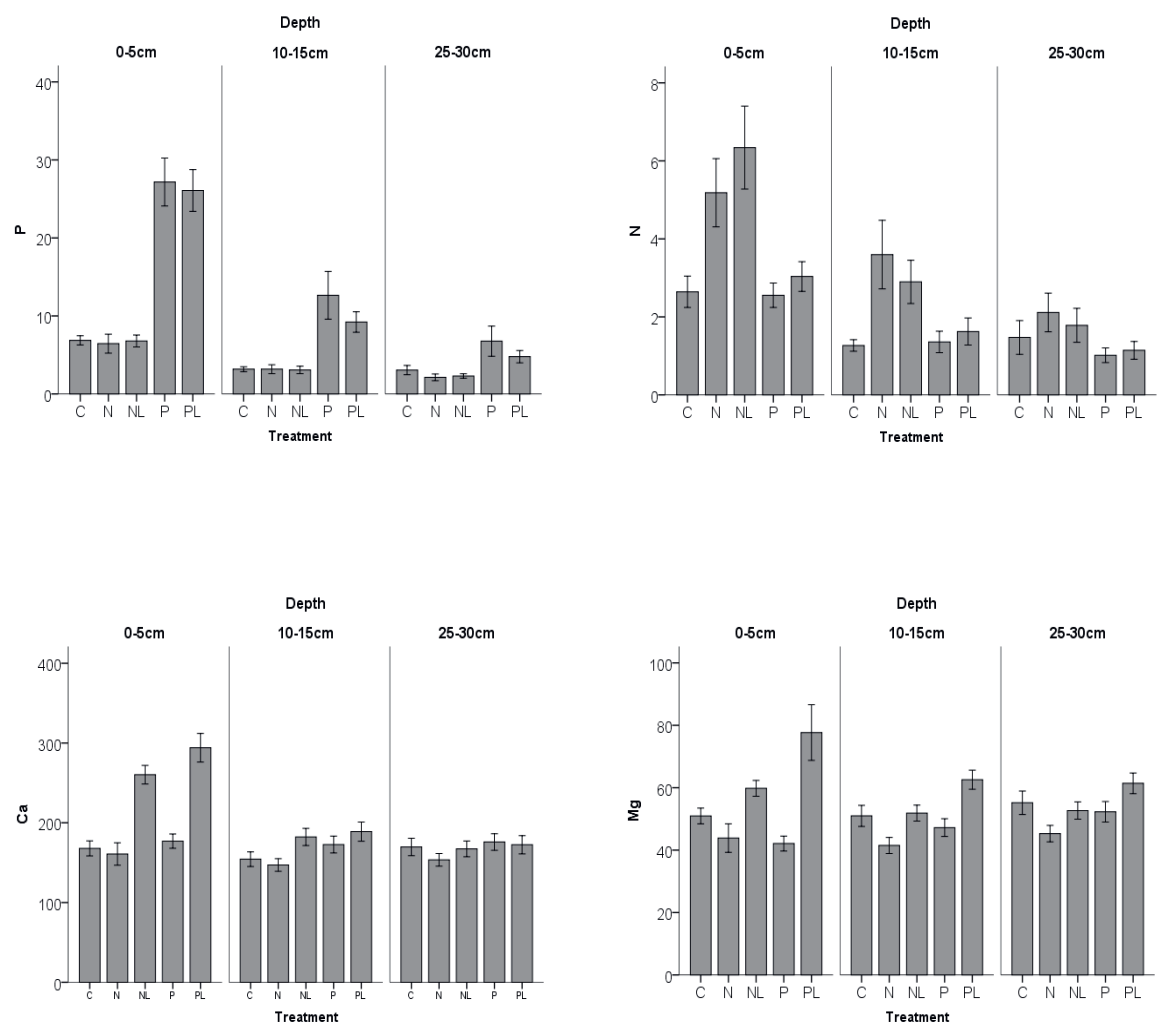


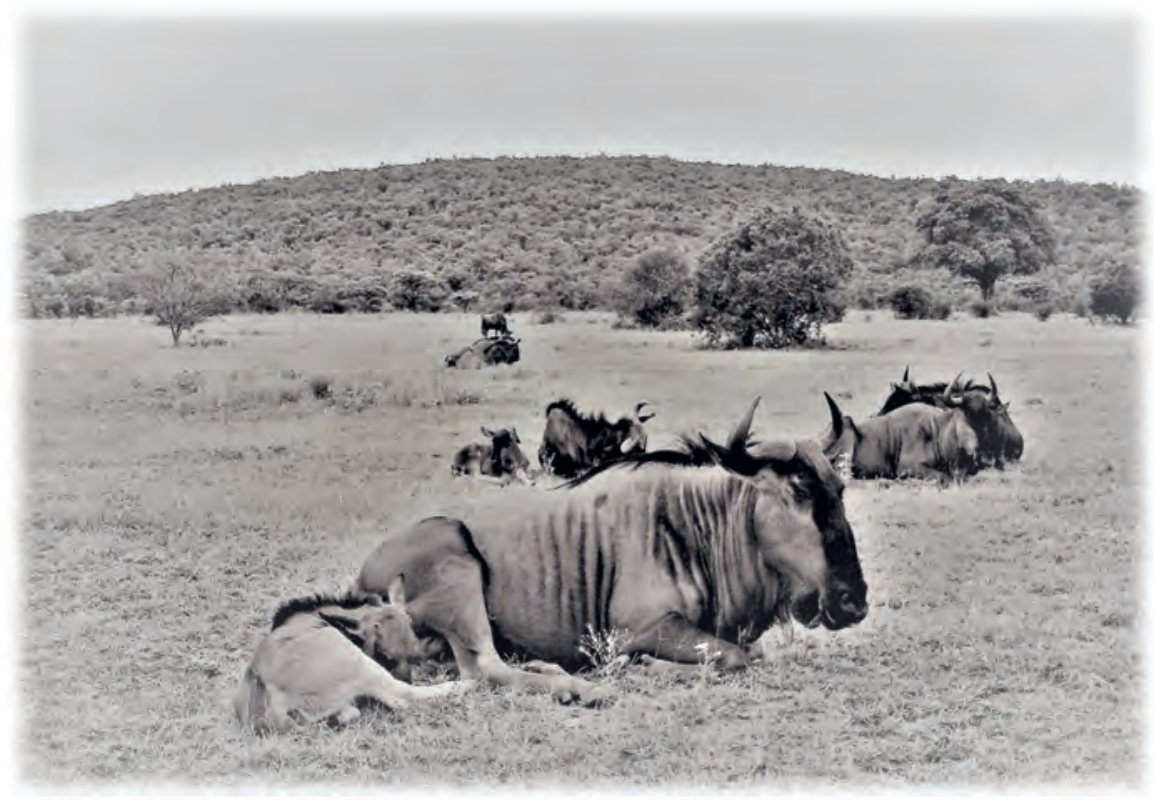

Photograph 6: Blue wildebeest resting, Figtree Plains, Welgevonden Game Reserve (Camera trap photograph) 


\section{Chapter 4}

\section{Chapter 4}

Nutrient addition on grazing lawns and selection by free-roaming mammalian herbivores

\section{in a nutrient poor savanna}

\section{BRADLEY SCHRODER}

Wildlife Ecology and Conservation Group, Wageningen University, Droevendaalsesteeg 3a, 6708 PB Wageningen, the Netherlands

\section{FRANK VAN LANGEVELDE}

Wildlife Ecology and Conservation Group, Wageningen University, Droevendaalsesteeg 3a, 6708 PB Wageningen, the Netherlands and School of Life Sciences, Westville Campus, University of KwaZuluNatal, Durban 4000, South Africa

HERBERT H. T. PRINS

Animal Sciences Group, Wageningen University, De Elst 1, 6708 WD Wageningen, the Netherlands

Submitted to Koedoe 


\section{Chapter 4}

\section{Abstract}

Grazing lawns are important food sources in nutrient poor savannas for free-roaming mammalian herbivores. It has been hypothesized that increased grazing pressure by mammalian herbivores can create and maintain patches of lawn grass. We tested whether the application of specific nutrients, nitrogen $(\mathrm{N})$, phosphorus $(\mathrm{P})$ or in combination with calcitic and dolomitic lime (Ca), in a nutrient poor African savanna, would make the grass sward more nutrient rich, which would attract mammalian herbivores to graze more frequently. We investigated the grazing patterns of six species of mammalian herbivores, namely, blue wildebeest (Connochaetes taurinus), Burchell's zebra (Equus quagga burchellii), common eland (Taurotragus oryx), impala (Aepyceros melampus), square-lipped rhinoceros (Ceratotherium simum) and warthog (Phacochoerus africanus). We show that the addition of $\mathrm{N}$ attracts and increases the grazing pressure for three of the herbivore species, namely, blue wildebeest, Burchell's zebra and impala. Our findings suggest that these often abundantly present mammalian herbivores with intermediate body mass, attracted to grazing lawns by the addition of $\mathrm{N}$, can maintain grazing lawns.

\section{Conservation implications}

Artificial fertilization with nitrogen attracts large free-roaming herbivore species to localized grazing lawns, stimulating the creation and expansion of high nutrient quality lawn grasses in nutrient poor savannas. This results in a nutrient high food source which would normally not be available in nutrient poor savannas.

Keywords: fertilization, camera traps, grazing, nutrients, population abundance, savanna 


\section{Chapter 4}

\section{Introduction}

Food quality and quantity are strongly linked to the survival and reproduction of mammalian herbivores (Gaillard et al. 2000; Uher-Koch et al. 2019). In nutrient poor savannas, the quality of grass is often below the requirements needed by mammalian herbivore survival (Demment and Van Soest 1985; Codron et al. 2007; Prins and Van Langevelde 2008). Foraging on grazing lawns in these dystrophic areas can increase the quality of their food resources (Archibald 2008; Cromsigt and Kuijper 2011; Novellie and Gaylard 2013). Grazing lawns are areas with nutritious, grazing-tolerant grass species, with a short-stature, such as couch grass (Cynodon dactylon; a.k.a. Bermuda grass), created by frequent and intense grazing (Archibald et al. 2005; Grant and Scholes 2006; Cromsigt and Kuijper 2011; Arnold 2012; Hempson et al. 2014). Stoloniferous, palatable lawn grasses can only persist under continued heavy grazing (Cingolani et al. 2005; Archibald 2008; Novellie and Gaylard 2013). If grazing pressure is relaxed, tall, fast-growing grass species of low food quality will outcompete the palatable grass species (O'Connor 1994; Uher-Koch et al. 2019). Previous research has shown that grazing lawns have been established in particular localities such as nutrient hotspots, including termite mounds and old cattle kraals (Van der Waal et al. 2011a; Cromsigt and Olff 2008), recently burnt areas (Archibald 2008; Donaldson et al. 2017) but also through the addition of nutrients to grazing lawns (Cromsigt and Olff 2006; Van der Waal et al. 2011a). These nutrient-enriched localities all attract mammalian herbivores and increase local grazing pressure (Cromsigt and Olff 2006; Hempson et al. 2014). The extent of patches of grazing lawns is influenced by the number of mammalian herbivores and the continued attractiveness of these patches to these animals (Archibald et al. 2005). It has been hypothesized that grazing by certain grazer species, such as squared-lipped rhinoceros (Ceratotherium simum) and hippopotamus (Hippopotamus amphibius), can result in the establishment of grazing 


\section{Chapter 4}

lawns because they are non-selective bulk grazers, utilising high quantities of low quality food

(Owen-Smith 1988; Verweij et al. 2006; Waldram et al. 2008; Cromsigt and Olff 2008; Kleynhans et al. 2011). Their concentrated grazing then results in areas with short and highquality grass.

Studies have demonstrated that free-roaming mammalian herbivores graze more frequently in nutrient rich (fertilized) grass patches as compared to nutrient poor (unfertilized) patches (Augustine et al. 2003; Cromsigt and Olff 2008; Van der Waal et al. 2011b; Mayengo et al. 2020). However, in nutrient poor savannas, it is unknown which added nutrient (nitrogen $\mathrm{N}$ or phosphorus P) attracts free-roaming mammalian herbivores to graze frequently (Schroder et al. submitted). Based on studies by Schroder et al. (submitted), fertilization of $\mathrm{N}$ and $\mathrm{P}$ resulted in higher concentrations of $\mathrm{P}$ in the grass leaf, thus the expectation was that the increased effect on grazing would have been larger on plots which were fertilized with P.

Fertilization experiments revealed that grasses in savannas are strongly co-limited by $\mathrm{N}$ and $\mathrm{P}$ (Penning de Vries and Djitèye 1982; Donaldson et al. 1984; Ludwig et al. 2008; Snyman 2002; Fynn and O'Connor 2005; Craine et al. 2008). For example, Van der Waal et al. (2011b) found that phosphorus and nitrogen fertilization increased leaf $\mathrm{P}$ and $\mathrm{N}$ concentrations in grasses in a semi-arid savanna, whereas Schroder et al. (submitted) found that only P concentrations increased in the leaf, not $\mathrm{N}$. The response of the grass to fertilization with a specific nutrient may have consequences for the mammalian herbivores grazing from these grasses. A deficiency of $\mathrm{N}$ and / or $\mathrm{P}$ may affect the growth, health, reproduction, lactation and survival of mammalian herbivores (Mattson 1980; Murry 1995; Augustine et al. 2003; Zhong-xian et al. 2007). Limitation of either $\mathrm{N}$ or $\mathrm{P}$ requires herbivores to select patches to obtain these nutrients, especially pregnant and lactating females (Prins and Van Langevelde 2008). 


\section{Chapter 4}

In an earlier study by Schroder et al. (submitted), elevated nutrient concentrations in both soil and grass were measured after the addition of nutrients ( $N, P$ or a combination with $\mathrm{Ca}$ ) to grazing lawns, with the result being an increase in grazing lawns. It is crucial to quantify the local grazing pressure of free-roaming mammalian herbivores, as this is important to understand and identify what the main drivers are which allow for the establishment and maintaining of patches of lawn grasses (Archibald 2008; Hempson et al. 2014; Griffith et al. 2017). In this paper, we test whether nutrient addition (N, P or a combination with $\mathrm{Ca}$ ) results in an increase in local grazing pressure by free-roaming mammalian herbivores in a nutrient poor African savanna. Ca was added to the soil to increase the $\mathrm{pH}$ levels, which allows the plants to absorb quantitatively more $\mathrm{P}$, which was previously fixed and unavailable (Chimdi et al. 2012; Higgins et al. 2012).

\section{Material and methods}

The study was conducted in the Welgevonden Game Reserve $\left(348 \mathrm{~km}^{2}\right)$, situated on the Waterberg Plateau in South Africa ( $24^{\circ} 10^{\prime} \mathrm{S} ; 27^{\circ} 45^{\prime} \mathrm{E}$ to $24^{\circ} 25^{\prime} \mathrm{S}$; $27^{\circ} 56^{\prime} \mathrm{E}$ ), over a period of three years (2016 - 2018). The area is classified as warm and temperate, with summer rainfall, having distinct wet and dry seasons, stretching from October to March and April to September respectively, with the mean annual rainfall recorded as $665 \mathrm{~mm}$. The mean annual maximum temperature is $27.4^{\circ} \mathrm{C}$ (reaching $40^{\circ} \mathrm{C}$ ) and the mean annual minimum temperature is $14.5^{\circ} \mathrm{C}$ (reaching $-4^{\circ} \mathrm{C}$ ). Two biomes occur in the study area, namely, the Savanna Biome and Grassland Biome, but the Waterberg Mountain Bushveld vegetation type describes the area well too (Mucina and Rutherford 2006). The area has dystrophic to mesotrophic yellowbrown apedal coarse sands (Parker 2004), characterised by ferruginous soils with a low pH. Accordingly, the vegetation is dominated by nutritionally poor broad-leaved savanna plant 


\section{Chapter 4}

species. Mucina and Rutherford (2006) classify this area as a nutrient poor savanna ecosystem (locally termed 'sour veld'). The area has a diverse mammalian herbivore assemblage, dominated by blue wildebeest (Connochaetes taurinus), Burchell's zebra (Equus quagga burchellii) and square-lipped rhinoceros. Sixty-three species of free-roaming mammals have been identified in the study area, including various antelope species, mega-herbivores and predators. Welgevonden is surrounded by a game proof fence, preventing inward and outward migration.

We tested our hypothesis in a large-scale field experiment with eight sites spread throughout the reserve (Figure 4.1). We divided each of the sites into five plots, each minimally $300 \mathrm{~m} \mathrm{x}$ $150 \mathrm{~m}$. We controlled the encroachment of trees and shrubs on the various plots by mowing with a tractor and slasher to reduce the woody component competition with the grasses (Van der Waal 2010) but also to remove prior to the experiments all moribund and combustible material. The plots were treated annually between the months of January and February with either the addition of nitrogen ( $\mathrm{N}$ at $0.25 \mathrm{ton} / \mathrm{ha}=250 \mathrm{~g} / \mathrm{m}^{2}$ ) or phosphorus ( $\mathrm{P}$ at 0.50 ton/ha $\left.=500 \mathrm{~g} / \mathrm{m}^{2}\right)$. We added lime in the form of calcitic lime at 1.5 tons/ha and dolomitic lime at 1.5 tons/ha: Ca at 3 tons/ha. In order to establish which plots the mammalian herbivores selected, camera traps were erected in the centre of each plot to capture the number of visits recorded per unit time of a species. Furthermore, animal droppings were recorded to estimate the number of animals located within the plots on the opposite side of the camera deployment in order to confirm the presence of these species (Figure 4.2). 


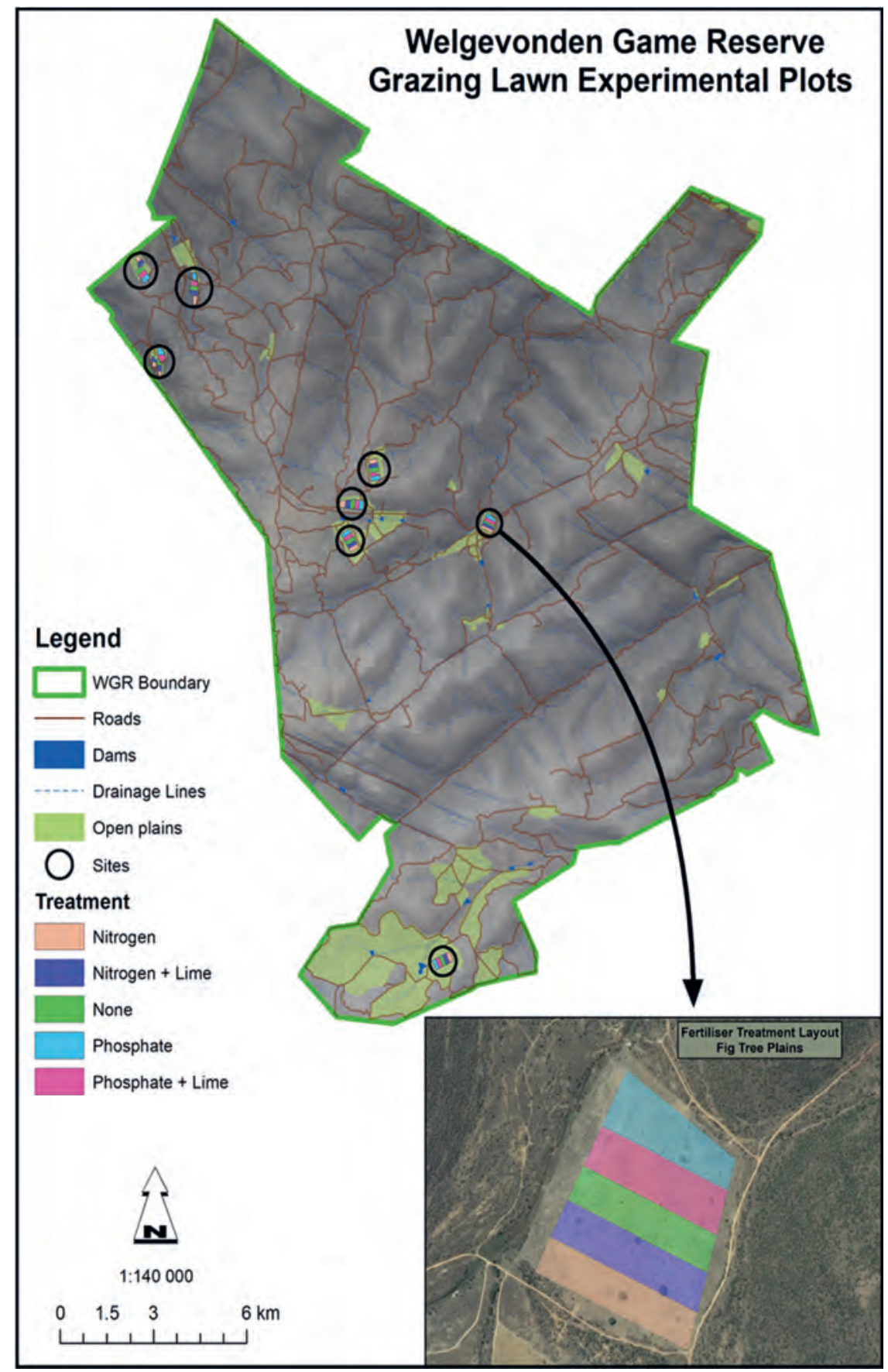

Figure 4.1 Map of the Welgevonden Game Reserve showing the grazing lawn experiment sites with the inlay of the fertiliser treatment layout at Fig Tree Plains 


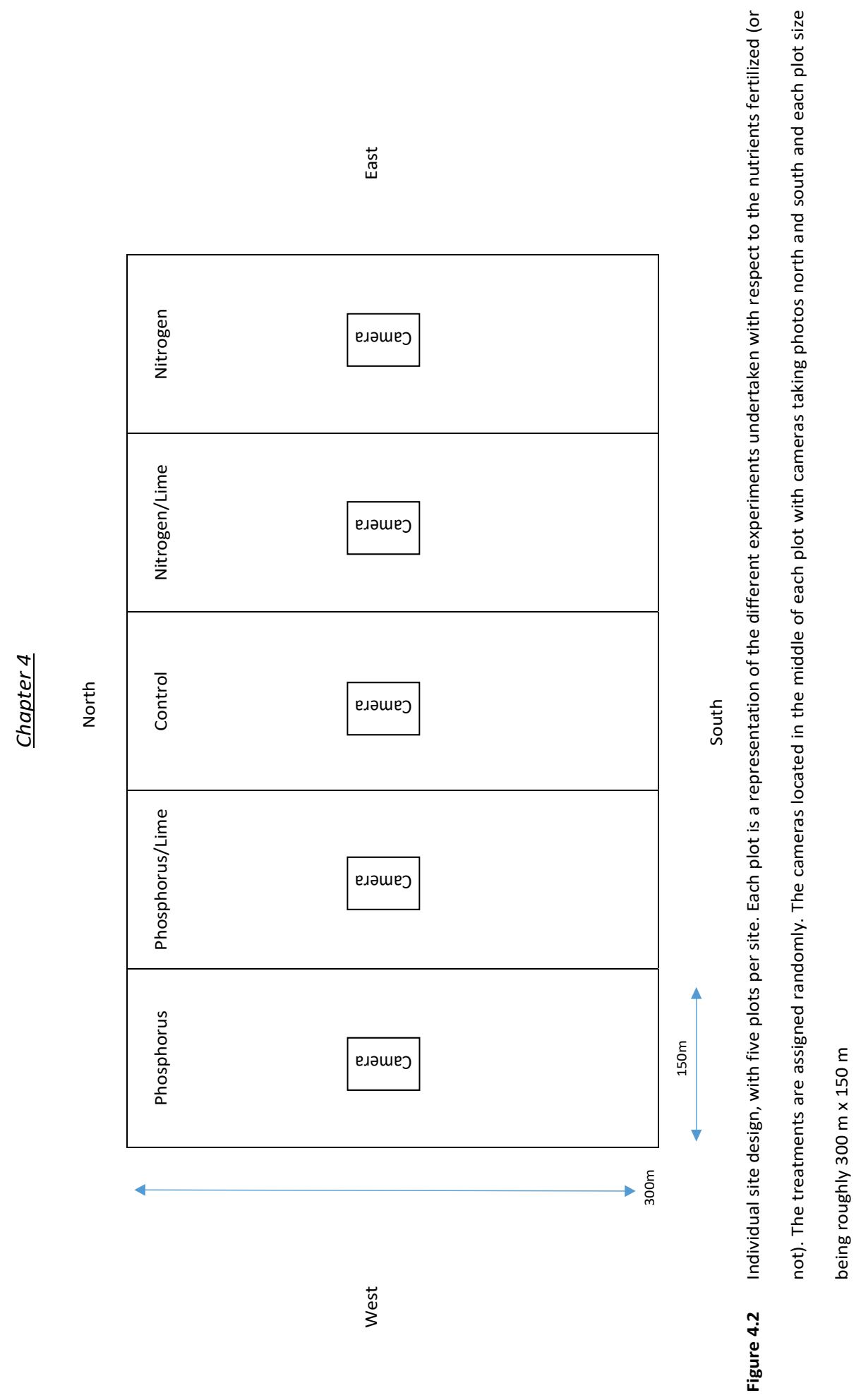




\section{Chapter 4}

Previous studies have shown that systematic collection of faeces help to estimate population size (Plumptre and Harris 1995; Kohn et al. 1999; Barnes 2001; Vicente et al. 2004; Acevedo et al. 2007), but the method has been criticised (Ahrestani et al. 2017; Hema et al. 2017). Our design allows to test possible differences between visitation to grazing lawns, measured by camera traps and dung counts. We expect the results from the dung counts would be similar to the results established from the camera traps.

\section{Photographs}

We used camera traps (randomized encounter model) triggered by infra-red sensors to derive relative abundance estimates, assuming that photographic capture rates, the number of visits recorded per unit time of a species, are proportional to its abundance (Carbone et al. 2001). The camera trap placements consisted of 40 Cuddeback C3-Black Flash camera traps, at roughly 1.2 meters above ground to target the majority of herbivores in the study area. We assumed that there was no difference in detection probability between the differently sized herbivores in our study (see Rowcliffe et al. 2011). The cameras were placed in the middle of each of the five plots distributed throughout the eight study sites. We sampled each plot over a two week period, the data were downloaded after which we rotated the direction of the camera from north to south or vice versa (to obtain observations from both directions, whilst avoiding photographs being impacted by the rising or setting sun). We aligned the viewing directions of the cameras parallel to the ground, so that the horizon was in the centre of each image (Jansen et al. 2014). We deployed the cameras both during the day and the night in order to obtain equal coverage of the animal activities. Data were collected over a three year period (2016 to 2018) during both wet and dry seasons. With each event when the camera was triggered, two sequential photographs were taken. Both images of animals were 


\section{Chapter 4}

recorded as one event only. The analyses were based on these events, with 134,654 events (thus consisting of 269,308 photographs). The photographs were uploaded to Agouti, which is a platform for managing wildlife camera trapping projects. The utilisation of Agouti allowed us to organise, report and archive the images and data (Casaer et al. 2019; https://www.agouti.eu). Individual sightings of animal species were identified and enumerated to obtain a total number of each animal species identified. For each photograph we established whether an animal was grazing on the experimental plot or not. All animals of the same species were taken to be grazing if fifty per cent or more of the animals were grazing; none were considered to be grazing if less than fifty per cent of the animals were observed grazing (Mayes and Dove 2000). All photographs of objects not relevant to the study, such as humans, predators, animals with only a few recorded sightings and the like were removed prior to analysis. After analysing the data for all the mammalian herbivore species observed in the photographs, we only utilised the data for the six species that had the highest number of photos, viz., blue wildebeest (a grazer), Burchell's zebra (a grazer), common eland (Taurotragus oryx) (a browser), impala (Aepyceros melampus) (a mixed feeder), square-lipped rhinoceros (a bulk grazer) and warthog (Phacochoerus africanus) (a grazer). The total number of individual qualifying photograph events recorded for the six species was 131,414.

\section{Dung counts}

Concurrent with the cameras, but on the opposite side to which the cameras were facing, we collected from each plot dung samples (faecal standing crop approach), which we identified for each mammal species, enumerated and then crushed so that they would not be recorded during a following dung sampling event. This was undertaken in the same photographic range 


\section{Chapter 4}

in which we placed the cameras to photograph the animals in order to obtain comparable results. We quantified one full pile of dung as a single recording (midden's were counted as ten animals per species other than rhinoceros, which were counted as one animal per midden (Ezenwa 2004). Data were collected every two weeks over a period of two years (2017 and 2018) during both wet and dry seasons, with 62,281 individual dung samples obtained. After considering the data for all the herbivore dung samples obtained, we only quantified the data for the six herbivore species that we selected for analysis in the photographs (yielding 52,604 dung samples).

\section{Statistical Analysis}

For each of the six grazing and browsing species (i.e., blue wildebeest, Burchell's zebra, common eland, square-lipped rhinoceros, impala and warthog) we tested our hypothesis using generalized linear mixed models (GLMMs), using a Poisson distribution with a log link, with the number of individuals on the photos or the number of dung samples as response variable, the nutrient treatments as fixed factor, and year, period and site as random factors. The differences between the nutrient treatments were compared using Šidák multiple comparisons tests. For the number of individuals on the photos, we separated the analysis between the animals visiting the plots and those animals observed grazing to establish grazing plot preference. Analyses were performed in SPSS v. 23 (SPSS Inc., Chicago, USA).

\section{Results}

\section{Photographs}

The analysis of the blue wildebeest data, comprised of 21,111 photographs (covering 50,032 individual animal sightings), showed that for grazing they selected the plots treated with $\mathrm{N}$ 


\section{Chapter 4}

(and slightly less for the plots with $\mathrm{N}$ in combination with Ca) (Figure 4.3, Table 4.1). The qualifying photographs for all blue wildebeest (grazing and non-grazing individuals) showed that the blue wildebeest selected the plots with $\mathrm{N}$, but the differences between the treatments were small, i.e., the effect size of the N-treated plots is negligible. The data on Burchell's zebra were comprised of 10,686 photographs (covering 14,587 individual animal sightings). The analysis of grazing Burchell's zebra only showed that they selected the plots with $\mathrm{N}$ in combination with $\mathrm{Ca}$ (Figure 4.3, Table 4.1). For all the Burchell's zebra, both grazing and non-grazing combined, there was no clear selection.

The data on common eland, which encompassed 2,916 photographs (covering 9,540 individual animal sightings), did not show clear differential use of differentially treated plots either for grazing or a combination of grazing and non-grazing animals (Figure 4.3, Table 4.1). The impala data which were made up of 9,893 photographs (covering 28,031 individual animal sightings) showed that the impala grazed more in plots fertilized with $\mathrm{N}$ (Figure 4.3, Table 4.1) than in other plots. The non-grazing impala did not show selective use of differentially treated plots. The data on both the square-lipped rhinoceros, which were made up of 2,649 photographs (covering 3,849 individual animal sightings), and the warthog, which were made up of 8,407 photographs (covering 14,587 individual animal sightings) showed no clear differential use of differently treated plots for either grazing or a combination of grazing and non-grazing animals (Figure 4.3, Table 4.1). 


\section{Chapter 4}

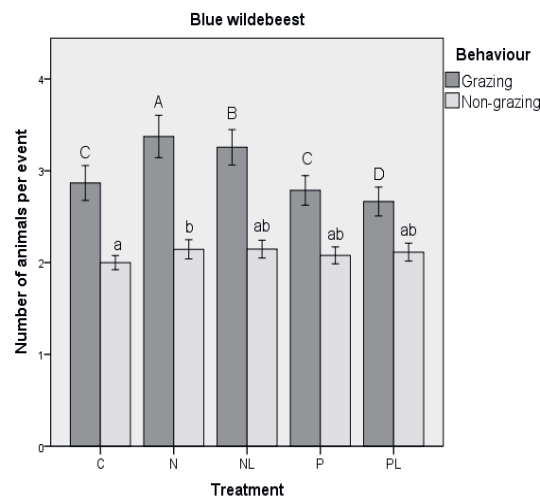

Error Bars: $95 \% \mathrm{Cl}$

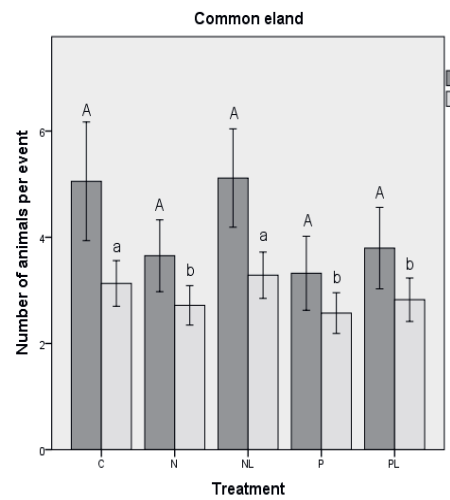

Error Bars: $95 \% \mathrm{Cl}$

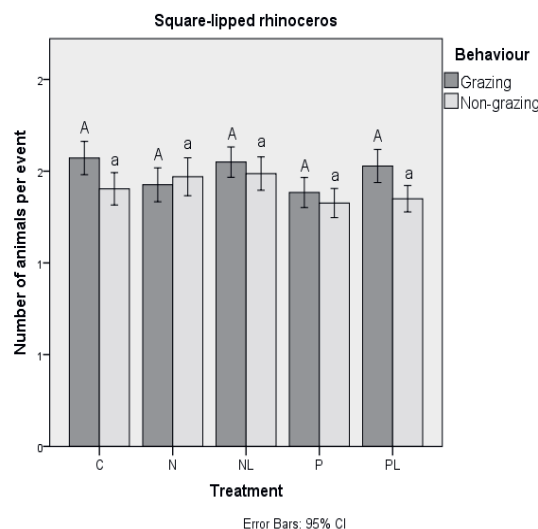

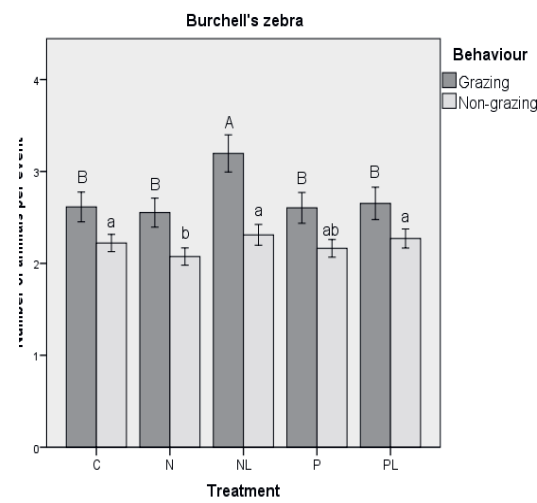

Error Bars: $95 \% \mathrm{Cl}$
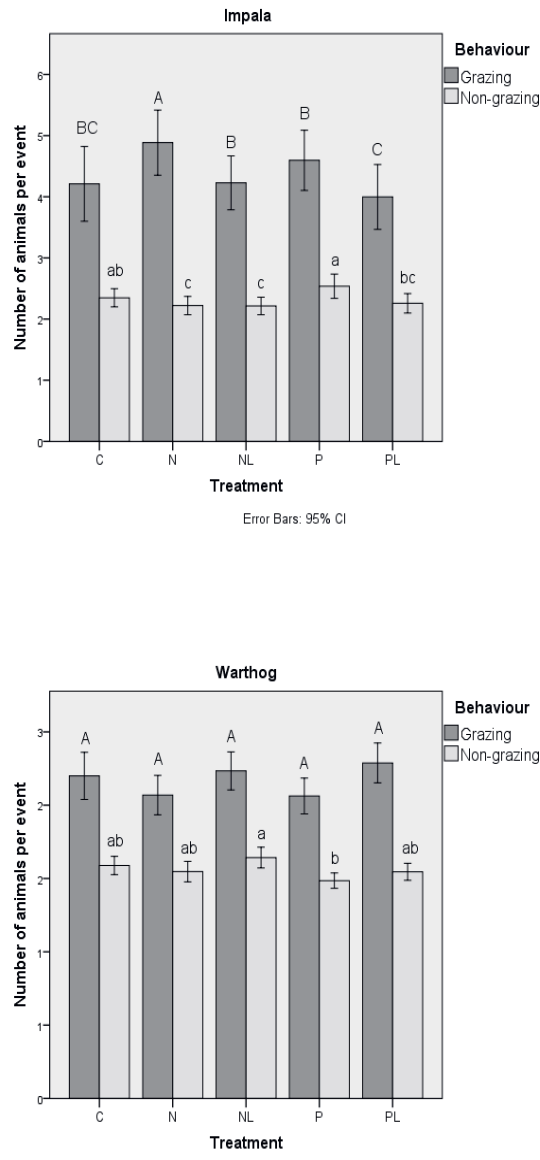

Error Bars: 95\% Cl 


\section{Chapter 4}

Figure 4.3 Number of animals grazing or not grazing per event for each herbivore species (viz., blue wildebeest (Connochaetes taurinus), Burchell's zebra (Equus quagga burchellii), common eland (Taurotragus oryx), impala (Aepyceros melampus), square-lipped rhinoceros (Ceratotherium simum) and the warthog (Phacochoerus aethiopicus) per treatment plot, collected over a three year period, 2016 - 2018, on the Welgevonden Game Reserve, South Africa. ( $C=$ control, $N=$ nitrogen, $\mathrm{NL}=$ nitrogen and calcitic and dolomitic lime, $\mathrm{P}=$ phosphorus, $\mathrm{PL}=$ phosphorus and calcitic and dolomitic lime). Error bars represent the 95\% confidence interval. Letters indicate significant differences between the treatments for grazing and non-grazing herbivores per species and per treatment based on Šidák multiple comparisons tests using a generalized linear mixed model (see Table 4.1 for the statistics)

Table 4.1 Results of the generalized linear mixed model (GLMM) for significance between the six herbivore species (viz., blue wildebeest (Connochaetes taurinus), Burchell's zebra (Equus quagga burchellii), common eland (Taurotragus oryx), impala (Aepyceros melampus), square-lipped rhinoceros (Ceratotherium simum) and the warthog (Phacochoerus aethiopicus) compared against the various treatment plots. The individual animal species are separated into observations of grazing and nongrazing. Year, period and site were the random factors, estimation methods was REML and the sample size $n=55,662$ (see Figure 4.3 for the graphs). (df) refers to the number of degrees of freedom for the treatment levels (df1) and for those of the number of observations (df2). Model refers to the summary of the GLMM. Treatment refers to the plot fertilization with $N, P$, or a combination with Ca and a control. The data were collected over a three year period, 2016 - 2018, on the Welgevonden Game Reserve, South Africa

\begin{tabular}{|c|c|c|c|c|}
\hline Blue wildebeest - grazing & $\mathrm{F}$ & df1 & df2 & Significance \\
\hline Model & 37.9 & 4 & 6.743 & $<.001$ \\
\hline Treatment & 37.9 & 4 & 6.743 & $<.001$ \\
\hline \multicolumn{5}{|c|}{ Blue wildebeest - non-grazing } \\
\hline Model & 3.3 & 4 & 14.358 & .011 \\
\hline Treatment & 3.3 & 4 & 14.358 & 011 \\
\hline
\end{tabular}




\section{Chapter 4}

\begin{tabular}{lcccc}
\hline Burchell's zebra - grazing & $\mathrm{F}$ & $\mathrm{df1}$ & $\mathrm{df2}$ & Significance \\
\cline { 1 - 2 } Model & 17.8 & 4 & 3.301 & $<.001$ \\
Treatment & 17.8 & 4 & 3.301 & $<.001$ \\
Burchell's zebra - non-grazing & & & & \\
\hline Model & 5.7 & 4 & 7.375 & $<.001$ \\
Treatment & 5.7 & 4 & 7.375 & $<.001$ \\
\hline
\end{tabular}

\begin{tabular}{|c|c|c|c|c|}
\hline Common eland - grazing & $\mathrm{F}$ & df1 & df2 & Significance \\
\hline Model & 16.8 & 4 & 757 & $<.001$ \\
\hline Treatment & 16.8 & 4 & 757 & $<.001$ \\
\hline \multicolumn{5}{|c|}{ Common eland - non-grazing } \\
\hline Model & 15.6 & 4 & 2.149 & $<.001$ \\
\hline Treatment & 15.6 & 4 & 2.149 & $<.001$ \\
\hline Impala - grazing & $\mathrm{F}$ & df1 & df2 & Significance \\
\hline Model & 16.1 & 4 & 2.428 & $<.001$ \\
\hline Treatment & 16.1 & 4 & 2.428 & $<.001$ \\
\hline \multicolumn{5}{|l|}{ Impala - non-grazing } \\
\hline Model & 13.4 & 4 & 7.455 & $<.001$ \\
\hline Treatment & 13.4 & 4 & 7.455 & $<.001$ \\
\hline
\end{tabular}

\begin{tabular}{|c|c|c|c|c|}
\hline Square-lipped rhinoceros - grazing & $\mathrm{F}$ & df1 & $\mathrm{df} 2$ & Significance \\
\hline Model & 1.1 & 4 & 1.273 & .353 \\
\hline Treatment & 1.1 & 4 & 1.273 & .353 \\
\hline \multicolumn{5}{|l|}{ Square-lipped rhinoceros - non-grazing } \\
\hline Model & 1.0 & 4 & 1.366 & .418 \\
\hline Treatment & 1.0 & 4 & 1.366 & .418 \\
\hline
\end{tabular}




\begin{tabular}{lcccc}
\hline Warthog - grazing & $\mathrm{F}$ & $\mathrm{df1}$ & $\mathrm{df2}$ & Significance \\
\cline { 1 - 3 } Model & 2.4 & 4 & 2.380 & .052 \\
Treatment & 2.4 & 4 & 2.380 & .052 \\
Warthog - Non-grazing & & & & \\
\cline { 1 - 2 } & 2.9 & 4 & 6.017 & .022 \\
Treatment & 2.9 & 4 & 6.017 & .022 \\
\hline
\end{tabular}

\section{Dung counts}

The data for blue wildebeest, which comprised of 28,597 faeces samples, and those for the common eland, which consisted of 1,377 faeces samples, both showed no clear difference in the amount of dung samples between the various treatment plots and the control. The data for Burchell's zebra, which involved of 4,033 faeces samples, showed a slightly higher number of dung samples in all the fertilized plots when compared to the control plots. The impala data, which comprised of 9,816 faeces samples, showed more dung in the plots with $\mathrm{N}, \mathrm{N}$ in combination with $\mathrm{Ca}$, and $\mathrm{P}$. The dung data for the square-lipped rhinoceros, which comprised of 883 faeces samples, showed more dung piles in the plots fertilized with $\mathrm{P}$ and then $\mathrm{N}$ in combination with Ca. For warthog, we collected 7,898 faeces samples, higher amounts of dung were found in the plots with $\mathrm{N}$ in combination with $\mathrm{Ca}$ and $\mathrm{P}$, and the amount of dung in the fertilized plots was higher than found in the control plot (Figure 4.4, Table 4.2). 


\section{Chapter 4}
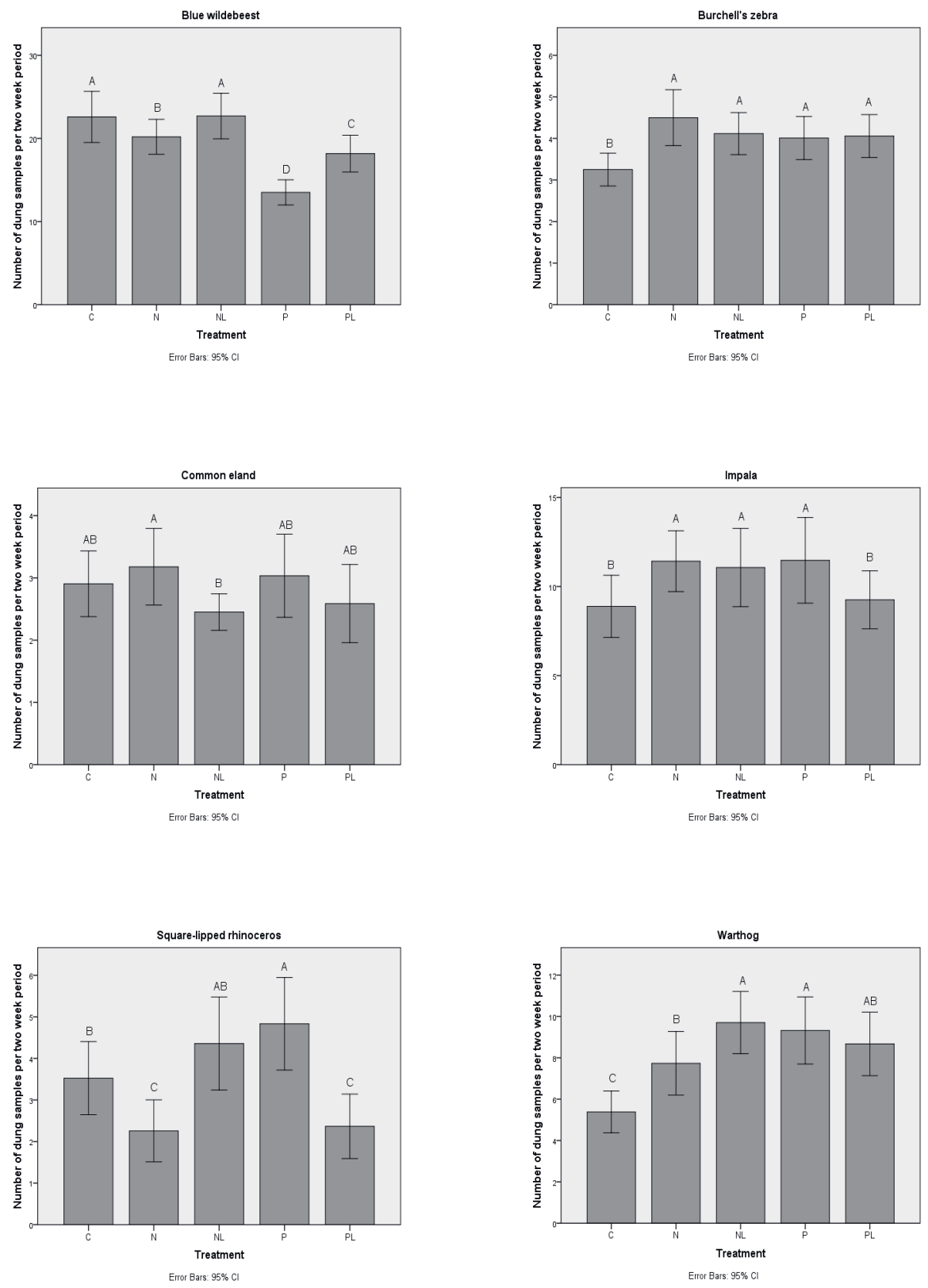

Figure 4.4 Number of dung samples observed per two week period for each herbivore species (viz., blue wildebeest (Connochaetes taurinus), Burchell's zebra (Equus quagga burchellii), common eland (Taurotragus oryx), impala (Aepyceros melampus), square-lipped rhinoceros (Ceratotherium 


\section{Chapter 4}

simum) and the warthog (Phacochoerus aethiopicus) per treatment plot, collected over a two year period, 2017 and 2018, on the Welgevonden Game Reserve, South Africa. ( $C=$ control, N = nitrogen, $\mathrm{NL}=$ nitrogen and calcitic and dolomitic lime, $\mathrm{P}=$ phosphorus, $\mathrm{PL}=$ phosphorus and calcitic and dolomitic lime). Error bars represent the $95 \%$ confidence interval. Letters indicate significant differences between the treatments for dung samples observed for the herbivores per species and per treatment based on Šidák multiple comparisons tests using a generalized linear mixed model (see Table 4.2 for the statistics)

Table 4.2 Results of the generalized linear mixed model (GLMM) for significance between the dung samples (faecal standing crop approach) identified for the six herbivore species (viz., blue wildebeest (Connochaetes taurinus), Burchell's zebra (Equus quagga burchellii), common eland (Taurotragus oryx), impala (Aepyceros melampus), square-lipped rhinoceros (Ceratotherium simum) and the warthog (Phacochoerus aethiopicus) compared against the various treatment plots. Year, period and site were the random factors, estimation methods was REML and the sample size $n=5,112$ (see Figure 4.4 for the graphs). (df) refers to the number of degrees of freedom for the treatment levels (df1) and for those of the number of observations (df2). Model refers to the summary of the GLMM. Treatment refers to the plot fertilization with N, P, or a combination with $\mathrm{Ca}$ and a control. The data were collected over a three year period, 2016 - 2018, on the Welgevonden Game Reserve, South Africa

\begin{tabular}{|c|c|c|c|c|}
\hline Blue wildebeest & $\mathrm{F}$ & df1 & $\mathrm{df2}$ & Significance \\
\hline Model & 203.2 & 4 & 1.465 & $<.001$ \\
\hline Treatment & 203.2 & 4 & 1.465 & $<.001$ \\
\hline Burchell's zebra & $\mathrm{F}$ & df1 & $d f 2$ & Significance \\
\hline Model & 10.9 & 4 & 1.003 & $<.001$ \\
\hline Treatment & 10.9 & 4 & 1.003 & $<.001$ \\
\hline
\end{tabular}




\section{Chapter 4}

\begin{tabular}{|c|c|c|c|c|}
\hline Common eland & $\mathrm{F}$ & df1 & $\mathrm{df2}$ & Significance \\
\hline Model & 2.8 & 4 & 483 & .027 \\
\hline Treatment & 2.8 & 4 & 483 & .027 \\
\hline
\end{tabular}

\begin{tabular}{|c|c|c|c|c|}
\hline Impala & $\mathrm{F}$ & df1 & $\mathrm{df2}$ & Significance \\
\hline Model & 41.8 & 4 & 934 & $<.001$ \\
\hline Treatment & 41.8 & 4 & 934 & $<.001$ \\
\hline
\end{tabular}

\begin{tabular}{lcccc}
\hline Square-lipped rhinoceros & $\mathrm{F}$ & $\mathrm{df1}$ & $\mathrm{df2}$ & Significance \\
\cline { 1 - 2 } Model & 15.5 & 4 & 239 & $<.001$ \\
Treatment & 15.5 & 4 & 239 & $<.001$
\end{tabular}

\begin{tabular}{lcccc}
\hline Warthog & $F$ & df1 & df2 & Significance \\
\cline { 1 - 2 } Model & 73.7 & 4 & 958 & $<.001$ \\
Treatment & 73.7 & 4 & 958 & $<.001$ \\
\hline
\end{tabular}

\section{Discussion}

In this paper, we test whether nutrient addition results in an increase in local grazing pressure by free-roaming mammalian herbivores in a nutrient poor African savanna. Therefore, we measure the presence and grazing pressure of six herbivore species on experimental plots that were fertilized by $\mathrm{N}, \mathrm{P}$ or a combination with $\mathrm{Ca}$ in order to make the grass sward more nutrient rich to test whether grazing lawns could expand (Schroder et al. submitted). To date, research has shown that fertilization with nutrients attracts herbivores to graze, yet in nutrient poor savannas it is unknown which nutrient (nitrogen $\mathrm{N}$ or phosphorus $\mathrm{P}$ ) attracts free-roaming mammalian herbivores (Schroder et al. submitted). Given the low $\mathrm{pH}$ in the soils of the study area, Ca was added to a number of the experiment plots, as Ca has been identified 


\section{Chapter 4}

to increase the $P$ value in grass leaves (Higgins et al. 2012). We found that after the application of the fertilizers, several herbivore species had preference for grazing in the plots with $\mathrm{N}$, namely, blue wildebeest, Burchell's zebra and impala. The addition of $\mathrm{N}$ combined with $\mathrm{Ca}$ promotes grazing by blue wildebeest and made them aggregate on these plots. Our study supports the idea that locally elevated soil nutrient levels attract grazing mammalian herbivores, especially when $\mathrm{N}$ is added. Furthermore, findings by Schroder et al. (submitted) and Van der Waal et al. (2011b), showed that plots fertilized with N and P, resulted in higher concentration of phosphorus $(\mathrm{P})$ in grass leaves. Thus our expectation was that the increased effect on local grazing pressure would have been larger on plots which were fertilized with P. However, our findings show that the herbivores in the study area concentrate more on grass fertilized with $\mathrm{N}$ and $\mathrm{Ca}$, which suggests that the herbivores select forage with elevated $\mathrm{N}$ as it is possibly less available in the nutrient poor study area.

Camera traps were used to record the number of herbivore species visits and to quantify the behaviour of the individual species (grazing or non-grazing) on the fertilized and control plots. At the same time herbivore dung samples were recorded to estimate the number of individual animals per species present on the plots on the opposite side to the cameras. These two methods were used to establish differential use of free-roaming herbivores of sour veld vegetation (i.e., a dystrophic or nutrient poor savanna) that received different types of experimental treatment with artificial fertilizer, namely, $\mathrm{N}$ only, $\mathrm{P}$ only, a combination of $\mathrm{N}$ or $\mathrm{P}$ with Ca. We analysed more than one hundred and thirty thousand photographs of individual herbivores and more than sixty two thousand dung samples during our study. We expected that the outcomes of the photo analysis and that of the dung samples would have yielded a similar conclusion about the use and choice of fertilized plots by the herbivores. However, this was not borne out by the results as the dung sampling did not yield an indication of 


\section{Chapter 4}

differential use of fertilized vs. non-fertilized plots, while the camera trap data show that the fertilized plots are grazed more frequently. Because a priori there is no heuristic to decide which of the two methods is superior, at first sight we find ourselves in a conundrum. Indeed, Putman (1984) posits that dung sampling techniques are important for population estimation and allow for maximum possible ecological information, but Dorji et al. (2013) and Sargent (2016) criticize the use of dung sampling as a measure for local grazing pressure; they also support the notion of Silveira et al. (2003) and Morgan et al. (2019) that camera traps give a more trustworthy indication of use intensity as compared to dung sampling. Of course, we do not have the proof that camera trapping data are superior to dung sampling data, but we adhere to the notion that direct measurements of the behaviour under scrutiny (i.e., the photos of grazing animals) must be closer to the truth than indirect measurements (i.e., the dung). We thus implore for the deployment of automated picture taking equipment for determining space use by animals at fine spatial scales relative to the throughput rate of the animals under scrutiny, if one were to rely on dung pellet counting. We believe, however, that at larger scales the dung count methods are perfectly acceptable.

Our study concurs with Van der Waal et al. (2011a), in that abundantly present herbivores species are observed to frequently graze on fertilized plots. Our study shows that of the six herbivore species observed to be grazing on the lawn grass systems, the contribution per species was blue wildebeest (40\%), Burchell's zebra (20\%), impala (15\%), warthog (14\%), square-lipped rhinoceros (7\%) and common eland (4\%) and shows the impact of large herbivores on these fertilized plots. Thus, our data shows that in a nutrient poor savanna, herbivorous species which we believe can induce a lawn-forming reaction of grass species have the propensity to form lawns (namely Burchell's zebra, blue wildebeest and squarelipped rhinoceros, but not impala) can be induced to concentrate their grazing efforts after 


\section{Chapter 4}

fertilizing. This concentration of grazing pressure by these herbivore species may lead to expansion of grazing lawns providing high-quality food for these herbivores.

\section{Management implications}

Artificial fertilization with nitrogen attracts large free-roaming herbivore species to localized grazing lawns, stimulating the creation and expansion of high nutrient quality lawn grasses in nutrient poor savannas. This results in a nutrient high food source which would normally not be available in nutrient poor savannas.

\section{Acknowledgements}

The authors would like to thank the students and friends involved in helping to identify the photographs on the Agouti platform. Numerous hours were spent identifying the specific animals and their grazing behaviour. Special thanks in alphabetical order must go to Ms Coby van Dooremalen, Mr Gregory Canning, Ms Janina Harms, Ms Marit ter Bogt and Ms NicolaAnne Jack. 


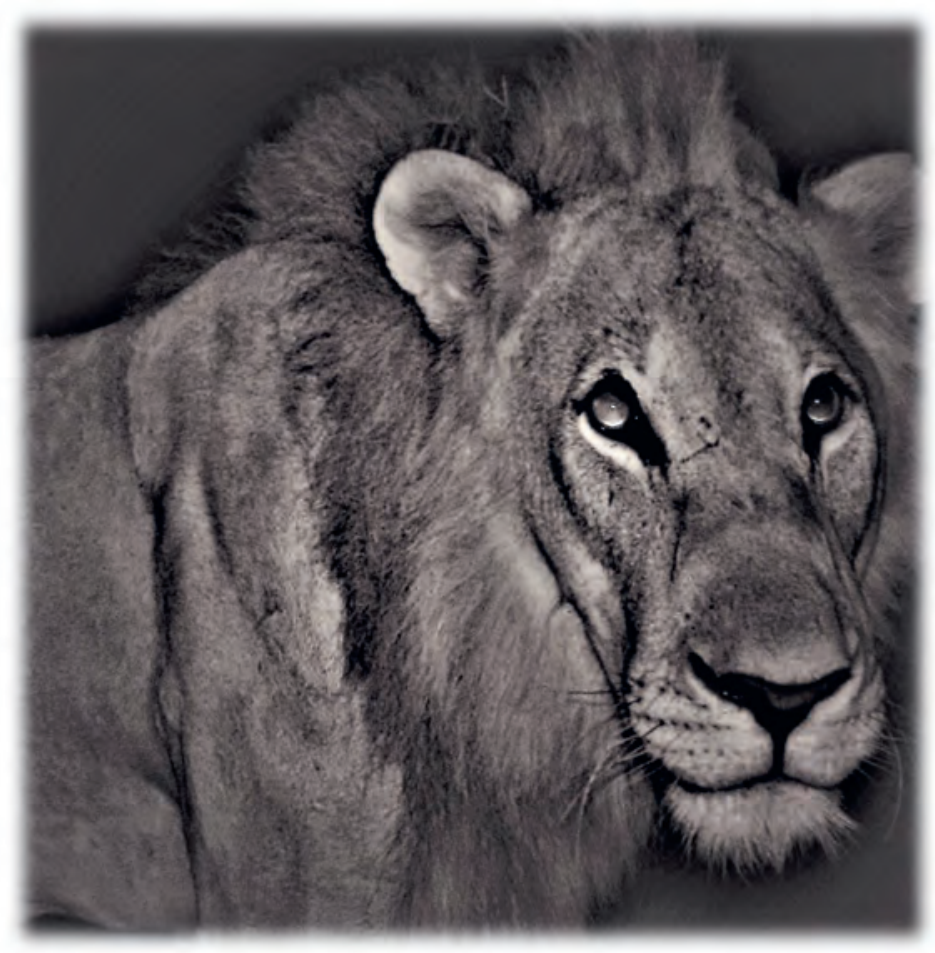

Photograph 7: Lion, Figtree Plains, Welgevonden Game Reserve (Camera trap photograph) 


\section{Chapter 5}

\section{Chapter 5}

Provisioning Polyethylene Glycol to large herbivores in nutrient poor savannas can break

$$
\text { food limitation }
$$

\section{BRADLEY SCHRODER}

Wildlife Ecology and Conservation Group, Wageningen University, Droevendaalsesteeg 3a, 6708 PB Wageningen, the Netherlands

\section{FRANK VAN LANGEVELDE}

Wildlife Ecology and Conservation Group, Wageningen University, Droevendaalsesteeg 3a, 6708 PB Wageningen, the Netherlands and School of Life Sciences, Westville Campus, University of KwaZuluNatal, Durban 4000, South Africa

HERBERT H. T. PRINS

Animal Sciences Group, Wageningen University, De Elst 1, 6708 WD Wageningen, the Netherlands

Submitted to Koedoe 


\section{Chapter 5}

\section{Abstract}

The reproduction and survival of many large herbivore species in nutrient poor savannas is low due to low nutrient availability, partly caused by high concentrations of condensed tannins. Polyethylene glycol (PEG) is known to increase the availability of proteins for herbivores by preferentially binding tannins. To date, the effect of PEG on the diet for freeroaming wild animals has not been tested. Our hypothesis was that deploying game lick blocks with PEG in a nutrient poor savanna will result in a broadening of the diet with higher percentages of browse species and higher amounts of utilization per browse species that have high levels of tannins. To test our hypothesis, we used a Before-After-Control-Impact (BACl) design. Prior to and after placing different types of game lick blocks (with and without PEG), faecal samples of five animal species, viz., impala (Aepyceros melampus), greater kudu (Tragelaphus strepsiceros), common eland (Taurotragus oryx), Burchell's zebra (Equus quagga burchellii) and blue wildebeest (Connochaetes taurinus) were collected. We show that the addition of PEG to the standard game lick blocks promotes a change in the dietary choices of four of the five herbivore species. These changes are expressed as a broader diet with the use of a higher number of browse species with higher concentrations of secondary compounds. The expectation was that the effect on dietary choice would be greater for browsers, but our findings showed that the broadest change in diet selection was for Burchell's zebra (a grazer) and impala (a mixed feeder).

\section{Conservation implications}

The use of PEG could allow large herbivore species to obtain more nutrients from a nutrient poor diet, especially during the dry season when many female herbivores in a dystrophic 


\section{Chapter 5}

savanna are gravid. Alleviating the effects of food limitation by providing PEG may have a positive repercussion on fecundity levels.

Keywords: diet selection, dystrophic savanna, food quality, game lick blocks, PEG, secondary compounds 


\section{Chapter 5}

\section{Introduction}

Nutrient poor savannas are dominated by broad-leaved trees, having leaves with low nutritional value because of high levels of secondary compounds, such as condensed tannin and other carbon-based secondary metabolites (Parker 2004; Mucina and Rutherford 2006; Hattas 2014). The secondary compounds are thought to be the plant's evolutionary response to herbivore utilisation (Cooper and Owen-Smith 1985; Hattas 2014; Scogings et al. 2014). Plants with high levels of secondary compounds can have relatively high nutrient concentrations in the leaves (Tomlinson et al. 2016). It is well documented that condensed tannins occur in a wide range of plant species in nutrient poor savannas (Salawu et al. 1997) and that tannins bind with proteins and often suppress the food intake and digestion by mammalian herbivores (McLeod 1974; Cooper and Owen-Smith 1985; Smit 2013; Scogings et al. 2014; Mkhize et al. 2015). Browsers and mixed feeders foraging preferences are strongly shaped by secondary compounds (Scogings et al. 2014).

Polyethylene glycol (PEG) (with commercial names such as Browse Plus or Movicol) is an inert and unabsorbed molecule, which binds with tannins to form a stable complex, preventing the binding between tannins and proteins (Badran and Jones 1965; Makkar et al. 1995; MajuvaMasafu and Linington 2006) and may increase the availability of macronutrients for herbivores and decrease malaise (Provenza et al. 2000). To date, several studies showed the effect of chemical defences and PEG on the diet of mammalian herbivores, such as goats (Capra aegagrus hircus), sheep (Ovis aries) and cattle (Bos taurus africanus) (Salawu et al. 1997; Decandia et al. 2000; Moujahed et al. 2000; Landau et al. 2003; Mkhize et al. 2015). Experiments have been undertaken on penned sheep and goats, with results showing that tannins not only act as digestibility reducers, but also as feeding deterrents that affect intake, 


\section{Chapter 5}

feeding behaviour and diet choice of these herbivores (Foley and Hume 1987; Marsh et al. 2003; Jansen et al. 2007; Mkhize et al. 2015; Mkhize et al. 2016). Polyethylene glycol has been shown to reduce these adverse effects of dietary tannins in these animals diets (Salawu et al. 1997; Moujahed et al. 2000; Mkhize et al. 2018). However, there is little known about the effect of PEG on free-roaming mammalian herbivores in nutrient poor savannas. Freeroaming herbivores encounter plant species that largely differ in their concentrations of nutrients and plant secondary compounds and they have the opportunity to select their own diet to counteract the differences in forage quality and plant defences (Prins and Van Langevelde 2008). According to Prins and Van Langevelde (2008) and Provenza et al. (2007), herbivores do better when they have access to a variety of plant species with different concentrations of nutrients and secondary compounds, than when constrained to a single food source.

In many game reserves in South Africa, especially on nutrient poor soils, nutrient lick blocks (standard game lick blocks) have been used, originally devised for domestic animals and now designed to supplement the diet of wild animals (Langman 1978; Makkar et al. 2007; SAFARI Feeds 2019; WES Feeds 2019) (see Supporting Information 5A for the mineral composition of the standard game lick block in South Africa). Putman and Staines (2004) reviewed a number of studies which show experimentally that supplementary feeding free-roaming herbivores with lick blocks resulted in an improvement of the animals health and productive life cycle. By adding PEG, we expect that large herbivores are able to access previously unusable proteins, indigestible fibres and other sources of energy, locked in plants which would otherwise be unpalatable. This allows the herbivores to include additional plant species in their diet that have levels of condensed tannins that are so high that they would not be consumed by herbivores without PEG supplementation, especially during the dry winter 


\section{Chapter 5}

months when good quality food is scarce. Here we report on the changes in diet of freeroaming mammalian herbivore species in response to the addition of game lick blocks with and without PEG. Our hypothesis is that deploying game lick blocks with PEG compared to the standard game lick blocks in a nutrient poor savanna will result in a broadening of the diet with higher percentages of browse species and higher amounts of utilization per browse species that have high levels of condensed tannins. To test for a difference in the quality of the diets, we compared the minerals in the faeces of the herbivores using the game lick blocks with PEG versus those using the standard game lick blocks.

\section{Material and methods}

\section{Study area}

The study was conducted in the Welgevonden Game Reserve $\left(348 \mathrm{~km}^{2}\right)$, situated on the Waterberg Plateau in South Africa $\left(24^{\circ} 10^{\prime} \mathrm{S} ; 27^{\circ} 45^{\prime} \mathrm{E}\right.$ to $24^{\circ} 25^{\prime} \mathrm{S}$; $\left.27^{\circ} 56^{\prime} \mathrm{E}\right)$, over a period of three years (2016-2018). The area is classified as warm and temperate, with summer rainfall, having distinct wet and dry seasons, stretching from October to March and April to September respectively, with the mean annual rainfall recorded as $665 \mathrm{~mm}$. The mean annual maximum temperature is $27.4^{\circ} \mathrm{C}$ (reaching $40^{\circ} \mathrm{C}$ ) and the mean annual minimum temperature is $14.5^{\circ} \mathrm{C}$ (reaching $-4^{\circ} \mathrm{C}$ ). The study area is situated in two biomes, the Savanna Biome and Grassland Biome, and falls mainly within the Waterberg Mountain Bushveld vegetation type (Mucina and Rutherford 2006). The area is characterized primarily by the soil types dystrophic to mesotrophic yellow-brown apedal coarse sands (Parker 2004), with ferruginous soils with a low $\mathrm{pH}$. Accordingly, the vegetation type is dominated by nutritionally poor broad-leaved savanna. Mucina and Rutherford (2006) classify this area as a nutrient poor savanna ecosystem (locally termed 'sour veld', a.k.a. 'dystrophic savanna'). The study area comprises 


\section{Chapter 5}

mountainous terrain that is dissected by deep valleys, with occasional old agricultural lands. Flat plateaus characterise most of the hilltops, and the elevation varies from $1050 \mathrm{~m}$ to 1800 $\mathrm{m}$ above sea level. The previous land use included agriculture, cattle ranching and hunting, with the area now only being utilised for conservation and eco-tourism. Sixty-three species of free-roaming mammals have been identified in the study area, including various antelope species, mega-herbivores and predators.

\section{Methods}

We used five mammalian herbivore species to establish the utilisation of PEG and the effect on herbivore diets: one mixed feeder, viz., impala (Aepyceros melampus), two browsers, viz., greater kudu (Tragelaphus strepsiceros) and the common eland (Taurotragus oryx), and two grazers, viz., Burchell's zebra (Equus quagga burchellii) and the blue wildebeest (Connochaetes taurinus). To test the effect of PEG and the standard game lick blocks on the diet of these herbivore species, we used a Before-After-Control-Impact (BACl) design. Prior to and after placing the game lick blocks in the reserve (Figure 5.1, shows the layout design of the game lick blocks in the study area), faecal samples of the five animal species were collected from predetermined sites for analysis. We laid the game lick blocks in particular valleys; the terrain of Welgevonden, with steep hillslopes flanking the valleys, constrains the animals to particular valleys. Thus, maximizing the chances that the animals would eat and defecate in the same area to ensure that we obtained faecal samples from animals which had consumed either the standard game lick blocks or the PEG game lick blocks for analysis. 


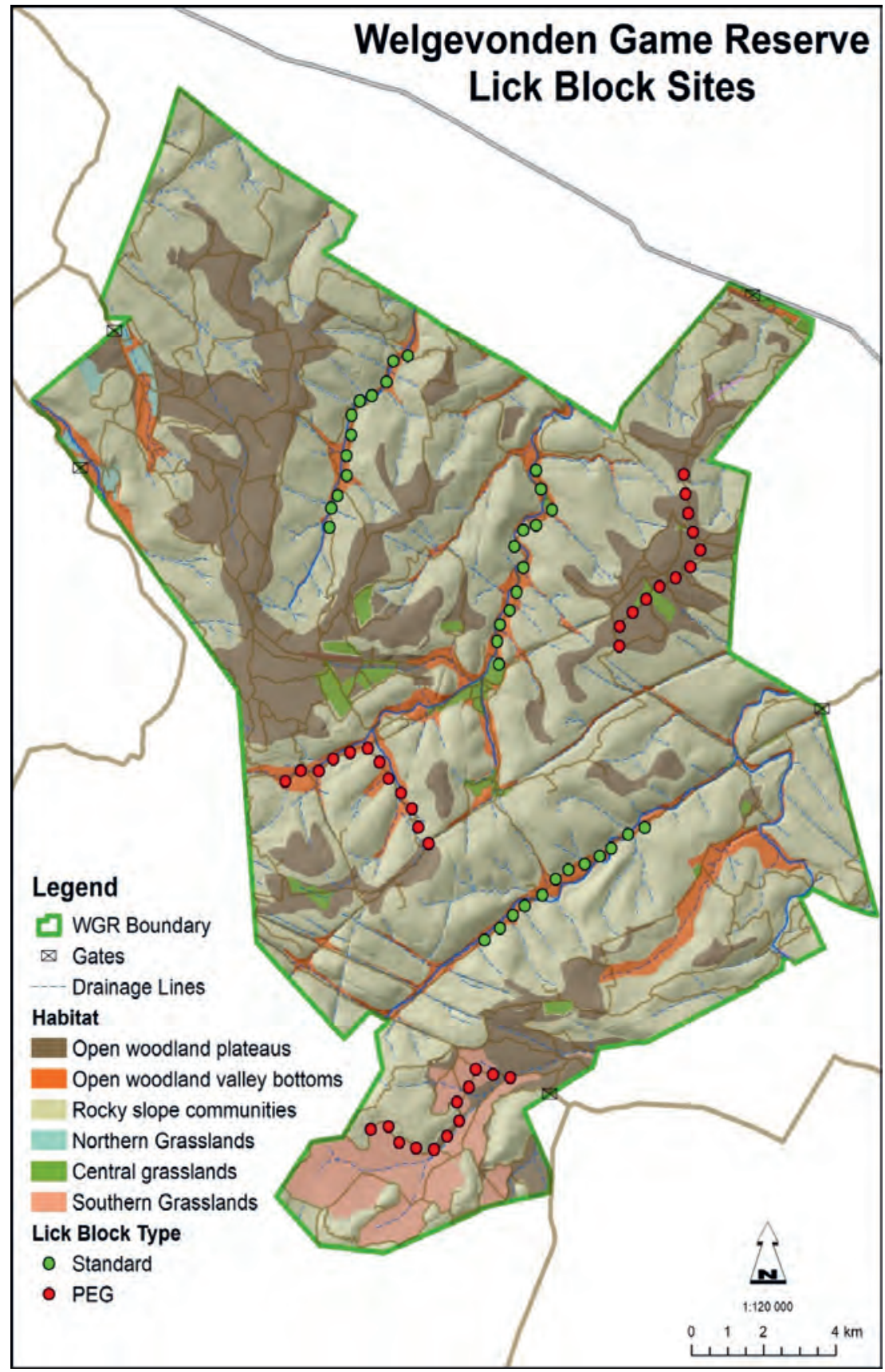

Figure 5.1 Map of the Welgevonden Game Reserve (South Africa) showing the layout of game lick blocks in the study area for the period $2016-2018$ 


\section{Chapter 5}

The resulting alignment of the game lick blocks we call 'transects'. Transects were situated roughly 4 to 5 kilometres apart to prevent individuals visiting more than one transect during the study. Since the topography of Welgevonden is determined by its underlying geology (viz., an uplifted sandstone plateau crisscrossed by rifts), roads and rivers typically are 4 to 5 kilometres apart. Due to the steep topography, the shape of the landscape and the normal movement patterns of these species individuals rarely move between transects and easily along them (Mr J. Swart 2017, Welgevonden Game Reserve, personal communication).

The 'Before assessment' was followed by placing two types of game lick blocks (both types of game lick blocks had an individual mass of $25 \mathrm{~kg}$ ) in the study area at three predetermined transects for both game lick block types. The first type was the standard game lick block (of which the nutrient supplements are given in Supporting Information $5 \mathrm{~A}$ ), the second was the standard game lick blocks with the addition of $35 \mathrm{~g}$ of PEG per $25 \mathrm{~kg}$ block (WES Feeds 2019, personal communication as per our request). The game lick blocks were placed along transects for consumption during the dry months of the year (May through October). The herbivores could voluntarily choose to consume the game lick blocks with or without PEG. The standard practice is not to provide game lick blocks during the wet season (November through May) as then they may negatively affect herbivores.

During this experiment, the health and welfare of the free-roaming animals was observed and checked regularly and at no stage during this experiment were any animals harmed.

\section{Data Collection}

The experiment was repeated over a three year period (2016 to 2018). The faecal sample collection prior to the game lick block application was undertaken in April of each year. The game lick blocks were placed in transects at the beginning of May and replaced every two to 


\section{Chapter 5}

three weeks until the end of October, for a period of six months of each year. The sample collection after the game lick block applications was done in November of each year. We collected 655 individual faeces samples from the five species of herbivores. A minimum of five samples per animal species were collected (estimated to be no older than five days) at each site before and after placement of the game lick blocks, and the identification process of the faeces was done separately for each sample. Each faeces sample was analysed for mineral concentrations and the presence of individual grass and woody plant species. We analysed the minerals in the faeces either as a percentage in the case of $(\mathrm{N}, \mathrm{Ca}, \mathrm{Mg}, \mathrm{K}, \mathrm{S}$ and $\mathrm{P}$ ) or as $\mathrm{mg} / \mathrm{kg}$ as with ( $\mathrm{Na}, \mathrm{Fe}, \mathrm{Mn}, \mathrm{Cu}, \mathrm{Zn}$ and $\mathrm{B})$.

Microhistological faecal analysis was used to describe the animals diet (Van Lieverloo et al. 2009). For that, we used plant cuticles or epidermis fragments found in the faeces (100 fragments per faeces sample), which have specific structures and patterns so that they can be identified using a microscope to the plant species level (De Jong et al. 1995). This allowed us to establish the individual species of browse and graze which the animals had been utilising. From the 100 fragments per faeces sample, we counted the number of individual fragments per species, which can be used as proxy for the amount per plant species consumed by the animal (De Jong et al. 1995). The Welgevonden Game Reserve plant species collection was used as reference to compare the samples. Both the woody plant species and grass species were ranked according to their estimated palatability. Tree species palatability ratings were established through the use of the 'Field Guide to Trees of Southern Africa', (Van Wyk and Van Wyk 1997) and through the independent advice of experts in the field (Supporting Information 5B). Grazing values were obtained from the 'Guide to grasses of Southern Africa', (Van Oudtshoorn 2002). We did not analyse the faeces for herbs (forbs). 


\section{Chapter 5}

\section{Statistical Analysis}

We first analysed the change in diet when comparing before vs. after and PEG-augmented game lick blocks vs. standard game lick blocks. Therefore, we compared the plant species composition in the diets using a Principal Component Analysis (PCA). The PCA allowed us to correlate the change in diet with the quality of the plant species (palatability for tree species and grazing values for grass species). We then tested our hypothesis using linear mixed models with the mineral concentrations of the faeces and the percentage of browse species in the diet as response variables, and animal species, before vs. after and PEG-augmented game lick blocks vs. standard game lick blocks as fixed factors and year and site as random factors. The differences between the animal species were analysed using the Šidák multiple comparisons tests. We verified whether the residuals of the Linear mixed models (LMMs) were normally distributed and, if not, transformation of the response variable was used. Analyses were performed in Canoco 5.0 (Šmilauer and Lepš 2014) and SPSS v. 23 (SPSS Inc., Chicago, USA).

We determined minerals in the faeces which have important uses for the five large freeroaming herbivores. Sodium $(\mathrm{Na})$ is an essential element used by animals in extracellular fluids such as blood plasma. Nitrogen $(\mathrm{N})$ is a major component of protein in animals and used for growth, reproduction and survival. Calcium (Ca) is the mineral found in greatest abundances in animals and is used for structural support especially in the bones. Magnesium $(\mathrm{Mg})$ is an important macromineral assisting with nerve and muscle function, immune system function and bone health. Potassium $(\mathrm{K})$ is necessary for the function of all living cells. Sulphur (S) is important for ruminants with respect to growth and milk production. Phosphorus $(\mathrm{P})$ is an essential mineral for cell development and a key component to store energy. Iron ( $\mathrm{Fe}$ ) is 


\section{Chapter 5}

used to produce haemoglobin, which delivers oxygen to the blood and carbon dioxide out of the body. Manganese $(\mathrm{Mn})$ is an important trace mineral for enzyme activation and stimulates growth. Copper $(\mathrm{Cu})$ is an essential trace element required for body, bone and white blood cell function. Zinc $(\mathrm{Zn})$ is used for cellular respiration, cellular use of oxygen and maintenance of cell membranes. Boron (B) is used for immune response, antioxidant, bone metabolism and enhancing animal performance (Roosendaal 1992; McDowell and Arthington 2005). The faecal mineral content analyses are useful as short-term indicators of diet selection and nutrient status of free-roaming herbivores (Botha and Stock 2005; Codron et al. 2005). Grant et al. (2000) posit that faecal $\mathrm{N}$ levels can indicate a dietary deficiency which may precipitate nutritional stress, while faecal P levels indicate a deficiency that may lead to low reproductive rates in herbivores.

\section{Results}

\section{Diet composition}

The changes in diet composition in terms of the different browse and graze species for the five species of herbivores after the introduction of the standard game lick blocks and PEG game lick blocks are shown in figure 5.2. In the PCA ordination diagrams, every dot represents the diet of a herbivore species before or after the addition of PEG game lick blocks or the standard game lick blocks. The location of these dots is determined by the plant species composition of the diet, so dots close to each other have more similar diets than dots further apart. 
Chapter 5

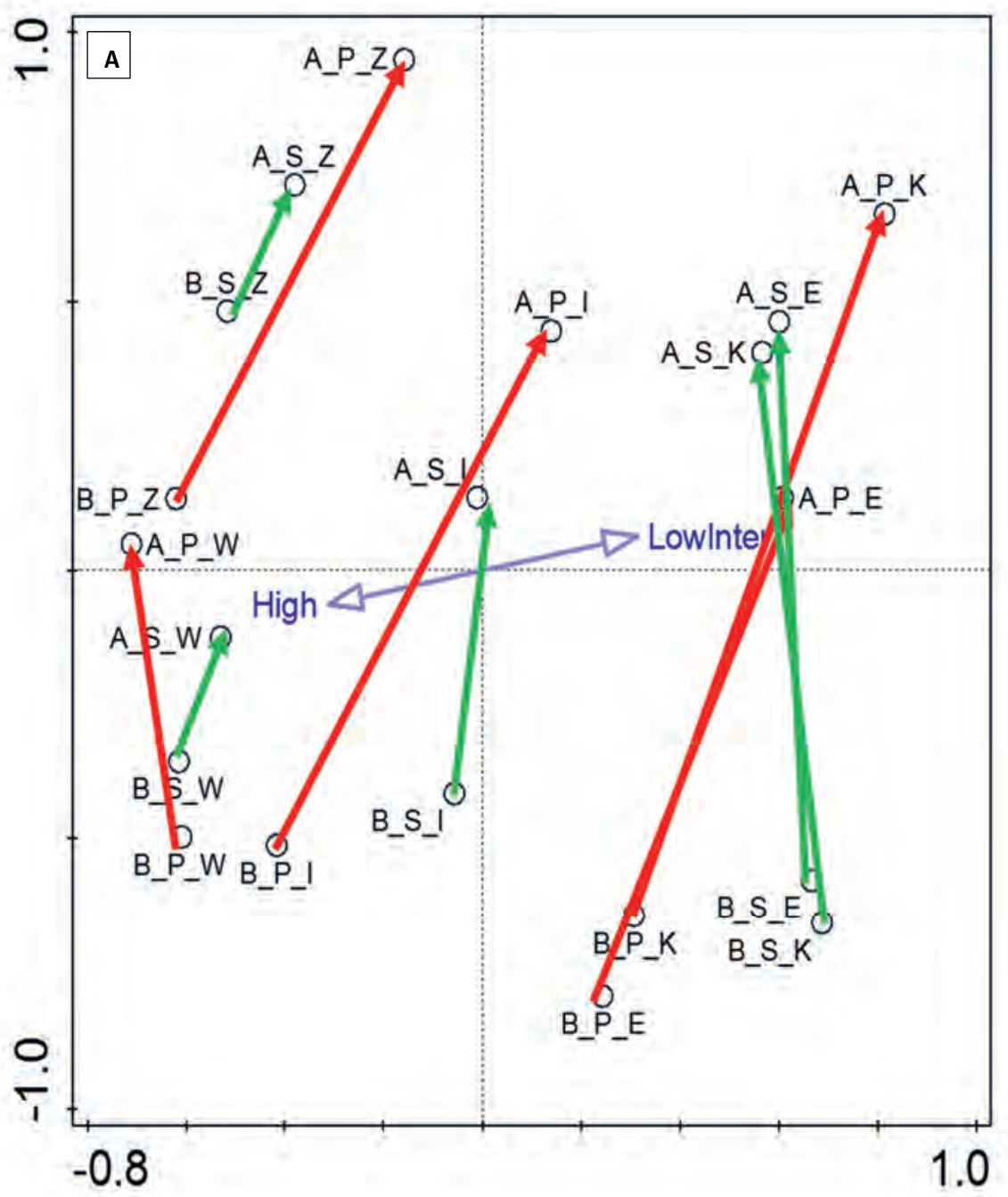




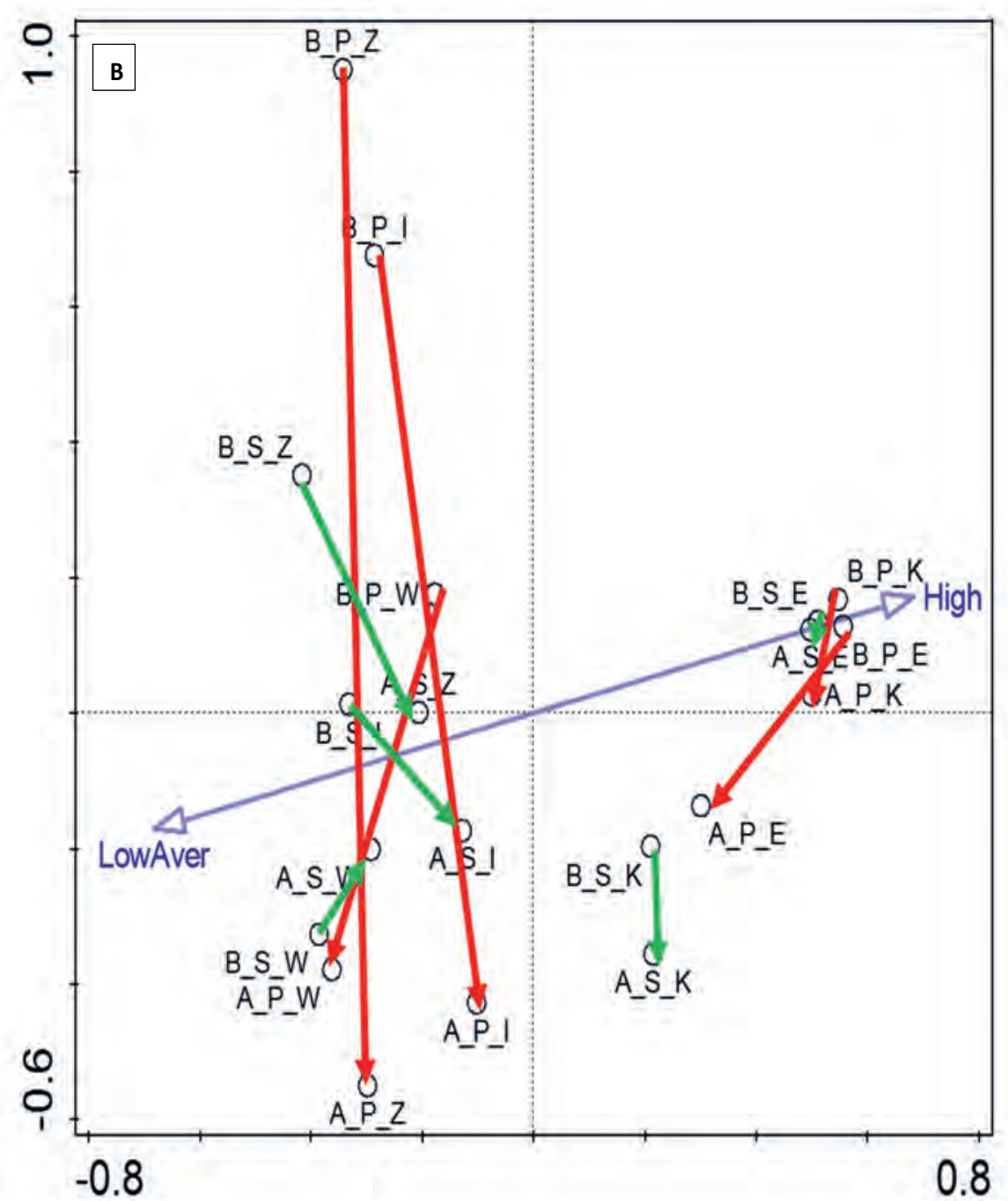

Figure 5.2 Diagrams of the first two axes of the Principal Components Analysis based on (A) the grass species and (B) the browse species in the diets of the five free-roaming herbivore species (viz., impala (Aepyceros melampus), greater kudu (Tragelaphus strepsiceros), common eland (Taurotragus oryx), Burchell's zebra (Equus quagga burchellii) and the blue wildebeest (Connochaetes taurinus) before and after the utilization of the Standard (STD) game lick blocks and Polyethylene glycol (PEG) enriched game lick blocks. The red arrows show changes in diet before and after application of the PEG blocks, whereas the green arrows refer to the changes in diet before and after the STD 


\section{Chapter 5}

blocks. The blue arrows show the gradients in the foraging ratings (in panel A; classes low and intermediate are merged and shown as "Lowlnter") and palatability (in panel B; classes low and average are merged and shown as "LowAver") in the diet. Abbreviations: $\mathrm{A}=$ After; $\mathrm{B}=$ Before; $\mathrm{S}$ = STD; $\mathrm{P}=$ PEG; $\mathrm{E}=$ Eland $; \mathrm{I}=\mathrm{Impala} ; \mathrm{K}=\mathrm{Kudu} ; \mathrm{W}=$ Wildebeest and $\mathrm{Z}=$ Zebra. This data waS collected over a three year period, 2016 - 2018, on the Welgevonden Game Reserve, South Africa

This figure suggests that the diet includes more browse species after adding PEG to the game lick blocks for common eland, impala, greater kudu and Burchell's zebra both at a species and individual level (Figure 5.2). The figure also shows that the changes in the diet after the application of the PEG game lick blocks are larger than the changes after the deployment of the standard game lick blocks. This is illustrated by the arrows in figure 5.2, as the length of the arrows represent a shift in diet and the longer the arrow, the larger the shift in diet. The red arrows show changes in diet before and after application of PEG game lick blocks, whereas the green arrows refer to the changes in diet before and after the standard game lick blocks. The lengths of the red arrows are longer than those of the green arrows suggesting that the change in diet is larger after PEG addition. The blue arrows show the gradients in the foraging ratings and palatability. These blue arrows illustrate that after the addition of PEG, there is generally an increase in the utilization of vegetation with medium and lower palatability ratings for the same four herbivore species: the changes in the diets are positively correlated with the low and intermediate grazing rating (Figure 5.2A) and the low and average palatability (Figure 5.2B). In Supporting Information 5B, 5C, 5D and E the individual species of browse and graze found in the faeces of the five animal species during the study period are listed, together with the palatability and grazing ratings of each plant species, coupled with the diet change per herbivore species. 


\section{Chapter 5}

\section{Percentage browse in diet}

We found that two of the five herbivore species had a change in the percentage of browse utilised due to the consumption of PEG (Figure 5.3, Table 5.1). Impala and Burchell's zebra utilised a higher percentage of browse species after the ingestion of PEG game lick blocks (Figure 5.3).

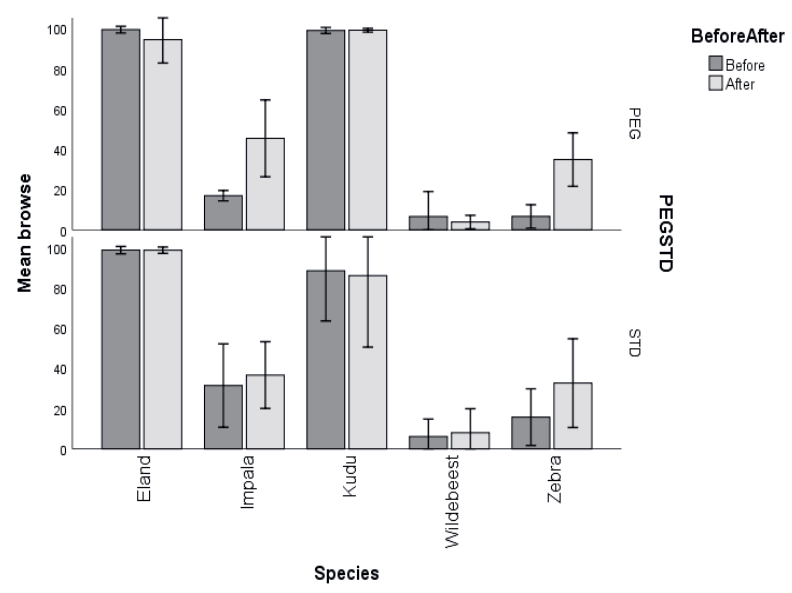

Figure 5.3 Percentage of browse species in the diet for each herbivore species (viz., impala (Aepyceros melampus), greater kudu (Tragelaphus strepsiceros), common eland (Taurotragus oryx), Burchell's zebra (Equus quagga burchellii) and the blue wildebeest (Connochaetes taurinus) per game lick block type, collected over a three year period, 2016 - 2018, on the Welgevonden Game Reserve, South Africa. Before and After refer to the fragments of the plant species in the diet taken before or after the utilisation of Polyethylene glycol (PEG) in the Standard game lick blocks (STD). Error bars represent the standard error of the mean. The stars indicate the differences between the PEG and STD game lick blocks per species and per treatment based on the Šidák multiple comparisons tests using a linear mixed model (see Table 5.1 for the statistics) 


\section{Chapter 5}

Table 5.1 Results of the linear mixed model for differences in percentage of browse species in the faeces before and after applying the Standard (STD) and Polyethylene glycol (PEG) game lick blocks ("block type") for the five herbivore species (viz., impala (Aepyceros melampus), greater kudu (Tragelaphus strepsiceros), common eland (Taurotragus oryx), Burchell's zebra (Equus quagga burchellii) and the blue wildebeest (Connochaetes taurinus). Year and site were the random factors, estimation methods was REML and the sample size $n=91$ (see Figure 5.3 for the graphs). Akaike Information Criterion (AIC) estimates the prediction error of the amount of information lost in the model and establishes the quality of the model. This data was collected over a three year period, 2016 - 2018, on the Welgevonden Game Reserve, South Africa

\begin{tabular}{|c|c|c|}
\hline & & Browse \\
\hline \multirow[t]{3}{*}{ Herbivore Species } & $\mathrm{F}$ & 185.6 \\
\hline & $d f$ & 124.7 \\
\hline & $\mathrm{P}$ & $<0.001$ \\
\hline \multirow[t]{3}{*}{ Block Type } & $\mathrm{F}$ & 0.08 \\
\hline & $\mathrm{df}$ & 125.8 \\
\hline & $P$ & 0.778 \\
\hline \multirow[t]{3}{*}{ Before - After } & $\mathrm{F}$ & 5.5 \\
\hline & $\mathrm{df}$ & 126.2 \\
\hline & $P$ & 0.020 \\
\hline \multirow[t]{3}{*}{ Herbivore species x Block Type } & $F$ & 1.2 \\
\hline & $\mathrm{df}$ & 124.5 \\
\hline & $P$ & 0.332 \\
\hline \multirow[t]{3}{*}{ Herbivore species x Before - After } & $\mathrm{F}$ & 4.0 \\
\hline & $\mathrm{df}$ & 124.6 \\
\hline & $P$ & 0.004 \\
\hline \multirow[t]{3}{*}{ Before - After x Block Type } & $\mathrm{F}$ & 0.912 \\
\hline & $\mathrm{df}$ & 126.2 \\
\hline & $P$ & 0.342 \\
\hline
\end{tabular}




\begin{tabular}{|c|c|c|}
\hline \multirow[t]{3}{*}{ Herbivore species x Before - After x Block Type } & $\mathrm{F}$ & 1.0 \\
\hline & $d f$ & 124.5 \\
\hline & $P$ & 0.393 \\
\hline \multirow[t]{2}{*}{ Year } & Wald Z & 0.8 \\
\hline & $P$ & 0.442 \\
\hline \multirow[t]{2}{*}{ Site } & Wald Z & 0.4 \\
\hline & $P$ & 0.667 \\
\hline AIC & & 1126.2 \\
\hline
\end{tabular}

\section{Minerals in the faeces}

We found minor differences in mineral concentrations in the faeces for the five species of animals. The differences in minerals in the faeces between standard game lick blocks and PEG game lick blocks were generally not significant (Figure 5.4, Table 5.2). The average concentrations of $\mathrm{N}$ and $\mathrm{P}$ found in the faeces for the five herbivore species based on the use of PEG or standard game lick blocks shows difference in a few occasions (Supporting Information 5F). Common eland, blue wildebeest and Burchell's zebra showed higher levels of $\mathrm{N}$ after the utilization of the game lick blocks with PEG. Impala was the only species which showed higher levels of $\mathrm{N}$ and $\mathrm{P}$ after utilization of the standard game lick blocks over the game lick blocks with PEG (Supporting Information 5F). 


\section{Chapter 5}
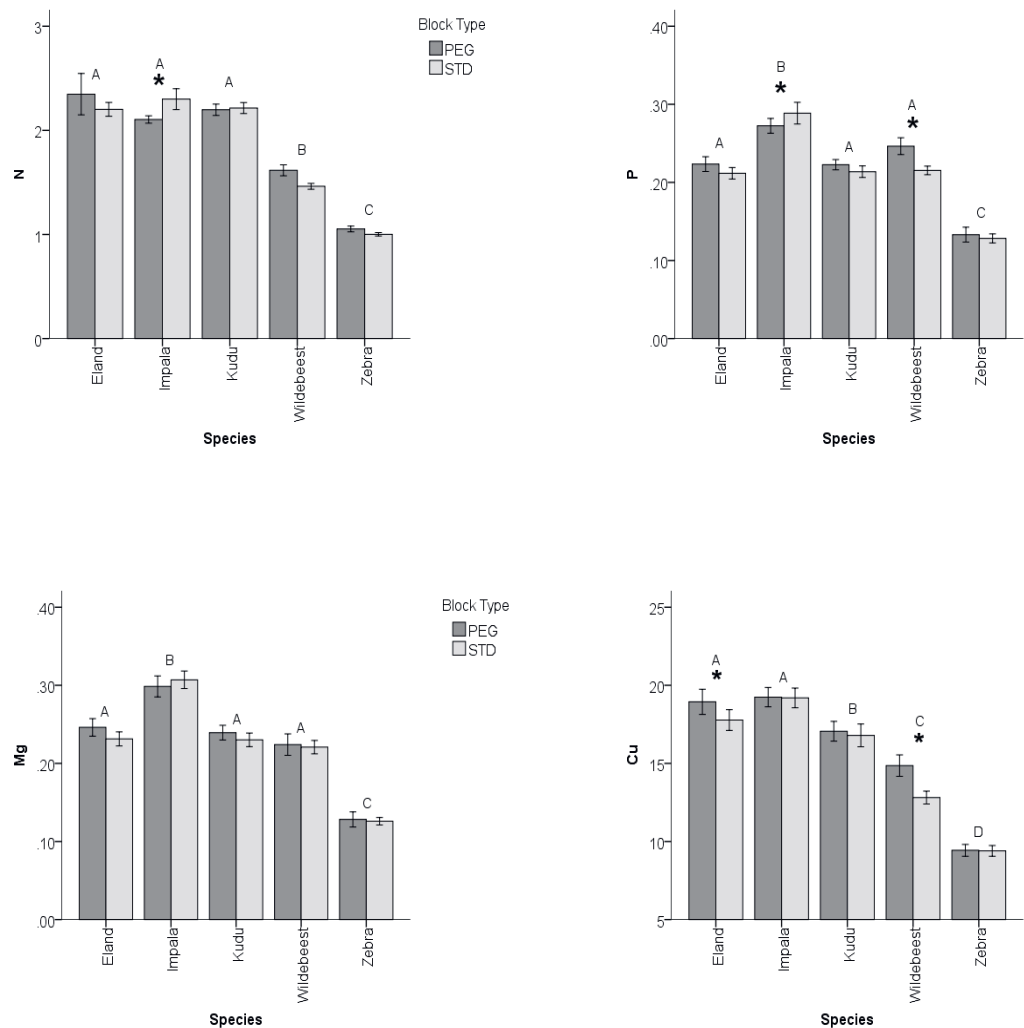

Elock Type
DPEG
DSTD
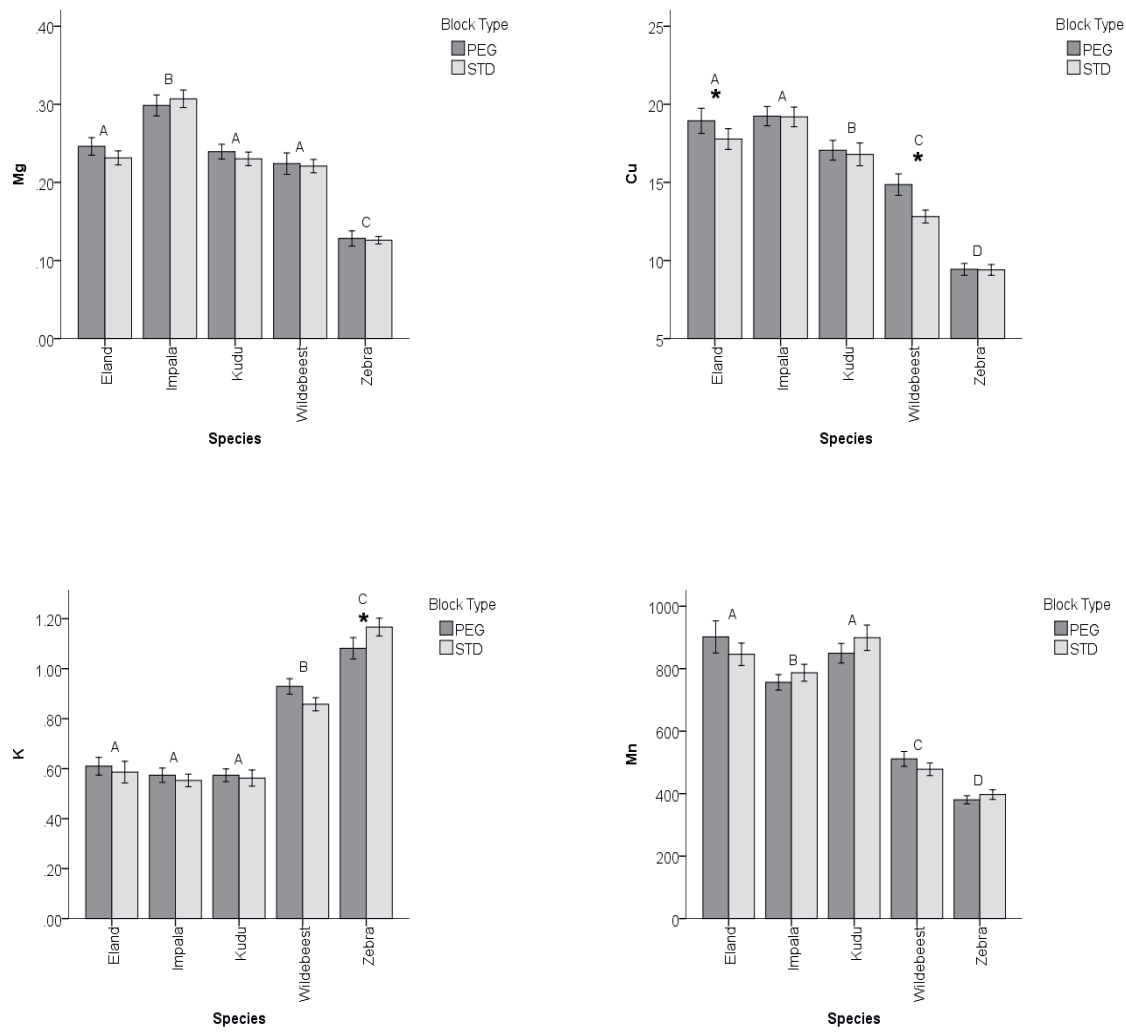


\section{Chapter 5}
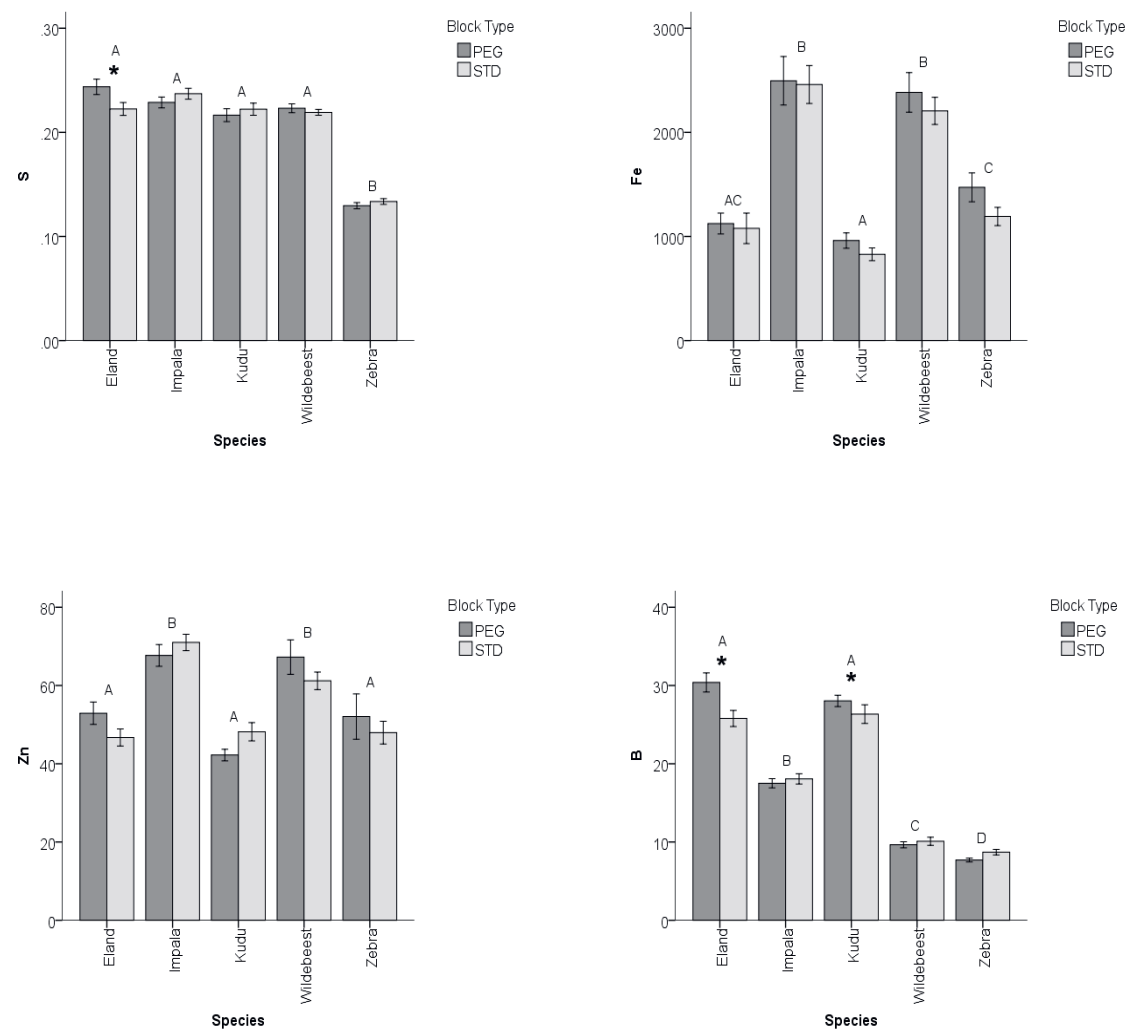

Block Type

ПPEG
DSTD

Figure 5.4 Mineral values in the faeces of the five herbivore species (viz., impala (Aepyceros melampus), greater kudu (Tragelaphus strepsiceros), common eland (Taurotragus oryx), Burchell's zebra (Equus quagga burchellii) and the blue wildebeest (Connochaetes taurinus) showing the effect of the availability of Polyethylene glycol (PEG) enriched game lick blocks or Standard (STD) game lick blocks. The analysis of the minerals in the faeces samples were either recorded as a percentage as in the case of ( $\mathrm{N}, \mathrm{Ca}, \mathrm{Mg}, \mathrm{K}, \mathrm{S}$ and $\mathrm{P}$ ) or as $\mathrm{mg} / \mathrm{kg}$ as with $(\mathrm{Na}, \mathrm{Fe}, \mathrm{Mn}, \mathrm{Cu}, \mathrm{Zn}$ and $\mathrm{B})$. Mineral values in the faeces are a measure of nutrient concentrations in the diet. Error bars represent the standard error of the mean. Letters indicate significant differences between the five herbivore species and the star indicates the differences in the mineral values between the PEG and STD game lick blocks in the same herbivore species, in the treatments based on the Šidák multiple comparisons tests using a linear mixed model (Table 5.2). This data was collected over a three year period, 2016 - 2018, on the Welgevonden Game Reserve, South Africa 


\section{Chapter 5}

Table 5.2 Results of the linear mixed model for differences in minerals in the faeces between the Standard (STD) and Polyethylene glycol (PEG) game lick blocks ("block type") for the five herbivore species (viz., impala (Aepyceros melampus), greater kudu (Tragelaphus strepsiceros), common eland (Taurotragus oryx), Burchell's zebra (Equus burchellii) and the blue wildebeest (Connochaetes taurinus). Year and Site were the random factors, estimation methods was REML and the sample size $n=648$ (see Figure 5.4 for the graphs). Akaike Information Criterion (AIC) estimates the prediction error of the amount of information lost in the model and establishes the quality of the model. This data was collected over a three year period, 2016 - 2018, on the Welgevonden Game Reserve, South Africa

\begin{tabular}{|c|c|c|c|c|c|}
\hline & & $N$ & $\mathbf{P}$ & $\mathrm{Ca}$ & $\mathrm{Na}$ \\
\hline \multirow[t]{3}{*}{ Herbivore species } & $\mathrm{F}$ & 163.9 & 85.0 & 273.9 & 12.2 \\
\hline & $\mathrm{df}$ & 634.3 & 634.2 & 631.2 & 633.4 \\
\hline & $P$ & $<0.001$ & $<0.001$ & $<0.001$ & $<0.001$ \\
\hline \multirow[t]{3}{*}{ Block Type } & $\mathrm{F}$ & 0.04 & 0.03 & 2.3 & 7.2 \\
\hline & $d f$ & 637.7 & 637.6 & 617.2 & 636.3 \\
\hline & $P$ & 0.850 & 0.873 & 0.128 & 0.008 \\
\hline \multirow[t]{4}{*}{ Herbivore species $\mathrm{x}$} & $\mathrm{F}$ & 3.4 & 2.3 & 1.0 & 0.1 \\
\hline & & & & & \\
\hline & $d f$ & 634.5 & 634.8 & 633.0 & 634.3 \\
\hline & $P$ & 0.010 & 0.056 & 0.406 & 0.964 \\
\hline \multirow[t]{2}{*}{ Year } & Wald Z & 1.0 & 1.0 & 0.6 & 0.9 \\
\hline & $P$ & 0.343 & 0.341 & 0.547 & 0.369 \\
\hline \multirow[t]{2}{*}{ Site } & Wald Z & 0.7 & 0.9 & 1.3 & 1.0 \\
\hline & $P$ & 0.507 & 0.388 & 0.197 & 0.295 \\
\hline \multirow[t]{2}{*}{ AIC } & & 971.7 & -1491.5 & 541.4 & 9911.7 \\
\hline & & $\mathrm{Mg}$ & K & $\mathbf{S}$ & $\mathrm{Fe}$ \\
\hline \multirow[t]{3}{*}{ Herbivore species } & $\mathrm{F}$ & 92.7 & 121.2 & 193.1 & 49.8 \\
\hline & df & 634.6 & 634.2 & 633.2 & 634.6 \\
\hline & $P$ & $<0.001$ & $<0.001$ & $<0.001$ & $<0.001$ \\
\hline
\end{tabular}




\section{Chapter 5}

\begin{tabular}{|c|c|c|c|c|c|}
\hline \multirow[t]{3}{*}{ Block Type } & $F$ & 0.09 & 0.2 & 0.1 & 3.1 \\
\hline & df & 636.8 & 637.9 & 634.7 & 637.3 \\
\hline & $P$ & 0.770 & 0.662 & 0.711 & 0.081 \\
\hline \multirow[t]{4}{*}{ Herbivore species $x$} & $F$ & 0.7 & 2.1 & 2.2 & 0.3 \\
\hline & & & & & \\
\hline & df & 635.1 & 634.4 & 633.6 & 635.2 \\
\hline & $\mathrm{P}$ & 0.619 & 0.085 & 0.069 & 0.888 \\
\hline \multirow[t]{2}{*}{ Year } & Wald Z & 0.9 & 0.9 & 0.8 & 0.9 \\
\hline & $P$ & 0.347 & 0.364 & 0.448 & 0.350 \\
\hline \multirow[t]{2}{*}{ Site } & Wald Z & 1.2 & 1.6 & 1.1 & 1.1 \\
\hline & $P$ & 0.220 & 0.524 & 0.288 & 0.284 \\
\hline \multirow[t]{2}{*}{$\mathrm{AIC}$} & & -1351.1 & 159.3 & -335.8 & 10883.7 \\
\hline & & $\mathrm{Mn}$ & $\mathrm{Cu}$ & $\mathrm{Zn}$ & B \\
\hline \multirow[t]{3}{*}{ Herbivore species } & $F$ & 144.4 & 134.7 & 20.7 & 382.4 \\
\hline & $\mathrm{df}$ & 633.8 & 633.5 & 633.0 & 634.2 \\
\hline & $\mathrm{P}$ & $<0.001$ & $<0.001$ & $<0.001$ & $<0.001$ \\
\hline \multirow[t]{3}{*}{ Block Type } & $\mathrm{F}$ & 0.08 & 1.3 & 0.4 & 7.2 \\
\hline & $d f$ & 635.2 & 635.3 & 626.4 & 636.6 \\
\hline & $P$ & 0.778 & 0.251 & 0.504 & 0.008 \\
\hline \multirow[t]{4}{*}{ Herbivore species $x$} & $\mathrm{~F}$ & 1.2 & 2.3 & 1.3 & 3.7 \\
\hline & & & & & \\
\hline & $d f$ & 634.0 & 633.2 & 634.7 & 635.0 \\
\hline & $\mathrm{P}$ & 0.327 & 0.054 & 0.266 & 0.006 \\
\hline \multirow[t]{2}{*}{ Year } & Wald Z & 0.8 & 1.0 & 0.7 & 1.0 \\
\hline & $\mathrm{P}$ & 0.399 & 0.323 & 0.491 & 0.338 \\
\hline \multirow[t]{2}{*}{ Site } & Wald Z & 1.3 & 0.3 & 0.9 & 1.1 \\
\hline & $\mathrm{P}$ & 0.192 & 0.757 & 0.343 & 0.262 \\
\hline AIC & & 8693.5 & 3657.9 & 6050.5 & 3946.8 \\
\hline
\end{tabular}




\section{Chapter 5}

\section{Discussion}

Large herbivores in nutrient poor savannas have to deal with vegetation that generally has low nutrient concentrations, and hence low forage quality (Parker 2004; Mramba et al. 2018). These large herbivores, which are subject to poor forage quality coupled with high condensed tannins seem to have little access to large amounts of food, especially during the dry winter months, and thus are found to have low reproduction and survival in Welgevonden Game Reserve (Parker 2004; Texeira et al. 2012; Mr J. Swart, 2020. Welgevonden Game Reserve, personal communication).

We tested the hypothesis that deploying game lick blocks with PEG compared to the standard game lick blocks in a nutrient poor savanna will result in a broadening of the diet with higher percentages of browse species and higher amounts of utilization per browse species that have high levels of condensed tannins. We tested this hypothesis for five free-roaming mammalian herbivore species (viz., common eland, impala, greater kudu, blue wildebeest and Burchell's zebra) in the nutrient poor savanna of Welgevonden Game Reserve using a BACl design. We show that the addition of PEG to the standard game lick blocks here, promotes a change in the dietary choices of four of the five herbivore species observed during this study. These changes can be expressed as a broader diet choice, either as a higher percentage of browse species or a higher number of individual species utilised with higher concentrations of secondary compounds in their diet. There were particularly large differences in the diet of the impala and the Burchell's zebra, with smaller changes in the greater kudu and the common eland, with the blue wildebeest not showing a change in diet. Despite the changes in diet after the utilization of PEG, levels of $\mathrm{N}$ and $\mathrm{P}$ in the faeces were hardly different except for impala where $\mathrm{N}$ and $\mathrm{P}$ were lower after the utilization of PEG, and for blue wildebeest which showed 


\section{Chapter 5}

increases in P after PEG. The expectation was that the effect on the dietary choices would have had a greater impact on browser species than on grazer species. However, we show that Burchell's zebra (a grazer) and impala (a mixed feeder) have the widest change in their diet selection.

For the standard game lick blocks, there was no significant change in the percentage of diet of the impala (mixed feeder, eating both grass and browse). There was a slight change in favour of utilization of normally unpalatable browse species. After the introduction of the PEG game lick blocks, there was a large change in percentage of diet from grass to browse species and a large increase in utilization of less palatable browse species. These results support findings of studies on penned animals that show that tannins act as both digestibility reducers and feeding deterrents that negatively affect intake (Mkhize et al. 2015) and for which PEG has been shown to reduce these adverse effects (Salawu et al. 1997; Landau et al. 2003). For Burchell's zebra, classified as grazers, we found a significant change in their diet from grass to browse with the utilization of PEG: from a diet of $93 \%$ grass to $65 \%$ grass with an increase from 16 to 31 browse species, increasing the use of less palatable species (Supporting Information 5D and $5 \mathrm{E}$ ). There was a slight increase in the utilization of browse after the use of the standard game lick blocks but not nearly as large as after the addition of PEG. This change in diet due to PEG has further repercussions for the vegetation due to the change in foraging behaviour. The greater kudu and common eland, classified as browsers, had no major change in their diet of grass and browse with the addition of the standard game lick blocks. After the consumption of PEG there was a major increase in the utilization of browse with higher secondary compounds. For blue wildebeest, classified as a grazer, there was no substantial change in their diet between grass and browse neither with nor without the 


\section{Chapter 5}

introduction of the standard game lick blocks or PEG game lick blocks (Figures 5.2 and 5.3, and Supporting Information 5D and 5E).

Faecal nutrient content analyses are useful as short-term indicators of diet selection and nutrient status of free-roaming herbivores (Botha and Stock 2005; Codron et al. 2005). Grant et al. (2000) posit that faecal $\mathrm{N}$ levels can indicate a dietary deficiency which may precipitate nutritional stress, while faecal P levels indicate a deficiency that may lead to low reproductive rates in herbivores. Although the diet choices for common eland, greater kudu, impala and Burchell's zebra broadened when PEG game lick blocks were introduced, we did not find clear differences of the minerals in the faeces. Given the nutritional differences between the plant species, a possible explanation for these results is that the animals absorbed the extra nutrients consumed in their broader diet, which may be necessary for survival in such nutrient poor environments (Parker 2004; Putman and Staines 2004; Texeira et al. 2012). Rainfall tends to decrease forage quality and the area becomes dominated by grass species with lower leaf $\mathrm{N}$ and $\mathrm{P}$ concentrations (Hopcraft et al. 2012). $\mathrm{N}$ and $\mathrm{P}$ concentrations in dry faeces of ruminants below the threshold of potential concern values of $1.2 \%$ and $0.25 \%$, respectively (Prins 1996; Wrench et al. 1997; Grant et al. 2011), would constitute an exceedance of these thresholds and would be a concern for animal survival. Based on the $\mathrm{N}$ and $\mathrm{P}$ faeces threshold values of Wrench et al. (1997) and Grant et al. (2000), the only concern pertaining to $\mathrm{N}$ in the study area is the Burchell's zebra and the only species with no concern pertaining to $P$, is the impala with PEG (Supporting Information 5F). This shows that the addition of $\mathrm{N}$ and $\mathrm{P}$ to a nutrient poor system is imperative for the long-term survival of these species. Furthermore, when looking at the individual minerals in the five study animals, Burchell's zebra and blue wildebeest, the two grazers, have the lowest amount of minerals available to them. 


\section{Chapter 5}

\section{Management implications}

Our study has shown that with the use of PEG, that four of the five free-roaming wild herbivores (viz., common eland, impala, greater kudu and Burchell's zebra) in a nutrient poor savanna are able to utilise a greater number of otherwise less palatable tree species with higher levels of condensed tannins. This could allow these herbivore species to obtain more nutrients from the nutrient poor diet, especially during the dry season, when many of the female herbivores in this dystrophic savanna are gravid. Alleviating the effects of food limitation by providing PEG may have a positive repercussion on fecundity levels. Furthermore, Scogings et al. (2014) stated that browsers and mixed feeders foraging preferences are strongly shaped by secondary compounds. Our study concurs with their findings but confirms that this is also the case with Burchell's zebra from this study area, which had a significant shift in diet from grass to browse. Our experiments thus potentially strengthen the ability to forge the critical link in the chain of reasoning between individual performance and individual food limitation on the one hand and population limitation and population dynamics on the other hand. This concurs with findings by Decandia et al. (2000), who used PEG in feed trials with goats, where they concluded that PEG can improve the nutritive value of the feed and hence optimising the goat's performance. These results lead to the conclusion that PEG is a valuable addition to the diet of the free-roaming wild herbivore species we studied. With these findings these results contribute to better understanding the diet of large herbivores in nutrient poor savannas and how management can act to improve foraging conditions. In order to conclusively prove that PEG can break food limitation, additional information is required through further research to establish birth and survival rates, coupled with body condition change, of herbivores which have and have not utilised PEG in their diet. 


\section{Chapter 5}

\section{Acknowledgements}

The authors would like to thank the management and Board of Welgevonden Game Reserve, Limpopo Province, South Africa for allowing the research to be undertaken on the reserve. The authors appreciate all the assistance from Mr Gregory Canning, Mr Samuel DavidsonPhillips, Mrs Phillipa Davidson-Phillips, Mr Jonathan Swart and Ms Carmen Warmenhove for their assistance with data collection and management. 


\section{Chapter 5}

\section{Supporting information}

Supporting Information 5A Standard game lick block composition (25kg blocks) as reported by the manufacturer WES Feeds (Thabazimbi, South Africa) (WES Feeds 2019)

\begin{tabular}{|c|c|c|c|}
\hline Nutrient & Minimum & Maximum & Unit \\
\hline Protein & 150 & & $\mathrm{~g} / \mathrm{kg}$ \\
\hline Calcium & 15 & & $\mathrm{~g} / \mathrm{kg}$ \\
\hline Phosphorus & 8 & & $\mathrm{~g} / \mathrm{kg}$ \\
\hline Magnesium & 6 & & $\mathrm{~g} / \mathrm{kg}$ \\
\hline Sulphur & 6 & & $\mathrm{~g} / \mathrm{kg}$ \\
\hline Manganese & 200 & & $\mathrm{mg} / \mathrm{kg}$ \\
\hline Copper & & 40 & $\mathrm{mg} / \mathrm{kg}$ \\
\hline Cobalt & & 0.5 & $\mathrm{mg} / \mathrm{kg}$ \\
\hline Iron & & 100 & $\mathrm{mg} / \mathrm{kg}$ \\
\hline lodine & & 2 & $\mathrm{mg} / \mathrm{kg}$ \\
\hline Zinc & & 350 & $\mathrm{mg} / \mathrm{kg}$ \\
\hline Selenium & & 1 & $\mathrm{mg} / \mathrm{kg}$ \\
\hline Vitamin A & 20000 & & $\mathrm{iu} / \mathrm{kg}$ \\
\hline Vitamin $\mathrm{E}$ & 30 & & $\mathrm{iu} / \mathrm{kg}$ \\
\hline
\end{tabular}




\section{Chapter 5}

Supporting Information 5B Browse species located in the faeces with their palability ratings. The palatability ratings were established through the use of the 'Field Guide to Trees of Southern Africa', (Van Wyk and Van Wyk 1997) and through the independent advice of experts in the field (Dr R. Grant (https://orcid.org/0000-0002-8419-5209), Dr M. Peel (https://orcid.org/0000-0003-1284-3665), Dr H. Bezuidenhout (http://orcid.org/0000-0002-6519-7321), Professor N. Owen-Smith (https://orcid.org/0000-0001-8429-1201), Professor K. Eloff (https://orcid.org/0000-0003-1494-9842), Mr J. Swart (Welgevonden Game Reserve Ecologist) and Mr G. Canning (https://orcid.org/0000-0001-6100-9541). The " $X$ " in the table refers to the median when referring to the palatability of these browse species for wild herbivores in the study area as described by the independent experts

\begin{tabular}{|c|c|c|c|}
\hline Browse Species & Low Palatability & $\begin{array}{l}\text { Intermediate } \\
\text { Palatability }\end{array}$ & High Palatability \\
\hline Acacia burkei & & & $x$ \\
\hline Acacia karoo & & $x$ & \\
\hline Apodytes dimidiata & $\mathrm{x}$ & & \\
\hline Bauhinia petersiana & $x$ & & \\
\hline Berchemia zeyheri & & & $x$ \\
\hline Brachylaena rotundata & $x$ & & \\
\hline Burkea africana & $\mathrm{x}$ & & \\
\hline Clerodendrum glabrum & $x$ & & \\
\hline Clutia pulchella & $\mathrm{x}$ & & \\
\hline Combretum apiculatum & & $x$ & \\
\hline Combretum hereroense & & $x$ & \\
\hline Combretum nelsonii & $x$ & & \\
\hline Combretum zeyheri & & $\mathrm{X}$ & \\
\hline
\end{tabular}




\section{Chapter 5}

\begin{tabular}{|c|c|c|c|}
\hline Cryptolepis oblongifolia & $x$ & & \\
\hline Cussonia spicata & $x$ & & \\
\hline Dichapetalum cymosum & $x$ & & \\
\hline Dichrostachys cinerea & & $x$ & \\
\hline Diplorhynchus condylocarpon & & $x$ & \\
\hline Dombeya rotundifolia & $x$ & & \\
\hline Ehretia rigida & & $x$ & \\
\hline Elephantorrhiza burkei & $x$ & & \\
\hline Englerophytum magalismontanum & $x$ & & \\
\hline Erythrina lysistemon & $\mathrm{X}$ & & \\
\hline Euclea crispa & $x$ & & \\
\hline Euclea linearis & $\mathrm{X}$ & & \\
\hline Euclea natalensis & $x$ & & \\
\hline Faurea saligna & $x$ & & \\
\hline Flueggea virosa & & $x$ & \\
\hline Gardenia volkensii & & & $x$ \\
\hline Grewia bicolor & & & $x$ \\
\hline Grewia flavescens & & $x$ & \\
\hline Gymnosporia tenuispina & $x$ & & \\
\hline Indigofera melanadenia & $x$ & & \\
\hline Jasminum multipartitum & $x$ & & \\
\hline Lannea discolor & $x$ & & \\
\hline Lannea edulis & $x$ & & \\
\hline Lippea javanica & & $x$ & \\
\hline Maytenus undata & $\mathrm{x}$ & & \\
\hline Mundulea sericea & & $x$ & \\
\hline Ochna pulchra & $x$ & & \\
\hline
\end{tabular}




\section{Chapter 5}

\begin{tabular}{|c|c|c|}
\hline Ozoroa paniculosa & $x$ & \\
\hline Ozoroa sphaerocarpa & $x$ & \\
\hline Parinari capensis & & $x$ \\
\hline Pavetta gardeniifolia & $X$ & \\
\hline Pellaea calomelanos & $x$ & \\
\hline Peltophorum africanum & $x$ & \\
\hline Protea caffra & $X$ & \\
\hline Protea welwitschii & $x$ & \\
\hline Pseudolachnostylis maprouneifolia & & $\mathrm{X}$ \\
\hline Psydrax livida & $\mathrm{x}$ & \\
\hline Pterolobium stellatum & $\mathrm{x}$ & \\
\hline Rhoicissus tridentata & $\mathrm{X}$ & \\
\hline Searsia pyroides & $x$ & \\
\hline Spirostachys africana & & $\mathrm{X}$ \\
\hline Strychnos pungens & & $\mathrm{X}$ \\
\hline Syzygium cordatum & $x$ & \\
\hline Syzygium guineense & $x$ & \\
\hline Tarchonanthus camphoratus & & $x$ \\
\hline Tarenna supra-axillaris & $\mathrm{x}$ & \\
\hline Terminalia brachystemma & $\mathrm{x}$ & \\
\hline Turraea obtusifolia & $\mathrm{x}$ & \\
\hline Vangueria infausta & & $\mathrm{X}$ \\
\hline Waltheria indica & $x$ & \\
\hline
\end{tabular}




\section{Chapter 5}

Supporting Information 5C Grass species found in the faeces with their grazing values obtained from the 'Guide to grasses of Southern Africa', (Van Oudtshoorn 2002). The " $X$ " in the table refers to the median when referring to the palatability of these grass species for wild herbivores in the study area as described by Van Oudtshoorn, 2002

\begin{tabular}{|c|c|c|c|}
\hline Grass Species & Grazing value low & $\begin{array}{c}\text { Grazing value } \\
\text { average }\end{array}$ & Grazing value high \\
\hline Andropogon chinensis & & $x$ & \\
\hline Aristida $s p$ & $\mathrm{x}$ & & \\
\hline Brachiaria brizantha & & $x$ & \\
\hline Brachiaria serrata & & $\mathrm{X}$ & \\
\hline Cenchrus ciliaris & & & $x$ \\
\hline Chloris pycnothrix & $x$ & & \\
\hline Chloris virgata & & $\mathrm{X}$ & \\
\hline Chrysopogon serrulatus & & & $x$ \\
\hline Cynodon dactylon & & & $x$ \\
\hline Dactyloctenium aegyptium & & $\mathrm{X}$ & \\
\hline Digitaria eriantha & & & $x$ \\
\hline Diheteropogon amplectens & & $x$ & \\
\hline Eragrostis sp & & $\mathrm{X}$ & \\
\hline Heteropogon contortus & & $x$ & \\
\hline Hyparrhenia filipendula & & $x$ & \\
\hline Hyparrhenia hirta & & $x$ & \\
\hline Hyperthelia dissoluta & & $x$ & \\
\hline Imperata cylindrica & $x$ & & \\
\hline Leersia hexandra & & & $x$ \\
\hline Loudetia simplex & & $x$ & \\
\hline Melinis nerviglumis & & $\mathrm{X}$ & \\
\hline
\end{tabular}




\section{Chapter 5}

\begin{tabular}{|c|c|c|c|}
\hline Melinis repens & $x$ & & \\
\hline Microchloa caffra & $\mathrm{x}$ & & \\
\hline Monocymbium ceresiiforme & & $x$ & \\
\hline Panicum dregeanum & & $x$ & \\
\hline Panicum maximum & & & $x$ \\
\hline Panicum natalense & $\mathrm{x}$ & & \\
\hline Paspalum scrobiculatum & & $\mathrm{x}$ & \\
\hline Paspalum urvillei & & $\mathrm{x}$ & \\
\hline Pogonarthria squarrosa & $\mathrm{x}$ & & \\
\hline Sacciolepis typhura & $x$ & & \\
\hline Schizachyrium jeffreysii & $x$ & & \\
\hline Schmidtia pappophoroides & & & $\mathrm{x}$ \\
\hline Setaria lindenbergiana & & & $x$ \\
\hline Setaria pumila & $x$ & & \\
\hline Setaria sphacelata & & & $\mathrm{x}$ \\
\hline Sporobolus pyramidalis & $x$ & & \\
\hline Themeda triandra & & $\mathrm{x}$ & \\
\hline Trachypogon spicatus & $\mathrm{x}$ & & \\
\hline Triraphis schinzii & $x$ & & \\
\hline Tristachya biseriata & & $x$ & \\
\hline Urelytrum agropyroides & $x$ & & \\
\hline Urochloa mosambicensis & & & $x$ \\
\hline
\end{tabular}




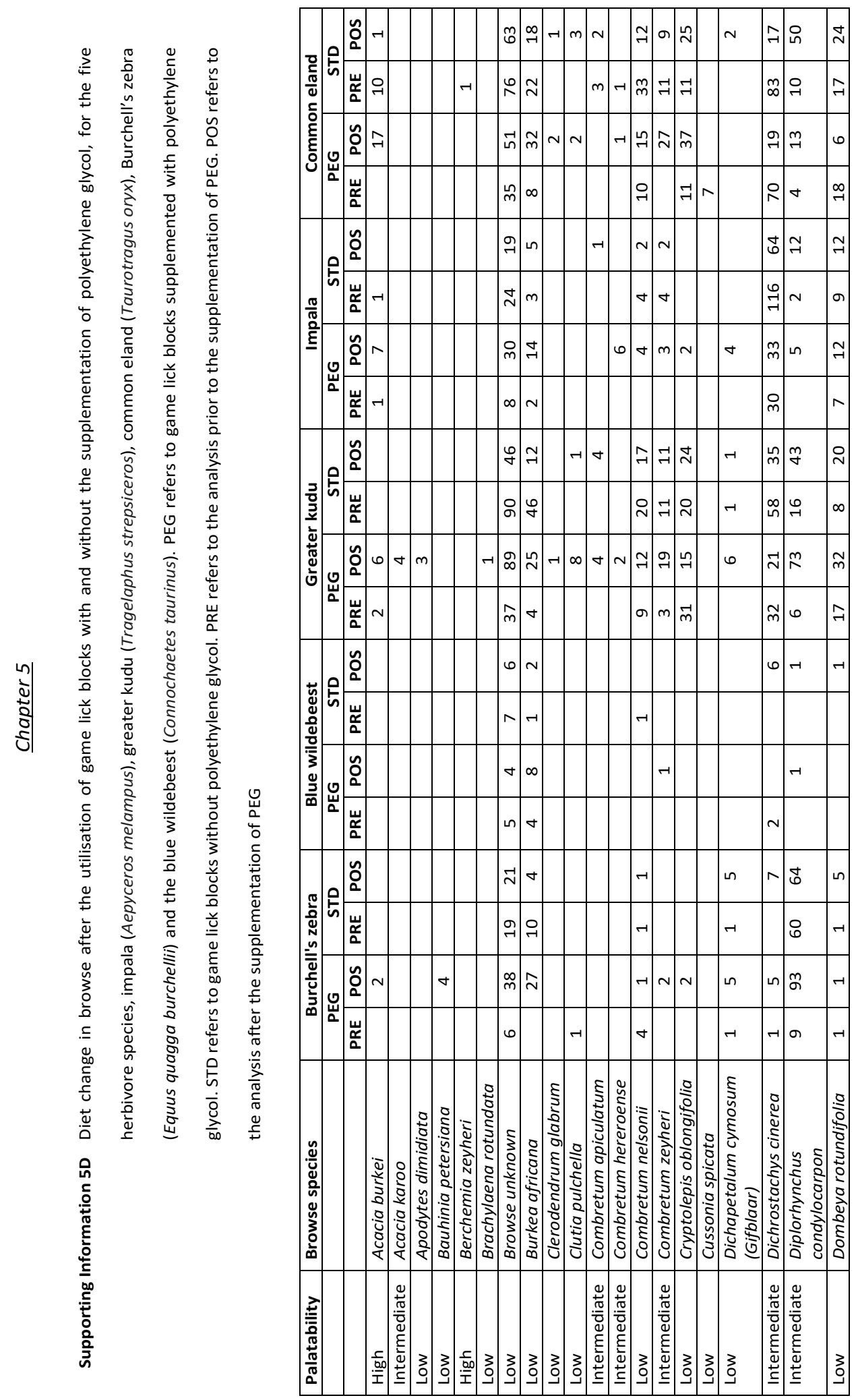




\begin{tabular}{|c|c|c|c|c|c|c|c|c|c|c|c|c|c|c|c|c|c|c|c|c|c|c|c|c|c|c|c|}
\hline 3 & กิ & & -1 & $\sim$ & & & & & & 6 & & m & $\approx$ & & $\infty$ & & $m$ & in 7 & -1 & m & & & n & $\sim$ & & $m \stackrel{\llcorner}{m}$ & \\
\hline s & & & $\stackrel{n}{\sim} 1$ & $\wedge$ & & & & & 6 & F & & ले & $\hat{m}$ & & $\begin{array}{l}0 \\
-1\end{array}$ & $\nabla$ & $\nabla$ & & -10 & & A & $\sim$ & $\hat{m}$ & $\exists$ & & กี & \\
\hline i & 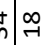 & & 6 , & $m$ & $\sim$ & & & $m$ & $\sigma$ & $\exists$ & & I & $\underset{\sim}{m}$ & $\wedge$ & $\exists$ & & เn & $m$ & & & & & a) & $\infty$ & in & m & \\
\hline$i$ & $\begin{array}{l}\text { s. } \\
\text { v }\end{array}$ & & $\nabla$ & & N & & & & & I & & 占 & $\underset{\sim}{\infty}$ & & & & & & & & & & $m$ & $\exists$ & $N$ & F & \\
\hline r & in & & -1 & $m$ & & & & & -1 & in & & $\underset{\sim}{\infty}$ & $\Lambda$ & & $m$ & & $\nabla$ & & $N$ & $r$ & & $\mathrm{~m}$. & -1 & -1 & & N & \\
\hline & N & & & 6 . & -1 & & & & & N & & $\exists$ & $\infty$ & & in & & $N$ & -1 & & & & 0 & -1 & $\approx$ & & in & \\
\hline in & $\sqrt{\sim} \underset{\sim}{\rightarrow}$ & & $r \mid$ & $m$ & & & & & & $\stackrel{m}{-1}$ & & 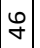 & n & & $m$ & & & $\nabla$ & & & & $\rightarrow$ & in & & & & \\
\hline & -1 & & & & & & & $r$ & & 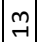 & & $\infty$ & -1 & & 0 & & & & & & & N & & 억 & & & \\
\hline 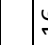 & $\underset{\sim}{\sim} \sim \approx$ & & $\wedge$ & 0 & & & - & & 욱 & $\vec{N}$ & & $\stackrel{\infty}{\sim}$ & $\stackrel{m}{\sim}$ & & $\exists$ & N & 6 & $N$ & 人 & $r$ & & $\nabla$ & & & in & 욱 & \\
\hline$m i$ & $-1 /$ & & $\stackrel{n}{m}:$ & $\Rightarrow$ & a & & & & & F & & $\stackrel{\infty}{\infty}$ & $\stackrel{2}{\sim}$ & -1 & $\infty$ & 0 & n & $m$ & & & & & $\vec{m}$ & $\underset{\sim}{2}$ & i & $\stackrel{\circ}{\wedge}$ & \\
\hline$\nabla \delta$ & $g \stackrel{\sim}{g}$ & & $\underset{\Im}{\Im}$ & 이. & $\nabla$ & & & & 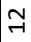 & ন & & $\begin{array}{l}\infty \\
\infty \\
0\end{array}$ & $\stackrel{\infty}{\sim}$ & & a & -1 & i) & a & 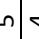 & 7 & & & $\begin{array}{c}0 \\
-1\end{array}$ & $\nabla$ & -1 & શิ & \\
\hline$\lesssim$ & V & & i: & $\exists$ & $\rightarrow r$ & ○ & & & & $\approx$ & & $\vec{z}$ & 6 & & & & & -1 & & ר & & -1 & in & $\stackrel{m}{-}$ & & นก & \\
\hline 4 & ก & & & & & & & & -1 & $m$ & & $\wedge$ & & & 0 & & & & -1 & & & & & & & & \\
\hline$\stackrel{5}{c}$ & $\hat{v}$ & & & $m$ & & & & & & & & 0 & & & in & & & & & & & $\sim$ & & $m$ & & $N$ & \\
\hline 4 & 0 & & & & & & & & & & & 0 & & & & & & & & & -1 & & & & & & \\
\hline 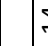 & & & & & & & & & & & & $\sim$ & & & & & & & & & & & & $\wedge$ & & 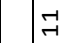 & \\
\hline 4 & $n$ & & & -1 & & & & & & & & $a$ & & & in & & $\rightarrow$ & & & & & $\mathrm{m}$ & & & & - & \\
\hline in & & & -1 & $N$ & & & & & & & & $N$ & & & $N$ & & & $\sim$ & & & & & & in & & $\sim$ & \\
\hline r & 人 & & & -1 & & & & & $m$ & $\mathrm{~m}$ & -1 & r & 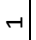 & & 49 & & & $\sim$ & & & & n & m & $N$ & & & $\mathrm{~m}$ \\
\hline 17 & -1 & & & -1 & & $r$ & & & & & & -1 & & & $m$ & & & & & & & & & n & & -1 & \\
\hline 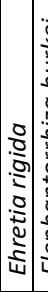 & 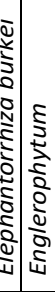 & 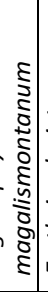 & 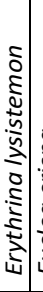 & \begin{tabular}{|c}
0 \\
0 \\
0 \\
0 \\
0 \\
0 \\
0 \\
3 \\
4
\end{tabular} & 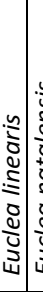 & & $\begin{array}{l}5 \\
\vdots \\
\vdots \\
\vdots \\
\vdots \\
\vdots \\
\vdots\end{array}$ & 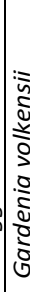 & $\begin{array}{l}0 \\
0 \\
0 \\
0 \\
0 \\
0 \\
0 \\
0 \\
0\end{array}$ & 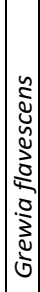 & 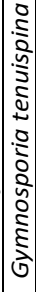 & 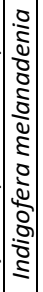 & 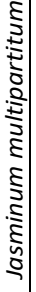 & 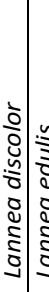 & 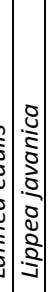 & 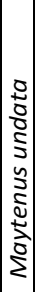 & 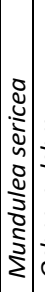 & 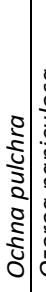 & 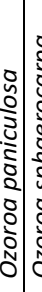 & 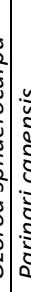 & 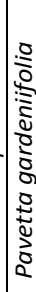 & 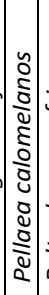 & 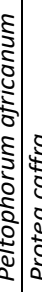 & 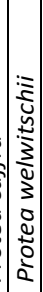 & 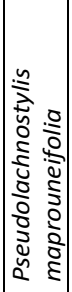 & 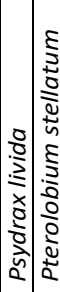 & 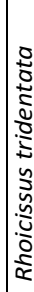 \\
\hline 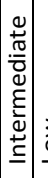 & |3:3 & & తa & o & $\sum$ & & 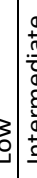 & & & 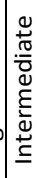 & ََ & 3 & $\begin{array}{l}3 \\
3 \\
3\end{array}$ & 3 & 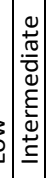 & 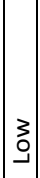 & 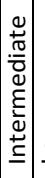 & $\begin{array}{l}3 \\
0 \\
3\end{array}$ & 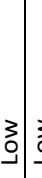 & & $z$ & . & $\begin{array}{l}3 \\
0 \\
3\end{array}$ & 9َ & 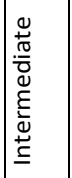 & $\begin{array}{lll}3 & 3 \\
0 & 0\end{array}$ & \\
\hline
\end{tabular}




\begin{tabular}{|c|c|c|c|c|c|c|c|c|c|c|}
\hline & 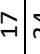 & i & & $\stackrel{m}{\rightarrow}$ & a & & & $\stackrel{\sim}{m}$ & & คำ \\
\hline & in & $m$ & N & $\stackrel{m}{-}$ & 0 & & & ને & & $\hat{n}$ \\
\hline & 6 ; & $\vec{N}$ & & 어 & $\nabla$ & & & $\stackrel{\infty}{m} .0$ & & ْ \\
\hline & -1 & N & & $\sigma$ & & & & $\sigma:$ & & v \\
\hline & $m:$ & $\underline{-1}$ & & N & $N$ & & & $\infty$. & 0 & ט. \\
\hline & -1. & -1 & & $N$ & $m$ & & & $\stackrel{m}{\rightarrow}$ & & $\mathbf{v}$ \\
\hline & 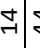 & $\forall$ & & in & -1 & & & $\vec{N}$ & & S \\
\hline & & & & $\sim$ & & & & in 0 & & 익 \\
\hline & $\underset{\neg}{\rightarrow}$ & in & & $\underset{\sim}{\mathscr{\sigma}}$ & $\approx$ & & & 위r & & $\stackrel{n}{\underset{n}{n}}$ \\
\hline & 워. & $N$ & & $\mathscr{q}$ & & & & $\underset{\sim}{m}$ & & $n \stackrel{\infty}{\Sigma}$ \\
\hline & 85 & J & $-1-1$ & $\exists$ & $\infty$ & 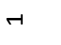 & $\rightarrow$ & 요 & & 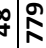 \\
\hline-1 & $\nabla u$ & in & & $\underset{-1}{0}$ & -1 & & & aL & & 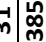 \\
\hline & & -1 & & $N$ & $m$ & & & $\sim \Omega$ & & $\begin{array}{ll}0 \\
\text { r }\end{array}$ \\
\hline & & & & $N$ & & & & -1. & & $m$ in \\
\hline & & $m-$ & -1 & & & & & & & $\sigma \overrightarrow{\mathrm{m}}$ \\
\hline & & & & -1 & & & & $N$ & -15 & : \\
\hline & & กิ & & in & & & & $\nabla$ & & $\begin{array}{l}\infty \\
-\pi\end{array}$ \\
\hline 6 & & $\underset{\sim}{\stackrel{1}{r}}$ & $\checkmark$ & -1 & & & & $\rightarrow$ & & $\sqrt{ }$ \\
\hline & & กิ & 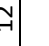 & 0 & & & & 워 & & $\vec{m}$ \\
\hline & & เ & & & & & & $m$ & & $\underset{7}{*}$ \\
\hline 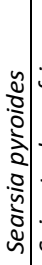 & 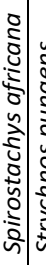 & 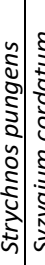 & 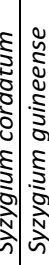 & 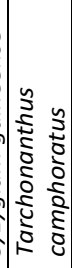 & 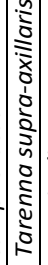 & 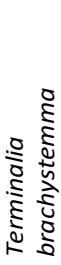 & \begin{tabular}{|c|}
0 \\
0 \\
0 \\
0 \\
5 \\
0 \\
0 \\
0 \\
0 \\
0 \\
0 \\
5 \\
5
\end{tabular} & 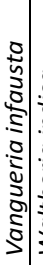 & 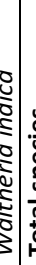 & 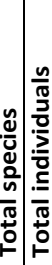 \\
\hline $\begin{array}{l}3 \\
0 \\
3\end{array}$ & 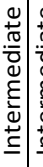 & 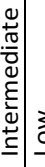 & 3 & 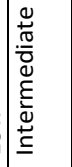 & $\mid \begin{array}{l}3 \\
0 \\
0\end{array}$ & فَ & 3 & 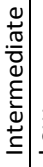 & & \\
\hline
\end{tabular}




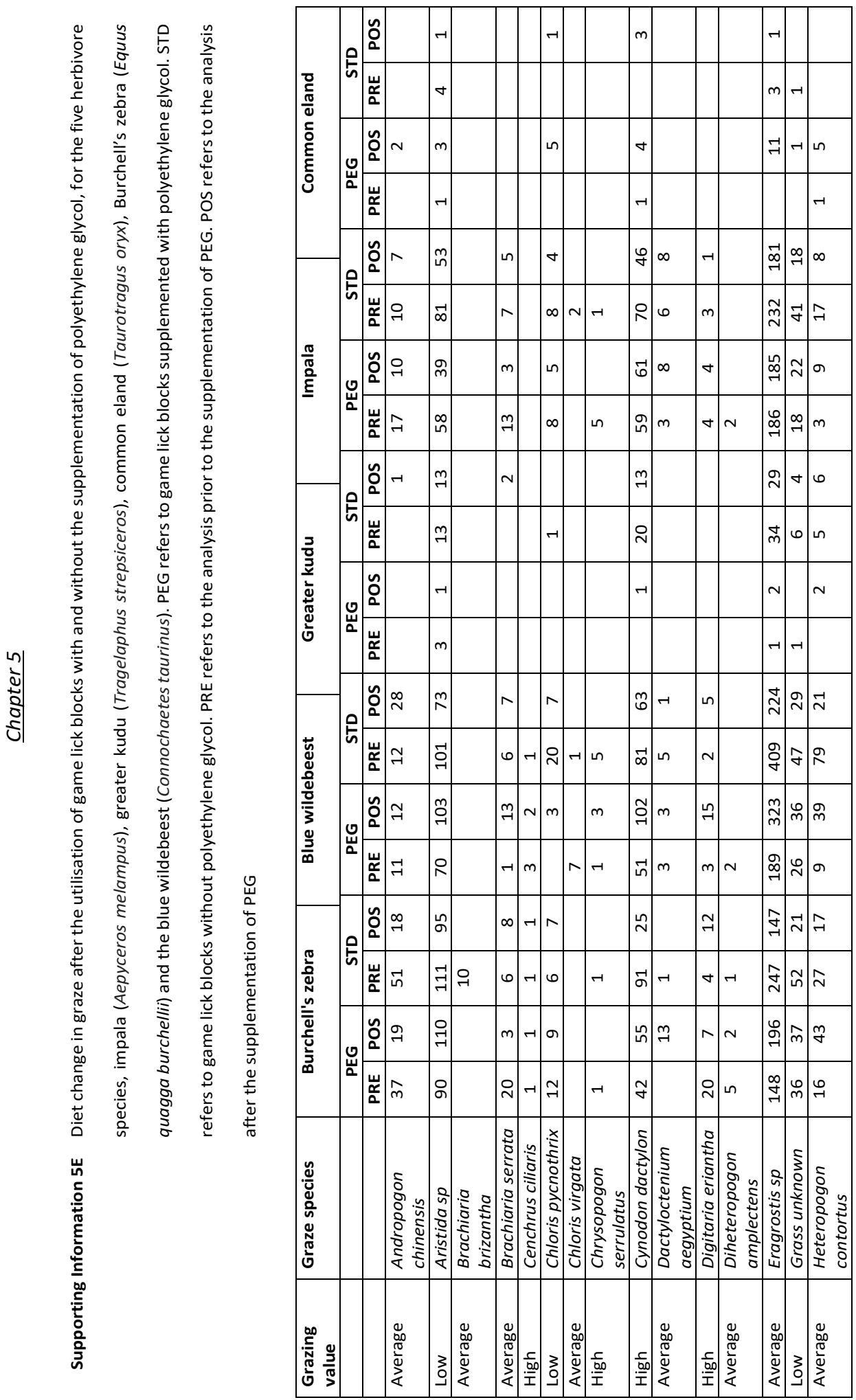




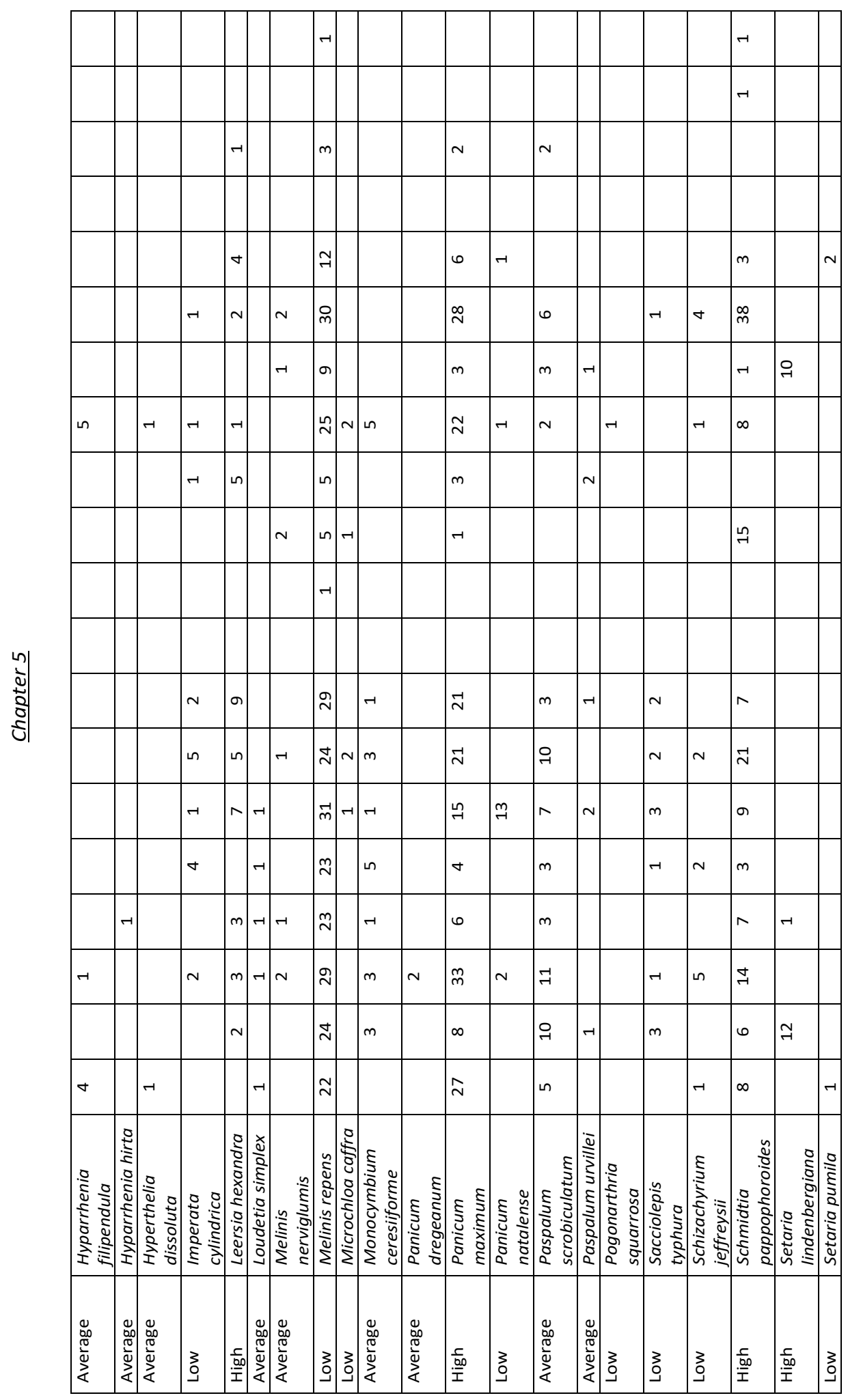




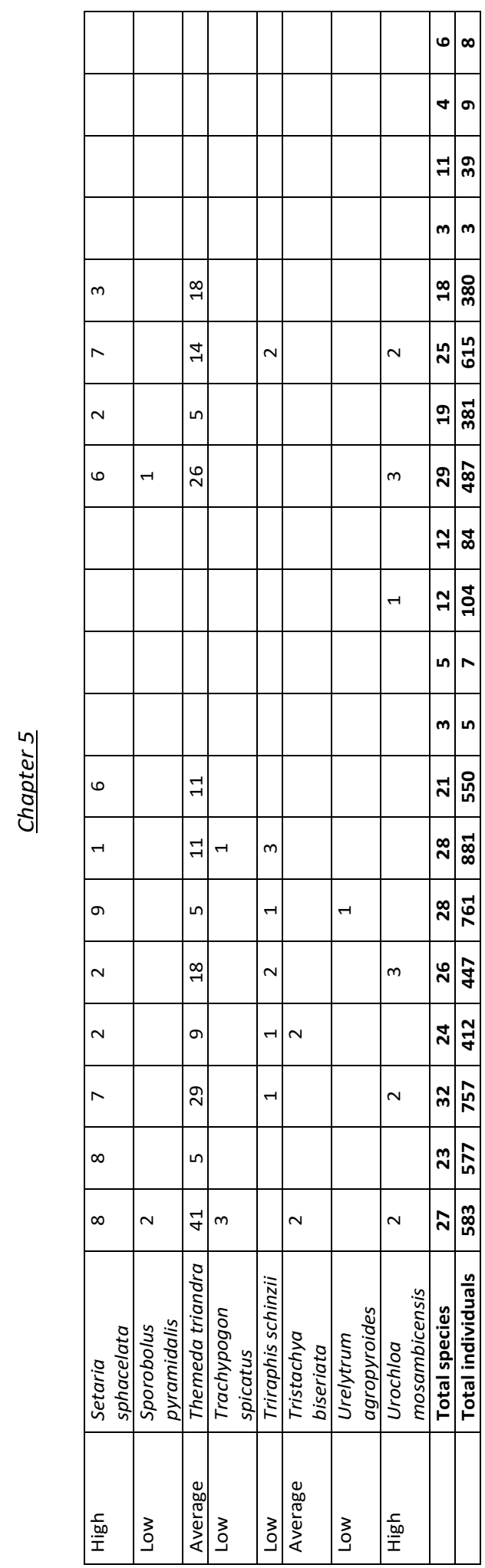




\section{Chapter 5}

Supporting Information $\mathbf{5 F}$ Average percentage (with the $95 \%$ confidence intervals) of $\mathrm{N}$ and $\mathrm{P}$ concentrations found in the faeces for the five herbivore species, impala (Aepyceros melampus), greater kudu (Tragelaphus strepsiceros), common eland (Taurotragus oryx), Burchell's zebra (Equus quagga burchellii) and the blue wildebeest (Connochaetes taurinus), based on the use of PEG or Standard game lick blocks

\begin{tabular}{l|c|c|c|c}
\hline Herbivore species & Average N-PEG & Average N-STD & Average P-PEG & Average P-STD \\
\hline Common eland & $2.35( \pm 0.40)$ & $2.17( \pm 0.14)$ & $0.22( \pm 0.02)$ & $0.21( \pm 0.01)$ \\
\hline Impala & $2.10( \pm 0.07)$ & $2.30( \pm 0.20)$ & $0.27( \pm 0.02)$ & $0.29( \pm 0.03)$ \\
\hline Greater kudu & $2.20( \pm 0.11)$ & $2.21( \pm 0.10)$ & $0.22( \pm 0.01)$ & $0.21( \pm 0.01)$ \\
\hline Blue wildebeest & $1.62( \pm 0.10)$ & $1.46( \pm 0.06)$ & $0.25( \pm 0.02)$ & $0.22( \pm 0.01)$ \\
\hline Burchell's zebra & $1.05( \pm 0.05)$ & $1.00( \pm 0.03)$ & $0.13( \pm 0.02)$ & $0.13( \pm 0.01)$ \\
\hline
\end{tabular}




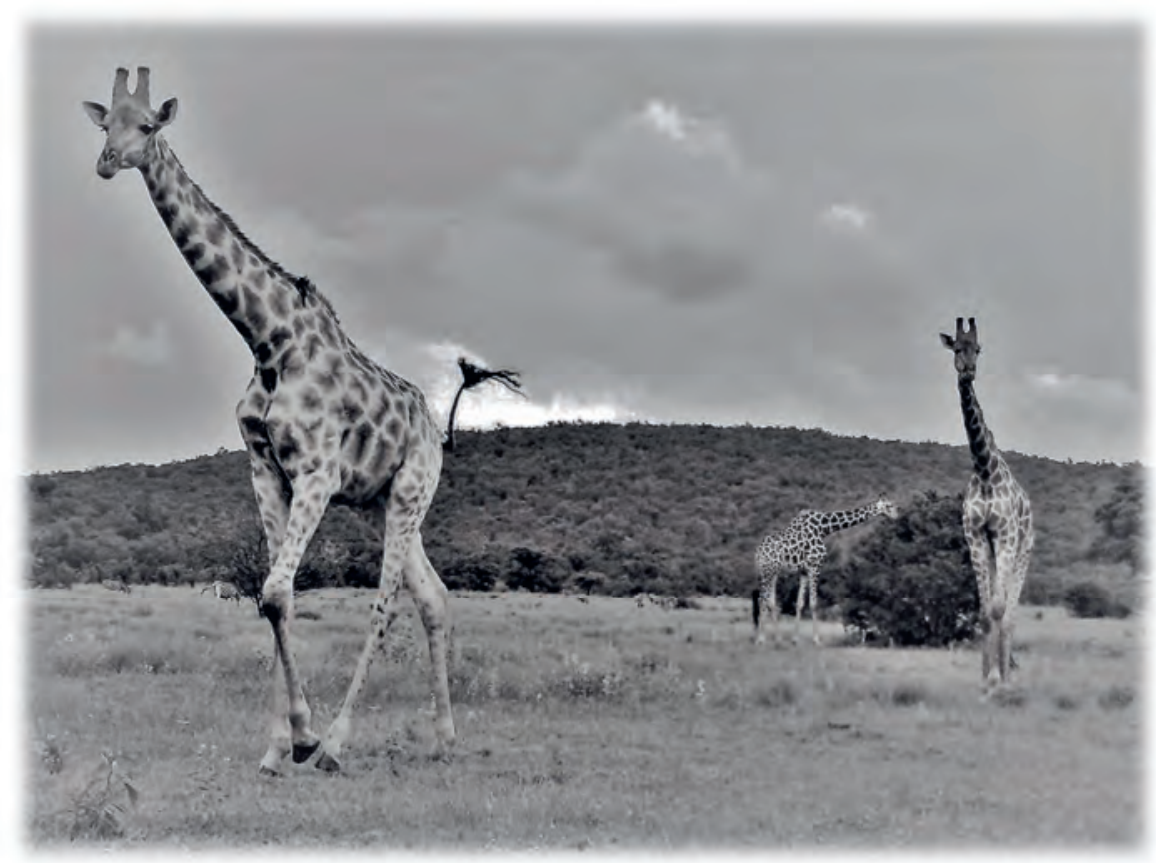

Photograph 8: Giraffe, Figtree Plains, Welgevonden Game Reserve (Camera trap photograph) 


\section{Chapter 6}

Methods to improve forage quality for mammalian herbivores in nutrient poor savannas:

\section{A Synthesis}

Bradley Schroder 


\section{Chapter 6}

\section{Introduction}

Savannas represent one of the largest biomes of the world, comprising roughly $20 \%$ of the earth's land area (Huntley and Walker 2012; Shorrocks and Bates 2015). In Africa they occupy almost $50 \%$ of the continent's land area and support not only a large portion of its humans and livestock, but some of the world's highest densities and diversity of wild mammalian herbivores and carnivores (Scholes and Archer 1997; Sankaran and Anderson 2009; Shorrocks and Bates 2015). Due to the ever increasing threat to conservation by human population growth and the associated need for land for agriculture and development places, conservation areas especially in savannas, are under threat. Savannas on nutrient poor soils are under less of a threat as these lands are marginal for agriculture.

Mammalian herbivores benefit from forage with high quality (nutrient availability) and quantity for their survival (Gaillard et al. 2000; Uher-Koch et al. 2019). To understand the implications pertaining to aggregation of herbivores (Drescher et al. 2006) and their effect on food quantity and quality, we need to understand herbivore dietary requirements for survival. The majority of herbivores strive to acquire forage of a higher quality in terms of nutrient and energy content, and digestibility, than the average forage available (Drescher 2003; Prins and Van Langevelde 2008). If protected savanna areas, have nutrient poor soils, then sustaining large numbers of mammalian herbivores and co-acting carnivores is challenging due to low forage quality for the herbivores, which results in negative consequences for game viewing (lowering sighting probability) and hence the critical financial income.

One of the largest challenges faced by wildlife managers in nutrient poor savannas is to ensure that mammalian herbivore densities are sufficiently high to maintain a herbivore-driven state, which is a system stimulated by mammalian grazers and browsers with patches often grazed 


\section{Chapter 6}

and re-grazed forming so-called "grazing lawns" (Grant and Scholes 2006; De Knegt et al. 2008; Hempson et al. 2014). This herbivore-driven state is in contrast to a fire-driven state, which is a system dominated by fire that generally has a homogenising influence on the landscape (Archibald and Bond 2004, Groen et al. 2017). Such a herbivore-driven state is thought to produce a richer diversity of animal species as a base for eco-tourism (Hempson et al. 2014).

Nutrient poor savannas generally have poor forage quality for both grazers and browsers (Olff et al. 2002) and it is accepted that food quality and quantity are the result of abiotic factors, such as soil nutrients and water, viz., a bottom-up process (Olff et al. 2002; Riginos and Grace 2008; Hopcraft et al. 2010). However, aggregations of herbivores and revisitation of earlier grazed locations can modify the vegetation through consumption, excretion and trampling, viz., a top-down process (Drescher et al. 2006; Waldram et al. 2007; De Knegt et al. 2008). Grazing lawns are generally found in smaller areas with a relatively high soil nutrient status, coupled with high grazing pressure (Grant et al. 2011; Seymour et al. 2013; Veldhuis et al. 2014). Higher soil nutrient levels should lead to higher nutrient concentrations in plants, which results in improved forage quality for mammalian herbivores (Grant and Scholes 2006). As forage quality of vegetation decreases with age, frequent grazing and browsing maintains the vegetation in a higher qualitative state (Drescher et al. 2006).

Commercial agricultural land is generally established in nutrient rich areas, which is good for both crop and stock farming. Conservation areas which have been established in nutrient poor areas consequently need to be managed in a far more intensive manner in order to ensure high mammalian herbivore densities. In order to address the challenges of management and conservation of wildlife in nutrient poor savannas, we need to better 


\section{Chapter 6}

understand the determinants of the quality of forage for mammalian herbivores. This understanding will contribute to evidence-based conservation decision making in these protected areas. The importance of wildlife management pertaining to food quality in nutrient poor savannas is not a localised problem but is important globally. The management of a protected area is not merely erecting a fence around a portion of land and declaring it a protected area and allowing the fauna and flora to manage themselves (laissez-faire approach). In my opinion, it is fundamental to ensure high densities of wildlife in protected areas and conservation managers need to consider managing certain characteristics of these areas along similar principles as agricultural farmers. This results in having to manage vegetation in order to increase forage quality and boost animal populations to achieve the desired outcomes of their respective protected areas. When manipulating fauna and flora, we need to consider the long-term effects principally relating to water availability, forage quality and quantity (especially high-quality forage), security and financial considerations, amongst others. Management of protected areas over the past few decades has become highly sophisticated and more reliant on evidence-based conservation, coupled with technology. In order to manage protected areas as comprehensively as possible, and to understand how to manipulate the vegetation in order to produce higher quality forage for herbivores, we need to understand the effects of nutrients on food quality and how they respond to a system. In order to understand this it is imperative to understand the physiology of animals. This allows management to better understand the environment in which we work and how to utilise interventions to better the forage quality for the survival of the herbivores in a protected area.

In this thesis, I address the question of whether or not nutrient addition promotes the establishment of grazing lawns in a nutrient poor savanna. Such addition is hypothesized to 


\section{Chapter 6}

result in a switch ("jolt") from tall, nutritionally poor, less palatable grass to short, more nutritional and palatable grass species (Mclvor et al. 2005; Stock et al. 2010; Hempson et al. 2014). The central management question here is how to turn a marginal, nutrient poor, firedriven system into a herbivore-driven system with higher densities of grazers and browsers, sustaining large predators that draw tourists (Lindsey et al. 2007)? Fundamental to this, I have developed evidence for management by exploring ways to improve the quality of forage in a nutrient poor savanna. I first address the reasons for protected area establishment, their management implications and how these affect current management of protected areas (Chapter 2, see also Figure 6.1). I then proceed with the question of whether the addition of different nutrients (nitrogen $\mathrm{N}$, phosphorous $\mathrm{P}$, calcitic and dolomitic lime $\mathrm{Ca}$ ) into a nutrient poor savanna system will increase the soil nutrient status and hence have a positive effect on the nutrient levels in the grass leaf (Chapters 3 and 4). I then set out to establish whether nutrient addition ( $\mathrm{N}, \mathrm{P}$ alone or in combination with $\mathrm{Ca}$ ) results in an increase in local grazing pressure by large free-roaming herbivores on lawn grass patches, assuming this will be a precursor to the establishment of grazing lawns (Chapter 4). Lastly, if the addition of polyethylene glycol (PEG) to standard game lick blocks (nutrient supplementation) will enable large herbivores to access previously unusable secondary compounds, tannins, proteins, indigestible fibres and other sources of energy, resulting in a diet change of free-roaming herbivore species (Chapter 5).

This thesis reveals novel findings on how the addition of nutrients to grazing lawns and the use of a polymer (PEG), which has tannin binding capabilities, in the diet has a positive effect on the quality and quantity of forage available for free-roaming herbivores in a nutrient poor savanna. 


\section{Chapter 6}

I conclude from this study that $\mathrm{N}$ but especially $\mathrm{P}$ and $\mathrm{Ca}$ increased in the soil when $\mathrm{N}, \mathrm{P}$ and Ca were applied. It was noted that with the addition of N, P and Ca to the soil, that only P was observed to be absorbed into the grass leaf. This could be as a result of the study area having soils with low $\mathrm{pH}$, and by adding $\mathrm{Ca}$ it increases the $\mathrm{pH}$ promoting $\mathrm{P}$-availability in the soil to the plants. The data suggests that $P$ is limiting for plant growth, and with these findings I contribute to the understanding under which conditions grazing lawns can establish. Observations of the plots fertilization with $\mathrm{N}, \mathrm{P}$ and Ca showed increased local grazing pressure on plots treated with $\mathrm{N}$ by three species of herbivore, viz., blue wildebeest (Connochaetes taurinus), Burchell's zebra (Equus quagga burchellii) and the impala (Aepyceros melampus), in the study area. Thus we can adopt the concept that abundantly present mammalian herbivores with intermediate body mass, attracted to grazing lawns by the addition of $\mathrm{N}$, can maintain grazing lawns. Furthermore, my study has shown that with the use of PEG in supplementary game lick blocks, four of the five free-roaming wild herbivores, viz., common eland (Taurotragus oryx), impala, greater kudu (Tragelaphus strepsiceros) and the Burchell's zebra, observed in the study area are able to utilise a greater number of less palatable tree species with higher levels of condensed tannins. The Burchell's zebra had a $28 \%$ change in diet from grazing to browsing, with an increase from 16 to 31 browse species, which shows how PEG allows a grazer to change their diet selection in a nutrient poor environment. Even though there was no large effect shown on blue wildebeest diet, this potentially has interesting ramifications for other grazer species, with the potential to alleviate food limitations and for the vegetation dynamics within the area, resulting in a requirement for further studies. These experiments were undertaken in the Welgevonden Game Reserve, South Africa, a nutrient poor savanna. However, the results of this study can 


\section{Chapter 6}

be used by conservation managers to improve forage quality in other protected areas, thus having far-reaching implications for nutrient poor savannas around the world.

I expect that the information presented in this thesis will fulfil at least four important functions: (1) draw attention to the present management implications of protected areas from the overview of the establishment of protected areas, (2) highlight the current gaps in our understanding of the role of specific nutrients in grazing lawn establishment, (3) identify gaps in the understanding of the role free-roaming herbivores play in grazing lawn establishment, and (4) the role of PEG in herbivore use of nutrient poor savannas. 


\section{Chapter 6}

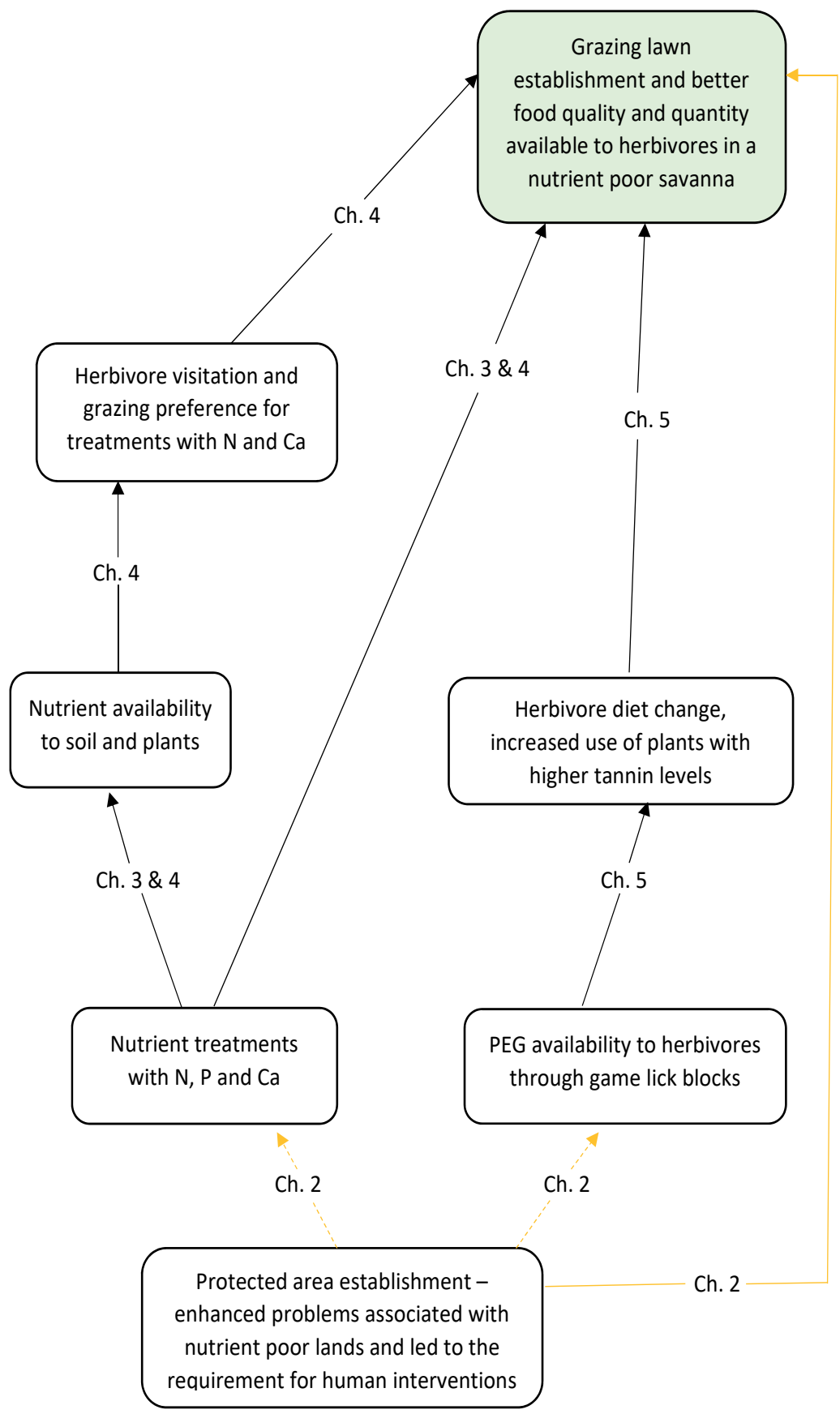

Figure 6.1 Schematic representation of the main focus of the different chapters in this thesis. The solid black lines with arrows show the increased nutrient availability, resulting in grazing lawn establishment and better quality forage for the herbivores. Chapters 3 and 4 had a range of nutrients fertilized 


\section{Chapter 6}

on the research plots ( $\mathrm{N}, \mathrm{P}, \mathrm{Ca}$ and a mixture thereof), increasing nutrient availability to the soil and plants. The increase in nutrient availability attracts grazing herbivores to the study sites, through increased grazing pressure, changing the grass species composition and ultimately producing grazing lawn monocultures with higher quality forage. Chapter 5 shows with the addition of Polyethylene glycol (PEG), a polymer, there is a change in herbivore diet selection allowing herbivores to browse more species of plants with higher secondary compounds (tannins). Chapter 2 was an overview of the establishment of 48 protected areas, which shows implications for managers of these areas today. The solid gold lines with arrows represent protected area establishments positive effects and the dotted gold lines with arrows the negative effects on forage quality and quantity

\section{Protected area establishment affects modern management}

Prior to undertaking experiments with nutrients, I felt it was important to obtain an understanding of why protected areas/wildlife undertakings were established in their current locations and what the potential implications would be for managers of those protected areas today. This is revealed in Chapter 2 of this thesis. This chapter gives further insight into why certain protected areas require higher levels of human interference through management interventions. I identified three "Periods" in which protected areas were established, Period 1: Area protection commences with some form of protection for wild animals from decimation; Period 2: Areas considered marginal for agriculture, prone to disease or sickness and considered uninhabitable for human settlement at the time; and Period 3: Areas are legislated with protected statues due to ecological or cultural importance. Each of these periods had certain ramifications for managers of these protected areas today, with Period 1 protected areas managed (or not) in some form of laissez-faire approach, and Period 2 and 3 protected areas being managed more intensively approaching passive adaptive management (Walters and Hilborn 1978). 


\section{Chapter 6}

The lack of evidence-based conservation during the establishment of protected areas has led to a number of protected areas being established in remote areas. These remotely established protected areas have challenges pertaining to location (supply chains and tourism logistics), land which was considered to have low land use value, normally low in nutrient status and fencing of these areas which prevented mammalian herbivores from significant regional movement during the drier months of the year to obtain better quality forage. The 'golden thread' which ties these individual chapters together in this thesis is the lack of evidencebased conservation to ensure high-quality forage in nutrient poor savannas.

\section{Forage quality for free-roaming mammalian herbivores in nutrient poor savannas}

In chapter 3 and 4,1 tested if fertilization with nitrogen $(N)$, phosphorus $(P)$ alone and a combination of calcitic and dolomitic lime ( $\mathrm{Ca}$ ) would increase available $\mathrm{N}$ or P in both soil and grass leaf. I also tested which nutrient or combination of nutrients the free-roaming mammalian herbivores had a preference for, thus helping to establish and maintain grazing lawns in a nutrient poor savanna by elevated grazing pressure. There are several studies in which nutrient supplements have been used to improve rangeland condition or create grazing lawns (Augustine et al. 2003; Cromsigt and Olff 2008; Van der Waal et al. 2011a). In chapter 3 , the unique aspect of my study is that I use specific nutrients (N, P and a combination with Ca) for fertilization in a nutrient poor savanna, to test which individual nutrient or combination of these nutrients will have the greatest effect on improving the quality of grass. This was measured using soil and grass samples which were analysed to establish the levels of all nutrients but more especially $\mathrm{N}, \mathrm{P}$ and $\mathrm{Ca}$. The results show that $\mathrm{P}$ is the limiting factor in plant leaf growth in the study area and that the addition of $\mathrm{P}$ and $\mathrm{Ca}$ to soil increases the amount of these nutrients significantly in the plant leaf. This was confirmed in similar studies 


\section{Chapter 6}

undertaken by Higgins et al. (2012). The application of $\mathrm{N}$ did not result in a significant increase of $\mathrm{N}$ levels in the grass leaf, which is in contrast with Coetsee et al. (2010) who showed that $\mathrm{N}$ levels increased when grass leaf was grazed and Van der Waal et al. (2011b), who posit that increases in both $\mathrm{N}$ and $\mathrm{P}$ levels in the grass leaf increased when fertilized. Van der Waal et al. (2011b), posit that $\mathrm{P}$ resources may give grasses a competitive advantage over trees. However, studies undertaken by Cech et al. (2008) differed from my findings in that they found that $\mathrm{N}$ was the limiting nutrient in aboveground production or co-limited by $\mathrm{N}$ and $\mathrm{P}$ in tropical savannas and forest areas, which are normally associated with clay soils and water limited, whereas nutrient poor savannas have higher grass growth as a result of higher rainfall and leaching. Cech et al. (2008) state that there is little information pertaining to the nutrient availability in grazing lawns.

In chapter 4, after fertilization of the different nutrient elements, I was able to show the preference of free-roaming mammalian herbivores in the study area, which is lawn fertilized with $\mathrm{N}$ and a combination of $\mathrm{N}$ and Ca. Findings by Augustine et al. (2003) and Van der Waal et al. (2011a) support my findings that herbivores require nutrients, in that glades and bomas (old cattle pens) which became nutrient rich from the faeces and urine of cattle (Bos taurus africanus), become nutrient enriched patches which support mineral rich grasses, however the nutrients were not separated in this study.

In chapter 5, I provided polyethylene glycol (PEG) to free-roaming mammalian herbivores to establish if this would affect their diet choice and intake volume to include plants with high tannin levels in their diet. There have been several studies on PEG, but all of these have been undertaken on domestic animals such as goats (Capra aegagrus hircus), sheep (Ovis aries) and cattle (Salawu et al. 1997; Decandia et al. 2000; Mkhize et al. 2015). I present novel findings 


\section{Chapter 6}

on free-roaming mammalian herbivores and the change in their diet. Scogings et al. (2014) stated that browsers and mixed feeders foraging preferences are strongly shaped by secondary compounds. My hypothesis was that browsers would most likely be affected by PEG, which concurs with findings by Decandia et al. (2000) on goats. My results showed that Burchell's zebra (a grazer) and impala (a mixed feeder) were the two species most influenced by PEG in their diet. More especially, the Burchell's zebra changing from their normal diet of grass to a higher percentage diet with browse. Mkhize et al. (2015) established that supplementing mixed feeding herbivores with PEG would successfully increase browse utilisation, which concurs with my findings pertaining to the impala. In research by Salawu et al. (1997) they refer to browsing marsupials being able to handle diets with higher tannin content more than grazing marsupials, which may indicate why when PEG is ingested, there is a larger effect on Burchell's zebra (grazers) and impala (mixed feeders) rather than the pure browsing herbivore species. Chapters 3,4 and 5 show the effect of different methods to ensure higher forage quality in nutrient poor savannas.

Chapter 3 suggests that $P$ is limited in the study area for plant growth, combined with $\mathrm{Ca}$ which stimulates the plants uptake of P. However, chapter 4 advocates that the free-roaming herbivores require more $\mathrm{N}$ based on the number of herbivores grazing on the different treatment plots. 


\section{Chapter 6}

Box 1 shows that preliminary results of an experiment where I added Sodium chloride ( $\mathrm{NaCl})$.

This experiment was limited to one site in Welgevonden. These results suggest that fertilization with $\mathrm{NaCl}$ could enhance lawn grass establishment in nutrient poor savannas.

\section{Box 1: Grazing lawn establishment using sodium chloride}

Sodium chloride $(\mathrm{NaCl})$ is not a requirement for grass growth, however, it may be sought after by freeroaming herbivores and thus would potentially stimulate grazing in areas where $\mathrm{NaCl}$ has been applied on a more regular basis (Grant and Scholes 2006; Veldhuis et al. 2014; Hempson et al. 2014). I established one experimental site during my study to look at the effect of $\mathrm{NaCl}$ as a potential driver for establishing grazing lawns. The primary concept in this experiment was to stress the grass by increasing the pF-values of the soil water, through the direct application of $\mathrm{NaCl}$ onto the grass: hence plants have to react by increasing their pF-values. Halophytes can do that by increasing salt concentration in their vacuoles; glycophytes cannot do this but they can increase the sugar concentration. It is hypothesized that this would jolt the carbon sinks from cellulose to sugar, and the grass would grow less and favour herbivores. This experiment ran for a period of two years from 2016 to 2018, however, with only one site not enough data were gathered to enable me to do a proper statistical analysis. In this Box I show the preliminary results of this experiment. In continuing with the same methodology as with $\mathrm{N}$ and $\mathrm{P}$ in chapters 3 and 4, I applied $\mathrm{NaCl}$ to four plots at quantities ranging from 312, 625, 1250 and $2500 \mathrm{~kg}$ per hectare or $31-250 \mathrm{~g} / \mathrm{p} / \mathrm{m}^{2}$, and a control plot with no treatment. The experiment area was not mowed prior to the application of $\mathrm{NaCl}$, which was applied to an area four hectares in size. In a two year period the grass had changed completely from tall, nutritionally poor grass to short, nutritionally rich grass and had expanded from 0.1 ha to 4.4 ha, of couch/Bermuda grass (Cynodon dactylon). Although the $\mathrm{NaCl}$ fertilization was only undertaken on one site, it shows an increase in the available $\mathrm{NaCl}$ in the soil and grass leaf, especially at the higher dosage levels. There is a positive increase in $\mathrm{Na}, \mathrm{N}, \mathrm{Ca}, \mathrm{Mn}$ and $\mathrm{S}$ in the grass leaf treated with the higher quantities of $\mathrm{NaCl}$, coupled with the expansion of the grazing lawn. This experiment warrants further research and could be a major driver for grazing lawns in nutrient poor savannas. 


\section{Chapter 6}

\section{Free-roaming mammalian herbivores as drivers of system change}

Based on studies by Parker (2004), the mammalian herbivore numbers in Welgevonden Game Reserve were reduced considerably. This may have led to a state with low herbivore numbers, with high grass biomass and low forage quality, resulting in a fire-driven state. Based on chapters 3 and 4 with the increased fertilizer experiments from 2014 to 2018, including the initial grazing lawn experiment undertaken in 2010 (Figure 6.2), I show that fertilization with specific nutrients can attract and retain mammalian herbivore species on grazing lawns. This, coupled with a game introduction programme of over 12000 mammalian herbivores into the system (Table 6.1) to increase the grazing pressure, may have led to the establishment and expansion of grazing lawns (Figure 6.2). This steered the reserve towards an alternate state of high herbivore numbers, with low grass biomass and higher forage quality, resulting in a herbivore-driven state creating the switch ("jolt") and increasing the ecological and tourism appeal of the study area. The addition of specific nutrients ( $\mathrm{N}$ and $\mathrm{Ca}$ ) into the nutrient poor system, resulted in the increased local grazing pressure that is paramount to grazing lawn creation and expansion (Archibald 2008; Hempson et al. 2014; Owen-Smith 2014). Figures 6.1 and 6.2 illustrate that with the addition of nutrients and the increase in large free-roaming mammalian herbivores (both from 2014), with the resultant increase in grazing pressure, that large herbivores (such as blue wildebeest) have been understated as potential main drivers for the establishment and maintenance of grazing lawns. My findings validate the statement by Venter et al. (2017) who suggested that rewilding of African rangelands with mid-Holocene herbivory pressure and diversity may shift a system from a tall unpalatable grass to a short more nutritious grass state, which may enhance nutrient cycling, conserve soil nutrient pools and benefit herbivore productivity. 


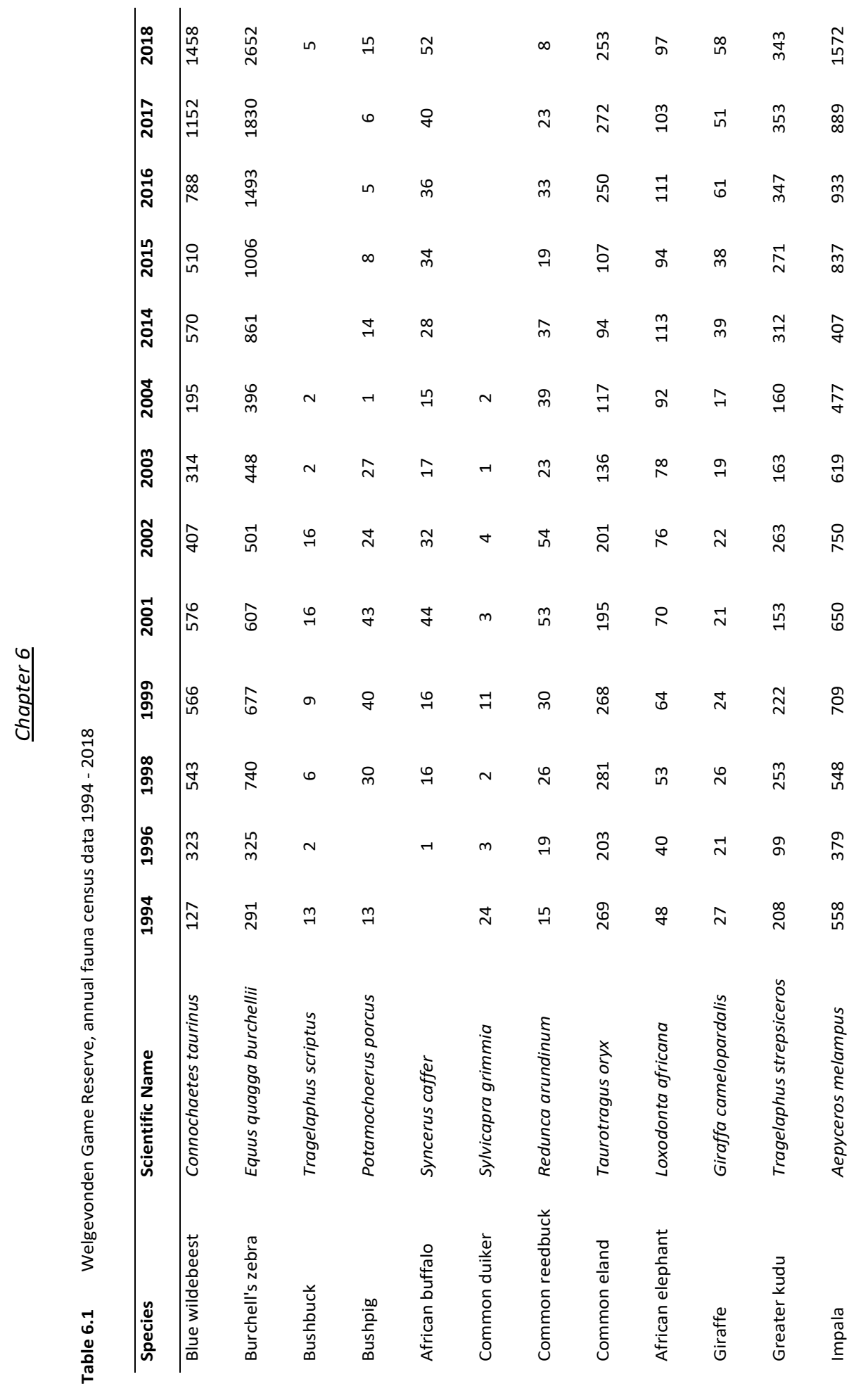




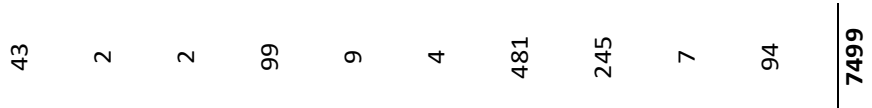

$$
\begin{aligned}
& \text { g d }
\end{aligned}
$$

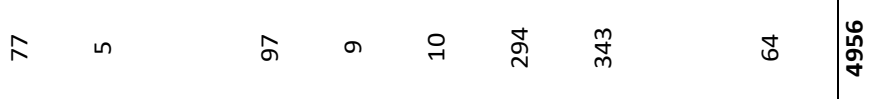

$$
\begin{aligned}
& \text { न } \Rightarrow \text { ने ब }
\end{aligned}
$$

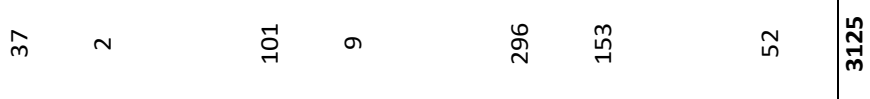

$$
\begin{aligned}
& \text { オ } \\
& \text { त }
\end{aligned}
$$

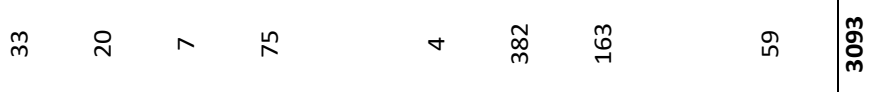

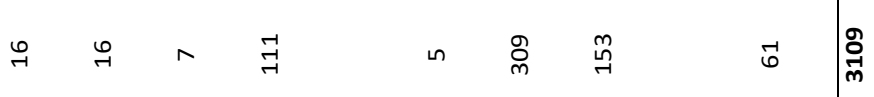

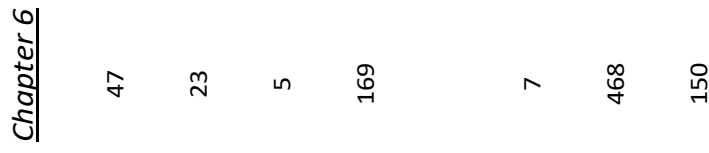

$$
\begin{aligned}
& \text { ก) }
\end{aligned}
$$

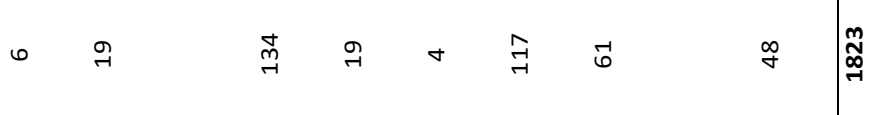

$$
\begin{aligned}
& g \stackrel{\sim}{\sim} \sim \sim \sim m \sim \infty
\end{aligned}
$$

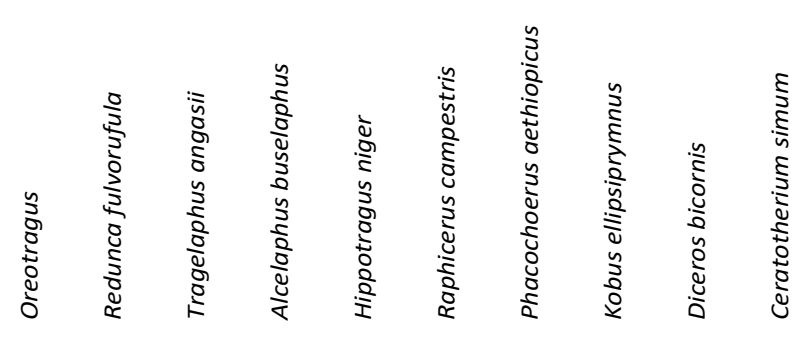

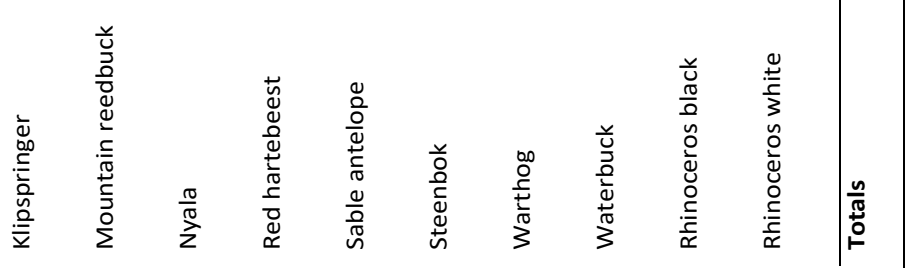




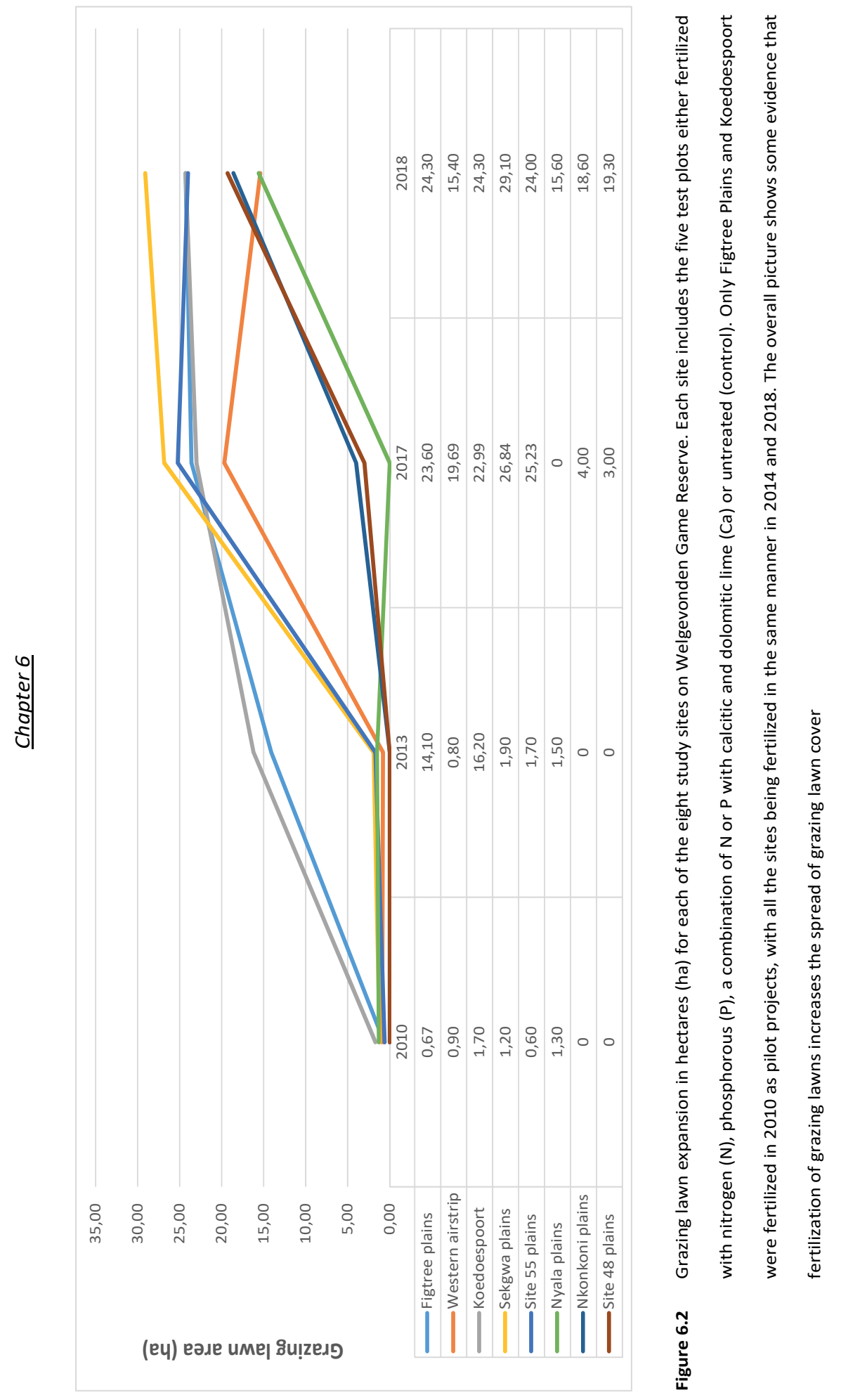




\section{Chapter 6}

\section{Evidence-based conservation - a 4th Period}

The ever increasing threats to protected areas associated with the growing human population and the need for arable land and pressure on protected areas, highlights that the original three periods identified in chapter 2 are not sufficient for the security of protected areas in this modern era. The establishment of new protected areas in locations with arable land is becoming constantly more challenging as this land is in high demand for agriculture (both crop and stock), land reform or other commercial ventures, thus it is required to establish alternative models when establishing new protected areas in the future. The results from Chapters 2, 3, 4 and 5 show that centred on evidence-based conservation, there is the potential for a $4^{\text {th }}$ Period when considering the establishment and security of protected areas. Period 4 introduces a new approach for the establishment and security of viable and economical long-term conservation initiatives on land considered ecologically unsuitable for agriculture or any other land use as identified in Period 2, which is under less threat from other human activities. The concept of Period 4 encompasses new potential protected areas in nutrient poor savannas, and may also be relevant for protected areas established earlier (such as in Period 2). The fourth period promotes for a new management style through the manipulation of vegetation and animal populations, especially for protected areas situated in nutrient poor savannas (Period 2), resulting in these areas becoming more nutrient rich and productive for wildlife. This land is not economically sought after by humans for agriculture and development, thus through using the concept of Period 4, the land can be used to establish protected areas, which will change the possibilities of conservation expansion in nutrient poor areas throughout the world. The findings of this thesis can be applied in nutrient poor savannas worldwide, resulting in the utilisation of land that currently has no land use 


\section{Chapter 6}

value for any purpose other than being turned into successful conservation based protected areas, ensuring their protection for future generations.

Through the manipulation of grazing lawns with the application of specific nutrients, increasing the number of mammalian herbivores and adding a polymer to supplementary game lick blocks, the current stable state of low herbivore numbers with high grass biomass and low forage quality will change into a new stable state of high herbivore numbers with low grass biomass and higher forage quality (McNaughton 1984; Linnell et al. 1995; Peel and Montague 1999; Coetsee et al. 2010; Veldhuis et al. 2014; Ripple et al. 2015; Zwerts et al. 2015; Nobel 2016). This will result in a herbivore-driven state, minimizing the negative effects of fire and achieving the conservation goals and objectives of the protected area, with excellent game viewing opportunities and reducing financial burdens.

Short of having land currently afforded conservation protection status de-gazetted from prime agricultural land, which is highly improbable, the $4^{\text {th }}$ period presents an ideal solution for protected areas in an era with growing human populations and the ensuing needs for food and development. The establishment of new protected areas in locations where land is not sought after by humans and deemed to have no or minimal use for agriculture, coupled with evidence-based conservation practices and manipulations, will result in effective protected areas.

\section{Implications for management of nutrient poor savannas}

This study provides directions for protected areas and their management in nutrient poor savannas throughout the world. It provides new practices and understanding into forage quality management and the diet of free-roaming mammalian herbivores in an area which typically would have been considered marginal land of no economic or social importance to 


\section{Chapter 6}

a specific region and being nutrient poor. Figure 6.1 shows how the interaction of forage quality is paramount for the survival of free-roaming mammalian herbivores in a nutrient poor savanna, which infers important implications for management of these areas.

The implications for management derived from this study are,

1. To ensure the long-term survival of protected areas in an era with growing human populations and attendant needs for food and economic development, one needs to establish ways of making protected areas on marginal land sustainable for conservation or wildlife undertakings as described in Period 4.

2. The addition of combinations of nutrients $\mathrm{N}, \mathrm{P}$ and calcitic and dolomitic lime (Ca) to the soil in a nutrient poor savanna resulted in significant increases in the amounts of available $\mathrm{P}$ and $\mathrm{Ca}$ in the grass leaf, with no significant increase in $\mathrm{N}$.

3. The addition of $\mathrm{N}$ and $\mathrm{Ca}$ combined as fertilizer in a nutrient poor savanna, is the main nutrient attraction for various free-roaming herbivores to grazing lawns. This allows for a better understanding of the preferred nutrients these herbivores require for survival in Welgevonden Game Reserve, stimulating the establishment of grazing lawns.

4. The use of PEG allows free-roaming wild herbivores in a nutrient poor savanna to utilise a greater number of less palatable tree species with higher levels of condensed tannins.

My thesis shows that forage requirements for free-roaming herbivores in nutrient poor savannas necessitates specific monitoring to ensure the survival of free-roaming herbivores, particularly in fenced protected areas, where herbivores are unable to migrate in search of better quality forage and water availability (Boone and Hobbs 2004; Owen-Smith 2014). The 


\section{Chapter 6}

population density of large herbivores is directly associated with the quality and quantity of available forage, and in nutrient poor savannas they have generally had to adapt to low nutrient value forage, resulting in lower fecundity and survival rates (Hopcroft et al. 2010; Ogutu et al. 2014; Murry et al. 2016). Lower numbers of herbivores result in the underutilisation of forage, resulting in a negative feedback cycle with generally longer, nutrient poor grasses in a fire-driven state. Through grazing lawn establishment, with high numbers of mammalian herbivores, lawn grass areas will be maintained, resulting in areas with short, nutritionally improved grass and a herbivore-driven state. Grazing lawns similarly result in an area which allows for better predator awareness for herbivores, as predators are easier to detect over longer distances in short grass areas (Anderson et al. 2010; Hempson et al. 2014).

My thesis has raised a number of important questions which require further study to develop evidence-based conservation outcomes.

(i) In order to conclusively prove that PEG can break food limitation, particularly in the drier months, additional research is required to understand the direct effect of PEG on the fecundity and survival rates of mammalian herbivores in a nutrient poor savanna.

(ii) The short two year experiment on sodium chloride $(\mathrm{NaCl})$ as a driver of grazing lawns has shown potential success but longer-term studies are required using $\mathrm{NaCl}$ to verify these results.

(iii) When applications of separate nutrients, $\mathrm{N}$ and $\mathrm{P}$, are fertilized on identical plots, there is a knowledge gap in the understanding of why the nutrient analysis only shows an uptake of $\mathrm{P}$ into the plant leaf and not $\mathrm{N}$ ? 


\section{Chapter 6}

(iv) Showing that experimental plots (grazing lawns) in Welgevonden Game Reserve, situated in a nutrient poor savanna, have sustainably shifted from a fire-driven state with tall, generally nutrient poor grass, to a herbivore-driven state with short nutrient rich grass, unlocks opportunities for advanced research to roll this concept out on larger scale areas.

In conclusion, my study has contributed to the current understanding of wildlife conservation pertaining to forage quality and the role certain nutrients and herbivores play in a nutrient poor system. I am optimistic that the outcomes of this study will assist researchers in finding further areas of importance with knowledge gaps, which will require further research. Protected area managers from around the world, need to understand that their daily decisions have the ability to change the status of the entire ecosystem in which they work, and to accept that forage quality and nutrient addition are imperative to the survival of freeroaming herbivores, especially in nutrient poor environments, and that this requires evidence-based conservation to ensure credible decision making. 

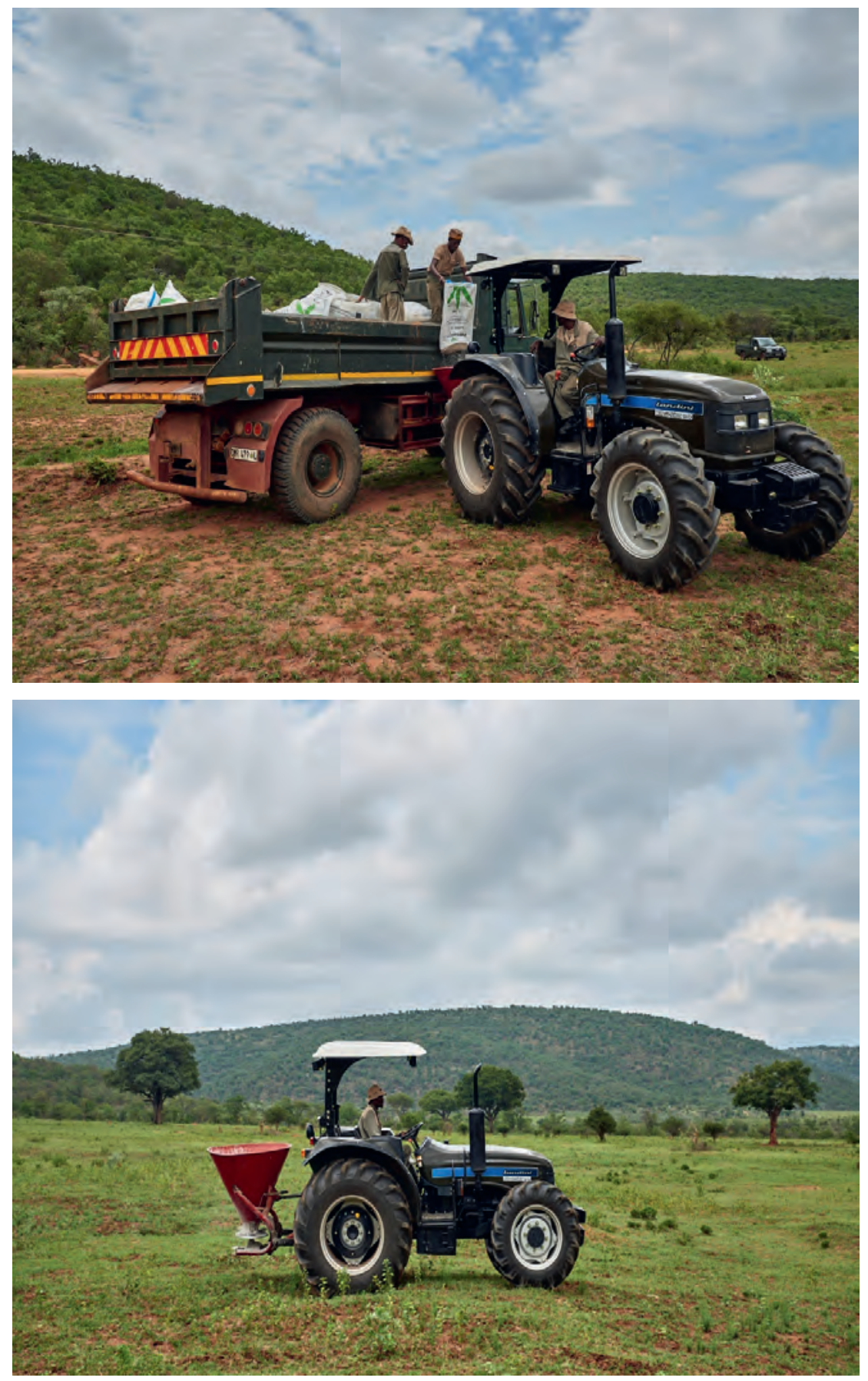

Photographs 9 \& 10: Fertilizing - Figtree Plains, Welgevonden Game Reserve (Credit: Mr. Jonathan Swart) 


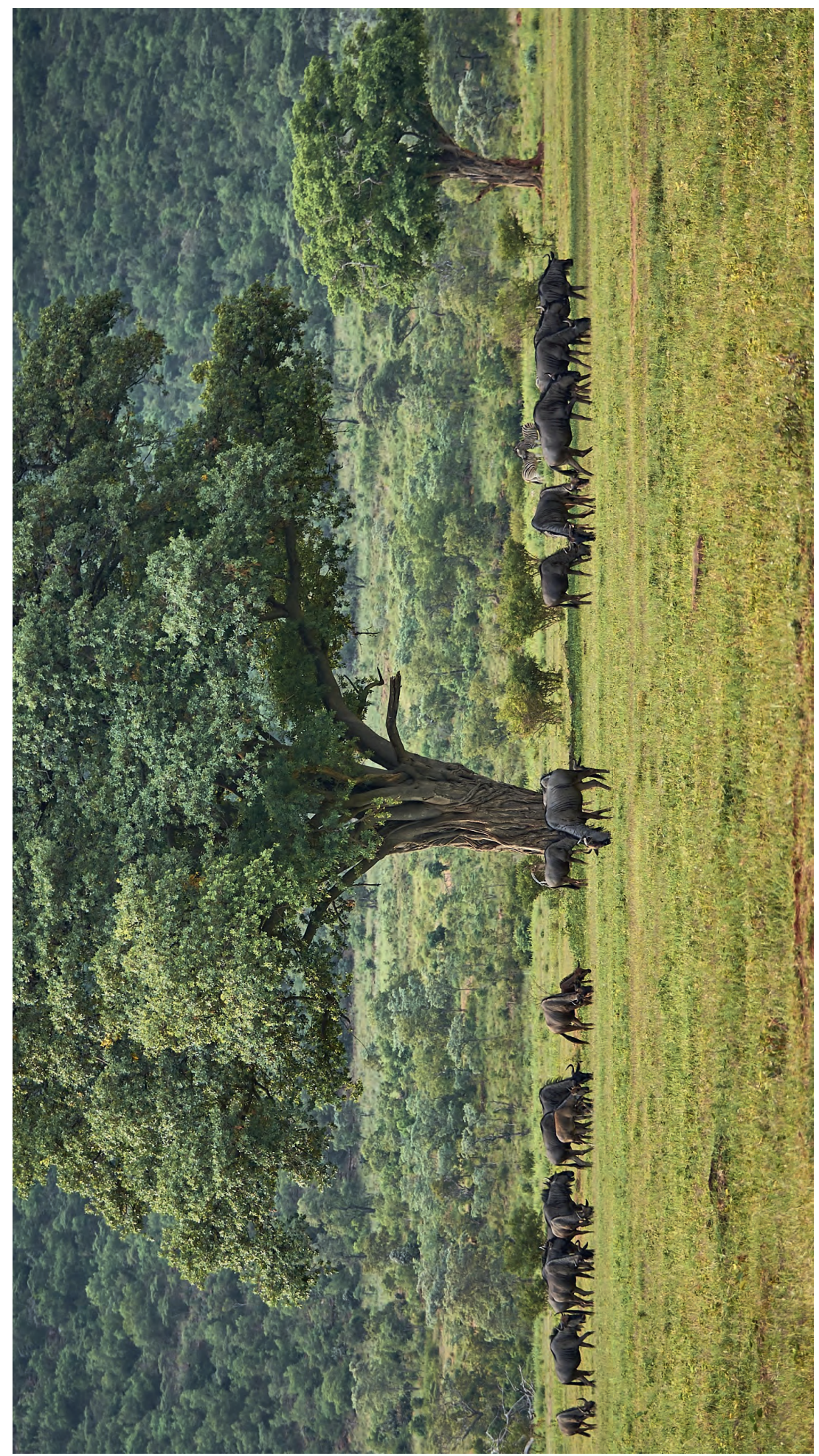

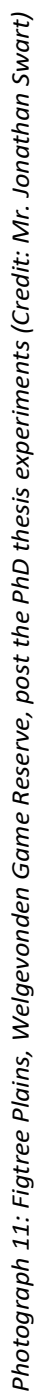




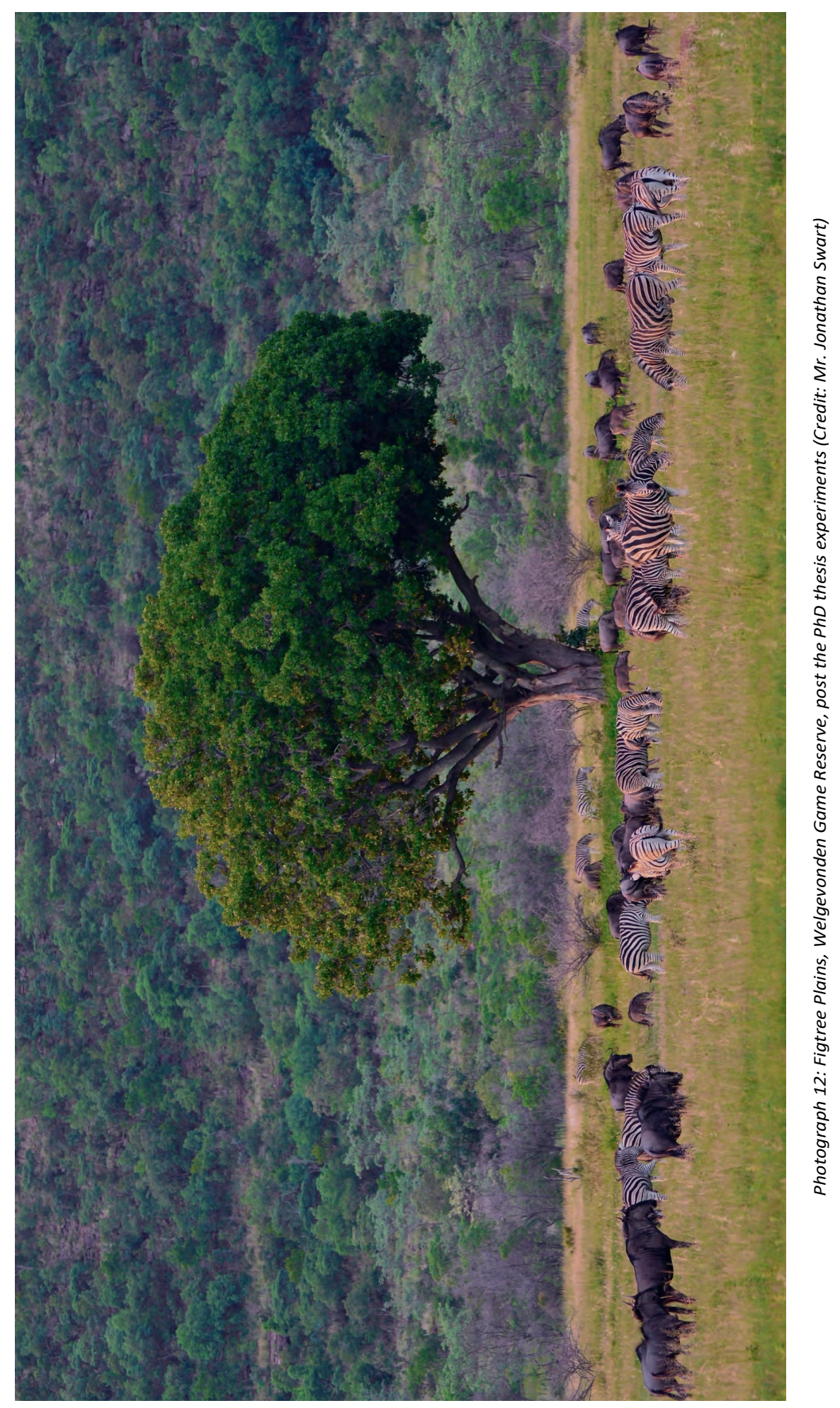




\section{References}

\section{References}

Acevedo, P., Vicente, J., Höfle, U., Cassinello, J., Ruiz-Fons, F., and Gortazar, C. 2007.

Estimation of European wild boar relative abundance and aggregation: a novel method in epidemiological risk assessment. Epidemiology and Infection 135: 519-527.

DOI:10.1017/S0950268806007059.

Adams, W. M., and Jeanrenaud, S. J. 2008. Transition to sustainability: Towards a humane and diverse world. Gland: IUCN.

https://www.iucn.org/sites/dev/files/import/downloads/transition_to_sustainability_sep_0 8_en_2.pdf.

Agouti. 2020. Project description: Camera trap data from PhD project Bradley Schroder, Welgevonden Game Reserve, South Africa. https://www.agouti.eu/\#/project/e9f82b7de19c-4344-b577-e4e526022932/overview.

AGRI Laboratory Association of Southern Africa. 2019. Determination of total Nitrogen by the BUMAS combustion Method and Wet Ashing (Digesting of ICP-OES analysis). https://www.agrilasa.co.za/.

Ahrestani, F. S., Kumar, N. S., Vaidyanathan, S., Hiby, L., Jathanna, D., and Karanth, K. U. 2017. Estimating densities of large herbivores in tropical forests: Rigorous evaluation of a dung-based method. Ecology and Evolution 8: 7312-7322. DOI:10.1002/ece3.4227.

Ajathi, H. M., and Krumme, K. 2002. Ecosystem Based Conservation Strategy for Protected Areas in Savannas. With special reference to East Africa. Thesis. Essen University, Germany. https://nbn-resolving.org/urn:nbn:de:hbz:464-20120803-162654-3. 


\section{References}

Anderson, T. M., Hopcraft, J. G. C., Eby, S., Ritchie, M., Grace, J. B., and Olff, H. 2010. Landscape-scale analyses suggest both nutrient and antipredator advantages to Serengeti herbivore hotspots. Ecology 91: 1519-1529. DOI:10.1890/09-0739.1.

Anderson, T. M., Kumordzi, B. B., Fokkema, W., Fox, H. V., and Olff, H. 2013. Distinct physiological responses underlie defoliation tolerance in African lawn and bunch grasses. International Journal of Plant Sciences 174: 769-778. DOI:10.1086/670237.

Anderson-Teixeira, K. J., Duval, B. D., Long, S. P., and DeLucia, E. H. 2012. Biofuels on the landscape: Is "land sharing" preferable to "land sparing"? Ecological Applications 22: 20352048. DOI:10.1890/12-0711.1.

Andrews, P., and O'Brien, E. M. 2000. Climate, vegetation and predictable gradients in mammal species richness in South Africa. Journal of Zoology 251: 205-231. DOl.org/10.1111/j.1469-7998.2000.tb00605.x.

Archibald, S. 2008. African grazing lawns - How fire, rainfall and grazer numbers interact to affect grass community states. Journal of Wildlife Management 72: 492-501. DOI:10.2193/2007-045.

Archibald, S. and Bond, W. J. 2004. Grazer movements: spatial and temporal responses to burning in a tall-grass African savanna. International Journal of Wildland Fire 13: 377-385. DOl.org/10.1071/WF03070.

Archibald, S., Bond, W. J., Stock, W. D., and Fairbanks, D. H. K. 2005. Shaping the landscape: Fire-Grazer interactions in an African savanna. Ecology of Applied Science 15: 96-109. DOI.org/10.1890/03-5210. 


\section{References}

Arnold, S. G. 2012. Grazing lawns across Africa: A case study comparison between Kruger National Park and Serengeti National Park. MSc Thesis. Graduate School, University of Missouri. http://hdl.handle.net/10355/33125.

Asner, G. P., Levick, S. R., Kennedy-Bowdoin, T., Knapp, D. E., Emerson, R., Jacobson, J., Colgan, M. S., and Martin, R. E. 2009. Large-scale impacts of herbivores on the structural diversity of African savannas. Proceedings of the National Academy of Sciences of the United States of America 106: 4947-4952. DOI:10.1073/pnas.0810637106.

Augustine, G. J., Santamaria, F., and Tanaka, K. 2003. Local Calcium Signalling in Neurons. Neuron 40: 331-346. Cell Press. DOl.org/10.1016/S0896-6273(03)00639-1.

Badran, A.M., and Jones, D. E. 1965. Polyethylene Glycols - Tannins Interaction in Extracting Enzymes. Nature International Journal of Science 206: 622-624. DOl.org/10.1038/206622a0.

Bardgett, R. D., and Wardle, D. A. 2003. Herbivore-mediated linkages between aboveground and belowground communities. Ecology 84: 2258-2268. DOI.org/10.1890/020274.

Barnard, R. O., Buys, A. J., Coetzee, J. G. K., Du Preez, C. C., Meyer, J. H., Van der Merwe, A. J., Van Vuuren, J. A. J., Volschenk, J. E., Bessinger, F., Lambrechts, J. J. N., and Loock, A. 1990. Handbook of standard soil testing methods for advisory purposes. Compiled by the Non-Affiliated Soil Analysis Work Committee. Published and distributed by the Soil Science Society of South Africa. DOI.org/10.1080/02571862.2004.10635066.

Barnes, R. F. W. 2001. How reliable are dung counts for estimating elephant numbers? African Journal of Ecology 39: 1-9. DOI.org/10.1111/j.1365-2028.2001.00266.x. 


\section{References}

Bartlett, M. K., Scofffoni, C., and Sack, L. 2012. The determinants of leaf turgor loss point and prediction of drought tolerance of species and biomes: a global meta-analysis. Ecology Letters 15: 393-405. DOI:10.1111/j.1461-0248.2012.01751.x.

Beard, P. H. 1988. The End of the Game. Chronicle Books, San Francisco, USA.

Biggs, H. C. 2003. The Kruger Experience: Ecology and Management of savanna heterogeneity. In J. T. Du Toit, K. H. Rogers, and H. C. Biggs, eds, An adaptive system to link science, monitoring and management in practice. Island Press, Washington. pp. 137-140.

Bond, W. J., and Archibald, S. 2003. Confronting complexity: fire policy choices in South African savanna parks. International Journal of Wildland Fire 12: 381-389.

DOI.org/10.1071/WF03024.

Boone, R. B., and Hobbs, N. T. 2004. Lines around fragments: effects of fencing on large herbivores. African Journal of Range and Forage Science 21: 147-158.

DOI.org/10.2989/10220110409485847.

Botha, M. S., and Stock, W. D. 2005. Stable isotope composition of faeces as an indicator of seasonal diet selection in wild herbivores in southern Africa. South African Journal of Science 101: 371-374.

https://www.ingentaconnect.com/content/sabinet/sajsci/2005/00000101/00000007/art00 015. 


\section{References}

Buitenland. 2019. Krimpende biodiversiteit bedreigt menselijk leven, waarschuwt.

https://nos.nl/artikel/2283456-krimpende-biodiversiteit-bedreigt-menselijk-levenwaarschuwt-onderzoek.html.

Carbone, C., Christie, S., Conforti, K., Coulson, T., Franklin, N., and Ginsberg, J. R. 2001. The use of photographic rates to estimate densities of tigers and other cryptic mammals. Animal Conservation 4: 75-79. DOI.org/10.1017/S1367943001001081.

Carruthers, E. J. 1988. Game Protection in the Transvaal 1846 to 1926. Dissertation. University of Cape Town, South Africa.

https://open.uct.ac.za/bitstream/handle/11427/23736/Carruthers_Game_protection_in_19 88_1.pdf?sequence=1\&isAllowed=y.

Carruthers, E. J. 2008. "Wilding the farm or farming the wild"? The evolution of scientific game ranching in South Africa from the 1960s to the present. Transactions of the Royal Society of South Africa 63: 160-181. DOl.org/10.1080/00359190809519220.

Carruthers, J. 1992. The Dongola Wild Life Sanctuary: 'psychological blunder, economic folly and political monstrosity' or 'more valuable than rubies and gold'? African Historical Review Kleio 24: 82-100. DOI.org/10.1080/00232089285310081.

Casaer, J., Milotic, T., Liefting, Y., Desmet, P., and Jansen, P. 2019. Agouti: A platform for processing and archiving camera trap images. Biodiversity Information Science and Standards 3. DOI.org/10.3897/biss.3.46690.

Cech, P. G., Kuster, T., Edwards, P. J., and Venterink, H. O. 2008. Effects of herbivory, fire and $\mathrm{N}_{2}$-fixation on nutrient limitation in a humid African savanna. Ecosystems 11: 991-1004. DOI:10.1007/s10021-008-9175-7. 


\section{References}

Child, B. A., Musengezi, J., Parent, G. D., and Child, G. F. T. 2012. The economics and institutional economics of wildlife on private land in Africa. Pastoralism: Research, Policy and Practice 2: 18. DOI.org/10.1186/2041-7136-2-18.

Child, G., and Riney, T. 1987. Tsetse control hunting in Zimbabwe, 1919-1958. Zambezia XIV: 11-71. PLOS ONE.

https://citeseerx.ist.psu.edu/viewdoc/download?doi=10.1.1.1053.7551\&rep=rep1\&type=pd f.

Chimdi, A., Gebrekidan, H., Kibret, K., and Tadesse, A. 2012. Effects of liming on acidityrelated chemical properties of soils of different land use systems in Western Oromia, Ethiopia. World Journal of Agricultural Sciences 6: 560-567. DOI:10.5829/idosi.wjas.2012.8.6.1686.

Cingolani, A. M., Posse, G., and Collantes, M. B. 2005. Plant functional traits, herbivore selectivity and response to sheep grazing in Patagonian steppe grasslands. Journal of Applied Ecology 42: 50-59. DOI.org/10.1111/j.1365-2664.2004.00978.x.

Cioc, M. 2009. The game of conservation. International treaties to protect the world's migratory animals. Ohio University Press Books. USA.

Codron, D., Codron, J., Sponheimer, M., and Clauss, M. 2016. Within-Population Isotopic Niche variability in savanna mammals: Disparity between carnivores and herbivores. Frontiers in Ecology and Evolution 4: 15. DOI:10.3389/fevo.2016.00015. 


\section{References}

Codron, D., Codron, J., Lee-Thorp, J. A., Sponheimer, M., and De Ruiter, D. 2005. Animal diets in the Waterberg based on stable isotopic composition of faeces. African Journal of Wildlife Research 35: 43-52.

https://www.ingentaconnect.com/content/sabinet/wild/2005/00000035/00000001/art000 06.

Codron, D., Lee-Thorp, J. A., Sponheimer, M., and Codron, J. 2007. Nutritional content of savanna plant foods: implications for browser/grazer models of ungulate diversification. European Journal of Wildlife Research 53: 100-111. DOI:10.1007/s10344-006-0071-1.

Coetsee, C., Stock, W. D., and Craine, J. M. 2010. Do grazers alter nitrogen dynamics on grazing lawns in South African savannah? African Journal of Ecology 49: 62-69. DOI.org/10.1111/j.1365-2028.2010.01236.x.

Cooper, S. M., and Owen-Smith, N. 1985. Condensed tannins deter feeding by browsing ruminants in a South African savanna. Oecologia Journal 67: 142-146.

DOI.org/10.1007/BF00378466.

Cousins, J. A., Sadler, J. P., and Evans, J. 2008. Exploring the Role of Private Wildlife Ranching as a Conservation Tool in South Africa: Stakeholder Perspectives. Ecology and Society 13: 43. https://www.jstor.org/stable/26267980.

Craine, J. M., Morrow, C., and Stock, W. D. 2008. Nutrient concentration ratios and colimitation in South African grasslands. New Phytologist 179: 829-836. DOI:10.1111/j.14698137.2008.02513.x. 


\section{References}

Cromsigt, J. P. G. M., and Kuijper, D. P. J. 2011. Revisiting the browsing lawn concept: Evolutionary interactions or pruning herbivores? Perspectives in Plant Ecology, Evolution and Systematics 13: 207-215. DOI:10.1016/j.ppees.2011.04.004.

Cromsigt, J. P. G. M., and Olff, H. 2006. Resource partitioning among savanna grazers mediated by local heterogeneity: An experimental approach. Ecology 87: 1532-1541. DOI.org/10.1890/0012-9658(2006)87[1532:RPASGM]2.0.CO;2.

Cromsigt, J. P. G. M., and Olff, H. 2008. Dynamics of grazing lawn formation: an experimental test of the role of scale-dependent processes. Oikos 117: 1444-1452. DOI:10.1111/j.2008.0030-1299.16651.x.

Culhane, D. 1998. The pleasure of the crown: Anthropology, law, and First Nations, 120. Talonbooks. Burnaby, Canada.

Dahlberg, A., Rohde, R., and Sandell, K. 2010. National Parks and Environmental Justice: Comparing Access Rights and Ideological Legacies in Three Countries. Conservation and Society 8: 209-224. https://www.jstor.org/stable/26393012.

De Jong, C. B., Gill, R. M. A., Van Wieren, S. E., and Burlton, F. W. E. 1995. Diet selection in Kielder Forest by roe deer Capreolus in relation to plant cover. Forest Ecology Management 79: 91-97. DOI.org/10.1016/0378-1127(95)03622-9.

De Knegt, H., Groen, T. A., Van de Vijver, C. A. D. M., Prins, H. H. T., and Van Langevelde, F. 2008. Herbivores as architects of savannas: inducing and modifying spatial vegetation patterning. Oikos 117: 543-554. DOI:10.1111/j.2008.0030-1299.16403.x. 


\section{References}

De Michele, C., Accatino, F., Vezzoli, R., and Scholes, R. J. 2012. Savanna domain in the herbivores-fire parameter space exploiting a tree-grass-soil water dynamic model. Journal of Theoretical Biology 289: 74-82. DOI:10.1016/j.jtbi.2011.08.014.

Decandia, M., Sitzia, M., Cabiddu, A., Kababya, D., and Molle, G. 2000. The use of polyethylene glycol to reduce the anti-nutritional effects of tannins in goats fed woody species. Small Ruminant Research 38: 157-164. DOI.org/10.1016/S0921-4488(00)00145-0.

Demment, M. W., and Van Soest, P. J. 1985. A nutritional explanation for body size patterns of ruminant and non-ruminant herbivores. American Naturalist 125: 641-672. DOI.org/10.1086/284369.

Department of Environmental Affairs and Tourism. 1997. White Paper on the Conservation and Sustainable Use of South Africa's Biological Diversity. Government Gazette, 28 July 1997. No. 18163.

https://www.environment.gov.za/sites/default/files/legislations/biodiversity_whitepaper_1 8163_gen1095.pdf.

Di Minin, E., Fraser, I., Slotow, R., and MacMillan, D. C. 2013. Understanding heterogeneous preference of tourists for big game species: implications for conservation and management. Animal Conservation 16: 249-258. DOI: 10.1111/cobi.12412.

Donaldson, C. H., Rootman, G., and Grossman, D. 1984. Long term nitrogen and phosphorous application to veld. Journal of the Grassland Society of Southern Africa 1: 2732. DOI.org/10.1080/02566702.1984.9647972. 


\section{References}

Donaldson, J. E., Archibald, S., Govender, N., Pollard, D., Luhdo, Z., and Parr, C. L. 2017. Ecological engineering through fire-herbivory feedbacks drives the formation of savanna grazing lawns. Journal of Applied Ecology 55: 225-235. DOI:10.1111/1365-2664.12956.

Dörgeloh, W. G., Van Hoven, W., and Rethman, N. F. G. 1998. Faecal analysis as an indicator of the nutritional status of the diet of roan antelope in South Africa. South African Journal of Wildlife Research 28: 16-23.

https://www.ingentaconnect.com/content/sabinet/wild/1998/00000028/00000001/art000 05.

Dorji, T., Totland, O., and Moe, S. R. 2013. Are droppings, distance from pastoralist camps and pika burrows good proxies for local grazing pressure? Rangeland Ecology and Management 66: 26-33. DOI: 10.2111/REM-D-12-00014.1.

Drescher, M. 2003. Grasping complex matter: large herbivore foraging in patches of heterogeneous resources. Thesis PhD. Wageningen University the Netherlands. https://library.wur.nl/WebQuery/wurpubs/fulltext/41896.

Drescher, M., Heitkönig, I. M. A., Raats, J. G., and Prins, H. H. T. 2006. The role of grass stems as structural foraging deterrents and their effects on the foraging behaviour of cattle. Applied Animal Behaviour Science 101: 10-26. DOI.org/10.1016/j.applanim.2006.01.011. Drescher, M., Heitkönig, I. M. A., Van den Brink, P. J., and Prins, H. H. T. 2006. Effects of sward structure on herbivore foraging behaviour in a South African savanna: An investigation of the forage maturation hypothesis. Austral Ecology 31: 76-87. DOI:10.1111/j.1442-9993.2006.01552.x. 


\section{References}

Duffy, R. 2014. Waging a war to save biodiversity: the rise of militarized conservation. International Affairs 90: 819-834. DOI.org/10.1111/1468-2346.12142.

Elton, F. 1873. Journal of an Exploration of the Limpopo River. The Journal of the Royal Geographical Society 42: 1-49. DOI.org/10.2307/1798590.

Emmott, S. 2013. Ten Billion. Penguin Books. London.

Enghoff, M. 1990. Wildlife Conservation, Ecological Strategies and Pastoral Communities. A contribution to the understanding of Parks and People in East Africa. Journal Nomadic Peoples 25-27: 93-107. https://www.jstor.org/stable/43123310.

Ezenwa, V. O. 2004. Selective defection and selective foraging: Antiparasite behaviour in wild ungulates? Ethology 110: 851-862. DOI.org/10.1111/j.1439-0310.2004.01013.x.

Ferwerda, J. G., Siderius, W., Van Wieren, S. E., Grant, C. C., Peel, M., Skidmore, A. K., and Prins, H. H. T. 2006. Parent material and fire as principle drivers of foliage quality in woody plants. Forest Ecology and Management 231: 178-183.

DOI.org/10.1016/j.foreco.2006.05.044.

Foley, W. J., and Hume, I. D. 1987. Digestion and Metabolism of High-Tannin Eucalyptus Foliage by the Brushtail Possum (Trichosurus vulpecula) (Marsupialia, Phalangeridae). Journal of Comparative Physiology B-Biochemical Systemic and Environmental Physiology 157: 67-76. DOI.org/10.1007/BF00702730.

Fryxell, J. M., Sinclair, R. E., and Caughley, G. 2001. Wildlife Ecology, Conservation, and Management. Third edition. Wiley Blackwell. Chichester: John Wiley and Sons. 


\section{References}

Fynn, R. W. S., and O'Connor, T. G. 2005. Determinants of community organization of a South African mesic grassland. Journal of Vegetation Science 16: 93-102.

DOI.org/10.1111/j.1654-1103.2005.tb02342.x.

Gaillard, J. M., Festa-Bianchet, M., Yoccoz, N. G., Loison, A., and Toigo, C. 2000. Temporal variation in fitness components and population dynamics of large herbivores. Annual Review of Ecology and Systematics 31: 367-393. DOI.org/10.1146/annurev.ecolsys.31.1.367.

Gibson, C. C., and Marks, S. A. 1995. Transforming rural hunters into conservationists: An assessment of community-based wildlife management programs in Africa. World Development 23: 941-957. DOI.org/10.1016/0305-750X(95)00025-8.

Giles-Vernick, T. 2011. Oral histories: Oral histories as methods and sources. In: E. Perecman \& S. R. Curran (eds.). A handbook for social science field research: Essays and bibliographic sources on research design and methods (pp. 85-95). SAGE Publications, London.

Grant, C. C., and Scholes, M. C. 2006. The importance of nutrient hot-spots in the conservation and management of large wild mammalian herbivores in semi-arid savannas. Biological Conservation 130: 426-437. DOI:10.1016/j.biocon.2006.01.004.

Grant, C. C., Peel, M. J. S., Zambatis, N., and Van Ryssen, J. B. J. 2000. Nitrogen and phosphorus concentration in faeces: An indicator of range quality as a practical adjunct to existing range evaluation methods. African Journal of Range and Forage Science 17: 81-92. DOI.org/10.2989/10220110009485743. 


\section{References}

Grant, R .C. C., Peel, M. J. S., and Bezuidenhout, H. 2011. Evaluating herbivore management outcomes and associated vegetation impacts. Koedoe 53: 1-15. DOI:10.4102/koedoe.

v53i2.1008.

Griffith, D. M., Anderson, T. M., and Hamilton III, E. W. 2017. Ungulate grazing drives higher ramet turnover in sodium-adapted Serengeti grasses. Journal of Vegetation Science 28: 815823. DOI:10.1111/jvs.12526.

Grobler, H. 1996. Dissecting the Kruger myth with blunt instruments: a rebuttal of Jane Carruthers's view. Southern African Studies 22: 355-472.

DOI.org/10.1080/03057079608708505.

Groen, T. A., Van de Vijver, C. A. D. M., and Van Langevelde, F. 2017. Do spatially homogenising and heterogenising processes affect transitions between alternative stable states? Ecological Modelling 365: 119-128. DOI.org/10.1016/j.ecolmodel.2017.10.002.

Groen, T. A., Van Langevelde, F., Van de Vijver, C. A. D. M., Govender, N., and Prins, H. H. T. 2008. Soil clay content and fire frequency affecting clustering in trees in South African savannas. Tropical Ecology 24: 269-279. https://www.jstor.org/stable/25172924.

Hasegawa, P. M., Bressan, R. A., Zhu, J-K., and Bohnert, H. J. 2000. Plant cellular and molecular responses to high salinity. Annual review. Plant Physiology and Plant Molecular Biology 51: 463-499.

https://www.annualreviews.org/doi/abs/10.1146/annurev.arplant.51.1.463?journalCode=a rplant.2. 


\section{References}

Hattas, D. 2014. Carbon based secondary metabolites in African savanna woody species in relation to anti-herbivore defence. Dissertation. University of Cape Town, South Africa. DOI:10.1016/j.phytol.2012.02.013.

Heijnsbergen, V. P. 1997. International legal protection of wild fauna and flora. Landsdale IOS Press. Amsterdam, the Netherlands.

Heitkönig, I. M. A., and Owen-Smith, N. 1998. Seasonal selection of soil types and grass swards by roan antelope in a South African savanna. African Journal of Ecology 36: 57-70. DOI.org/10.1046/j.1365-2028.1998.114-89114.x.

Hema, E. M., Di Vittorio, M., Barnes, R. F. W., Guenda, W., and Luiselli, L. 2017. Detection of interannual population trends in seven herbivores from West African savannah: a comparison between dung counts and direct counts of individuals. African Journal of Ecology 55: 609-617. DOI.org/10.1111/aje.12397.

Hempson, G. P., Archibald, S., Bond, W. J., Ellis, R. P., Grant, C. C., Kruger, F. J., Kruger, L. M., Moxley, C., Owen-Smith, N., Peel, M. J. S., Smit, I. P. J., and Vickers, K. J. 2014. Ecology of grazing lawns in Africa. Biological Reviews 90: 979-994. DOI:10.1111/brv.12145.

Hempson, G. P., Archibald, S., Donaldson, J. E., and Lehmann, C. E. R. 2019. Alternate grassy ecosystem states are determined by palatable-flammability trade-offs. Trends in Ecology and Evolution 34: 286-290. DOI:10.1016/j.tree.2019.01.003.

Higgins, S., Morrison, S., and Watson, C. J. 2012. Effect of annual applications of pelletized dolomitic lime on soil chemical properties and grass productivity. Soil Use and Management 28: 62-69. DOI:10.1111/j.1475-2743.2011.00380.x. 


\section{References}

Hilbers, J. P., Van Langevelde, F., Prins, H. H. T., Grant, C. C., Peel, M., Coughenour, M. B., De Knegt, H. J., Slotow, R., Smit, I., Kiker, G. A., and De Boer, W. F. 2015. Modeling elephantmediated cascading effects of water point closure. Ecological Applications 25: 402-415. DOI.org/10.1890/14-0322.1.

Hitchcock, R. K. 2001. Hunting is our Heritage: The struggle for hunting and gathering rights among the San of Southern Africa. Senri Ethnological Studies 59: 139-156.

DOI.org/10.15021/00002791.

Hitchcock, R. K. 2019. The Impacts of Conservation and Militarization on Indigenous Peoples. A Southern African San Perspective. Human Nature 30: 217-241. DOI.org/10.1007/s12110-019-09339-3.

Hobbs, N. T. 1996. Modification of ecosystems by ungulates. Journal of Wildlife Management 60: 695-713. DOI.org/10.2307/3802368.

Holdo, R. M., Holt, R. D., and Fryxell, J. M. 2009. Grazers, browsers, and fire influence the extent and spatial pattern of tree cover in the Serengeti. Ecological Applications 19: 95-109. DOI.org/10.1890/07-1954.1.

Holdo, R. M., Holt, R. D., Coughenour, M. B., and Ritchie, M. E. 2007. Plant productivity and soil nitrogen as a function of grazing, migration and fire in an African savanna. Journal of Ecology 95: 115-128. DOI:10.1111/j.1365-2745.2006.01192.x.

Hopcraft, J. G. C., Anderson, T. M., Pérez-Vila, S., Mayemba, E., and Olff, H. 2012. Body size and the division of niche space: food and predation differentially shape the distribution of Serengeti grazers. Journal of Animal Ecology 81: 201-213. DOI:10.1111/j.13652656.2011.01885.x. 


\section{References}

Hopcroft, J. G. C., Olff, H., and Sinclair, A. R. E. 2010. Herbivores, resources and risks: alternating regulation along primary environmental gradients in savannas. Trends in Ecology and Evolution 25: 119-128. DOI:10.1016/j.tree.2009.08.001.

House, J. I., Archer, S., Breshears, D. D., Scholes, R., and Participants, N. T. G. I. 2003. Conundrums in mixed woody-herbaceous plant systems. Journal of Biogeography 30: 17631777. DOI.org/10.1046/j.1365-2699.2003.00873.x.

Huang, Z. Y. X., Van Langevelde, F., Estrada-Pena, A., Suzan, G., and De Boer, W. F. 2016. The diversity-disease relationship: evidence for and criticism of the dilution effect. Parasitology 143: 1075-1086. Cambridge University Press. DOI:10.1016/S0031182016000536.

Huntley, B. J., and Walker, B. H. 2012. Ecology of tropical savannas. Springer Science and Business Media: Munich, Germany.

IBM Corp. Released 2015. IBM SPSS Statistics for Windows, Version 23.0. IBM Corp., Armonk, New York, USA.

IPBES. 2019. Global assessment report on biodiversity and ecosystem services of the Intergovernmental Science-Policy Platform on Biodiversity and Ecosystem Services. Chapter 2.1: 108-120. E. S. Brondizio, J. Settele, S. Díaz, and H. T. Ngo (editors). IPBES secretariat, Bonn.

Jacobs, S. M., Bechtold, J. S., Biggs, H. C., Grimm, N. G., Lorentz, S., McClain, M. E., Naiman, R. J., Perakis, S. S., Pinay, G., and Scholes, M. C. 2007. Nutrient vectors and riparian processing: a review with special reference to African semiarid savanna ecosystems. Ecosystems 10: 1231-1249. DOI:10.1007/s10021-007-9092-1. 


\section{References}

James, A. N., Green, M. J. B., and Paine, J. R. 1999. A Global Review of Protected Area Budgets and Staffing. World Conservation Monitoring Centre. World Conservation Press. Cambridge, U.K. https://www.cbd.int/financial/expenditure/g-spendingglobal-wcmc.pdf. Jansen, A. W. A. M., Van Langevelde, F., De Boer, W. F., and Kirkman, K. P. 2007. Optimisation or satiation, testing diet selection rules in goats. Small Ruminant Research 73: 160-168. DOI.org/10.1016/j.smallrumres.2007.01.012.

Jansen, P. A., Forrester, T. D., and McShea, W. J. 2014. Protocol for camera-trap surveys of mammals at CTFS-ForestGEO sites. Smithsonian Tropical Research Institute Center for Tropical Forest Science. Version 1.0: April 2014.

Kambatuku, J., Cramer, M., and Ward, D. 2013. Nitrogen fertilisation reduces grass-induced $\mathrm{N}_{2}$ fixation of tree seedlings from semi-arid savannas. Plant and Soil 365: 307-320. DOI:10.1007/s11104-012-1389-y.

Kepe, T., Wynberg, R., and Ellis, W. 2005. Land reform and biodiversity conservation in South Africa: complementary or in conflict? International Journal of Biodiversity Science and Management 1: 3-16. DOI.org/10.1080/17451590509618075.

Kesteloot, L. 1992. Myth, Epic, and African History. In V. Y. Mudimbe (ed.), The Surreptitious speech: Présence africaine and the politics of otherness, 1947-1987 (pp. 136). University of Chicago Press, USA.

Kirby, C., and Kirby, E. 1931. The Stuart game prerogative. The English Historical Review 46: 239-254. https://www.jstor.org/stable/552949. 


\section{References}

Kleynhans, E. J., Jolles, A. E., Bos, M. R. E., and Olff, H. 2011. Resource partitioning along multiple niche dimensions in differently sized African savanna grazers. Oikos 120: 591-600. DOI:10.1111/j.1600-0706.2010.18712.x.

Klop, E., and Prins, H. H. T. 2008. Diversity and species composition of West African ungulate assemblages: effects of fire, climate and soil. Global Ecology and Biogeography 17: 778-787. DOI.org/10.1111/j.1466-8238.2008.00416.x.

Kohn, M. H., York, E. C., Kamradt, D. A., Haught, G., Sauvajot, R. M., and Wayne, R. K. 1999. Estimating population size by genotyping faeces. The Royal Society 266: 657-663. DOl.org/10.1098/rspb.1999.0686.

Landau, S., Xue, B., Dvash, L., Friedman, S., and Mabjeesh, S. J. 2003. Polyethylene glycol, used to alleviate the negative effects of dietary tannins, can also serve as a marker of fecal output in goats. Small Ruminant Research 48: 37-43. DOI:10.1016/S0921-4488(02)00293-6. Langman, V. A. 1978. Giraffe Pica Behaviour and Pathology as Indicators of Nutritional Stress. The Journal of Wildlife Management 42: 141-147. DOI.org/10.2307/3800701.

Lindsey, P. A., Alexander, R., Mills, M. G. L., Romañach, S., and Woodroffe, R. 2007. Wildlife Viewing Preferences of Visitors to Protected Areas in South Africa: Implications for the Role of Ecotourism in Conservation. Journal of Ecotourism 6: 19-33. DOI.org/10.2167/joe133.0.

Linnell, J. D. C., Aanes, R., and Andersen, R. 1995. Who killed Bambi? The role of predation in the neonatal mortality of temperate ungulates. Wildlife Biology 1: 209-223. DOI.org/10.2981/wlb.1995.0026.

London Gazette. 1889. Charter of the British South African Company. www.rhodesia.me.uk/charter. 


\section{References}

Ludwig, F., De Kroon, H., Berendse, F., and Prins, H. H. T. 2008. The influence of savanna trees on nutrient, water and light availability and the understorey vegetation. Plant Ecology 170: 93-105. DOI:10.1023/B:VEGE.0000019023.29636.92.

Majuva-Masafu, M. M., and Linington, M. J. 2006. The effect of Browse Plus on nutrient intake, rumen $\mathrm{pH}$ and digestibility of a sole diet of Leucaena leucocephala forage. African Journal of Range and Forage Science 23: 171-175. DOI:10.2989/10220110609485901.

Makkar, H. P. S., Blummel, M., and Becker, K. 1995. Formation of complexes between polyvinyl pyrrolidones or polyethylene glycols and tannins, and their implication in gas production and true digestibility in in vitro techniques. British Journal of Nutrition 73: 897913. DOI:.org/10.1079/BJN19950095.

Makkar, H. P. S., Sanchez, M., and Speedy, A. W. 2007. Feed Supplementation Blocks. Ureamolasses multinutrient blocks: simple and effective feed supplement technology for ruminant agriculture. Food and Agriculture Organization of the United Nations. http://www.fao.org/3/a0242e/a0242e.pdf.

Marsh, K. J., Wallis, I. R., and Foley, W. J. 2003. The effect of inactivating tannins on the intake of Eucalyptus foliage by a specialist Eucalyptus folivore (Pseudocheirus peregrinus) and a generalist herbivore (Trichosurus vulpecula). Australian Journal of Zoology 51: 31-42. DOI.org/10.1071/ZO02055

Marston, A. 1996. Aquaculture and the Public Trust Doctrine: Accommodating competing uses of coastal waters in New England. Vermont Law Review 21: 335-374.

https://heinonline.org/HOL/LandingPage?handle=hein.journals/vlr21\&div=17\&id=\&page=. 


\section{References}

Martin, B. 2017. The nitrogen cycle. Britannica Educational Publishing (a trademark of Encyclopaedia Britannica, Inc) in association with the Rosen Publishing Group, Inc. New York.

Masocha, M., Skidmore, A. K., Poshiwa, X., and Prins, H. H. T. 2011. Frequent burning promotes invasions of alien plants into a mesic African savanna. Biological Invasions 13 : 1641-1648. DOI.org/10.1007/s10530-010-9921-6.

Mattson, W. J. 1980. Herbivory in relation to plant nitrogen content. - Annual Review of Ecology and Systematics 11: 119-161. DOI.org/10.1146/annurev.es.11.110180.001003. Mayengo, G., Piel, A. K., and Treydte, A. C. 2020. The importance of nutrient hotspots for grazing ungulates in a Miombo ecosystem, Tanzania. PLoS ONE 15: 1-15. e0230192. DOI.org/10.1371/journal.pone.0230192.

Mayes, R. W., and Dove, H. 2000. Measurement of dietary nutrient intake in free-ranging mammalian herbivores. Nutrition Research Reviews 13: 107-138.

DOl.org/10.1079/095442200108729025.

Mbaiwa, J. E., and Mbaiwa, O. I. 2006. The effects of veterinary fences on wildlife populations in Okavango Delta, Botswana. International Journal of Wilderness 12: 17-41. http://hdl.handle.net/10311/28.

Mbatha, K. R., and Ward, D. 2010. The effects of grazing, fire, nitrogen and water availability on nutritional quality of grass in semi-arid savanna, South Africa. Journal of Arid Environments 74: 1294-1301. DOI:10.1016/j.jaridenv.2010.06.004.

McDowell, L. R., and Arthington, J. D. 2005. Minerals for Grazing Ruminants in Tropical Regions. Mosaic Feed Ingredients $4^{\text {th }}$ edition. University of Florida. 


\section{References}

Mclvor, J. G., McIntyre, S., Saeli, I., and Hodgkinson, J. J. 2005. Patch dynamics in grazed subtropical native pastures in south-east Queensland. Austral Ecology 30: 445-464. DOI.org/10.1111/j.1442-9993.2005.01488.x.

McLeod, M. N. 1974. Plant tannins - their role in forage quality. Nutrition Abstract Review 44: 803-815. http://hdl.handle.net/102.100.100/309310?index=1.

McNaughton, S. J. 1984. Grazing lawns: Animals in herds, plant form, and coevolution. The American Naturalist 124: 863-886. DOI.org/10.1086/284321.

Mkhize, N. R., Heitkönig, I. M. A., Scogings, P. F., Dziba, L. E., Prins, H. H. T., and De Boer, W. F. 2015. Condensed tannins reduce browsing and increase grazing time of free-ranging goats in semi-arid savannas. Journal of Applied Animal Behaviour Science 169: 33-37. DOI.org/10.1016/j.applanim.2015.04.012.

Mkhize, N. R., Heitkönig, I. M. A., Scogings, P.F., Hattas, D., Dziba, L. E., Prins, H. H. T., and De Boer, W. F. 2016. Supplemental nutrients increase the consumption of chemically defended shrubs by free-ranging herbivores. Agriculture, Ecosystems and Environments 235: 119-126. DOI.org/10.1016/j.agee.2016.10.014.

Mkhize, N. R., Heitkönig, I. M. A., Scogings, P. F., Dziba, L. E., Prins, H. H. T., and De Boer, W. F. 2018. Effects of condensed tannins on live weight, faecal nitrogen and blood metabolites of free-ranging female goats in a semi-arid African savanna. Small Ruminant Research 166: 28-34. DOI.org/10.1016/j.smallrumres.2018.07.010.

Morgan, H. R., Ballard, G., Fleming, P. J. S., Reid, N., Van der Ven, R., and Vernes, K. 2019. Estimating macropod grazing density and defining activity patterns using camera-trap image analysis. Wildlife Research 45: 706-717. DOI.org/10.1071/WR17162. 


\section{References}

Moujahed, N., Kayouli, C., Thewis, A., Beckers, Y., and Rezgui, S. 2000. Effects of multinutrient blocks and polyethylene glycol 4000 supplies on intake and digestion by sheep fed Acacia cyanophylla Lindl. Foliage-based diets. Animal Feed Science and Technology 88: 219-238. DOI.org/10.1016/S0377-8401(00)00211-X.

Mramba, R. P., Andreassen, H. P., Mlingi, V., and Skarpe, C. 2018. Activity patterns of African elephants in nutrient-rich and nutrient-poor savannas. Mammalian Biology 94: 1824. DOI:10.1016/j.mambio.2018.12.001.

Mucina, L., and Rutherford, M. C. 2006. The vegetation of South Africa, Lesotho and Swaziland. Strelitzia 19: 472-473.

Muir-Leresche, K., and Nelson, R. H. 2000. Private Property Rights to Wildlife: The Southern African Experiment. Competitive Enterprise Institute: 1-31.

http://citeseerx.ist.psu.edu/viewdoc/download?doi=10.1.1.1070.1252\&rep=rep1\&type=pdf

Munns, R. 2002. Comparative physiology of salt and water stress. Plant, Cell and Environment 25: 239-250. DOI.org/10.1046/j.0016-8025.2001.00808.x.

Murombedzi, J. C. 2003. Pre-colonial and colonial conservation practices in Southern Africa and their legacy today. Unpublished IUCN manuscript. http://www.iccaconsortium.org.

Murry, M. G. 1995. Specific nutrient requirements and migration of wildebeest. In 'Serengeti' II: Dynamics, management and conservation of an ecosystem'. The University of Chicago Press: 231-256.

Murry, M. H., Becker, D. J., Hall, R. J., and Hernandez, S. M. 2016. Wildlife health and supplemental feeding: A review and management recommendations. Biological Conservation 204: 163-174. DOI.org/10.1016/j.biocon.2016.10.034. 


\section{References}

Mutwira, R. 1989. Southern Rhodesian Wildlife Policy (1890-1953): A Question of Condoning Game Slaughter? Journal of Southern African Studies 15: 250-262. DOI.org/10.1080/03057078908708199.

Nash, D. J., and Endfield, G. H. 2002. A $19^{\text {th }}$ Centuary climate chronology for the Kalahari region of central southern Africa derived from missionary correspondence. International Journal of Climatology 22: 821-841. DOI.org/10.1002/joc.753.

Neumann, R. P. 2002. The Post-war Conservation Boom in British Colonial Africa. Environmental History 7: 22-47. DOI.org/10.2307/3985451.

Nobel, N. D. 2016. A modelling study on the effects of annual rainfall and herbivore body size on top-down and bottom-up control. MSc. Resource Ecology Group, Wageningen University, The Netherlands.

Novellie, P., and Gaylard, A. 2013. Long-term sustainability of grazing lawns in a small protected area, the Mountain Zebra National Park. Koedoe 55: 1-7. DOI.org/10.4102/ koedoe.v55i1.1108.

NviroTek Laboratories. 2018. Nviro Business Hub, unit 6. Ou Wapad Street, Ifafi, Hartebeesport, 0260. www.nviroteklabs.co.za.

O'Connor, T. G. 1994. Composition and population responses of an African savanna grassland to rainfall and grazing. Journal of Applied Ecology 31: 155-171. DOl.org/10.2307/2404608.

Ogutu, J. O., Piepho, H. P., and Dublin, H. T. 2014. Reproductive seasonality in African ungulates in relation to rainfall. Wildlife Research 41: 323-342. DOI.org/10.1071/WR13211. 


\section{References}

Olff, H., Ritchie, M. E., and Prins, H. H. T. 2002. Global environmental controls of diversity in large herbivores. Nature 415: 901-904. DOI:10.1038/415901a.

Osborne, C. P., Charles-Dominique, T., Stevens, N., Bond, W. J., Midgley, G., and Lehmann, C. E. R. 2018. Human impacts in African savannas are mediated by plant functional traits. New Phytologist 220: 10-24. DOl.org/10.1111/nph.15236.

Ottichilo, W. K., De Leeuw, J., and Prins, H. H. T. 2001. Population trends of resident wildebeest (Connochaetes taurinus hecki) and factors influencing them in the Masai Mara ecosystem, Kenya. Biological Conservation 97: 271-282. DOI.org/10.1016/S00063207(00)00090-2.

Ottichilo, W. K., De Leeuw, J., Skidmore, A. K., Prins, H. H. T., and Said, M. Y. 2000. Population trends of large non-migratory wild herbivores and livestock in the Masai Mara ecosystem, Kenya, between 1977 and 1997. East African Wildlife Society, African Journal of Ecology 38: 202-216. DOI.org/10.1046/j.1365-2028.2000.00242.x.

Owen-Smith, N. 1988. Megaherbivores: The influence of very large body size on ecology. Cambridge University Press, United Kingdom.

Owen-Smith, N. 2007. Introduction to Modelling in Wildlife and Resource Conservation. Blackwell Publishing. Oxford. DOI:10.1017/\$0376892909005360.

Owen-Smith, N. 2014. Spatial ecology of large herbivore populations. Ecography 37: 416430. DOI:10.1111/j.1600-0587.2013.00613.x.

Oxford Dictionary. 2017, January 5. www.en.oxforddictionaries.com/definition/res_nullius. 


\section{References}

Pangeti, G., and Manyanga, M. Unpublished. The Antiquity of Hunting in Southern Africa:

The Past to the Present.

https://www.academia.edu/2284761/The_Antiquity_of_Hunting_in_southern_Africa_The_ Past_to_the_Present.www.5.msu.ac.zw.

Parker, A. H. 2004. The vegetation ecology of Welgevonden Private Game Reserve in the Waterberg region of South Africa. Dissertation for the degree Master of Science. The University of Witwatersrand. Johannesburg.

Paterson, A. R. 2009. Legal Framework for Protected Areas: South Africa. www.iucn.org/downloads.South_Africa.

Peel, M. J. S., and Montagu, G. P. 1999. Modelling predator-prey interactions on a Northern Province game ranch. Journal of Wildlife Research 29: 31-34. https://www.ingentaconnect.com/content/sabinet/wild/1999/00000029/00000002/art000 02.

Penning de Vries, F. W. T., and Djiteye, M. A. 1982. La productivite des paturages saheliens: une etude des sols, des vegetations et de l'exploitation de cette ressource naturelle. Agricultural research reports, no. 918, Pudoc, Wageningen. https://edepot.wur.nl/302929. Plug, I., Scott, K., and Fish, W. 2000. Schoemansdal: faunal remains from selected sites in an historic village. Annals of the Transvaal Museum 37: 125-130.

https://journals.co.za/doi/10.10520/AJA00411752_47.

Plumptre, A. J., and Harris, S. 1995. Estimating the biomass of large mammalian herbivores in a tropical montane forest: a method of faecal counting that avoids assuming a 'steady state' system. Journal of Applied Ecology 32: 111-120. DOI.org/10.2307/2404420. 


\section{References}

Pringle, R. M., Prior, K. M., Palmer, T. M., Young, T. P., and Goheen, J. R. 2016. Large herbivores promote habitat specialization and beta diversity of African savanna trees. Ecology 97: 2640-2657. DOI.org/10.1002/ecy.1522.

Prins, H. H. T. 1996. Behaviour and Ecology of the African Buffalo: Social inequality and decision making. Chapman \& Hall, London.

Prins, H. H. T., and Olff, H. 1998. Species richness of African grazer assemblages: towards a functional explanation. In: D.M. Newbery, H. H. T. Prins and N. D. Brown (eds). Dynamics of tropical communities. British Ecological Society Symposium Vol. 37, pp. 449-490. Blackwell Science, Oxford.

Prins, H. H. T., and Van Langevelde, F. 2008. Assembling a diet from different places. In: H. H. T. Prins and F. Van Langevelde (eds). Resource Ecology: Spatial and Temporal Dynamics of Foraging. Springer, Dordrecht, pp. 129-158.

Prins, H. H. T., and Van Langevelde, F. 2008. Resource Ecology. Spatial and Temporal Dynamics of Foraging. Springer, The Netherlands.

Provenza, F. D., Burritt, E. A., Perevolotsky, A., and Silanikove, N. 2000. Self-regulation of intake of polyethylene glycol by sheep fed diets varying in tannin concentrations. Journal of Animal Science 78: 1206-1212. DOI.org/10.2527/2000.7851206x.

Provenza, F. D., Villalba, J. J., Haskell, J., MacAdam, J. W., Griggs, T. C., and Wiedmeier, R. 2007. The value to herbivores of plant physical and chemical diversity in time and space. Crop Science 47: 382-398. DOI.org/10.2135/cropsci2006.02.0083.

Putman, R. J. 1984. Facts from faeces. Mammal Review 14: 79-97. DOI.org/10.1111/j.13652907.1984.tb00341.x. 


\section{References}

Putman, R. J., and Staines, B. W. 2004. Supplementary winter feeding of wild red deer Cervus elaphus in Europe and North America: justifications, feeding practice and effectiveness. Journal of Mammal review 34: 285-306. DOI.org/10.1111/j.13652907.2004.00044.x.

Rangarajan, M. 2003. Parks, Politics and History: Conservation Dilemmas in Africa.

Conservation and Society 1: 77-98. https://www.jstor.org/stable/26396455.

Rao, M., Naro-Maciel, E., and Sterling, E. J. 2009. Protected Areas and Biodiversity

Conservation II: Management and Effectiveness. Network of Conservation Educators and Practitioners (ncep.amnh.org).

https://www.researchgate.net/publication/259266417_Protected_Areas_and_Biodiversity_ Conservation_II_Management_and_Effectiveness.

Rayment, G. E., and Lyons, D. J. 2011. Soil Chemical Methods - Australia. CSIRO Publishing. Australia.

Redfern, J. V., Grant, R., Biggs, H., and Getz, W. M. 2003. Surface-water constraints on herbivore foraging in the Kruger National Park, South Africa. Ecology 84: 2092-2107. DOl.org/10.1890/01-0625.

Reilly, B. K. 2014. Game Ranching in South Africa. In: Haukos (eds) The Wildlife Professional Summit, 2014. Conference Paper: 36-41.The Wildlife Society, Nashville.

www.researchgate.net/publication/272164294. 


\section{References}

Renwick, A., and Schellhorn, N. 2016. A perspective on land sparing versus land sharing. Learning from agri-environment schemes in Australia: Investing in biodiversity and other ecosystem services on farms (pp. 117-125). Australian National University Press Canberra, Australia. www.researchgate.net/publication/302885108.

Riginos, C., and Grace, J. B. 2008. Savanna tree density, herbivores, and the herbaceous community: Bottom-up Vs. Top-down effects. Ecology 89: 2228-2238. DOI.org/10.1890/071250.1.

Ripple, W. J., Newsome, T. M., Wolf, C., Dirzo, R., Everatt, K. T., Galetti, M., Hayward, M. W., Kerley, G. I. H., Levi, T., Lindsey, P. A., Macdonald, D. W., Malhi, Y., Painter, L. E., Sandom, C. J., Terborgh, J., and Van Valkenburgh, B. 2015. Collapse of the world's largest herbivores. Science Advances 1: 1-12. DOI: 10.1126/sciadv.1400103.

Roosendaal, B. 1992. Wildlife nutrition and feeding. http://www.alzu.co.za/img/WNutrition. Accessed 23 Feb 2020.

Rowcliffe, J. M., Carbone, C., Jansen, P. A., Kays, R., and Kranstauber, B. 2011. Quantifying the sensitivity of camera traps: an adapted distance sampling approach. Methods in Ecology and Evolution 2: 464-476. DOI:10.1111/j.2041-210X.2011.00094.x.

SAFARI Feeds. 2019. Hammanskraal, Gauteng, South Africa. www.safarifeeds.co.za. Accessed 02 Mar 2019. 


\section{References}

Salawu, M. B., Acamovic, T., Stewart, C. S., and Hovell, F. D. 1997. Quebracho tannins with or without Browse Plus (a commercial preparation of polyethylene glycol) in sheep diets: effect on digestibility of nutrients in vivo and degradation of grass hay in sacco and in vitro. Journal of Animal Feed Science Technology 69: 67-78. DOI.org/10.1016/S03778401(97)81623-9.

Sandbrook, C., Fisher, J. A., Holmes, G., Luque-Lora, R., and Keane, A. 2019. The global conservation movement is diverse but not divided. Nature Sustainability 2: 316-323. DOI.org/10.1038/s41893-019-0267-5.

Sankaran, M., and Anderson, T. M. 2009. Management and restoration in African Savannas: Interactions and feedbacks. In R. J. Hobbs, \& K. N. Suding (eds.). New Models for Ecosystem Dynamics and Restoration (pp. 136-155). Island Press. Washington DC.

Sankaran, M., Ratnam, J., and Hanan, N. 2008. Woody cover in African savannas: The role of resources, fire and herbivory. Global Ecology and Biogeography 17: 236-245. DOI:10.1111/j.1466-8238.2007.00360.x.

Sankaran, M., Ratnam, J., and Hanan, N. P. 2004. Tree-grass coexistence in savannas revisited -insights from an examination of assumptions and mechanisms invoked in existing models. Ecology Letters 7: 480-490. DOI.org/10.1111/j.1461-0248.2004.00596.x.

Sargent, R. 2016. Investigating the effect of grassland management techniques on vegetation and wildlife at Lewa wildlife conservancy, Kenya. MRes Thesis. Faculty of Natural and Environmental Sciences Centre for Biological Sciences. University of South Hampton, England. https://www.lewa.org/wp-content/uploads/2020/09/Sargent-Rebecca.-2016..pdf. 


\section{References}

Scholes, R. J., and Archer, S. R. 1997. Tree-grass interactions in savannas. Annual Review of Ecology and Systematics 28: 517-544. DOI.org/10.1146/annurev.ecolsys.28.1.517.

Schroder, B., Van Langevelde, F., and Prins, H. H. T. Submitted 2020. Effects of mineral addition on the establishment of grazing lawns in a nutrient poor savanna. Ecosphere.

Schroder, B., Van Langevelde, F., and Prins, H. H. T. Submitted 2021. Nutrient addition on grazing lawns and selection by free-roaming mammalian herbivores in a nutrient poor savanna. Koedoe.

Scogings, P. F., Hjalten, J., Skarpe, C., Hattas, D., Zobolo, A., Dziba, L., and Rooke, T. 2014. Nutrient and secondary metabolite concentrations in a savanna are independently affected by large herbivores and shoot growth rate. Plant Ecology 215: 73-82. DOI:10.1007/s11258013-0279-6.

Seymour, C. L., Milewski, A. V., Mills, A. J., Joseph, G. S., Cumming, G. S., Cumming, D. H. M., and Mahlangu, Z. 2013. Do the large termite mounds of Macrotermes concentrate micronutrients in addition to macronutrients in nutrient poor African savannas? Journal of Soil Biology and Biochemistry 68: 95-105. DOI.org/10.1016/j.soilbio.2013.09.022.

Shorrocks, B., and Bates, W. 2015. The Biology of African Savannahs. Oxford University Press, UK.

Silveira, L., Jácomo, A. T. A., and Diniz-Filho, J. A. F. 2003. Camera trap, line transect census and track surveys: a comparative evaluation. Biological Conservation 114: 351-355. DOI:10.1016/S0006-3207(03)00063-6.

Šmilauer, P., and Lepš, J. 2014. Multivariate Analysis of Ecological Data using Canoco 5, Cambridge University Press, Cambridge CB2 8BS, United Kingdom. 


\section{References}

Smit, G. N. 2013. Grazing capacity - game - Calculation of grazing capacity and browse capacity for game species. Department of Animal, Wildlife and Grassland Sciences, University of the Free State. Wildlife Ranching.

http://www.wildliferanching.com/content/grazing-capacity-game. Accessed 15 Jan 2019.

Snyman, H. A. 2002. Short-term response of rangeland botanical composition and productivity to fertilization ( $\mathrm{N}$ and $\mathrm{P}$ ) in a semi-arid climate of South Africa. Journal of Arid Environments 50: 167-183. DOI.org/10.1006/jare.2001.0858.

South African National Parks. 2020. Marakele National Park. https://www.sanparks.org/parks/marakele/conservation/ff/vegetation.php.

Spinage, C. A. 1973. A review of ivory exploitation and elephant population trends in Africa. East African Wildlife Journal 11: 281-289. DOI.org/10.1111/j.1365-2028.1973.tb00093.x.

STATS SA. 2020. Statistics South Africa. The South Africa I know, the home I understand. http://www.statssa.gov.za/?page_id=593.

Stevenson-Hamilton, J. 1938. South African Eden: From Sabi Game Reserve to Kruger National Park. Penguin, 2008. (First Published 1938). Johannesburg.

Stock, W. D., Bond, W. J., and Van de Vijver, C. A. D. M. 2010. Herbivore and nutrient control of lawn and bunch grass distributions in a southern African savanna. Plant Ecology 206: 15-27. DOI:10.1007/s11258-009-9621-4.

Strang, D. 1996. Contested sovereignty: the social construction of colonial imperialism. In T. J. Biersteker, and C. Weber (eds.) State sovereignty as social construct (pp. 22-49). Cambridge University Press, UK. 


\section{References}

Taylor, R. D., and Martin, R. B. 1987. Effects of veterinary fences in Zimbabwe.

Environmental Management 11: 327-334. DOI: 10.1007/BF01867160.

Ter Braak, C. J. F., and Smilauer, P. 1998. Canoco Reference Manual and User's Guide to Canoco for Windows: Software for Canonical Community Ordination (Version 4). Ithaca: New York. Microcomputer Power.

Texeira, M., Baldi, G., and Paruelo, J. 2012. An exploration of direct and indirect drivers of herbivore reproductive performance in arid and semi-arid rangelands by means of structural equation models. Arid Environments 81: 26-34. DOI:10.1016/j.jaridenv.2012.01.017.

Thomson, R. 2003. A Game Warden's Report. Magron Publishers. South Africa.

Tomlinson, K. W., Van Langevelde, F., Ward, D., Prins, H. H. T., De Bie, S., Vosman, B., Sampaio, E. V. S. B., and Sterck, F. J. 2016. Defence against vertebrate herbivores trades off into architectural and low nutrient strategies amongst savanna Fabaceae species. Oikos 125: 126-136. DOI.org/10.1111/oik.02325.

Trading Economics. 2020. South Africa - Economic Indicators.

https://tradingeconomics.com/south-africa/indicators.

Uher-Koch, B. D., Schmutz, J. A., Wilson, H. M., Anthony, R. M., Day, T. L., Fondell, T. F., Person, B. T., and Sedinger, J. S. 2019. Ecosystem-scale loss of grazing habitat impacted by abundance of dominant herbivores. Ecosphere 10: 1-10. DOI.org/10.1002/ecs2.2767.

United Nations. 2011. Population Facts: Department of Economic and Social Affairs. https://www.un.org/en/development/desa/population/publications/pdf/popfacts/PopFacts _2011-2.pdf. 


\section{References}

Van der Waal, C,. Kool, A., Meijer, S. S., Kohi, E., Heitkonig, I. M. A., De Boer, W. F., Van Langevelde, F., Grant, R. C., Peel, M. J. S., Slotow, R., De Knegt, H. J., Prins, H. H. T., and De Kroon, H. 2011a. Large herbivores may alter vegetation structure of semi-arid savannas through soil nutrient mediation. Oecologia 165: 1095-1107. DOI:10.1007/s00442-010-18993.

Van der Waal, C. 2010. Nutrients in an African Savanna: The consequences of supply heterogeneity for plants and animals. PhD Thesis. Wageningen University. https://edepot.wur.nl/146149.

Van der Waal, C., De Kroon, H., Heitkönig, I. M., Skidmore, A. K., Van Langevelde, F., De Boer, W. F., Slotow, R., Grant, R. C., Peel, M. P., Kohi, E. M., and De Knegt, H. J. 2011b. Scale of nutrient patchiness mediates resource partitioning between trees and grasses in a semiarid savanna. Journal of Ecology 99: 1124-1133. DOI:10.1111/j.1365-2745.2011.01832.x. Van Langevelde, F., Van de Vijver, C. A. D. M., Kumar, L., Van de Koppel, J., De Ridder, N., Van Andel, J., Skidmore, A., Hearne, J., Stroosnijder, L., Bond, W. J., Prins, H. H. T., and Rietkerk, M. 2003. Effects of fire and herbivory on the stability of savanna ecosystems. Ecology 84: 337-350. DOI.org/10.1890/0012-9658(2003)084[0337:EOFAHO]2.0.CO;2.

Van Lieverloo, R. J., Schuiling, B. F., De Boer, W. F., Lent, P. C., De Jong, C. B., Brown, D., and Prins, H. H. T. 2009. A comparison of faecal analysis with backtracking to determine the diet composition and species preference of the black rhinoceros (Diceros bicornis minor). European Journal of Wildlife Research 55: 505-515. DOI:10.1007/s10344-009-0264-5. Van Oudtshoorn, F. 2002. Guide to Grasses of Southern Africa. Briza Publications. Pretoria, South Africa. 


\section{References}

Van Wyk, B., and Van Wyk, P. 1997. Field Guide to Trees of Southern Africa. Struik

Publishers. Cape Town, South Africa.

Veldhuis, M. P., Howison, R. A., Fokkema, R. W., Tielens, E., and Olff, H. 2014. A novel mechanism for grazing lawn formation: large herbivore-induced modification of the plantsoil water balance. Journal of Ecology 102: 1506-1517. DOI:10.1111/1365-2745.12322.

Venter, Z. S., Hawkins, H. J., and Cramer, M. D. 2017. Implications of historical interactions between herbivory and fire for rangeland management in African savannas. Ecosphere 8: 114. DOI.org/10.1002/ecs2.1946.

Verweij, R. J. T., Verrelst, J., Loth, P. E., Heitkönig, I. M. A., and Brunsting, A. M. H. 2006. Grazing lawns contribute to the subsistence of mesoherbivores on dystrophic savannas. OIKOS 114: 108-116. DOI.org/10.1111/j.2006.0030-1299.14209.x.

Vesey-FitzGerald, D. F. 1969. Utilization of the habitat by buffalo in Lake Manyara National Park. African Journal of Ecology 7: 131-145. DOI.org/10.1111/j.1365-2028.1969.tb01201.x. Vesey-Fitzgerald, D. F. 1974. Utilization of the grazing resources by buffaloes in the Arusha National Park, Tanzania. African Journal of Ecology 12: 107-134. DOl.org/10.1111/j.13652028.1974.tb01029.x.

Vicente, J., Segalés, J., Höfle, U., Balasch, M., Plana-Durán, J., Domingo, M., and Gortázar, C. 2004. Epidemiological study on porcine circovirus type 2 (PCV2) infection in the European wild boar (Sus scrofa). Veterinary Research 35: 243-253. DOI:10.1051/vetres:2004008.

Vidal, J. 2011. Africa's declining wildlife. The Guardian.

www.theguardian.com/environment/2011/jun/20/africa-declining-wildlife 12. 


\section{References}

Wagner, R. 1980. Zoutpansberg: the dynamics of a hunting frontier 1848-67. In S. Marks, \&

A. Atmore (eds.) Economy and Society in Pre-Industrial South Africa (pp. 313-349). Longman, London.

Waithaka, J. 2012. Historical facts that shaped Wildlife Conservation in Kenya. The Kenya Wildlife Service in the 21st century: Protecting globally significant areas and resources. The George Wright Forum 29: 21-29. World Journal of Agricultural Research 4: 43-48. https://www.jstor.org/stable/43598971.

Waldram, M. S., Bond, W. J., and Stock, W. D. 2007. Ecological engineering by a megagrazer: White Rhino impacts on a South African savanna. Ecosystems 11: 101-112. DOI:10.1007/s10021-007-9109-9.

Waldram, M., Bond, W., and Stock, W. 2008. Ecological engineering by a mega-grazer: White rhino impacts on a South African savanna. Ecosystems 11: 101-112. DOI.org/10.1007/s10021-007-9109-9.

Walker, B. H., and Noy-Meir, I. 1982. Aspects of the stability and resilience of savanna ecosystems. In Huntley, B. J. and Walker, B. H. (eds), Ecology of tropical savannas: 556-590. Springer, Berlin Heidelberg.

Waller, R. 1985. Ecology, Migration, and Expansion in East Africa. African Affairs 84: 347370. DOI.org/10.1093/oxfordjournals.afraf.a097698.

Walters, C. J., and Hilbron, R. 1978. Ecological optimization and adaptive management. Annual Review of Ecology and Systematics 9: 157-188.

DOI.org/10.1146/annurev.es.09.110178.001105. 


\section{References}

Watterson, G. G. 1961. Conservation of Nature and Natural Resources in modern African

States. IUCN Publications 1. William Clowes and sons, Limited. London.

https://www.iucn.org/content/conservation-nature-and-natural-resources-modern-africanstates-report-a-symposium.

WES Feeds. 2019. Thabazimbi, Limpopo, South Africa. www.wesenterprises.co.za.

Accessed 13 Sep 2018.

Worboys, G. L., and Trzyna, T. 2015. 'Managing Protected Areas', in G. L. Worboys, M.

Lockwood, A. Kothari, S. Feary, \& I. Pulsford (eds.). Protected Area Governance and Management (pp. 207-250). ANU Press, Canberra, Australia.

https://www.jstor.org/stable/j.ctt1657v5d.15.

World Bank. 2020. Population Estimates and Projections.

https://datacatalog.worldbank.org/dataset/population-estimates-and-projections.

World Wildlife Fund. (accessed 2019). http://worldwildlife.org/ecoregions/at0717.

Wrench, J. M., Meissner, H. H., and Grant, C. C. 1997. Assessing diet quality of African ungulates from faecal analyses: the effect of forage quality, intake and herbivore species. Koedoe 40: 125-136. DOl.org/10.4102/koedoe.v40i1.268.

Zhong-xian, L., Xiao-ping, Y., Heong, K. L., and Cui, H. 2007. Effect of nitrogen fertilizer on herbivores and its stimulation to major insect pests in rice. Rice Science 14: 56-66. DOI.org/10.1016/S1672-6308(07)60009-2.

Zulu, N. 2015. An analysis of the post 1980s transition from pastoral to game farming in South Africa: a case study of the Marico district. Dissertation. University of Witwatersrand, South Africa. http://wiredspace.wits.ac.za/handle/10539/19985. 


\section{References}

Zwerts, J. A., Prins, H. H. T., Bomhoff, D, Verhagen, I., Swart, J. M., and De Boer, W. F. 2015.

Competition between a Lawn-Forming Cynodon dactylon and a Tufted Grass Species

Hyparrhenia hirta on a South-African Dystrophic Savanna. PLoS ONE 10: 1-17.

DOI:10.1371/journal.pone.0140789.

\section{References - Management plans}

Addo Elephant National Park. 2015-2025. Park Management Plan (Spies, A and various other stakeholders). https://www.sanparks.org/parks/addo/.

Amboseli Game Reserve. 2008-2018. Amboseli Ecosystem Management Plan (Amboseli Ecosystem Stakeholders and Kenya Wildlife Service's Biodiversity Planning, Assessment and Compliance Department). http://www.kws.go.ke/amboseli-national-park.

Chobe National Park. 1992. Management Plan. Deloitte \& Touche Management Consultants (Pty) Ltd.

https://library.wur.nl/ojs/index.php/Botswana_documents/article/view/15956.

Etosha Management Plan. 2007. http://www.the-

eis.com/data/literature/Etosha\%20Management\%20Plan\%20August\%202007.

Hluhluwe Imfolozi Park. 2011. Protected Area Management Plan (Udidi Environmental Planning and Development Consultants). http://www.kznwildlife.com/hluhluwe-gamereserve.html.

Ithala Game Reserve. 2009-2013. Integrated Management Plan (Ezemvelo KZN Wildlife). http://www.ithala.info/. 


\section{References}

Kidepo Valley National Park. 2012-2022. General Management Plan (Uganda Wildlife Authority: Conservation Department). http://www.ugandawildlife.org/explore-ourparks/parks-by-name-a-z/kidepo-valley-national-park.

Kruger National Park. 2008. Management Plan (Freitag-Ronaldson, S and Venter, F). https://www.sanparks.org/.

Lewa Conservancy - Mount Kenya National Park. 2013. Management Plan. IUCN Evaluation Report. https://whc.unesco.org/document/154309.

Limpopo-Lipadi Private Game Reserve. 2009. Management Plan (Ecological Developments Botswana (Pty) Ltd). http://limpopo-lipadi.org/.

Maasai Mara National Park. 2010-2020. Management Plan (African Wildlife Foundation and Stakeholders). https://cleanupmara.files.wordpress.com/2010/03/2nd-draftmanagement-plan1.pdf.

Mapungubwe National Park. 2013-2018. Management Plan. https://www.sanparks.org/. Marakele National Park. 2014-2024. Park Management Plan (Novellie, P and Spies, A). https://www.sanparks.org/.

Mkhuze Game Reserve. 2011-2016. iSimangaliso Wetland Park Integrated Management Plan (iSimangaliso Wetland Park Authority). http://www.kznwildlife.com/mkhuze-park.html. Mudumu National Park. 2013-2018. Management Plan (Ministry of Environmental and Tourism, Namibia). http://www.met.gov.na/national-parks/mudumu-national-park/223/. 


\section{References}

Murchison Falls National Park. 2012-2022. General Management Plan (Uganda Wildlife Authority: Conservation Department). http://www.ugandawildlife.org/explore-ourparks/parks-by-name-a-z/murchison-falls-national-park.

Pilanesberg National Park. 2015. Management Plan (Busica cc - for North West Parks and Tourism Board). http://www.tourismnorthwest.co.za/pilanesberg-game-reserve/\#tab=tab1.

Queen Elizabeth National Park. 2012. General Management Plan 2011-2021. Ministry of Tourism, Wildlife and Antiquities. Uganda Wildlife Authority.

https://www.ugandawildlife.org/wildlife-a-conservation-2/researchers-corner/generalmanagement-plans.

Tanzania National Report. 2001. National Report on the implementation of the convention on biological diversity (Division of Environment - Vice President's Office). http://www.tanzaniaparks.go.tz/.

Tembe Elephant Park. 2015. Protected Area Management Plan (Ezemvelo KwaZulu-Natal Wildlife Protected Area Management Unit and Tembe Elephant Park Planning Committee). http://tembe.co.za/.

Thornybush Game Reserve. 2015. Management Plan and Elephant Management Plan (Peel, M). T. Coetzee, Reserve Manager

Tsavo Conservation Area. 2008. Management Plan 2008 - 2018. Kenya Wildlife Service. https://www.kws.go.ke/file/1473/download?token=_Kyeb-P4.

Welgevonden Game Reserve. 2014. Protected Area Management Plan. J. Swart, Reserve Ecologist. 


\section{References}

Zambia Protected Area Planning. 2008. Zambia Wildlife Authority (Siamudaala, V.M.).

https://www.cbd.int/doc/meetings/pa/ewsipals-01/other/ewsipals-01-presentation-18en.pdf. 


\section{Summary}

The savanna biome covers roughly one eighth of the earth's land surface area and contains high levels of biodiversity. Many people inhabit savannas and utilise them for agriculture and livestock farming. Particularly in this biome, biodiversity conservation is under an ever mounting threat by the rapidly growing human population with livestock and their associated requirements for arable land use. The quality of the browse and graze is paramount to the survival of the many free-roaming herbivores, especially in nutrient poor savannas that are characterized by unpalatable grasses and broad-leaved trees with high concentrations of secondary metabolites in their foliage. Grazing lawns, with short, stoloniferous grasses, could provide high-quality food for grazers in these areas, but lawn grasses occur only sporadically in nutrient poor savannas. There is not much known about the effects of adding specific nutrients on the establishment of grazing lawns in nutrient poor savannas and the resultant quality of the forage. Therefore, this thesis aims to improve the understanding of the effect between large free-roaming herbivores in a nutrient poor savanna and improving the quality of the forage.

Often conservation practices lack scientific underpinning, which is the motivation for this thesis. I address the question whether nutrient addition leads to the establishment of grazing lawns in a nutrient poor savanna, coupled with mowing with a tractor and slasher to reduce the woody components which could compete with the grasses. Such addition is hypothesized to result in a switch ("jolt") from tall, nutritionally poor grass to short, highly nutritional grass species. The main hypothesis of this thesis is that a savanna can be forced from a state with low quality forage as food for large free-roaming herbivores, to a state with high-quality forage through management interventions of these systems. 
Before understanding the intricacies of evidence-based conservation experiments in forcing a savanna to change its state of food quality, it is important to understand the complexities of managing protected areas and to understand the origins for their establishment. Therefore, I first summarized the motives for establishing protected areas in Southern and Eastern Africa, and the possible consequences for management of these areas today. The findings illustrate that the establishment of protected areas occurred in three periods, and that these periods gave rise to ramifications for management of these areas today. One of the ramifications is to enhance the quality of the vegetation as food for mammalian herbivores.

I then tested whether we could use the addition of fertilizer to establish grazing lawns in a nutrient poor savanna, in order to achieve a switch from a vegetation of tall, nutritionally poor grass species to a short vegetation comprised of (highly) nutritional grass species. The experiments demonstrate that fertilization in nutrient poor savannas can trigger the establishment of grazing lawns, coupled with mowing with a tractor and slasher to reduce the woody components which could compete with the grasses. I found that phosphorus supplementation resulted in a shift from tall grasses to short grasses within three years with a higher nutrient concentration in the grass species than without supplementation. When grazed, the biomass of lawn grasses was higher compared to the other grasses when not grazed, demonstrating the role of grazers in lawn grass patch establishment.

I continued to study the effects of increased grazing pressure by mammalian herbivores on maintaining patches of lawn grass and tested whether the application of specific nutrients, nitrogen, phosphorous or in combination with calcitic and dolomitic lime, would attract mammalian herbivores to graze frequently. I showed that the addition of $\mathrm{N}$ attracts and 
increases the grazing pressure for a number of herbivore species and our findings suggest that often abundantly present mammalian herbivores with intermediate body mass can maintain grazing lawns. This study illustrates that the distribution of specific nutrients to an area has an effect on the vegetation, causing elevated local grazing pressure by mammalian herbivores resulting in improved quality of forage. I concluded that the ongoing local fertilization in nutrient poor savannas is a practical and achievable method of ensuring that herbivores obtain high-quality forage in nutrient poor savannas.

Further to obtaining a better understanding of improving the quality of the forage for freeranging herbivores, I wanted to study how herbivores could obtain additional nutrients or better forage quality from the broad-leaved trees in a nutrient poor savanna. So finally, I deployed game lick blocks with polyethylene glycol (PEG), a polymer, to standard game lick blocks (nutrient supplements) in an attempt to establish if we could broaden the diet of herbivores with higher percentages of browse species and higher amounts of utilisation per browse species that had high levels of condensed tannins. I showed that the addition of PEG to standard game lick blocks supported a change in the dietary choices of herbivore species in the study area and that these changes are expressed as a broader diet choice (higher percentage of browse species) and a higher number of browse species utilised with higher concentrations of secondary compounds in their diet. The findings showed that the largest change in diet selection was for Burchell's zebra (a grazer) and impala (a mixed feeder).

My thesis shows that there is a need for the manipulation of vegetation and animals through evidence-based conservation, in a nutrient poor savanna to help with survival of the herbivore species. I have shown that through the addition of specific nutrients, and the use of a polymer to combat tannin, in a practical manner will improve forage quality in a nutrient poor savanna. 
As a consequence, this better quality food that would otherwise not have been utilised, thus helps in alleviating the effect of food shortages during the dry winter season.

My thesis provides scientific understanding of the association between large free-roaming herbivores in a nutrient poor savanna and methods of improving the quality of the forage. In conclusion, this study provides new information on nutrient-plant-herbivore associations that helps evidence-based conservation, forcing a nutrient poor savanna from a state with low quality forage for large free-roaming herbivores, to a state with high-quality forage, through management of these systems. These findings have important consequences for the management of nutrient poor savannas around the world. 


\section{Samenvatting}

De Savanne beslaat ongeveer een achtste van het landoppervlak van de aarde en bevat een hoge biodiversiteit. De biodiversiteit in de Savanne staat steeds meer onder druk door de snelgroeiende menselijke populatie en de daarmee samenhangende vereisten voor het gebruik van akkerland. Een goede kwaliteit van gras en gebladerte is van het grootste belang voor het in stand houden van de diversiteit aan vrij rondlopende herbivoren. De biodiversiteit staat vooral onder druk in voedselarme savannes die worden gekenmerkt door onverteerbare grassen en loofbomen met hoge concentraties aan secundaire metabolieten in hun loof. Weides met korte, goed verteerbare grassen, kunnen grazers in deze gebieden kwalitatief goed voedsel bieden. Maar dit soort weides komt slechts sporadisch voor in de voedselarme savannes. Er is niet veel bekend over de effecten van specifieke voedingsstoffen op de totstandkoming van goede graasweides en daarmee ook op de kwaliteit van het voer.

In mijn proefschrift presenteer ik resultaten gericht op het ophelderen van het verband tussen de conditie van grote vrij rondlopende herbivoren (in een voedselarme savanne) en de verbetering van de kwaliteit van hun voer. Vaak mist de uitoefening van natuurbeheersactiviteiten wetenschappelijke onderbouwing, dit proefschrift wil daar verandering in brengen. Ik ga in dit proefschrift in op de vraag of het toevoegen van kunstmest in combinatie met het maaien van de velden en het gebruik van een hakselaar (om de houtachtige componenten te verminderen die zouden kunnen concurreren met de grassen) leidt tot het ontstaan van betere graasweides. Een dergelijke aanpak kan hypothetisch resulteren in een omschakeling van lang, voedingsarm gras naar korte, voedselrijke grassoorten. De belangrijkste hypothese van dit proefschrift stelt dat de verschijningsvorm van een savanne door managementinterventies kan worden veranderd van een situatie 
(staat) met een lage voedingskwaliteit, voor grote vrij rondlopende herbivoren, naar een situatie met een hoge voedingskwaliteit.

Alvorens de fijne kneepjes van op wetenschappelijk onderzoek gebaseerde natuurbeheer experimenten, waarmee de voedselkwaliteit van een savanne kan worden veranderd, te begrijpen is het van belang de complexiteit in het beheer van beschermde gebieden te begrijpen en de oorsprong van hun ontstaan te doorgronden. Daarom heb ik eerst de motieven voor het instellen van beschermde gebieden in zuidelijk en oostelijk Afrika benoemd en de mogelijke gevolgen voor het beheer van deze gebieden beschreven. De bevindingen illustreren dat de instelling van beschermde gebieden plaatsvond in drie verschillende perioden en dat deze perioden verschillende consequenties hebben voor het beheer van deze gebieden vandaag de dag. Een daarvan is bijvoorbeeld het beheer van de kwaliteit van de vegetatie als voedsel voor zoogdierherbivoren.

Vervolgens heb ik getest of de toevoeging van kunstmest kan worden gebruikt om graasweides te creëren in voedselarme savannes, om zo een omschakeling te bewerkstelligen van een vegetatie van lange, voedingsarme grassoorten naar een korte vegetatie bestaande uit (zeer) voedingsrijke grassoorten. De experimenten tonen aan dat bemesting (in combinatie met maaien en het gebruik van een hakselaar) van de savannes kan leiden tot het ontstaan van voedselrijke graasweiden. Ik ontdekte dat fosforsuppletie binnen 3 jaar resulteerde in een verschuiving van hoge grassen naar korte grassen met een hogere nutriëntenconcentratie in de grassoort dan zonder suppletie. Bij beweiding was de biomassa van de grassen hoger in vergelijking met dat van grassen zonder beweiding, wat de rol van grazers bij de aanleg van deze graasvelden aantoont. 
Vervolgens bestudeerde ik de effecten van een verhoogde begrazingsdruk door herbivoren op het behoud van graasvelden en testte ik of de toepassing van specifieke voedingsstoffen, stikstof, fosfor of in combinatie met kalk- en dolomietkalk, zoogdierherbivoren zou aantrekken om vaker te grazen. Ik toonde aan dat de toevoeging van Stikstof $(N)$ de begrazingsdruk aantrekt en verhoogt voor een aantal herbivoren soorten en suggereerde onze bevindingen dat vaak overvloedig aanwezige zoogdierherbivoren met een gemiddeld lichaamsgewicht graasweides kunnen behouden. Mijn studie illustreert dat de toevoeging van specifieke meststoffen aan een gebied een positief effect heeft op de vegetatie, waardoor de lokale graasdruk door zoogdierherbivoren wordt verhoogd, wat resulteert in een verbeterde voedselkwaliteit. Ik concludeerde dat de voortdurende lokale bemesting in voedselarme savannes een praktische en haalbare methode is om ervoor te zorgen dat herbivoren voer van hoge kwaliteit krijgen in deze voedselarme gebieden.

Om een beter begrip te krijgen van het verbeteren van de kwaliteit van het voer voor vrij rondlopende herbivoren, heb ik onderzocht hoe herbivoren aanvullende voedingsstoffen of voedsel met een hogere voedingswaarde konden verkrijgen van de loofbomen en struiken in de savanne. Daartoe heb ik standaard (game)-likblokken vervangen door (game)-likblokken met polyethyleenglycol (voedseladditief) in een poging om vast te stellen of we het dieet van herbivoren konden verbeteren met loof van struiken met een hoog gehalte aan gecondenseerde tannines. Ik heb laten zien dat de toevoeging van PEG aan standaard gamelikblokken (die in de winter aan de wildsoorten worden gegeven uit oogpunt van dierenwelzijn) een verandering mogelijk maakt in de voedingskeuzes van herbivore soorten in het studiegebied en dat deze veranderingen in een breder spectrum kan worden uitgedrukt. De bevindingen toonden aan dat de grootste verandering in de voedingsselectie optrad bij de Burchell's zebra (een grazer) en impala (een gemengde feeder). 
Mijn proefschrift laat zien dat er behoefte is aan vegetatiebeheer en dat wilde hoefdieren door middel van evidence-based natuurbescherming, in een voedselarme savanne, geholpen kunnen worden in hun strijd te overleven. Ik heb aangetoond dat door de toevoeging van specifieke additieven (namelijk het gebruik van een polymeer om tannine te binden), op een praktische manier de voederkwaliteit in een voedselarme savanne kan verbeteren. Als gevolg hiervan helpt deze verbeterde toegang tot voedsel van betere kwaliteit dat anders niet zou worden gebruikt, het effect van voedseltekorten tijdens het droge winterseizoen te verlichten waardoor er een toename van het aantal herbivoren kan zijn.

Mijn proefschrift geeft wetenschappelijk inzichten in de associatie tussen de conditie van grote vrij rondlopende herbivoren in een voedselarme savanne en methoden om de kwaliteit van het voer te verbeteren. Concluderend levert deze studie nieuwe informatie op over associaties tussen nutriënt-plant-conditie herbivoor die helpt bij wetenschappelijk onderbouwde natuurbeheersactiviteiten, door een voedselarme savanne te transformeren van een voedingsarme staat voor grote vrij rondlopende herbivoren naar een voedingsrijke staat middels beheer van deze systemen. De bevindingen in dit proefschrift hebben belangrijke gevolgen voor het beheer van voedselarme savannes over de hele wereld. 


\section{Samevatting (Afrikaans)}

\section{Samevatting}

Die savanne-bioom beslaan ongeveer een agtste van die aarde se landoppervlak en bevat hoë vlakke van biodiversiteit. Baie mense bewoon savanne en gebruik dit vir landbou en veeboerdery. Veral in hierdie bioom is die bewaring van biodiversiteit onder toenemende bedreiging vanweë vinnig groeiende menslike bevolking, met veeboerery en die gepaardgaande vereistes vir bewerkbare saaigrond. Die kwaliteit van weiding is van die allergrootste belang vir die oorlewing van vele vrylopende herbivore, veral in savanne arm in voedingstof, wat gekenmerk word deur onsmaaklike grasse en breëblaarbome met hoë konsentrasies van sekondêre metaboliete in hul blare. Weigrasperke, met kort, lootgrasse, kan weiding van hoë gehalte in sulke omgewings voorsien, maar sulke grasperke kom slegs sporadies voor in voedselarm savanne. Daar is nie veel bekend wat betref die effek van die toevoeging van spesifieke voedingstowwe op die vestiging van wei grasperke nie, en gevolglik ook nie die kwaliteit daarvan nie. Die doel van hierdie tesis is dus om kennis oor die verhouding tussen groot vrylopende herbivore in ' $n$ area met ' $n$ gebrek aan voedingstowwe en hoe om die kwaliteit van die weiding te bevorder.

Bewaring word gereeld aangepak met 'n gebrek aan wetenskaplike onderbou en dit is dus die motivering van hierdie tesis. Die tesis spreek die vraag aan of die toevoeging van voedingstowwe ' $\mathrm{n}$ bydrae lewer tot die vestiging van weilande in voedselarm savanne, tesame met die gebruik van ' $n$ trekker met snyer om die houtagtige komponente wat met die wei grasperk kan kompeteer te verminder. Die vermoede is dat dié toediening 'n oorskakeling ('ruk') van lang, voedingsarm gras na kort, baie voedsame gras spesies tot gevolg het. Die vernaamste hipotese van hierdie tesis is dat 'n savanna gedwing kan word om toestand te 
verander, vanaf lae gehalte voer na 'n toestand met 'n hoë gehalte voer deur middel van bestuursingryping op sulke stelsels.

Dit belangrik om die kompleksiteit van die bestuur van beskermde gebiede te verstaan en ook die oorsprong van hul vestiging. Daarna kan mens die ingewikkeldheid van bewys-gebaseerde bewaringseksperimente begryp om 'n savanna te dwing om die toestand van voedselkwaliteit te verander. Daarom het ek eers die motiewe vir die vestiging van beskermde gebiede in Suider- en Oos-Afrika opgesom en die moontlike gevolge van die huidige bestuur van hierdie gebiede. Die bevindings illustreer dat die vestiging van beskermde gebiede in drie periodes plaasgevind het, en dat hierdie tydperke aanleiding gegee het tot gevolge vir die bestuur van hierdie gebiede. Een van die gevolge is die verbetering van die kwaliteit van plantegroei as voedsel vir soogdier-herbivore..

Daarna het ek getoets of ons die toevoeging van kunsmis kan gebruik om weiding in ' $n$ voedingsarme savanna te vestig, om sodoende 'n oorskakeling te maak van van lang, voedingsarm plantegroei na 'n kort plantegroei bestaande uit gras spesies met (hoë) voedingswaarde. Die eksperimente toon dat bemesting in voedingsarm savanne die totstandkoming van weidingsgrasperke kan teweeg bring, tesame met die sny van 'n trekker en snyer om die houtagtige komponente wat met die grasse kan meeding, te verminder. Ek het gevind dat fosforaanvulling binne drie jaar gelei het tot ' $n$ verskuiwing van lang gras na kort gras, met 'n hoër voedingskonsentrasie in die grassoort as sonder aanvulling. By beweiding was die biomassa van weidingsgras hoër in vergelyking met die ander grasse wanneer dit nie bewei is nie, wat die rol van weidiere in die vestiging van grasperkplekke gedemonstreer het. 
Ek het voortgegaan om die effekte van verhoogde weidingsdruk deur soogdier-herbivore op die handhawing van grasperke te bestudeer en getoets of die toediening van spesifieke voedingstowwe, stikstof, fosfor of in kombinasie met kalsitiese en dolomitiese kalk, soogdierherbivore sal lok om gereeld te wei. Ek het getoon dat die toevoeging van stikstof die weidingsdruk vir ' $n$ aantal herbivoorspesies lok en verhoog, en ons bevindinge dui daarop dat die teenwoordigheid van ' $n$ oorvloed van soogdier-herbivore, met ' $n$ intermediêre liggaamsmassa, weidingsgrasperke kan handhaaf. Hierdie studie illustreer dat die verspreiding van spesifieke voedingstowwe na 'n gebied 'n uitwerking op die plantegroei het, wat verhoogde plaaslike weidingsdruk deur soogdier-herbivore teweeg bring. Dit het gelei tot verbeterde kwaliteit voer. Ek het tot die gevolgtrekking gekom dat voortdurende plaaslike bemesting in voedingsarm savanne ' $\mathrm{n}$ praktiese en haalbare metode is om te verseker dat plantvreters voer van hoë gehalte verkry in voedingsarm savanne.

Om 'n verdere begrip te verkry van die verbetering van die gehalte van die voer vir vrylopende herbivore, wou ek ondersoek hoe herbivore addisionele voedingstowwe, of beter voerkwaliteit van breëblaarbome in 'n voedingsarm savanne kon verkry. Uiteindelik het ek wildlekblokke met poliëtileenglikol (PEG), 'n polimeer, aan standaard wildblokkies (voedingsaanvullings) ontplooi in 'n poging om vas te stel of ons die dieet van herbivore kan verbreed, met 'n hoër persentasie blaarsoorte en hoër verbruik per blaarsoort wat hoë vlakke van gekondenseerde tanniene bevat. Ek getoon dat die toevoeging van PEG aan standaard wildlekblokke ' $n$ verandering in die voedingskeuse van herbivoorspesies in die studiegebied ondersteun het; en verder dat hierdie veranderinge 'n breër uitdrukking gegee het aan dieetkeuse (hoër persentasie blaarsoorte), en 'n hoër aantal blaarsoorte wat gebruik was, met hoër konsentrasies sekondêre verbindings in hul dieet. Die bevindinge toon dat die grootste 
verandering in die dieetkeuse vir Burchell se sebra ('n "grasvreter") en rooibok ('n gemengde voerder) was.

My tesis toon dat daar ' $n$ behoefte is aan die manipulering van plantegroei en diere deur bewys-gebaseerde bewaring, in ' $n$ voedingsarm savanna om te help met die oorlewing van plantvreterspesies. Ek het getoon dat deur die toevoeging van spesifieke voedingstowwe, die vermeerdering van die aantal herbivore en die gebruik van ' $n$ polimeer om tannien te bestry, die voerkwaliteit van ' $n$ voedingsarme savanna op 'n praktiese manier sal verbeter. As gevolg hiervan, het hierdie verbeterde toegang tot voedsel van beter gehalte, wat andersins nie gebruik sou word nie, gehelp om die effek van voedseltekorte gedurende die droë winterseisoen te verlig.

My tesis voorsien wetenskaplike begrip van die verband tussen groot vrylopende herbivore in 'n voedingsarme savanna en metodes om die kwaliteit van die voer te verbeter. Ten slotte bied hierdie studie nuwe inligting oor voeding-plant-herbivoor assosiasies wat bewysgebaseerde bewaring bystaan, waar ' $n$ voedingsarm savanna gedwing word om van ' $n$ toestand van lae gehalte voer vir groot vrylopende herbivore, na 'n toestand met hoë gehalte voer te verander deur middel van bestuur van hierdie stelsels. Hierdie bevindinge het belangrike gevolge vir die bestuur van voedingsarme savanne regoor die wêreld. 


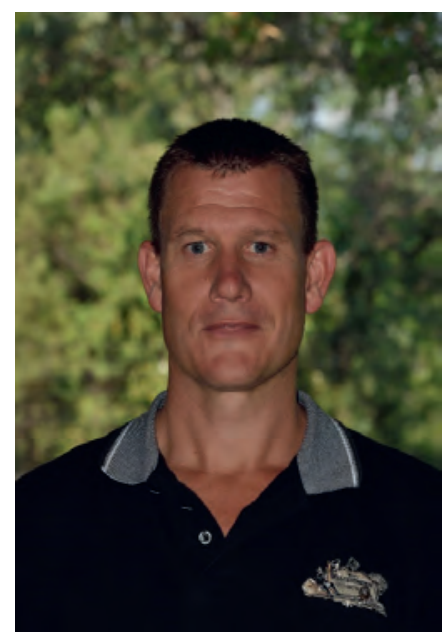

\section{Biography - Bradley Schroder}

Bradley Schroder was born on 11 August 1973 in Cape Town, South Africa. Bradley achieved his senior certificate from Pretoria Boys High School in 1991. He then went to the Lowveld region close to the Kruger National Park to do In-service Training in a Hotel. This is where Bradley's love for nature developed. He started off as a tourist guide doing open vehicle safaris escalating to dangerous game walking trails.

Bradley got his first opportunity to work as a conservationist in the position of conservation officer of Mokolodi Nature Reserve in Gaborone, Botswana. At this time he also completed two diplomas, one in "hotel and catering management" and one in "veterinary surgery assistant". In 2003, Bradley became the reserve manager for Marakele Contractual National Park and at the same time started his Bachelor's degree in Nature Conservation. In 2012, he finished his Master's degree from Tshwane University of Technology in Entomology, with his thesis entitled "Seasonal abundance and control of economically important ticks on a 
commercial game ranch, Thabazimbi, Limpopo Province". Bradley is a registered professional natural scientist with the South African Council for Natural Scientific Professions.

In 2016 he commenced with his PhD at Wageningen University and undertook both his PhD and his full time job, until July 2018 when he took a one year sabbatical to advance his PhD. Over the years, Bradley managed a number of conservation areas in both Botswana and South Africa in a diverse set of environmentss, with his last appointment at Welgevonden Game Reserve as Chief Executive Officer from February 2014 until July 2018.

In September 2019, he moved to Australia to become the manager of a conservation conservancy in the Outback approximately 5 hours north of Adelaide in South Australia. Bradley returned to South Africa in November 2020. 


\section{List of publications}

\section{List of publications}

Canning, G., Camphor, H., and Schroder, B. 2019. Rabies outbreak in African Wild Dogs (Lycaon pictus) in the Tuli region, Botswana: Interventions and management mitigation recommendations. Journal of Nature Conservation 48: 71-76.

DOI.org/10.1016/j.jnc.2019.02.001.

Davidson-Phillips, S., Davidson-Phillips, P., Canning, G., Schroder, B., Swart, J., and Burger, A. 2019. Canine distemper virus management in lions (Panthera leo) on Welgevonden Game Reserve. African Journal of Wildlife Research 49: 155-166. DOI.org/10.3957/056.049.0155. Eikelboom, J. A. J., Nuijten, R. J. M., Wang, Y. X. G., Schroder, B., Heitkönig, I. M. A., Mooij, W. M., Van Langevelde, F., and Prins, H. H. T. 2020. Will legal international rhino horn trade save wild rhino populations? Global Ecology and Conservation 23: 1-14.

DOl.org/10.1016/j.gecco.2020.e01145.

Eikelboom, J. A. J., Wind, J., Van de Ven, E., Kenana, L. M., Schroder, B., De Knegt, H. J., Van Langevelde, F., and Prins, H. H. T. 2019. Improving the precision and accuracy of animal population estimates with aerial image object detection. Methods in Ecology and Evolution 10: 1875-1887. DOI:10.1111/2041-210X.13277.

Schroder, B., and Reilly, B. K. 2013. A comparison between tick species collected in a controlled and control free area on a game ranch in South Africa. Journal of the South African Veterinary Association 84: 1-5. DOI.org/10.4102/jsava.v84i1.907.

Schroder, B., and Reilly, B. K. 2013. Seasonal variations in ixodid tick populations on a commercial game farm in the Limpopo Province, South Africa. African Invertebrates 54: 491498. 


\section{List of publications}

Schroder, B., Uys, A. C., and Reilly, B. K. 2006. A survey of free-living ixodid ticks on a commercial game farm in the Thabazimbi District, Limpopo Province, South Africa. Journal of the South African Veterinary Association 77: 141-144. 
PE\&RC Training and Education Statement

With the training and education activities listed below the PhD candidate has complied with the requirements set by the C.T. de Wit Graduate School for Production Ecology and Resource Conservation (PE\&RC) which comprises of a minimum total of 32 ECTS ( $=22$ weeks of activities)

\section{Review of literature (5 ECTS)}

- The ecological and economical foundations for successful Game Reserves in nutrient poor savannas

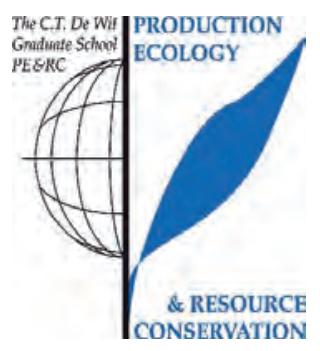

\section{Writing of project proposal (4 ECTS)}

- The ecological and economic foundations for successful Game Reserves in nutrient poor savannas

\section{Post-graduate courses (4.4 ECTS)}

- International wildlife forensic seminar; European Commission; SA Wildlife College; Netherland Forensic Institute, Ministry of security and Justice; Scheveningen, the Netherlands (2016)

- Introduction to "R" Stats package; PE\&RC (2017)

- Consumer resource interactions; PE\&RC (2018)

- Data management planning; WGS (2018)

- $\quad$ Linear models; PE\&RC (2019)

\section{Laboratory training and working visits (4 ECTS)}

- Laboratory training faecal sample analysis; NviroTech Labs South Africa

- Laboratory training grass sample analysis; NviroTech Labs South Africa

- Laboratory training soil sample analysis; NviroTech Labs South Africa

- Laboratory training water sample analysis; NviroTech Labs South Africa

\section{Invited review of (unpublished) journal manuscript (2 ECTS)}

- International J ournal of Ecology and Ecosolution: effect of seasonal variations on distribution of parasites in camels at assiut locality (2015)

- International Journal of Acarology: abundance estimations of ixodid ticks on Boran cattle and Somali sheep in Northern Tanzania (2015)

\section{Deficiency, refresh, brush-up courses (1.5 ECTS)}

- Basic Statistics; PE\&RC (2017)

\section{Competence strengthening / skills courses ( 2.1 ECTS)}

- The essentials of scientific writing and presenting; WGS (2017)

- Data science ethics; University of Michigan (2019)

\section{Discussion groups / local seminars / other scientific meetings (11.4 ECTS)}

- Elephant expert panel (2016)

- Welgevonden scientific steering committee meeting $(2016,2017,2018)$

- Wageningen University PhD symposium (2020)

\section{International symposia, workshops and conferences (5.4 ECTS)}

- Workshop on Elephant Conservation Norms \& Standards (2017)

- Savanna International Science Networking Meeting; Kruger National Park, South Africa $(2017,2018)$

\section{Supervision of MSc students (3 ECTS)}

- Tick densities in relation to host density and vegetation characteristics in South-African grazing lawns

- Adding PEG to tannin-rich diets of African herbivores: ideal or ineffective; polyethylene glycol effects on the dietary preferences of impala, kudu and wildebeest in a South African woodland savanna 
The research described in this thesis was financially supported by Wageningen University.

Financial support from Wageningen University for printing this thesis is gratefully acknowledged.

Cover design by Bradley Schroder and Lisa Plets (Stagiair Graphic Design)

Printed by PROEFSCHRIFTMAKEN, the Netherlands 

